\title{
An Innovative Foundation System for Bollards and Barriers
}

\author{
by
}

George Adom

A thesis submitted to the Faculty of Graduate and Postdoctoral Affairs in partial fulfillment of the requirements for the degree of

Master of Applied Science

in

Civil Engineering

Carleton University

Ottawa, Ontario

(C) 2015, George Adom 


\section{Abstract}

Vehicle barriers are high security infrastructure systems commonly used for protection of buildings and infrastructure. The global increase in terrorism as well as the need to effectively protect humans and infrastructure has led to various research on improving security infrastructure systems. One of the several alternatives for providing security to infrastructure is the use of anti-ram vehicle barriers such as bollards. A vehicular bollard is a barrier system used to restrict movement of vehicles around buildings. An important factor to consider in the design of a bollard is the impact resistance of the bollard which is dependent on its foundation. Previous studies conducted on foundation systems for bollards mostly focuses on the use of shallow concrete foundation systems. However, a simple deep foundation technology can be employed for bollards with minimum cost.

This thesis investigates the use of such deep foundation technology for bollards. An extensive experimental study into innovative foundation systems for vehicle bollards using soil was conducted in the laboratory to evaluate the performance of different pile systems under both static and impact lateral loads. The results demonstrated that part of the bollard can be used as a pile to design a simple deep foundation system which is capable of resisting the vehicular load acting on the bollard. The implementation of Fins on the pile significantly increased the resistance capacity of the foundation under lateral impact loads. 


\section{Dedication}

I dedicate this thesis to my parents, siblings, and friends and love ones who have supported me throughout my entire studies. I love you all. God bless you. 


\section{Acknowledgements}

First of all, I will like to thank God Almighty for His grace throughout this work. I also want to express profound gratitude and thank the efforts of my supervisors: Dr. Mohammad Rayhani and Dr. Abass Braimah for their guidance throughout my studies. To all who contributed in a way to this thesis, I say to you thank you. 


\section{Table of Contents}

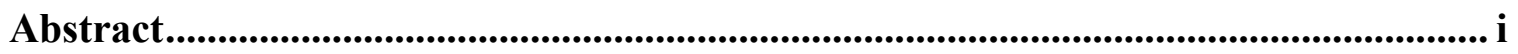

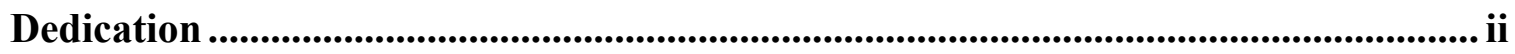

Acknowledgements ......................................................................................................... ii

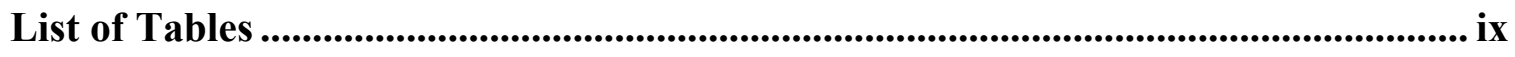

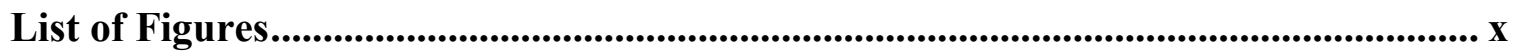

List of Abbreviations .................................................................................................... xiii

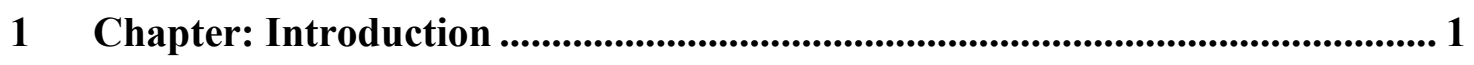

$1.1 \quad$ Statement of the Problem.................................................................... 1

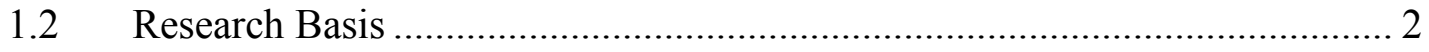

1.3 Research Objectives ....................................................................... 2

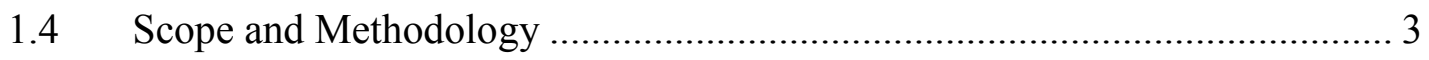

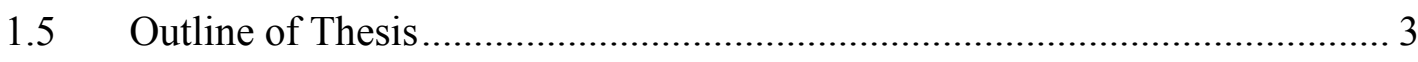

2 Chapter: Literature Review ................................................................5

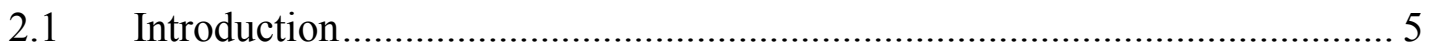

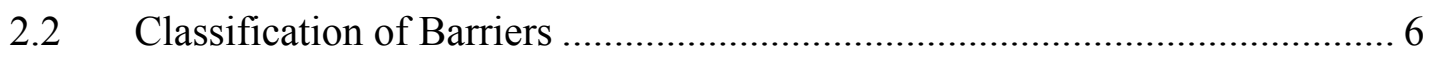

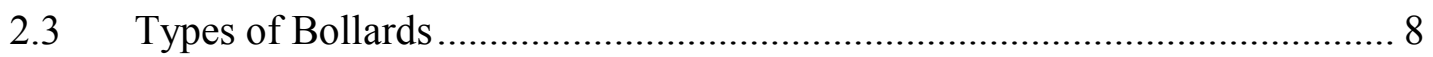

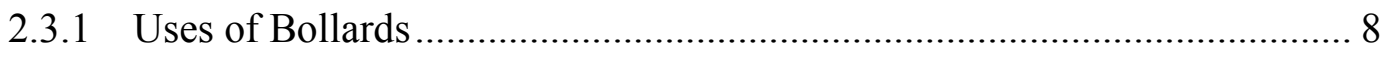

2.3.2 Installation Methods for Bollards ............................................... 9

2.3.3 Impact Load Test for Bollards and Barriers ........................................ 9

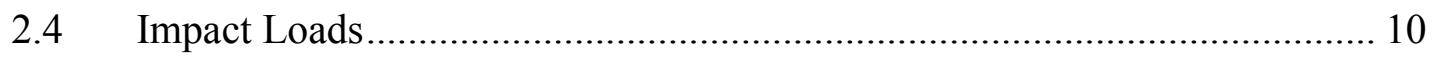

2.4.1 Types of Impact Loads........................................................... 10

2.4.2 Mechanism of Estimating Impact Loads for Bollards ........................... 11

2.4.3 Analysis of Impact Force ............................................................ 13 
2.4.4 Relevant Studies of Impact Loads on Vehicular Barriers....................... 14

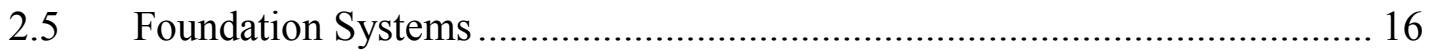

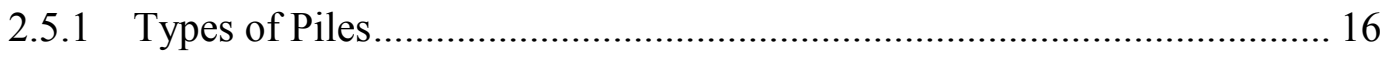

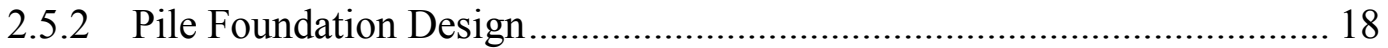

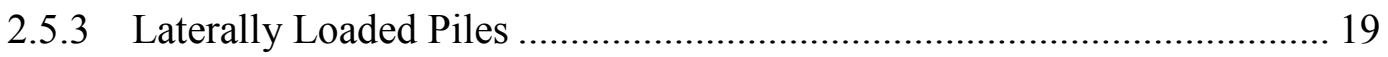

2.5.3.1 Lateral capacity under static loading ...................................... 21

2.5.3.2 Lateral capacity under dynamic loading .................................. 27

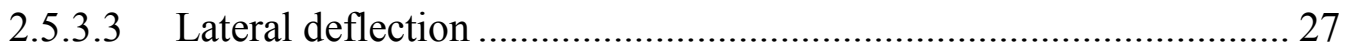

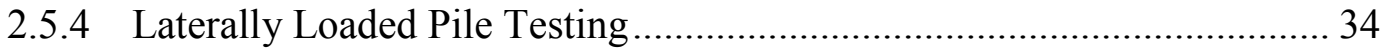

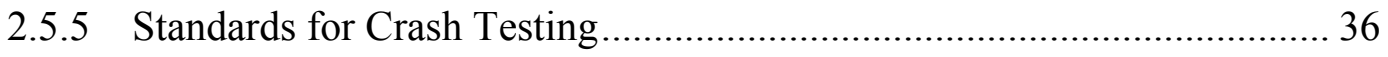

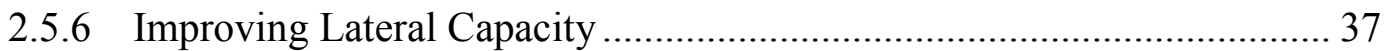

2.6 Methods for Predicting the Design of Bollards ...................................... 39

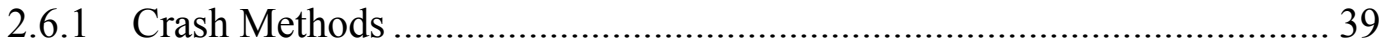

2.6.2 Equivalent Force Methods ............................................................... 40

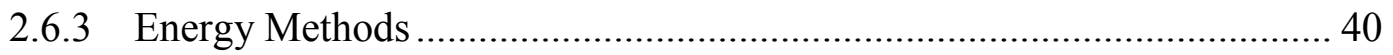

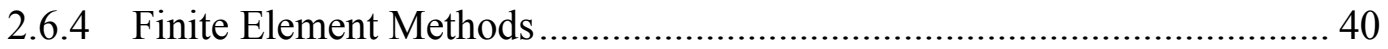

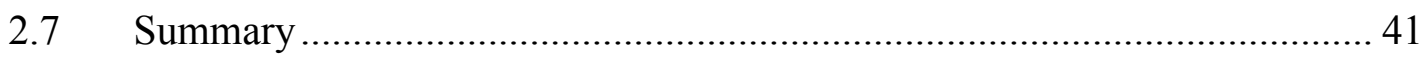

3 Chapter: Experimental Program ............................................................ 43

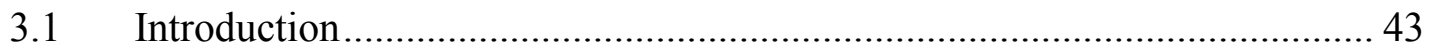

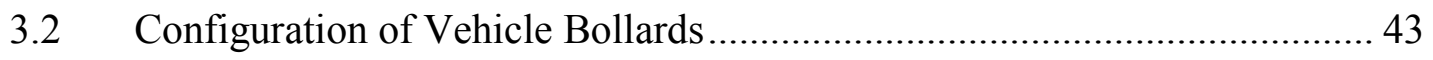

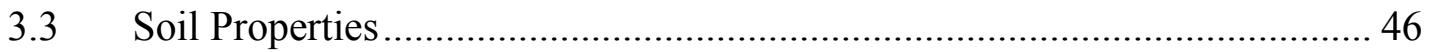

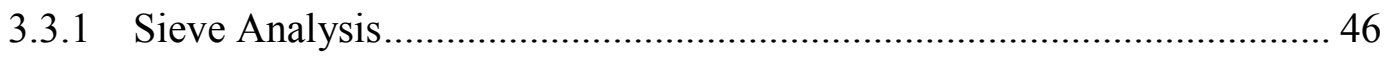

3.3.2 Standard Proctor Compaction Test ................................................... 47 


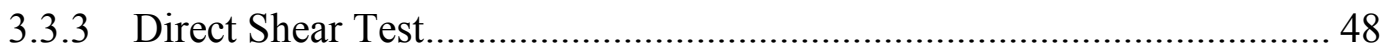

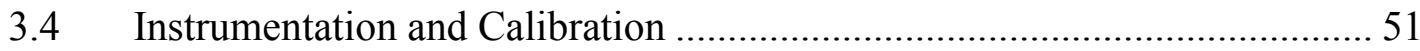

3.4.1 Calibration of 100-kip Compression Load cell..................................... 51

3.4.2 Calibration of Celesco String Potentiometers ........................................... 53

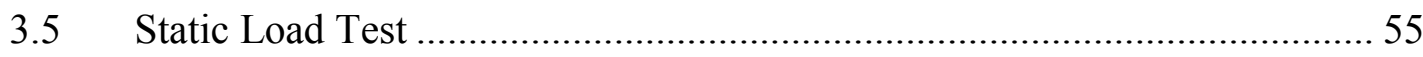

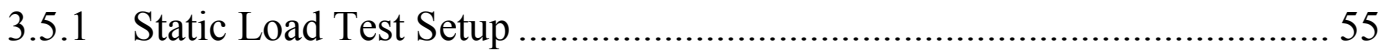

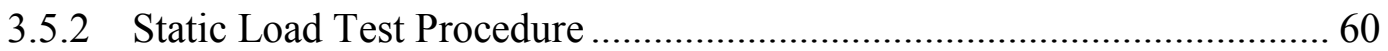

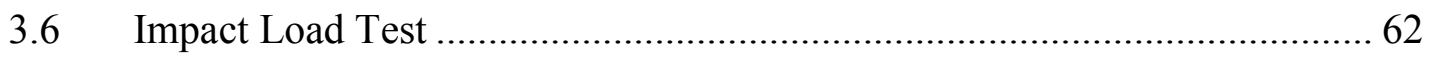

3.6.1 Impact Load Test Configuration and Adjustments ................................... 62

3.6.1.1 Pendulum-weight configuration....................................................... 62

3.6.1.2 Procedure for the impact load configuration with elastomeric pad

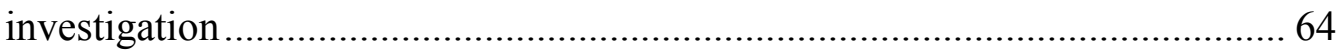

3.6.1.3 Summary of impact load test configuration....................................... 66

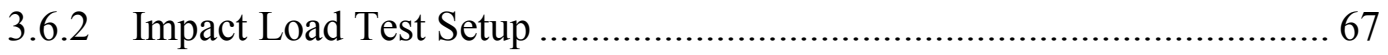

3.6.3 Impact Load Test Procedure ……………............................................ 70

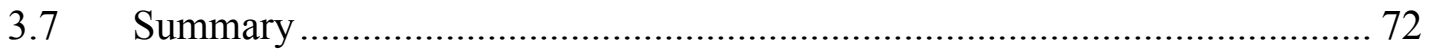

4 Chapter: Results and Discussions........................................................................... 73

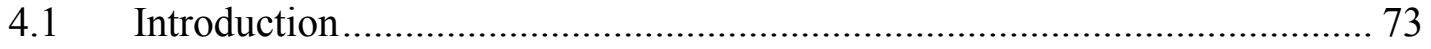

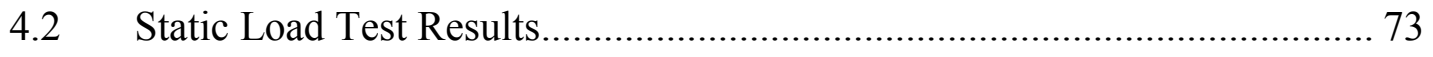

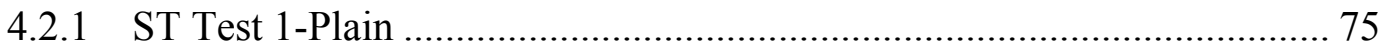

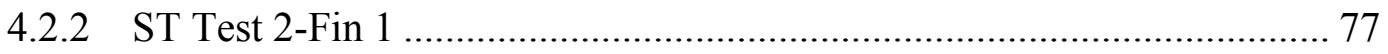

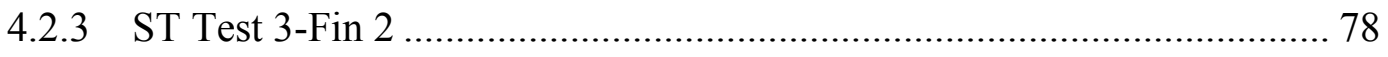

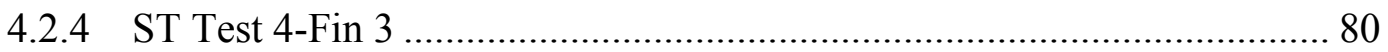




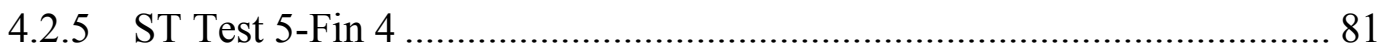

4.2.6 Comparison of Bollard Systems under Static Loading ……...................... 83

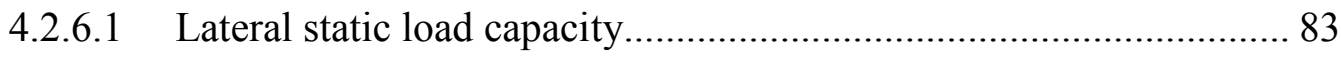

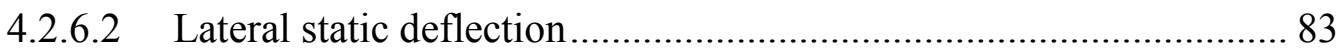

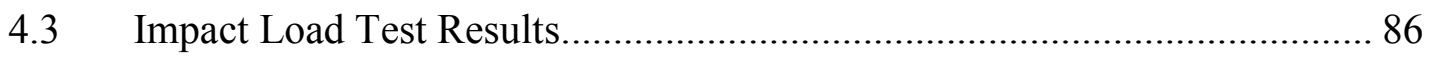

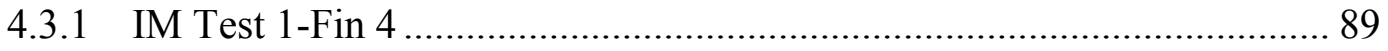

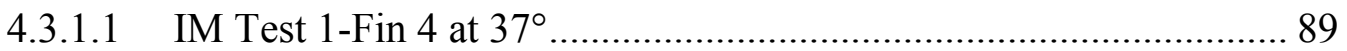

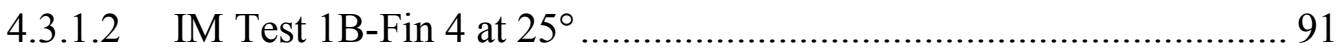

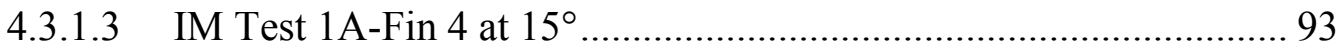

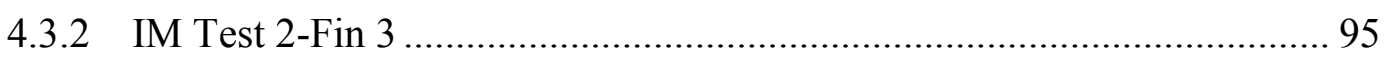

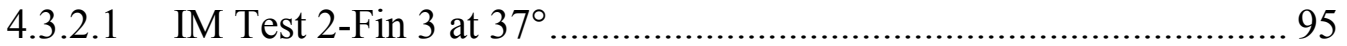

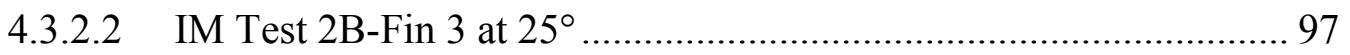

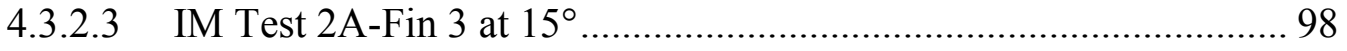

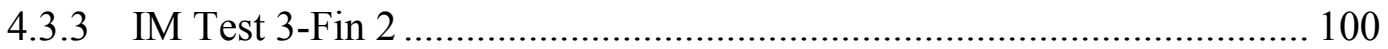

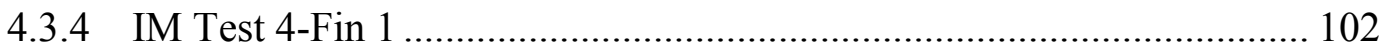

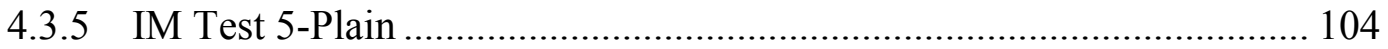

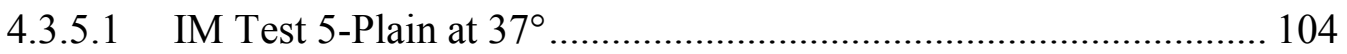

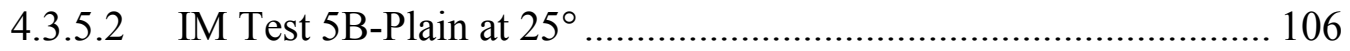

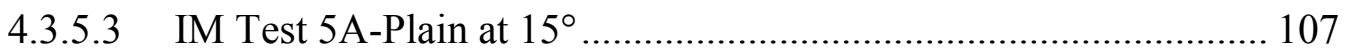

4.3.6 Comparison of Bollard Systems under Impact Loading .......................... 109

4.3.6.1 Lateral impact load capacity .......................................................... 110

4.3.6.2 Lateral impact deflection ........................................................... 112

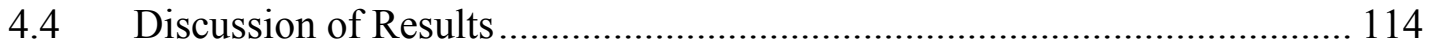


4.4.1 Comparison of Load and Deflection Results for Static and Impact Load Tests 114

4.4.1.1 Lateral load capacity ......................................................... 114

4.4.1.2 Lateral deflections........................................................... 115

4.4.1.3 Analysis of deflections for static and impact load tests ................ 116

4.4.2 Effects of Fins on Lateral Capacity and Deflection ............................. 117

4.4.2.1 Shape of Fins................................................................... 118

4.4.2.2 Surface area of Fins ......................................................... 120

4.4.2.3 Position and depth of Fins.................................................... 121

4.4.3 Comparison of Conventional Bollard Foundation to Proposed Pile

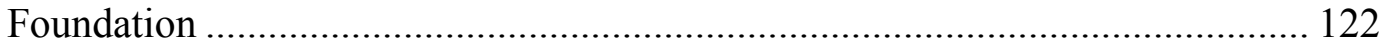

5 Chapter: Conclusion and Recommendations......................................... 124

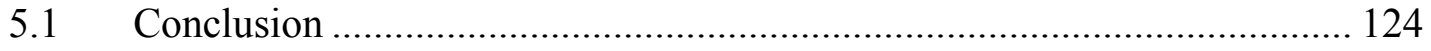

5.2 Recommendations ......................................................................... 125

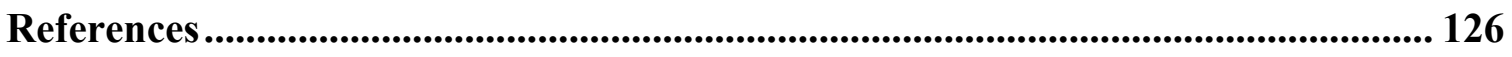

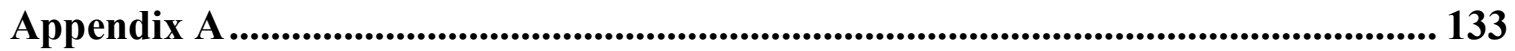

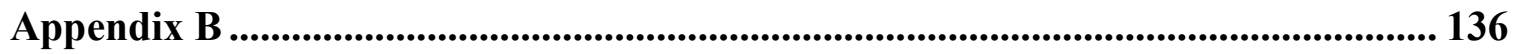




\section{List of Tables}

Table 2-1: Impact condition designation for a vehicle weight of 6,800 kg. (U.S. Department of State, 2003)

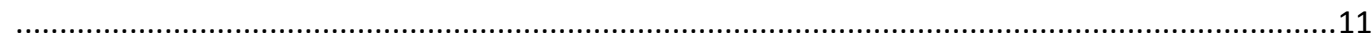

Table 2-2: Recommended soil foundation material for bollard design (from AASHTO, 1990) .....................37

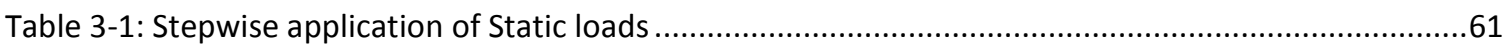

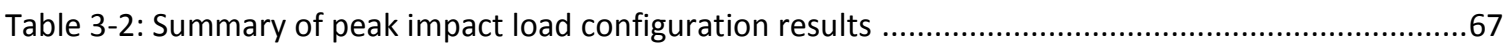

Table 4-1: Summary of peak loads and deflections at various locations for static load tests.......................84

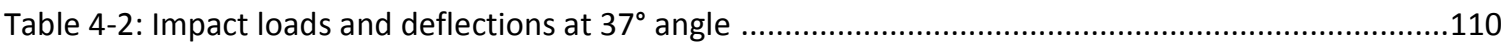

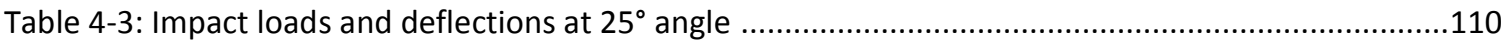

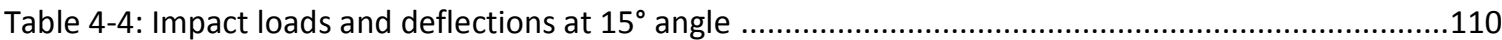

Table 4-5: Kinetic energy and impulse for impact loads ..................................................................111

Table 4-6: Fin efficiency factors for static load tests ................................................................................120 


\section{List of Figures}

$\begin{array}{ll}\text { Figure 2-1: Examples of vehicle barriers } & 7\end{array}$

Figure 2-2: Resistant function of a bollard (De Clerck et al., 2012) 13

Figure 2-3: Failure mechanism for short and long piles (Cudoto, 2001) 20

Figure 2-4: Pile head fixity (Das, 2010) 20

Figure 2-5: Failure mechanisms of short piles (Broms, 1964) 22

Figure 2-6: Broms' graph for finding lateral capacity of short piles in cohesive soils 23

Figure 2-7: Broms' graph for finding lateral capacity of short piles in cohesionless soils 24

Figure 2-8. Failure mechanism for long piles

Figure 2-9: Broms' graph for finding lateral capacity of long piles in cohesive soils 26

Figure 2-10: Broms' graph for finding lateral capacity of long piles in cohesionless soils 26

Figure 2-11: Soil resistance per unit length as a function of deflection (Cudoto, 2001) 28

Figure 2-12: The concept of $p$-y curves (Cudoto, 2001) 31

Figure 2-13: Graph of elastic coefficient $I_{\rho H}$

Figure 2-14: Graph of elastic coefficient IOM 33

Figure 2-15: Graph of elastic coefficients $I_{\rho M}$ and $I_{\theta H}$

Figure 2-16: An example of a full-scale lateral load test (Cudoto, 2001) 34

Figure 2-17: Examples of lateral pile improvement techniques 38

Figure 3-1: Bollard-pile configurations $\quad 44$

Figure 3-2: Section view of the bollard-pile configuration setup 45

Figure 3-3: Particle size distribution for sand $\quad 47$

Figure 3-4: Standard proctor compaction test for sand $\quad 48$

Figure 3-5: Direct shear test (a) shear stress versus displacement, (b) Vertical versus horizontal displacements, (c) Mohr-Coulomb's failure criterion $\quad 50$

Figure 3-6: Calibration of load cell

Figure 3-7: 100 kip load cell calibration scale $\quad 52$

Figure 3-8: Calibration of string pot

Figure 3-9: String pots calibration scale

Figure 3-10: Pile with wooden cork

Figure 3-11: Installation of lower string pot: (a) location of pipe for string pot (b) location of string pot 57

Figure 3-12: Final level of the soil with middle string pot installed 58

Figure 3-13: Position of top string pot 59

Figure 3-14: Static load test setup (a) schematic sketch (b) photograph 60

Figure 3-15: Pendulum-weight configuration (a) sketch (b) photograph 63

Figure 3-16: Sketch of impact load configuration setup 65 
Figure 3-17: Pulley system connection for impact load test (a) pulley connection (b) release mechanism 66 Figure 3-18: Point of impact configuration on bollard: (a) sketch of configuration (b) bollard with load cell

Figure 3-19: Impact load test setup (a) sketch (b) photograph 69

Figure 3-20: Load time profile of trial tests $\quad 71$

Figure 4-1: Bollard-pile configurations tested under static loading 74

Figure 4-2: Pretest images of static load test; (a) final surface level (b) measurement of surface level 75

Figure 4-3: Load-deflection response of static test 1 (Plain bollard) 76

Figure 4-4: Post-test image of static test 1 (Plain) 76

Figure 4-5: Load-deflection response of static test 2 (Fin 1) 77

Figure 4-6: Post-test image of static test 2 (Fin 1) 78

Figure 4-7: Load-deflection response of static test 3 (Fin 2) 79

Figure 4-8: Post-test image of static test 3 (Fin 2) 79

Figure 4-9: Load-deflection response of static test 4 (Fin 3) 80

Figure 4-10: Post-test image of static test 4 (Fin 3) 81

Figure 4-11: Load-deflection response of static test 5 (Fin 4) 82

Figure 4-12: Post-test image of static test 5 (Fin 4) 82

Figure 4-13: Load - deflection graphs for top string pot measurements 85

Figure 4-14: Load- deflection graphs for middle string pot measurements 85

Figure 4-15: Load-deflection graphs for bottom string pot measurements 86

Figure 4-16: Bollard-pile configurations tested under impact loading 87

Figure 4-17: Pre-test images of impact load tests at $37^{\circ}$

Figure 4-18: Pre-test images of impact load test at 25ㅇ 88

Figure 4-19: Pre-test images of impact load test at 15² 89

Figure 4-20: Load deflection time graph for Fin 4 at 37 99

Figure 4-21: Post-test images of impact load test 1-Fin 4 at 37 ${ }^{\circ}$

Figure 4-22: Load deflection time graph for Fin 4 at 25

Figure 4-23: Post-test images of impact load test 1-Fin 4 at 25

Figure 4-24: Load deflection time graph for Fin 4 at 15² 93

Figure 4-25: Post-test images of impact load test 1-Fin 4 at 15 ${ }^{\circ} 94$

Figure 4-26: Load deflection time graph for Fin 4 at 37, $25^{\circ}$ and $15^{\circ}$

Figure 4-27: Load deflection time graph for Fin 3 at 37

Figure 4-28: Post-test images of impact load test 2-Fin 3 at $37^{\circ} 96$

Figure 4-29: Load deflection time graph for Fin 3 at $25^{\circ}$

Figure 4-30: Post-test images of impact load test 2-Fin 3 at $25^{\circ}$ 
Figure 4-31: Load deflection time graph for Fin 3 at $15^{\circ}$

Figure 4-32: Post-test images of impact load test 2-Fin 3 at $15^{\circ}$

Figure 4-33: Load deflection time graph for Fin 3 at 37, $25^{\circ}$ and $15^{\circ}$

Figure 4-34: Load deflection time graph for Fin 2 at 37 101

Figure 4-35: Post-test images of impact load test 3-Fin 2 at 37

Figure 4-36: Load deflection time graph for Fin 1 at 37

Figure 4-37: Post-test images of impact load test 4-Fin 1 at 37

Figure 4-38: Load deflection time graph for Plain at 37 105

Figure 4-39: Post-test images of impact load test 5-Plain at 37 ${ }^{\circ} 105$

Figure 4-40: Load deflection time graph for Plain at 25ำ 106

Figure 4-41: Post-test images of impact load test 5-Plain at 25

Figure 4-42: Load deflection time graph for Plain at 15² 108

Figure 4-43: Post-test images of impact load test 5-Plain at 15 ${ }^{\circ} 108$

Figure 4-44: Load deflection time graph for Plain at 37, $25^{\circ}$ and $15^{\circ}$

Figure 4-45: Load time profile for impact load test 111

Figure 4-46: Top deflections for Impact load test 112

Figure 4-47: Middle deflections for Impact load test 113

Figure 4-48: Bottom deflections for Impact load test 113

Figure 4-49: Load deflection time graph for 37 impact angle considering top deflections 121 


\section{List of Abbreviations}

$\begin{array}{ll}\text { AASHTO } & \text { American Association of State Highway and Transportation Officials } \\ \text { DSTM } & \text { American Society for Testing and Materials } \\ \text { EFM } & \text { Data Acquisition System } \\ \text { ESF } & \text { Equivalent Force Methods } \\ \text { FEM } & \text { Finite Element Method } \\ F_{y} & \text { Yield strength } \\ \text { IM } & \text { Impact load test } \\ \text { LRFD } & \text { Load Resistance Factor Design } \\ \text { PDF } & \text { Peak Dynamic Forces } \\ \rho_{\text {max }} & \text { Maximum density } \\ \text { p-y } & \text { Soil Resistance-Deflection } \\ \text { SP } & \text { Poorly graded sand } \\ \text { ST } & \text { Static load test } \\ \text { USCS } & \text { Onified Soil Classification System } \\ \text { VBIED } & \text { Vehicle-Borne Improvised Explosive Devices } \\ \text { DAm water content }\end{array}$




\section{Chapter: Introduction}

\subsection{Statement of the Problem}

In recent times, the increase in terrorist attacks has led to the increased use of security systems in all jurisdictions. Governments of different countries, especially western nations, are taking tremendous steps to protect their infrastructure systems. Measures to ensure effective protection of infrastructure range from limited security checks at points of entry to major security systems including the use of equipment and protective infrastructures such as security scanners and barriers. Security systems are employed based on the type of attack anticipated. A barrier is a typical example of a security system used to protect the safety of people and infrastructure. There are different kinds of barriers with each having a peculiar mode of operation. Examples of barriers mostly used include, jersey barriers, planters, gates, vehicular bollards, etc. Of all these barrier types, vehicular bollards have become very common because of the ease of their installation and low cost of construction.

Depending on its use, a vehicular bollard may be defined as a high security infrastructure system used to obstruct the movement of vehicles into protected areas (or guarded perimeters). Vehicular bollards can be found almost everywhere especially in front of important buildings and monuments. Vehicular bollards are in demand due to their

effective performance in resisting high impact loads. Literature shows that the use of vehicular bollards has been successful. Although it is capable of resisting impact loads, the performance of a vehicular bollard depends on its design and construction. 


\subsection{Research Basis}

A vehicular bollard is an example of a high security infrastructure system used to prevent major impact loads such as those resulting from vehicles. For effective resistance of impact loads the method of design is of utmost importance. The design of vehicular bollards depends on the type of vehicular impact it can resist; which consequently depends on the foundation system that supports the vehicular bollard.

Most research studies on security barriers including vehicular bollards focus on the behavior of the barrier under impact loading and also the residual capacity of the bollard; which is an important parameter of interest. Although most of the force is resisted by the foundation system supporting the barrier, there is limited study on the foundation system used for vehicular bollards. Many foundation designs can be built for vehicular bollards but the designs must be economical while resisting the maximum impact load from the vehicle.

\subsection{Research Objectives}

The primary objective of this thesis is to develop a simple and cost effective foundation design for vehicular bollards subjected to impact loads. The specific objectives of this research are;

- To assess the effect of vehicular impact on a bollard foundation.

- $\quad$ To develop a new and efficient foundation system for bollards and barriers.

- To examine the effect of impact load on performance of the new foundation system. 


\subsection{Scope and Methodology}

The investigation into the foundation system for vehicular bollards can be done either through experimental or numerical studies. Numerical simulations may be a less expensive option over most experimental works. Numerical studies, however, often need to be validated using experimental studies. Experimental studies mostly simulate the actual field program which may result in a more practical solution. Most research works including Nasr (2013) and Itoh et al. (2011) used experimental programs to satisfactorily investigate barriers. In carrying out the objectives of this thesis, an experimental program is implemented to arrive at the relevant results and conclusions. The program is done to be economical while meeting the purpose of the study. The development of the program is such that all the necessary information needed for the report is achieved.

\subsection{Outline of Thesis}

This thesis is made up of five chapters. The first part as described in Chapter 1 introduces the purpose and reason for the study. The remaining chapters discuss the following topics: Chapter 2: Literature Review

This chapter reviews topics relevant to the focus of this study. First of all, it talks about the classification of bollards. It further discusses the theory of impact loads focusing more on the type of impact load which occurs in vehicular bollard design analyses. Lastly, it considers the design of foundations for impact loads. This dwells more on the foundation system used to resist laterally loaded piles. 


\section{Chapter 3: Experimental Program}

This chapter discusses the methodology and processes used for the experiments. The procedure for each step is briefly discussed in a chronological order. Both static and impact load tests are described in detail. The tests setup, instrumentation and data acquisition are also presented.

Chapter 4: Results and Discussion

The results for both static and impact load tests are presented in this chapter. Analyses of the results are also discussed. The results mainly focused on the findings of the tests. Comparison of the static and impact load tests are also made in the analyses.

\section{Chapter 5: Conclusion and Recommendation}

Conclusions from the results and analyses of the different tests are discussed here. Recommendations for future work based on the results and the need for continuous study is presented as well. 


\section{Chapter: Literature Review}

\subsection{Introduction}

Global terrorism and use of explosives in attacks against critical buildings and monuments has resulted in increased research in blast protective designs aimed at decreasing the vulnerability of buildings subjected to blast loading. The primary design edict used for blast protective design is increased standoff distance - the distance from the center of explosion to the building under consideration. To protect buildings and critical infrastructure against vehicle-borne improvised explosive devices (VBIED), the design basis standoff distance must be safeguarded and guaranteed. There are many ways to guarantee and safeguard the standoff distance against vehicles; the most common of which is to use of vehicle barrier system that prevents unauthorized access. The vehicle barrier system must be robust enough to resist impact from a vehicle with specified weight and approach speed. Vehicle barriers are used to restrict movement of vehicles into perimeters where pedestrian and infrastructure maybe exposed to specified hazards.

For effective performance of vehicle barriers, the foundation design must be able to support the loads acting on the barrier system. Therefore, the impact loads and foundation need to be investigated thoroughly to ascertain the correct design method to employ. The most common foundation method used for vehicle barriers is shallow foundation system; where concrete is poured around the base of the barrier in a form of footings. Although barriers can be used as high security infrastructure system, the effectiveness of a security barrier system such as the anti-ram security bollard depends on many factors. This has led to many research investigations on methods of improving the performance of security bollard systems. This chapter reviews literature on the importance 
of vehicle bollards, some techniques employed in their design and the type of foundation used for the bollards.

\subsection{Classification of Barriers}

Barriers can be classified in accordance with their function, application, or material from which it is made. Typical examples of barriers include bollards, guardrails, gates, and fences. American Association of State Highway and Transportation Officials (AASHTO, 2004) classified barriers as rigid, semi-rigid or flexible depending on the mechanism of resisting impact forces and the amount of deflection observed after vehicle crash. Rigid barriers have higher impact resistance than flexible barriers. Examples of rigid barriers include jersey barriers (short permanent concrete walls), and that of flexible barriers include corrugated guardrails and cable barriers. Figure 2-1 shows examples of vehicle barriers.

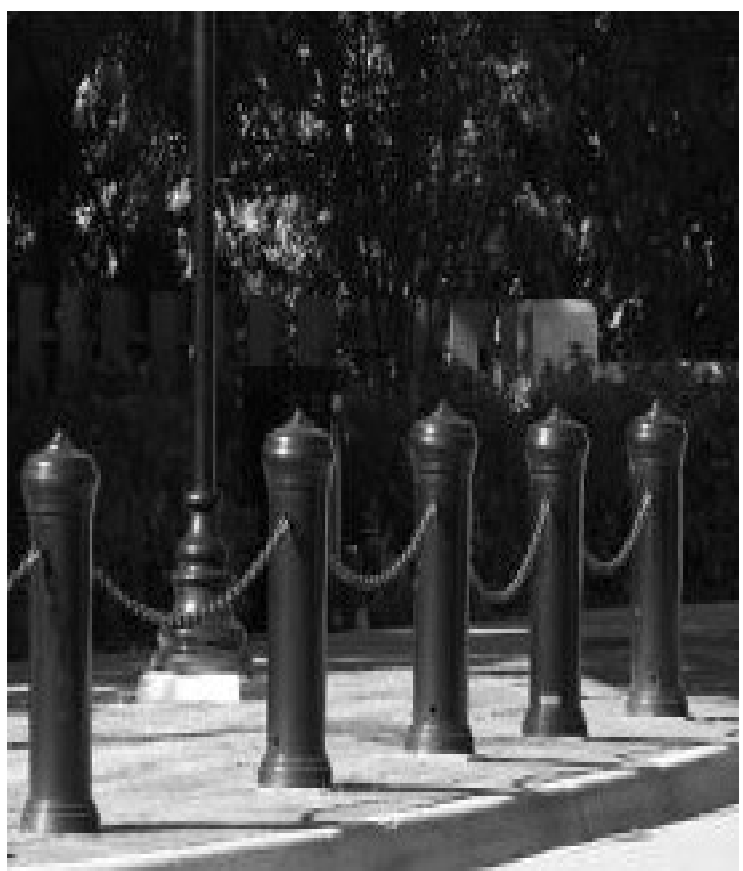

(a) Bollards (Baker and Benny, 2013)

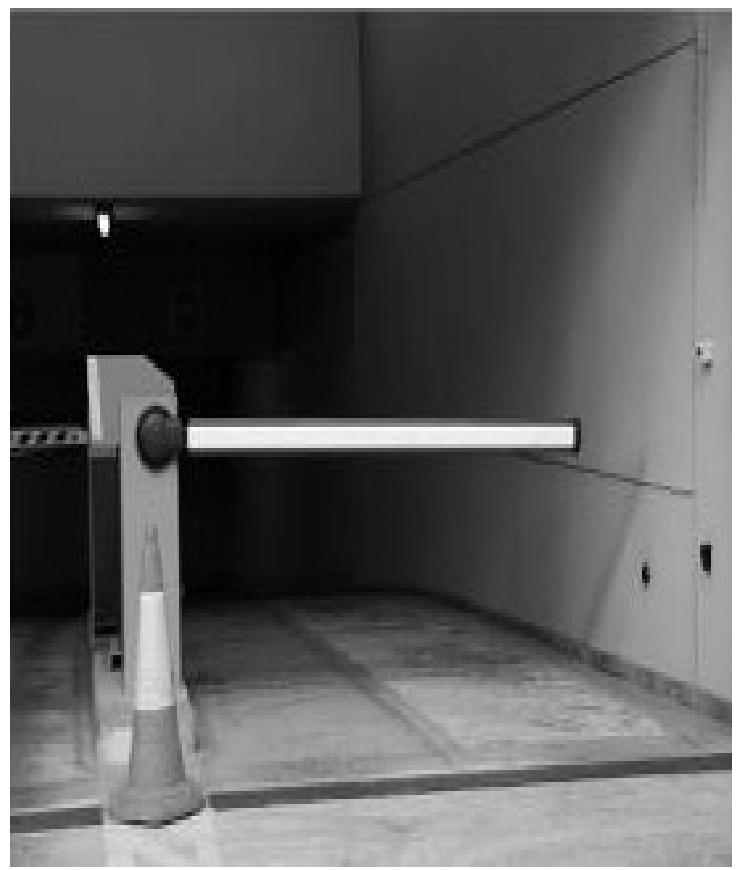

(b) Gate (Baker and Benny, 2013) 


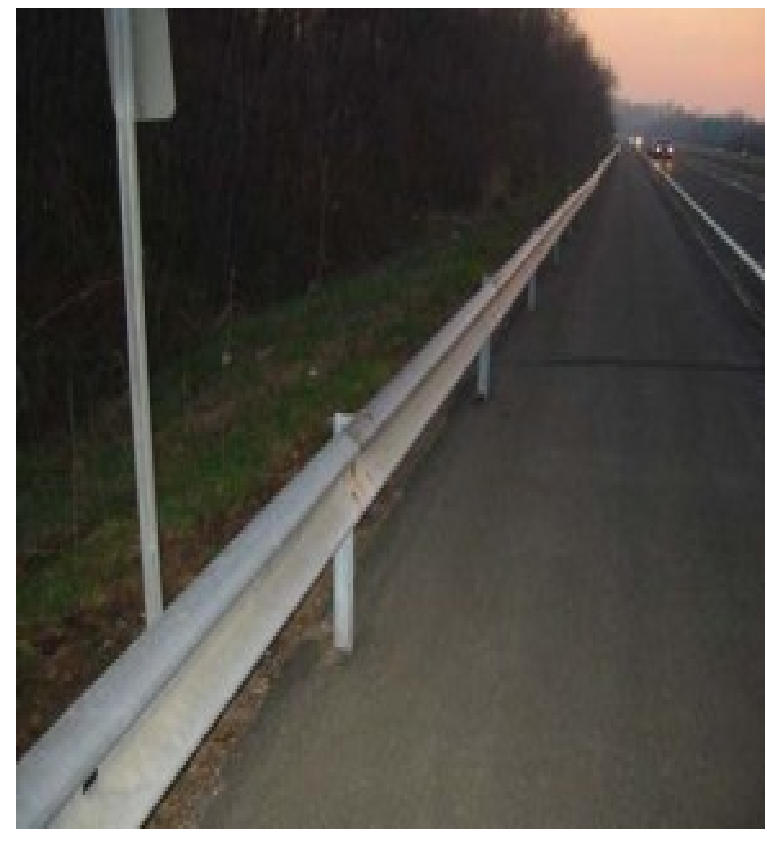

(c) Corrugated steel barrier (Gabler et al., 2005)

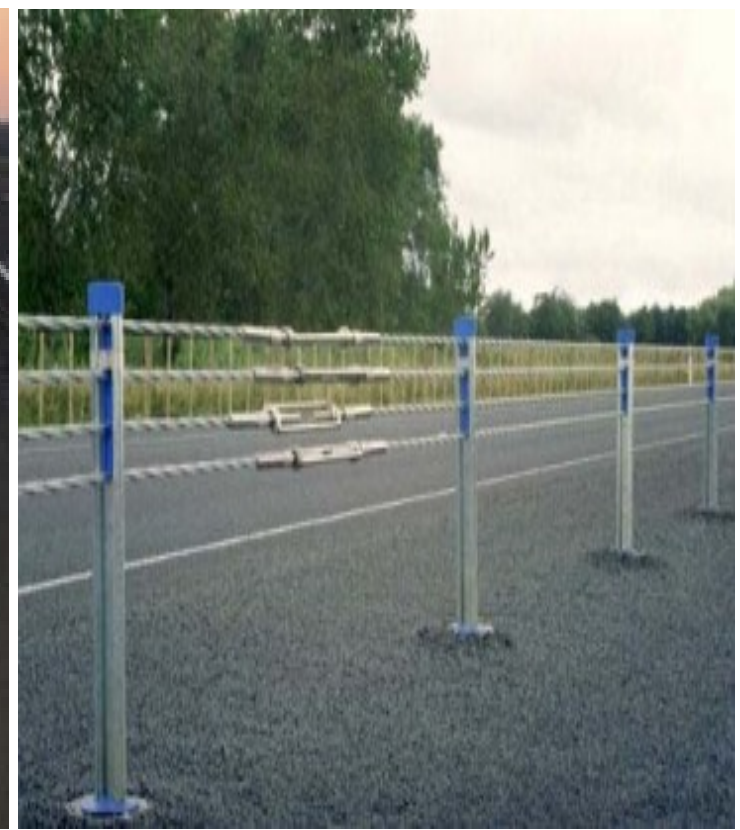

(d) Cable barrier (Gabler et al., 2005)

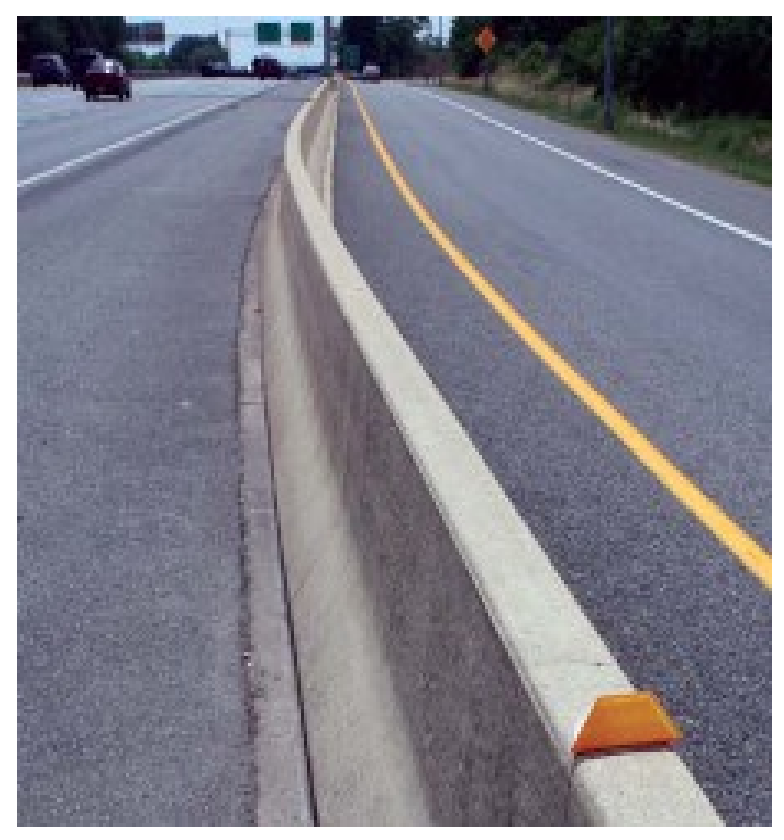

(e) Jersey barrier (FHWA, 2010)

Figure 2-1: Examples of vehicle barriers 


\subsection{Types of Bollards}

American Society for Testing and Materials (ASTM 2007) defines a vehicle bollard as a vertical post used to restrict vehicular access and traffic to infrastructure. The bollard can be constructed from concrete, steel, wood or a combination of these materials. Apart from the construction material, bollards can be described by its function and configuration as fixed, removable, and operable or retractable.

Fixed bollards are designed against a defined level of threat and installed permanently in a foundation capable of resisting the threat. Removable bollards are installed in a sleeve or mount buried underground. It usually flush with the ground surface and can be removed to allow access. Removable bollards are usually designed to resist low impact loads in comparison with fixed bollards and are installed temporarily at locations where there is a possibility of change of access. Retractable bollards, on the other hand, maybe automatically or manually operated and are made to retract underground. Retractable bollards may use lift assistance mechanisms to deploy its lift operations.

Conversely, a bollard can be categorized as rigid or flexible depending on its

function and type of material from which it was made. A rigid bollard is mostly made of concrete or steel and used to resist high impact loads especially in security systems whilst a flexible bollard can be made of plastic or soft wood and are normally used to delineate areas for parking and restrict pedestrian access.

\subsubsection{Uses of Bollards}

The function of bollards includes resisting low and high speed vehicular impacts that may or may not be associated with deliberate attack. Bollards can be used for a wide variety of applications including providing for the safety of pedestrian, protection of buildings, 
equipment, utilities and for access control. Bollards can also be used along roadways instead of barrier walls such as jersey barriers when space is limited.

The use of bollards provides pedestrian accessibility and aesthetics while offering an equal level of protection as continuous barrier structures, hence they serve as an economic alternative for road side barriers (Grzebieta and Rechnitzer, 2013). Moreover, rigid bollards can be used to resist high velocity impacts like vehicular impact thus increasing standoff distance to protected infrastructure during terrorist attacks. Bollards serving this purpose are normally considered as anti-ram security bollards and can commonly be seen in front of high security buildings including embassies, government buildings and state houses.

\subsubsection{Installation Methods for Bollards}

Installation of a bollard depends on the type of foundation used. Some bollards are mounted on a hard finished surface such as a slab while others are installed firmly beneath the ground surface in the foundation. Installation methods provide different resistance capacities to the bollard systems. Surface mounted installation is achieved by placing the bollard in shallow foundations or on a hard flat surface. This is a cheaper method and mostly has limited impact load resistance. Bollards mounted in deep foundations are usually used to resist higher impact loads and maybe expensive based on the type of foundation employed.

\subsubsection{Impact Load Test for Bollards and Barriers}

There is no specific criterion or standard for vehicular impact load test on bollards and barriers. However, the American Society of Testing Materials (ASTM) and European standard methods for vehicle barriers could serve as a basis for performing vehicular impact load test on bollards (De Clerck et al., 2012). Basically, crash tests on bollards 
involve the application of impact loads on the bollards. The specification for the test depends on the type of loading the bollard is expected or designed to resist. The impact loads may vary from small dynamic loads such as small vehicular crash to high impact loads such as blast loading.

\subsection{Impact Loads}

Impact load is the result of a dynamic force against a body. Impact loads are very common with vehicular collision on barriers and may result in deflections, elastic and plastic deformations, material non-linearity and material behavior under high strain rates (Wright, 2012).

\subsubsection{Types of Impact Loads}

According to Miyamoto et al. (1991), impact can be classified as soft or hard impact based on the mechanism of kinetic energy absorbed by the impacted body or transferred from the colliding body. With soft impact, the velocity of impact is very low such that the kinetic energy is usually not transferred to the impacted body but rather absorbed by the colliding body. For a hard impact, the kinetic energy is transferred to the impacted body. The velocity of hard impact is high and deformations may be observed in the impacted body. In antiram security bollards, the velocity of impact is high and hence hard impact assessment is implemented in the design. Anti-ram bollards are further classified according to U.S Department of State (2003) as K4, K8 and K12 bollard ratings depending on the velocity of impact.

U.S Department of State (2003) provides the criteria through which an agency can appropriately select a barrier for use at facilities with respect to the type of impact. This 
selection is done based on crash-rated barrier or engineer-rated systems using penetration distances (L). The penetration distance for trucks is the distance between the original barrier locations to the front of the cargo bed at its final position. Specification for anti-ram bollards also considers the speed and the mass of the approaching vehicle. Again, the U.S Department of State, (2003) provides rating of anti-ram bollards based on the resistance to impact of a truck of a specific speed and weight (kinetic energy), and the penetration distance. Using a 6,800 $\mathrm{kg}(14,991 \mathrm{lbs}$.) vehicle, the bollard rating is presented in Table 2-1. The K-rating is a measure of impact kinetic energy in lb-ft or N-m units. For example K4 represents resistance against a 400,000 lb-ft or 55,302 N-m.

Table 2-1: Impact condition designation for a vehicle weight of 6,800 kg. (U.S. Department of State, 2003)

\begin{tabular}{|c|c|c|c|c|}
\hline $\begin{array}{l}\mathrm{K} \\
\text { rating }\end{array}$ & $\begin{array}{l}\text { Description of } K \\
\text { rating }\end{array}$ & $\begin{array}{l}\mathrm{L} \\
\text { rating }\end{array}$ & Description of $L$ rating & Kinetic energy \\
\hline K4 & $48 \mathrm{kph}(30 \mathrm{mph})$ & L1 & $\begin{array}{l}6100 \mathrm{~mm}-15300 \mathrm{~mm} \\
(20 \mathrm{ft}-50 \mathrm{ft})\end{array}$ & $610 \mathrm{KJ}$ \\
\hline K8 & $65 \mathrm{kph}(40 \mathrm{mph})$ & L2 & $\begin{array}{l}915 \mathrm{~mm}-6100 \mathrm{~mm}(3 \\
\mathrm{ft}-20 \mathrm{ft})\end{array}$ & $1085 \mathrm{KJ}$ \\
\hline K12 & $80 \mathrm{kph}(50 \mathrm{mph})$ & L3 & $915 \mathrm{~mm}(3 \mathrm{ft})$ or less & $1695 \mathrm{KJ}$ \\
\hline
\end{tabular}

\subsubsection{Mechanism of Estimating Impact Loads for Bollards}

According to El-Tawil (2004), a bollard's ability to resist vehicular impact is a function of its properties, the type of foundation, the mass and velocity of the crash vehicle and the angle of approach. Therefore, in analyzing the effect of impact loads on bollards, the aforementioned functional parameters as well as loading rate, degree of eccentricity and shape 
of the impact loads should be considered. The dimensions of a bollard include the diameter, the heights above and below the ground level, and the cross-sectional area. De Clerck et al., (2012) stated that according to European standard, the impact height of bollards depends on the type of impact vehicle. For trucks (lorries), the impact height can be between $0.5 \mathrm{~m}$ to $1.5 \mathrm{~m}$ above the ground surface and for cars, the impact height can be 0.5 $\mathrm{m}$ above the ground surface.

The effectiveness of vehicle anti-ram bollards is dependent on their ability to resist the energy from the impact (Dawson and Tennant, 2008). Design methods used for analyzing impact loads of vehicle anti-ram bollards may include AASHTO Load Resistance Factor Design (AASHTO-LRFD) impact design force, Peak Dynamic Force (PDF) and Equivalent Static Force (ESF) methods (El-Tawil, 2004). A method is chosen based on the type of impact analysis required. For example, during the analysis of a collision involving the impact of a force for a very short duration, ESF can be employed to measure design structural demands. In ESF methods, force measurements vary linearly with velocity. The AASHTO-LRFD method is mostly used for lower impact forces while the Peak Dynamic Forces (PDF) method is recommended for higher and longer duration impacts.

Some researchers including Chopra (2001) explain that ESF analysis can be used as a representation of PDF analysis because the equivalent static force is the force required to cause an equal deflection as the deflection resulting in dynamic analysis on the same element. In describing the nature of impact load on a vehicle anti-ram bollard, De Clerck et al. (2012) suggested that the dynamic impact load on a bollard is represented in ESF as:

$$
F=v_{r} \sqrt{k M}
$$


where $F$ is the equivalent static force acting on the bollard, $v_{r}$ is the resultant impact velocity, $k$ is the stiffness of the vehicle and $M$ is the mass of vehicle. De Clerck et al. (2012) further explained that although the ESF provides a simplified method for analyzing vehicle impact on anti-ram bollards, determining the vehicle stiffness is complex and may require experimental data. However, the Euler beam theory can be used to determine the elastic response of a bollard impact. During impact on a bollard, a force $R_{m}$ is applied to obtain a deformation, $y_{e}$ represented as resistant function as seen in Figure 2-2. Beyond the elastic limit, plastic deformation occurs and a plastic hinge is assumed at the maximum moment location. The plastic moment $M_{p}$ can be expressed by equation 2.2 .

$$
M_{p}=f_{y} Z
$$

where, $f_{y}$ is the yield strength of the bollard material and $\mathrm{Z}$ is the plastic sectional modulus.

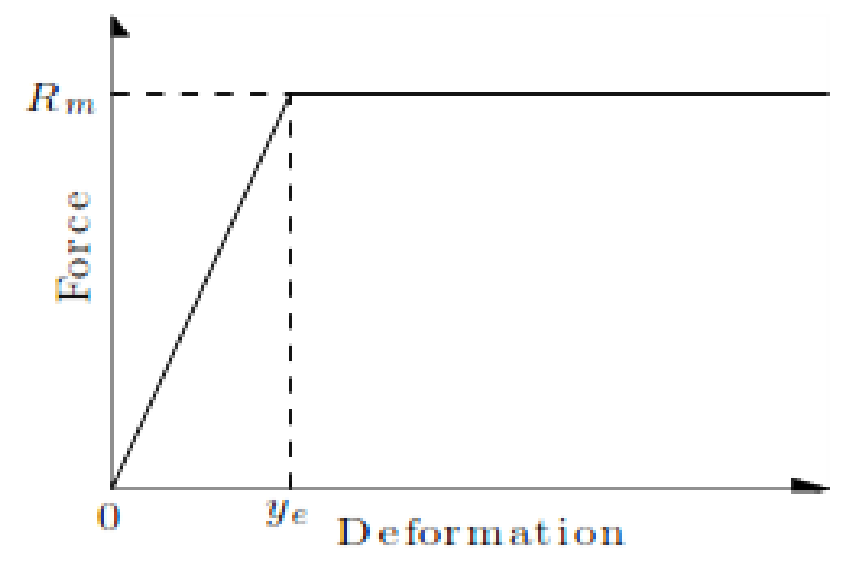

Figure 2-2: Resistant function of a bollard (De Clerck et al., 2012)

\subsubsection{Analysis of Impact Force}

According to El-Tawil (2004), for effective analysis of the impact force on a structure considering the conservation of momentum and impulse, momentum is transferred to the structure as an impulse effect. This may be expressed as 


$$
I=\int F(t) d t=M \int a d t=M \times \Delta V
$$

where, $I$ is impulse of the load (the momentum), $F(t)$ is the impact force, $M$ is mass of impacting body and $\Delta V$ is the change in velocity due to impact.

In discussing result of a pendulum impact load test on a crash barrier, El-Salakawy et al. (2004) assumed that the kinetic energy impacted on the barrier is equal to the potential energy from the ball and is expressed as

$$
M g h=\frac{1}{2} M v^{2}
$$

where, $M$ is mass of the pendulum, $g$ is the acceleration due to gravity, $h$ is the reference height of the ball, and $v$ is the velocity of the pendulum.

Itoh et al. (2007) summarized the mechanism of energy transfer as follows. A greater portion of the kinetic energy from the crash is absorbed by the anti-ram bollard in a form of residual deflection, the vehicle absorbs a significant amount and the remainder is transferred to the foundation. The amount of energy transferred and absorbed depends on the type of bollard. For a rigid bollard, a large portion of the kinetic energy is transferred to the colliding vehicle compared to the amount absorbed by the bollard itself due to the low elastic-deformation properties of the rigid bollard whilst for a flexible bollard, a lesser portion of the kinetic energy is transferred to the vehicle.

\subsubsection{Relevant Studies of Impact Loads on Vehicular Barriers}

Most research, focused on impact loads on barrier systems including bollards, significantly analyze the stresses and strains in the materials due to the impact load and deformation characteristics of the bollards. These analyses are based on deflection versus time, acceleration versus time, impact loads versus time, energy versus speed, etc. graphs and 
may use any of the design methods discussed above to analyze the loads (El-Sakawaky et al., 2004; El-Tawil, 2004; Itoh et al., 2011).

AASHTO (2002) proposed two design impact loads for traffic barrier analyses: $44.5 \mathrm{kN}$ and $240 \mathrm{kN}$. The $240 \mathrm{kN}$ is a dynamic load used during ultimate strength analysis while the $44.5 \mathrm{kN}$ is used as an equivalent static load in elastic analysis. Bligh et al. (2010) conducted a study of the stability of a $690 \mathrm{~mm}$ high $\times 241 \mathrm{~mm}$ thick precast concrete barrier tested over $3050 \mathrm{~mm}$ long section using a bogie vehicle. The results showed that the ultimate static load distributed over a longitudinal barrier length of $1 \mathrm{~m}$ was $40.5 \mathrm{kN}$ and the maximum dynamic load from the impact load test was $189 \mathrm{kN}$ at a speed of $20.9 \mathrm{~km} / \mathrm{h}$. The maximum dynamic deflection from the impact load test was $200 \mathrm{~mm}$ measured at the top of the barrier and $69 \mathrm{~mm}$ at the ground level without the barrier wall shearing. For the static load tests, the maximum horizontal deflection at the top of the barrier was $18 \mathrm{~mm}$ and the ground level was $3 \mathrm{~mm}$.

From an impact experiment on a reinforced concrete barrier using an iron ball pendulum conducted by El-Sakawaky et al. (2004), it was observed that the duration of impact averaged $0.1 \mathrm{~s}$ with the peak value recorded at $0.03 \mathrm{~s}$. During the impact, the initial energy of the striking body caused a deformation on the impacted body and after the impacted body had reached its maximum deflection, the velocity of the colliding body reached zero and by which time all the kinetic energy was transferred to the impacted body. In an experiment to determine the impact performance of a fence post using a $470 \mathrm{~kg}$ pendulum, Itoh et al. (2011) concluded that the dissimilarities in the deflection versus impact load graphs for the same experimental studies was as a result of the different positions of the load cells at the points of collision. 


\subsection{Foundation Systems}

A foundation is a structure that transmits the loads from a structure to the soil. Foundations are classified into two main types: shallow and deep foundations depending on factors such as ground conditions, site and environmental conditions, as well as mode of load transfer. A foundation may be designed to resist static, dynamic or impact loads depending on the load application and the nature of load transfer. The response of the structure to the applied load, either static, dynamic or impact depends largely on the type of foundation used.

Shallow foundation is employed when the depth of the foundation is less than the width of the footing. Typical examples of shallow foundation include spread, mat and raft foundations. For deep foundations, the depth of the foundation is greater than the width of the footing. Different types of deep foundation include, piers, caissons and pile foundations. Deep foundation is normally used when the ground or surface soil conditions are unsuitable to support the structure. However, for some structures like vehicle bollards, deep foundations such as piles maybe recommended due to the configuration of the design and the method of load transfer.

\subsubsection{Types of Piles}

Piles can be classified based on method of load transfer, method of installation and type of material used. Based on the nature of load transfer, piles can be classified into frictional and end-bearing piles. Friction piles transfer load through skin friction between the surface of the pile and the soil. These piles normally do not rest on hard stratum like rock materials. The load is transferred through vertical and lateral distribution to the surrounding stratum using friction between the pile and the surrounding soil. End-bearing piles, on the other 
hand, transmits load to the soil through the lower end of the pile by direct load application. The load resistance is derived from the base. Due to the nature of load transfer, these types of piles are normally supported on stiff or hard stratum such as hard rock and very dense gravel and sand materials.

Based on the method of installation, piles can be classified as large volume displacement piles, small volume displacement piles and non-displacement piles. For large volume displacement piles, a significant volume of soil is displaced during installation. Examples of these piles include closed-ended steel pipe piles and driven precast solid concrete piles (piles driven into the ground without any pre-bored hole). For small volume displacement piles, a small volume of soil is displaced during installation. Typical examples of these types of piles are $\mathrm{H}$ and open-ended steel pipe piles. For nondisplacement piles, a considerable volume of soil is removed and replaced with concrete during installation. Typical examples are bored and cast-in-place concrete piles.

Based on the type of material used in construction, a pile may be classified as steel, timber, concrete or composite pile. Timber piles are made from branches or whole tree trunks with bark removed and treated with preservatives. Timber is readily available and can be cut to desired lengths for its use. Although timber has a limited structural capacity, it is a cheaper material and durable for construction and stabilization of slopes and buildings in marshy areas. Concrete piles are constructed by installing precast concrete or cast in-situ. Precast concrete piles may be reinforced or prestressed depending on the use of the pile while cast in-situ maybe cast-in-place by pouring concrete into a drilled hole. Due to high capacity and reasonable cost, concrete piles are mostly employed in various constructions. However, these piles can be damaged by organic soils or acidic 
environments and may experience abrasion due to wave action when used for offshore foundations. Piles made of steel are often driven into the ground. These piles have high structural capacity and can carry relatively heavier loads since it can be driven to higher depths. They are mostly light weight and easy to handle. Composite piles are combinations of different materials to form a single pile. This may include combination of steel, timber, concrete and polymer materials. However, when constructing composite piles, timber piles have to be installed above the ground water table since it is vulnerable to insect attack and decay. These types of piles have high cost of manufacturing and are susceptible to corrosion in marine environments.

\subsubsection{Pile Foundation Design}

Pile foundation is a type of foundation system used to transfer surface loads from a structure to underlying layers with higher strength capacity. This type of foundation consists of a single or group of piles. According to Bowles (1997), the mode of load transfer may be through bearing of the pile at the end or through friction along the pile shaft. Piles are designed to resist axial and horizontal (lateral) loads depending on the direction of loading relative to the axis of the pile. In any circumstance, the pile foundation is designed to provide resistance against ultimate load capacity and deflection from the superstructure. The lateral load transmission mechanism of piles is particularly relevant to the design of vehicle anti-ram bollard systems. This is because horizontal impact load from the vehicle is applied at the top of the bollard and hence the design of laterally loaded piles can be employed. The mode of design is to check for critical safety factors against ultimate lateral capacity and deflection (i.e., foundation movements, soil-pile interaction). 


\subsubsection{Laterally Loaded Piles}

Laterally loaded piles are vertically slender structural members which are partially or fully embedded in the soil for effective performance. Typical applications of laterally loaded piles are sign posts, vehicular bollards, marine piles and power poles (Bowles 1997). The mechanism for the operation of a laterally loaded pile is to resist translation, rotation and bending in the direction of the applied load. The analysis of piles subjected to lateral loads considers the length of the pile, the top boundary conditions (the head fixity) and the soilpile interaction response to failure (stiffness of soil and pile). A pile may be categorized as a short or a long pile. The embedment depth of a short pile in the soil is smaller and will either translate or rotate under lateral loads as opposed to a long pile with higher embedment depth which will bend due to its slenderness and the high passive resistance at the lower part of the long pile. The ultimate lateral capacity of a short pile is controlled by the yielding of the soil (stiffness of soil along the whole length of the pile embedment depth). Conversely, the lateral capacity of a long pile is controlled by the failure of the pile itself at the point of maximum moment because it will yield structurally before the soil fails as seen in Figure 2-3.

The pile head fixity can be considered as a fixed or free head condition as observed in Figure 2-4. An example of a free head pile is vehicular bollard where a significant portion of the pile protrudes at the surface or a drilled shaft supporting a highway sign post. Free head piles have no restrictions on the lateral movement of the head and also rotate when subjected to horizontal loads (including shear and moment). Fixed head piles, such as a pile group connected with a pile cap at the top, have their head restricted from moving laterally but rotate when subjected to shear and moment loading. 
The ultimate lateral capacity (ultimate limit state) and deflection (serviceability limit state) conditions are considered for the design of laterally loaded piles. But the deflection is most likely to control the design unless for structures such as anchor piles for offshore construction where large deflections can be allowed.

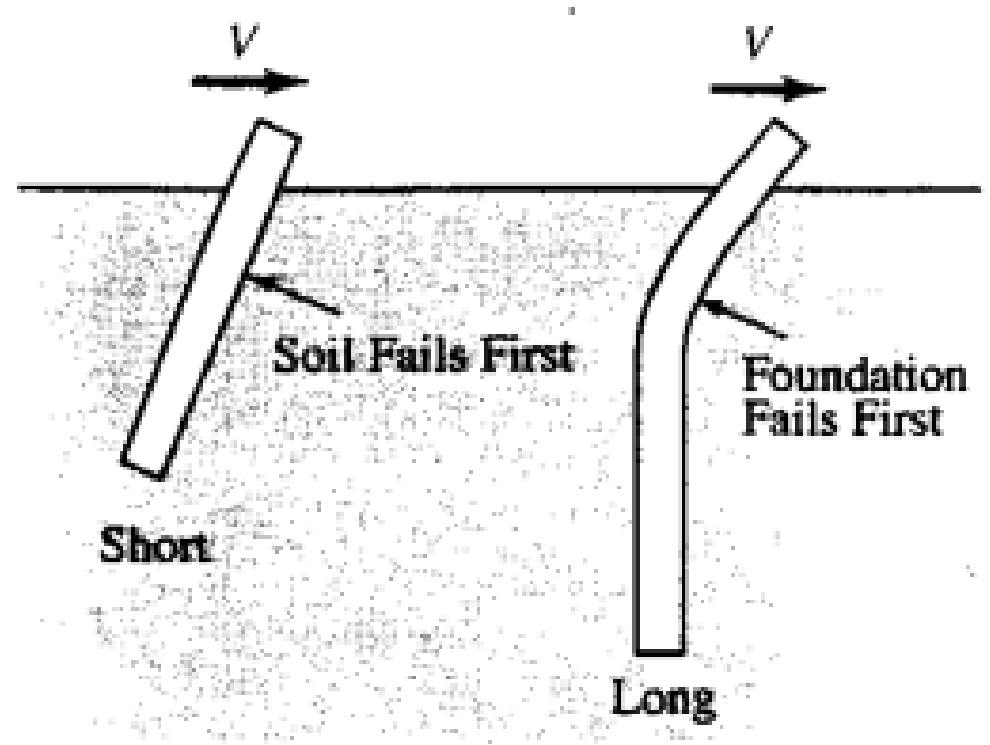

Figure 2-3: Failure mechanism for short and long piles (Cudoto, 2001)

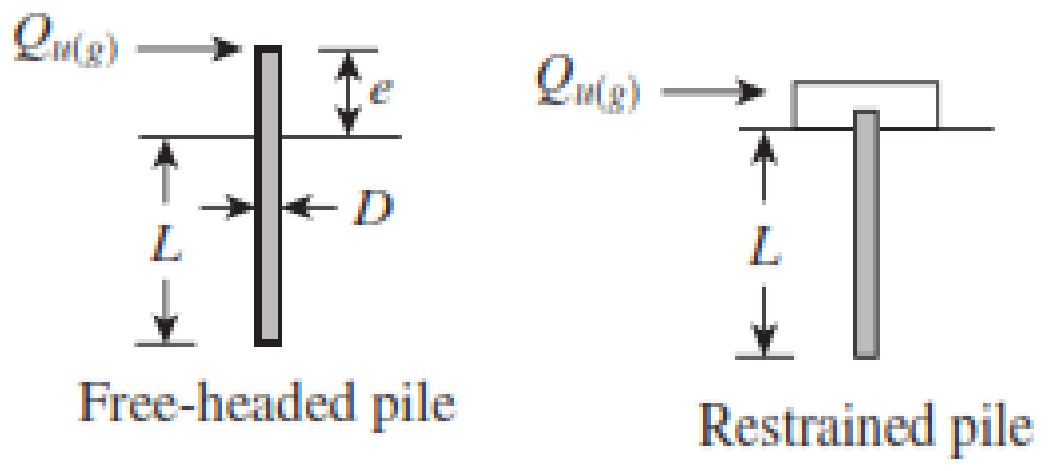

Figure 2-4: Pile head fixity (Das, 2010) 


\subsubsection{Lateral capacity under static loading}

Broms (1964) proposed a method to determine the ultimate lateral capacity of piles under free or fixed head conditions for cohesive and cohesionless soils. For vehicular bollards which exhibit free head conditions, Broms' proposed method for free head piles may be considered. This method considers the distribution of ultimate lateral pressures along the pile and the static equilibrium of the pile at the point of failure. The ultimate lateral pressure can be expressed for different soils.

Cohesive soils

$$
q_{u}=9 C_{u}
$$

where, $C_{\mathrm{u}}$ is the shear strength of the soil.

Cohesionless soils

$$
q_{u}=3 K_{p} \sigma_{z}
$$

where, $K_{\mathrm{p}}$ is the coefficient of passive earth pressure and $\sigma_{z}$ is the effective stress of the soil which is equal to the overburden pressure.

$$
K_{p}=\tan ^{2}\left(45+\frac{\phi}{2}\right)
$$

where, $\phi$ is the friction angle of the cohesionless soil.

a) Ultimate lateral capacity of a short piles under free-head conditions:

For a short pile where the failure mechanism is a result of yielding of the soil,

$$
M_{\text {max }}<M_{\text {yield }}
$$

where, $M_{\max }$ is the moment resistance from the soil and $M_{\text {yield }}$ is the moment resistance of the pile itself. The failure mechanism is presented in Figure 2-5. 


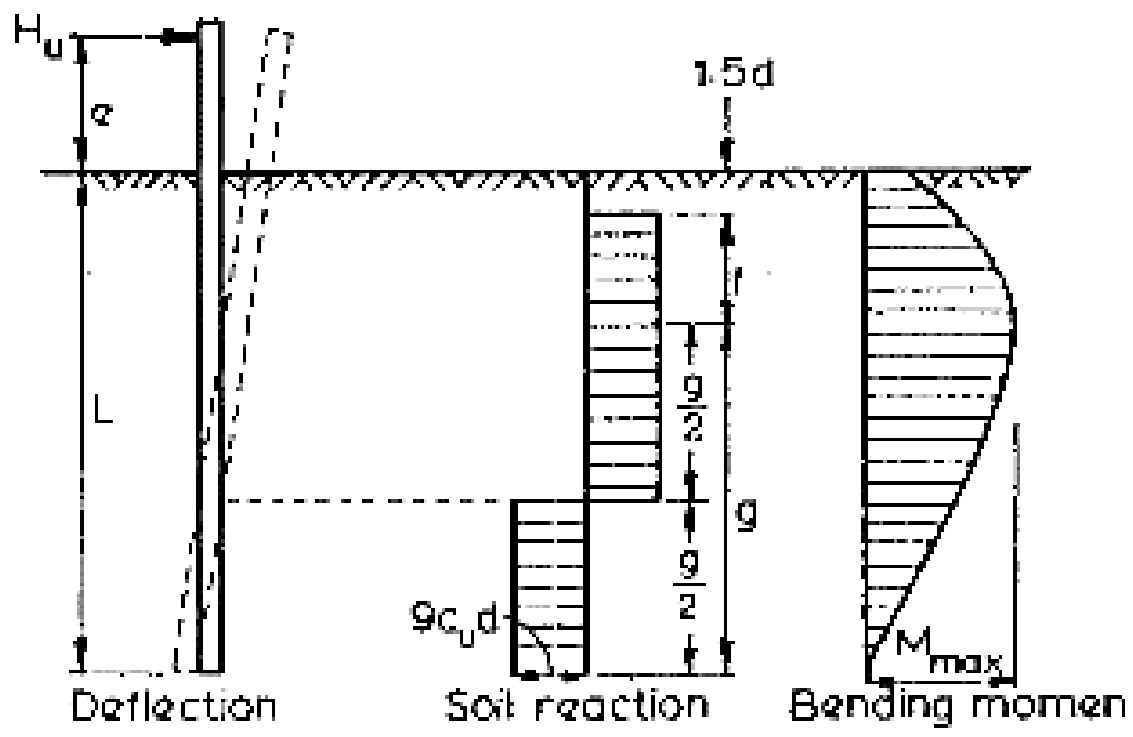

Figure 2-5: Failure mechanisms of short piles (Broms, 1964)

At static equilibrium conditions, the following equations can be deduced for a free head short pile in cohesive soil.

$$
M_{\max }=H_{u}\left(e+1.5 d+\frac{f}{2}\right)
$$

also,

$$
H_{u}\left(e+1.5 d+\frac{f}{2}\right)=\frac{9 c_{u}}{4}(L-1.5 L-f)^{2}
$$

and

$$
f=\frac{H_{u}}{9 c_{u} d}
$$

where, $H_{\mathrm{u}}$ is the lateral load capacity, $d$ is the diameter of the pile, $e$ is the eccentricity (distance from the ground surface to the load application of the pile).

$$
M_{\text {yield }}=\frac{2 E_{p} I_{p}}{d}
$$


where, $E_{p}$ is the elastic modulus of the pile and $I_{p}$ is the sectional modulus of the pile. Alternatively, the lateral capacity of short piles in cohesive soils can be obtained from Figure 2-6 below. The lateral capacity $P=H_{u}$ of short piles in cohesionless soils can also be obtained from the Figure 2-7.

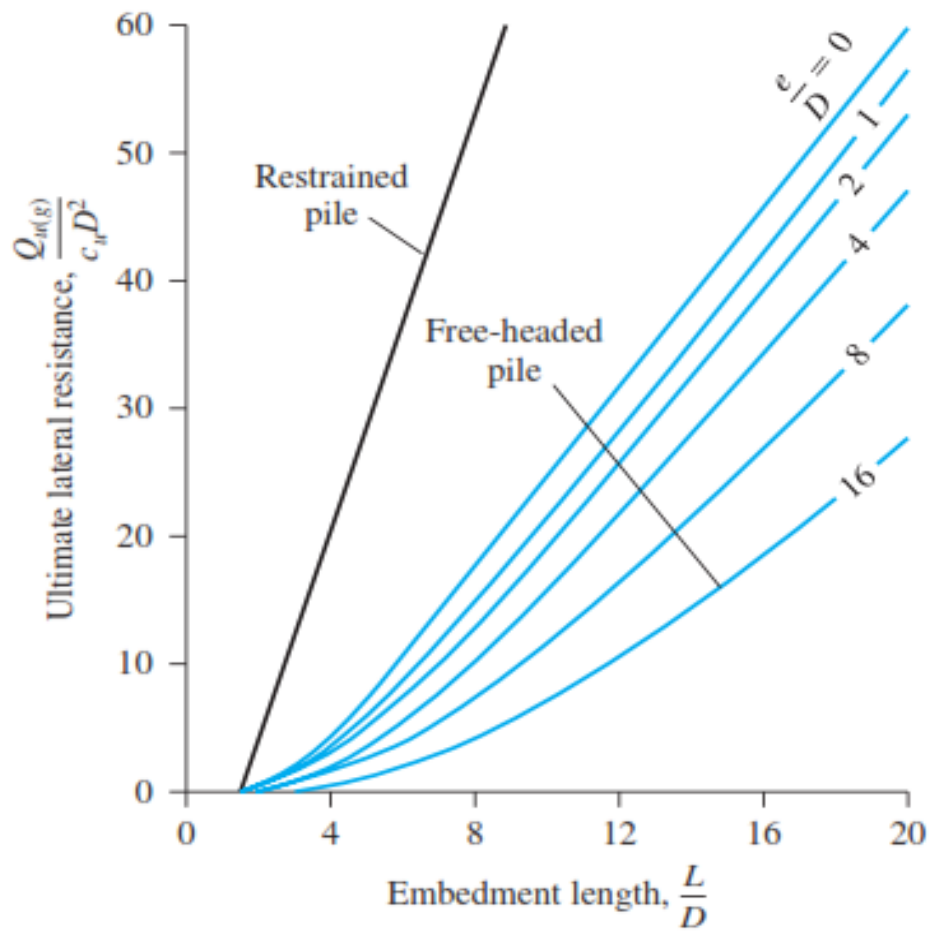

Figure 2-6: Broms' graph for finding lateral capacity of short piles in cohesive soils 


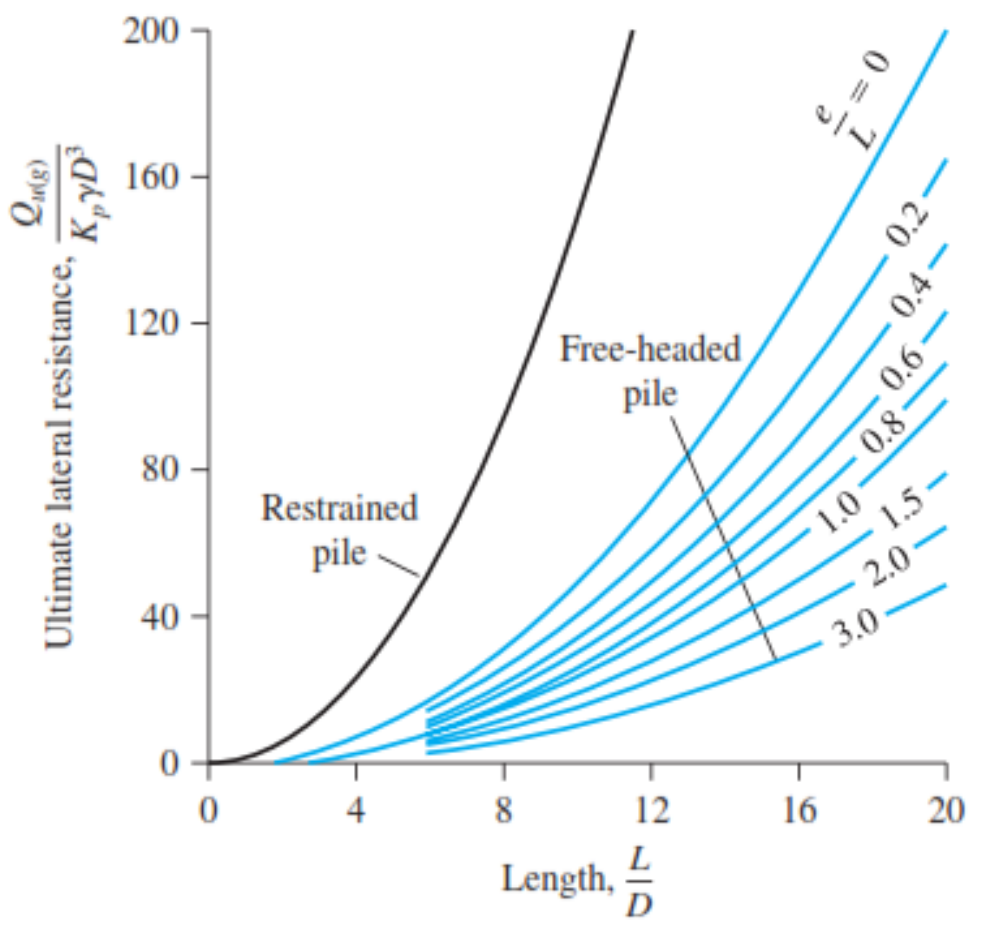

Figure 2-7: Broms' graph for finding lateral capacity of short piles in cohesionless soils

b) Ultimate lateral capacity of a long pile under free-head conditions:

Since the ultimate lateral capacity of a long pile is due to the yielding of the pile itself, the maximum moment of the pile will be reached prior to the failure of the soil.

$$
\boldsymbol{M}_{\text {yield }}<\boldsymbol{M}_{\text {max }}
$$

The failure mechanism for long piles can be seen in Figure 2-8. 


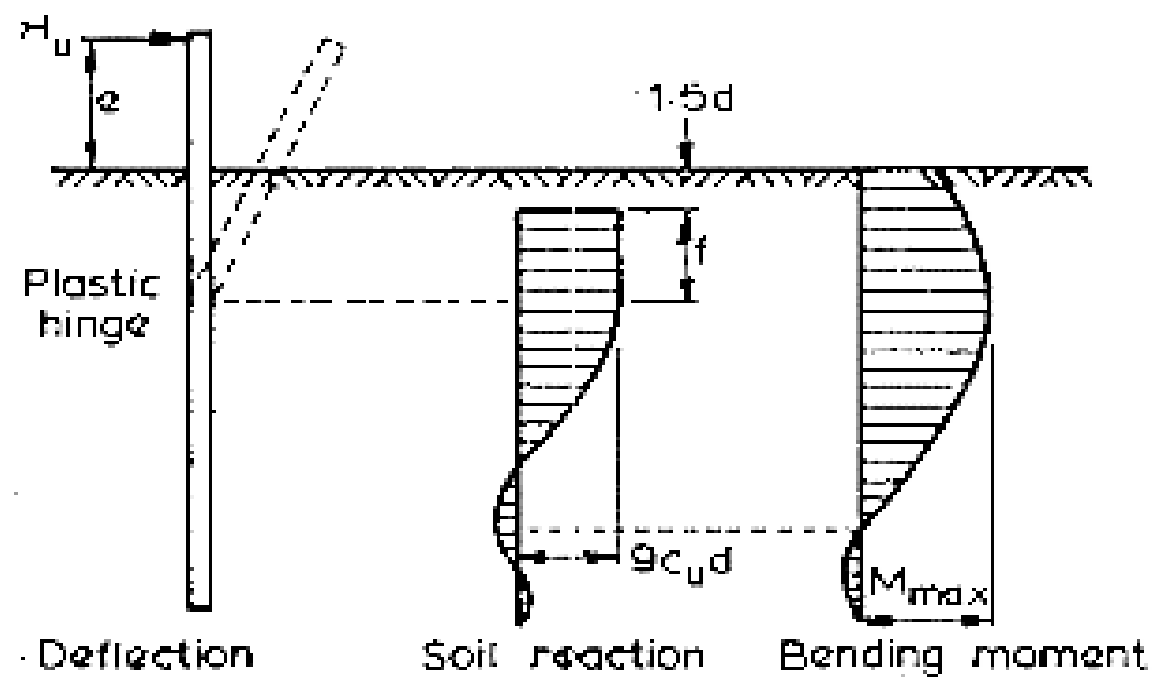

Figure 2-8. Failure mechanism for long piles

For cohesive soils, at failure, $M_{\text {yield }}=M_{\max }$ and lateral capacity is given as;

$$
\boldsymbol{H}_{u}=\frac{\boldsymbol{M}_{\text {yield }}}{(\boldsymbol{e}+1.5 d+0.5 f)}
$$

Alternatively, the lateral capacity of long piles in cohesive soils can be obtained from Figure 2-9. The lateral capacity $P=H_{u}$ of long piles in cohesionless soils can also be obtained using Figure 2-10. 


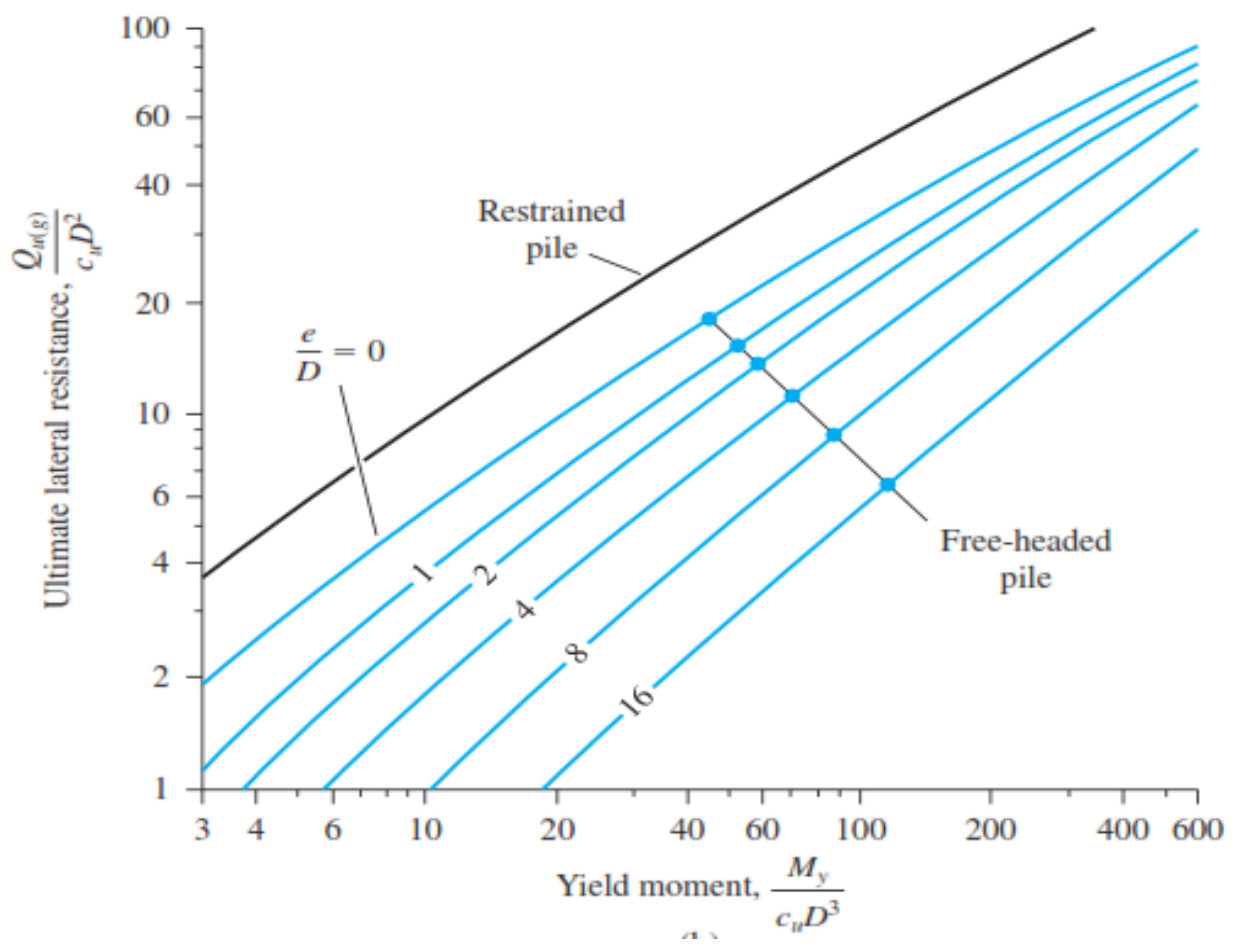

Figure 2-9: Broms' graph for finding lateral capacity of long piles in cohesive soils

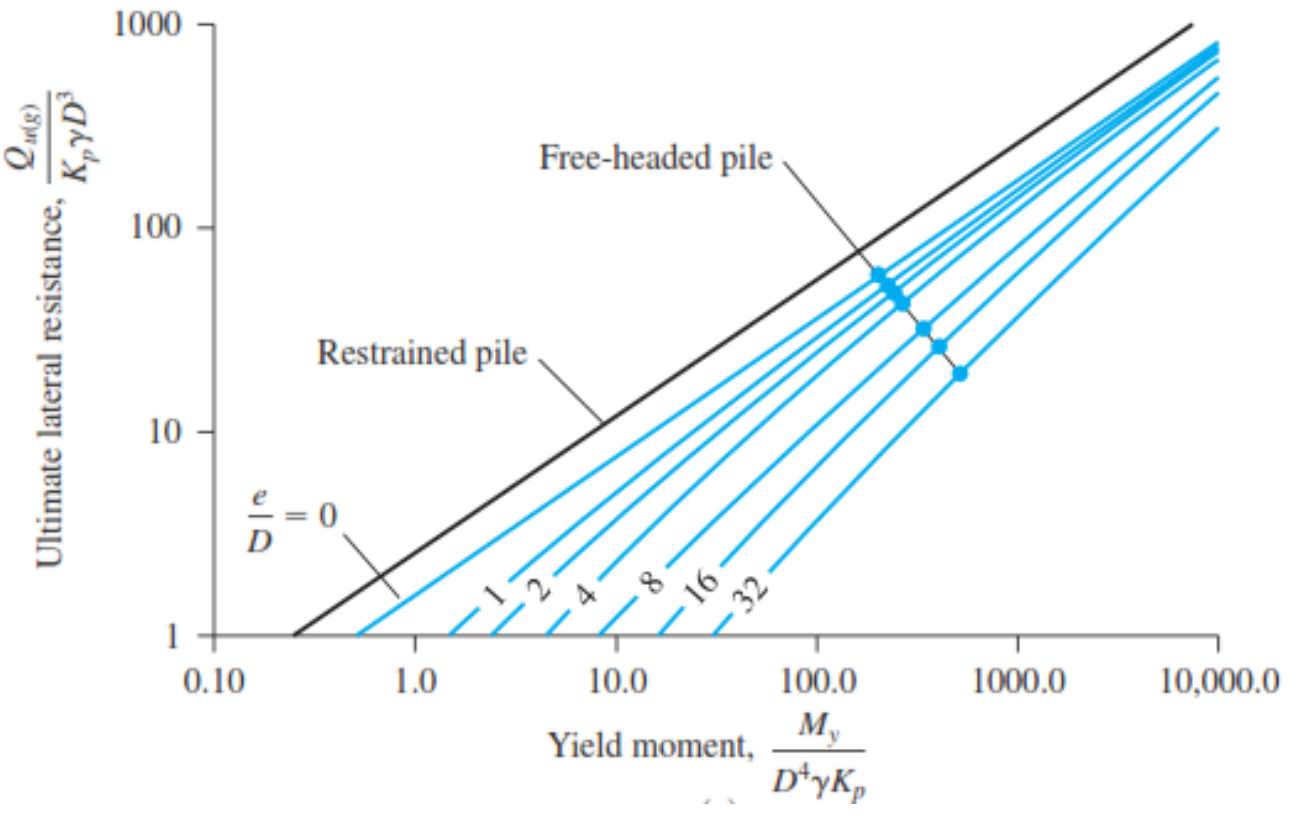

Figure 2-10: Broms' graph for finding lateral capacity of long piles in cohesionless soils 


\subsubsection{Lateral capacity under dynamic loading}

The causes of horizontal dynamic loads on piles may be as a result of wind effect, machine vibration and earthquake vibration (mainly through wave propagation). According to Cudoto (2001), the effect of dynamic loads result in lateral movement and flexural failure which could eventually lead to excessive settlements and pushes the foundation out of position. Lateral dynamic loads cause lateral deflections, which can be evaluated using $\mathrm{p}$ y analyses.

Majority of foundation failures due to dynamic loads are as a result of liquefaction. Foundation designs in liquefiable soils should have enough stiffness, strength and ductility to resist dynamic loads. Soil and pile interaction under dynamic loads are normally nonlinear and hence the damping and stiffness must be considered in terms of the shear modulus of the soil. Therefore, effective prediction of dynamic pile response depends on factors such as pile dimensions and soil properties including material damping, soil shear modulus, geometrical damping and strain level (Puri and Prakash, 2010). Some methods for predicting the lateral dynamic response of piles include equivalent cantilever analysis explained by Poulos and Davis (1980) and Novak's analysis (Novak, 1974).

\subsubsection{Lateral deflection}

According to Cudoto (2001), lateral resistance of a pile is induced in the soil as a result of lateral deflection (Figure 2-11). Close to the ground surface, the load applied is opposed by the resistance of the soil which results in a decrease of the deflection with depth. The deflection is induced in the opposite direction to the applied load. The magnitude and shape of the deflection curve is mainly predicted based on the type of applied loads (i.e. shear and moment), the resistance-deflection relationship of the soil (p-y curve) and the flexural 
rigidity of the foundation. The flexural rigidity is a product of the elastic modulus and the moment of inertia of the foundation. Also, deflection is mostly caused at the top of the foundation when a lateral load is applied to the structure.

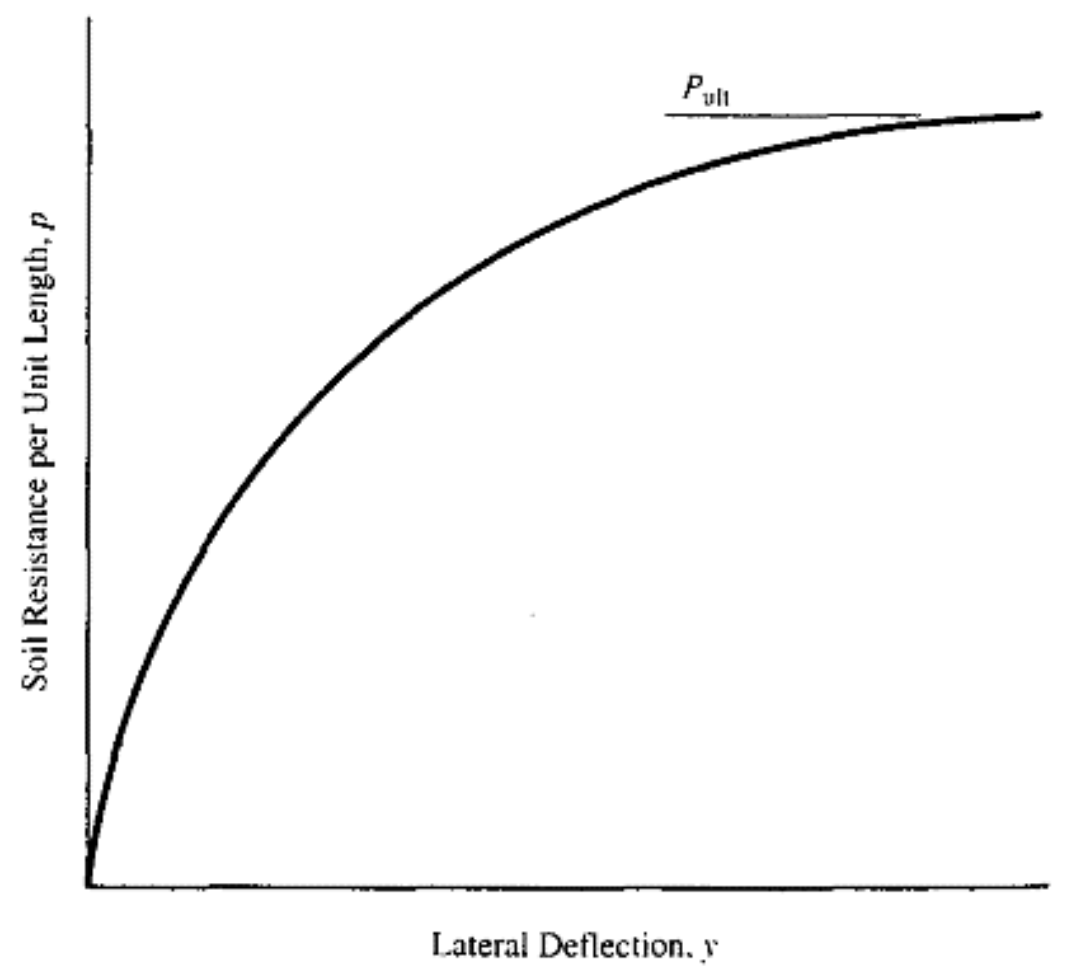

Figure 2-11: Soil resistance per unit length as a function of deflection (Cudoto, 2001)

There are three main methods for determining the deflection of a laterally loaded pile. These methods include subgrade reaction method, elastic analysis (or elastic continuum) method, and p-y method.

a) The subgrade method

This method involves modelling the pile and soil, and assumes that deformation occurs where loading exists and the soil behaves as a series of unconnected linearly-elastic springs. The advantage of this method is its simplicity of use. However, it has the 
disadvantage that the spring modulus of the subgrade is dependent on the foundation and the lack of continuity in the stress distribution of the soil.

Poulos and Davis (1980) summarize the subgrade method as follows. The deflection of the pile can be related to the pressure at a point as

$$
\boldsymbol{p}=\boldsymbol{k}_{h} \boldsymbol{\rho} \quad 2.15
$$

or

$$
\boldsymbol{w}=\boldsymbol{K} \boldsymbol{\rho}
$$

where, $p$ is the pressure at a given point, $\rho$ is the deflection, $k_{h}$ is the modulus of subgrade reaction, $w$ is the soil reaction and $K$ is the subgrade modulus given by

$$
\boldsymbol{K}=\boldsymbol{k}_{\boldsymbol{h}} \boldsymbol{d}
$$

where, $d$ is the diameter of the pile and $k_{h}$ can be determined from numerical methods.

The pile is governed by the beam equation below

$$
E_{p} I_{p} \frac{d^{4} \rho}{d z^{4}}=-p d
$$

where $E_{p}$ is the modulus of elasticity of the pile, $I_{p}$ is the moment of inertia of the pile section, and $z$ is the depth of the pile in soil. Combining equations (2.15) and (2.18), the governing equation for the deflection of a laterally loaded pile is

$$
E_{p} I_{p} \frac{d^{4} \rho}{d z^{4}}+k_{h} d \rho=0
$$

\section{b) The p-y method}

This method is mostly used for flexible laterally loaded piles and is based on a beam on nonlinear wrinkler foundation, hence pile and soil modelling. Ashford et al., (2013) stated 
that this method uses a series of nonlinear soil springs to represent a relationship between soil resistance, $p$, and relative deflection, $y$. The method relies on a series of $p-y$ curves which depend on data from lateral pile load tests (Zhang, 2009). However, the disadvantage of this method is that it cannot be used to solve deflection problems with a complex three dimensional interaction between soil and piles (Basu et al., 2009).

The p-y method used for deflection analysis in determining the finite-difference solution is described by Reese and Matlock (1956), as follows

$$
\frac{d^{2} M}{d z}+\left(P_{z}\right) \frac{d^{2} \rho}{d z^{2}}-p=0
$$

where, $\rho$ is the deflection, $M$ is the moment at depth $\mathrm{z}$ in the pile, $P_{z}$ is the axial load on the pile at depth $\mathrm{z}$, and $p$ is the line loading or soil reaction per unit length. The solution to Equation 2.20 is by the use of a series of p-y curves for different points along the pile, which shows the independent soil behavior at different locations (Poulos and Davis, 1980). Typical of these curves is shown in Figure 2-12 below. 

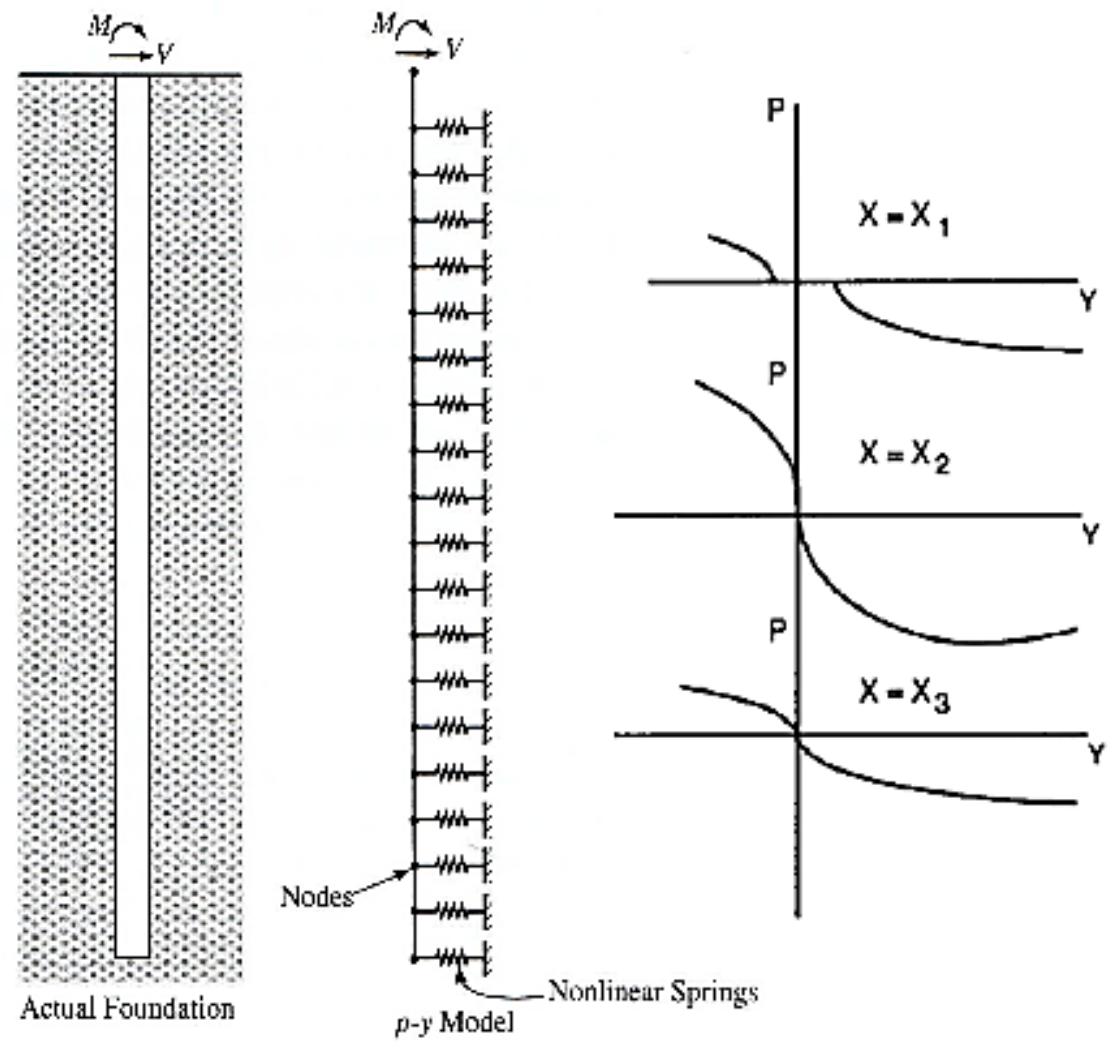

Figure 2-12: The concept of p-y curves (Cudoto, 2001)

\section{c) The elastic continuum method}

This method incorporates the use of three dimensional methods such as finite element method and takes into account the continuous nature of the soil. The advantage of this method is that it takes into account the continuity of the soil and allows the analysis of total movements. However, this method is complex to use in practice due to the difficulty in determining the exact soil modulus.

The following assumptions are also made.

1. The horizontal stress $p$ is assumed constant across the width of the pile

2. The soil at the back of the pile near the surface adheres to the pile. 
According to Poulos and Davis (1980), using the continuum method, the deflection and rotation of the pile can be analyzed as

$$
\begin{gathered}
\rho=\frac{H_{u}}{E_{S} L}\left(I_{\rho H}+\frac{e}{M} I_{\rho M}\right) \\
\theta=\frac{H_{u}}{E_{s} L^{2}}\left(I_{\theta H}+\frac{e}{M} I_{\theta M}\right)
\end{gathered}
$$

where, $H_{u}$ is the horizontal load applied to the pile, $E_{s}$ is the elastic modulus of the soil, $L$ is the length of pile, $e$ is the load eccentricity and $M$ is the moment acting on the pile. $I_{\rho H}$ and $I_{\theta M}$ are elastic coefficients for deflection due to horizontal applied load and elastic coefficients for head rotation due to bending moment respectively as seen in Figure 2-13 and Figure 2-14. Also, $I_{\rho M}$ and $I_{\theta H}$ are elastic coefficients for deflection due to bending moment and elastic coefficients for head rotation due to horizontal applied load respectively. These are obtained from Figure 2-15. From the graphs, L and d, are the length and diameter of the pile while $V_{s}$ is the poison ratio of the soil. The elastic coefficients are a function of elastic constant, $K_{R}$ given by:

$$
K_{R}=\frac{E_{p} I_{p}}{E_{s} L^{4}}
$$

where, $E_{s}$ is the modulus of elasticity for the soil. 


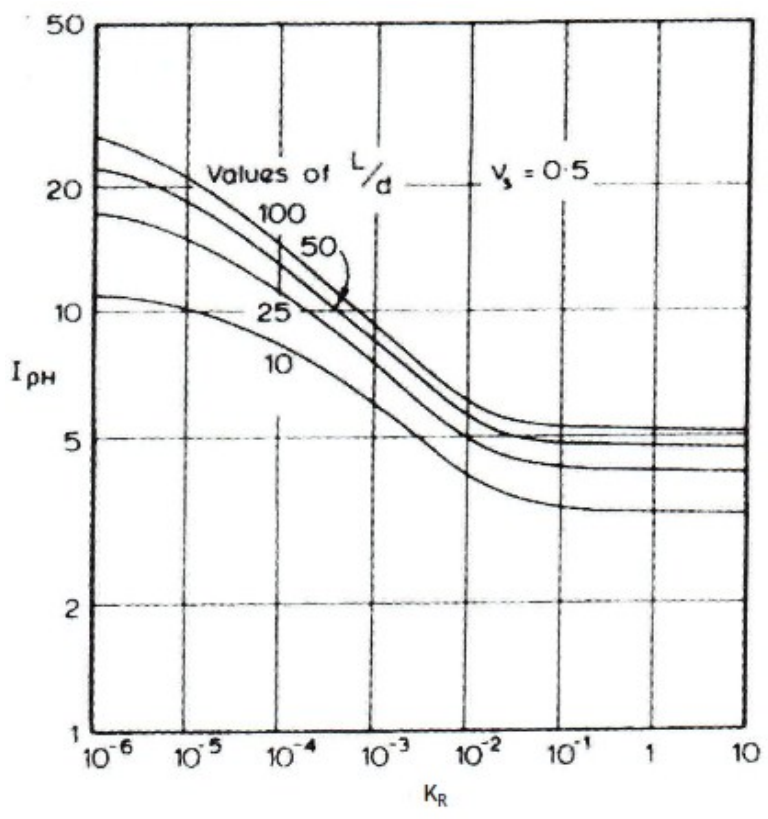

Figure 2-13: Graph of elastic coefficient $I_{\rho H}$

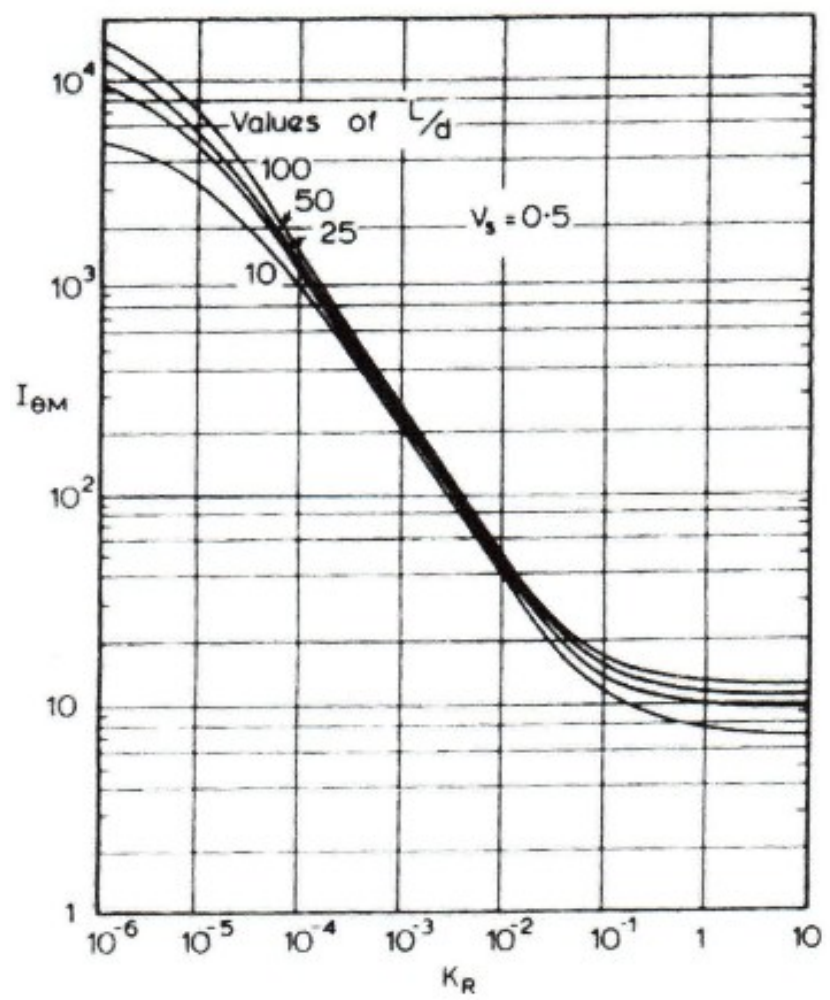

Figure 2-14: Graph of elastic coefficient $I_{\theta M}$

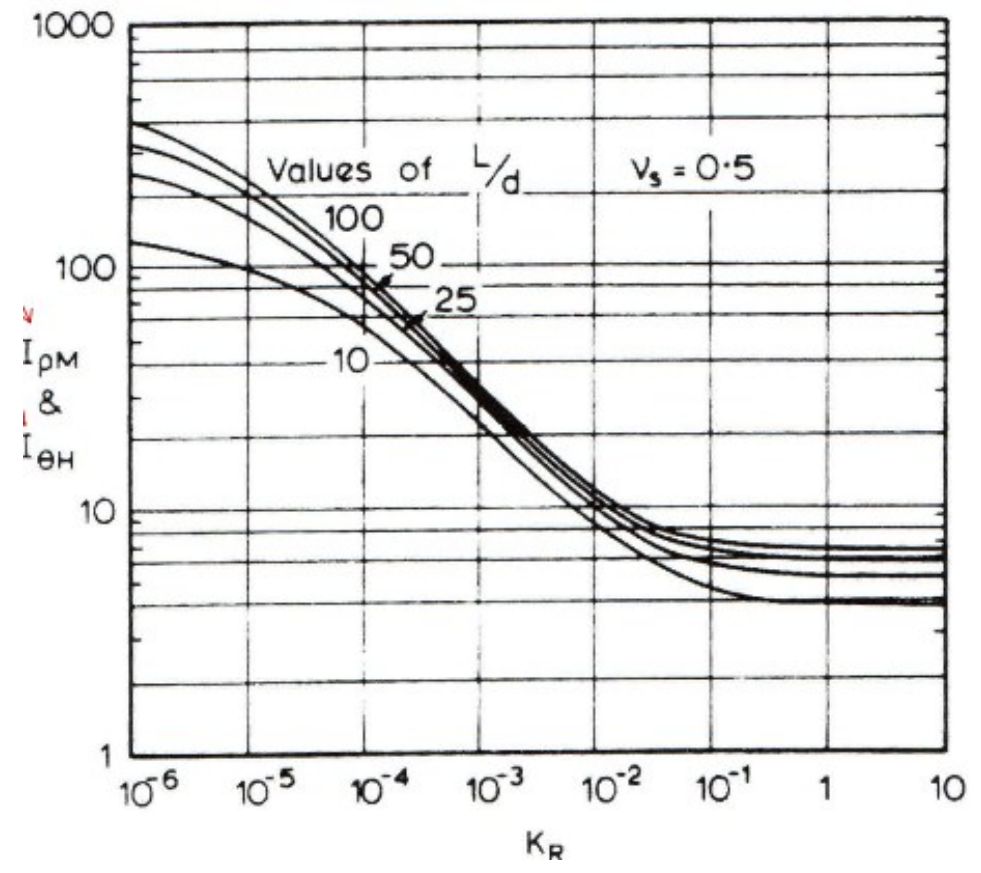

Figure 2-15: Graph of elastic coefficients $I_{\rho M}$ and $I_{\theta H}$ 


\subsubsection{Laterally Loaded Pile Testing}

Lateral capacity for a foundation can be evaluated experimentally or analytically. A fullscale load test is an example of experimental evaluation of lateral capacity of foundations (Figure 2-16). Cudoto (2001) summarized that lateral load test is done to measure the deflection after applying a series of lateral loads. Strain gages may be placed at different depths and used to calculate the deformation and the results can be plotted on a loaddeflection curve. Lateral load test for piles can be done under static or dynamic load test conditions in the laboratory or in the field.

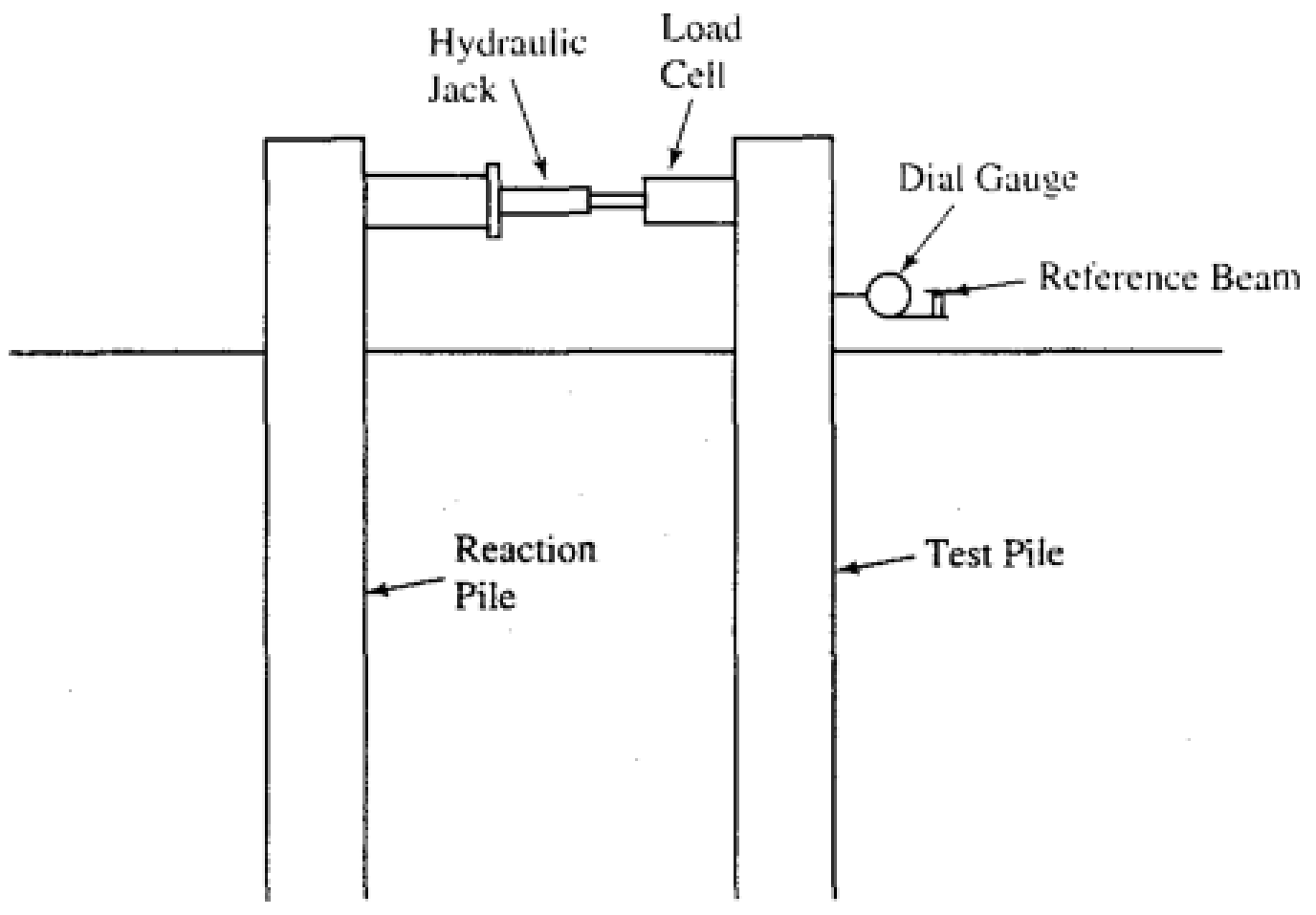

Figure 2-16: An example of a full-scale lateral load test (Cudoto, 2001)

A full scale static load test is carried out as a load controlled test or deflection controlled test (i.e. constant rate of penetration test and constant settlement increment). In 
the load controlled method, the loads are applied in steps from about a quarter of the design load to a total of about twice the design load. At each step, the load is for a period depending on the rate of testing. For a slow test, the load at a step maybe maintained between one to two hours while it can be held for two to fifteen minutes with a quick load controlled test. In the deflection controlled method (constant rate of penetration test), a rate between 0.25 to $2.5 \mathrm{~mm} / \mathrm{min}$ is mostly specified before loading. The load on the pile is increased to maintain the constant rate of penetration specified. Similar to the load controlled method, in the constant rate of penetration test the load is increased to a total of twice the design load and gradually unloaded upon reaching the maximum load. In the constant settlement increment test, the load is repeatedly applied and removed. ASTM D3699 (2007) describes the standard test methods for laterally loaded pile foundations subjected to static loading.

Dynamic load test also known as high strain impact testing is normally used to determine pile resistance during pile driving and after driving. In this method, the pile elastic response to the impact force of the hammer during driving is measured. This is done by using strain transducers and accelerometers to record compressive waves travelling down the pile shaft as a result of impact force application during pile driving. Some of the compressive waves are reflected on the pile-soil shaft and toe resistance. A pile drive analyzer device is also used to compute the pile resistance based on numerical interpretation of a dynamic wave equation. Numerical interpretation software including GRLWEAP and CAPWAP by Pile Dynamics Inc. (2010) can be used in analyzing data obtained from dynamic pile driving. ASTM D4945 (2012) describes the standard testing methods for dynamic pile driving. 


\subsubsection{Standards for Crash Testing}

In order to avoid excessive deformation, and to be able to resist the impact load from a vehicle, the foundation for a barrier system should have sufficient stiffness and strength (Dawson and Tennant, 2008). According to El Naggar (2008), in the design of foundations for impact loads, the soil parameters needed to be addressed include the density, shear modulus, Poisson's ratio and material damping ratio. Also, El-Tawil, (2004) stated that the resistance of impact load due to foundation depends on the type of soil used and the area of the base of foundation. Therefore, the soil used for crash testing in the design of vehicular bollards must meet the specification materials for soil aggregate sub-base, base and surface courses and also be compacted according to AASHTO (1990).

Researchers describe specification of soil used for impact load testing in different ways. Ross et al. (1993) briefly explained that the dimensions of the soil embedment should be able to support the impact loading. If the dimensions cannot be determined, the lateral distance of the test soil outside the embedded soil should be about 1.3 times the embedment length and the depth must be kept approximately 1.2 times the embedment length of the test. According to ASTM (2007) the characteristics of the soil used for bollard design must be low-cohesive, well-graded crashed stone or broken gravel of similar size distribution in Table 2-2. The soil must be either a fill material compacted to a density of not less than $90 \%$ maximum dry density or an in-situ natural soil. 
Table 2-2: Recommended soil foundation material for bollard design (from AASHTO, 1990)

\begin{tabular}{|l|l|}
\hline Sieve size, mm (in.) & Mass \% Passing \\
\hline $\mathbf{5 0 . 0}(\mathbf{2})$ & 100 \\
\hline $\mathbf{2 5 . 0}(\mathbf{1})$ & $75-95$ \\
\hline $\mathbf{9 . 5}(\mathbf{3} / \mathbf{8})$ & $40-75$ \\
\hline $\mathbf{4 . 7 5}($ No. 4) & $30-60$ \\
\hline $\mathbf{2 . 0 0}$ (No. 10) & $20-45$ \\
\hline $\mathbf{0 . 4 2 5}$ (No.40) & $15-30$ \\
\hline $\mathbf{0 . 0 7 5}$ (No. 200) & $5-20$ \\
\hline
\end{tabular}

\subsubsection{Improving Lateral Capacity}

The lateral capacity of a pile can be improved by strengthening the deflection area close to the surface of the ground. Many methods can be used to increase the lateral capacity. Some of these methods include the use of a collar, wings or fins, high strength top soil, short piers, beams or prefabricated concrete or mortar pile (Figure 2-17). The method to be used depends on the type of pile and load to be resisted. For a short pile such as a security bollard, the attachment of fins is appropriate. 


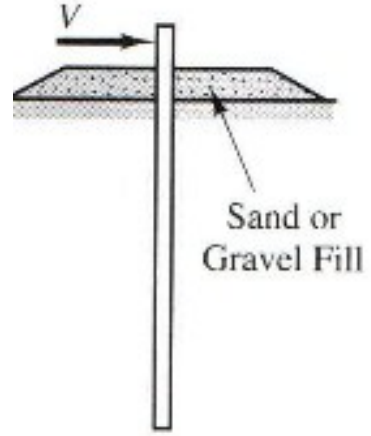

(a)

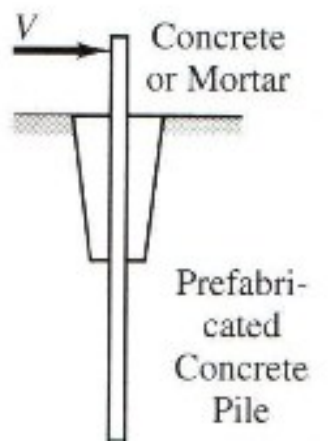

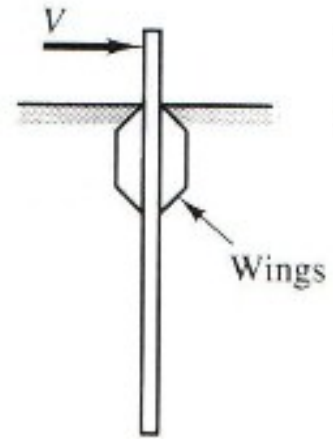

(b)
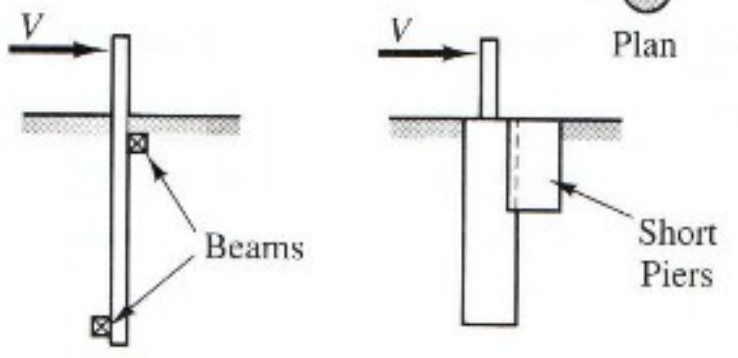

Figure 2-17: Examples of lateral pile improvement techniques

The design of piles with fins has significant effects in resisting loads. Introduction of fins to a pile increases the ultimate lateral load resistance and enhances the performance (Peng et al., 2004). Lateral deflection of a pile also reduces with the effect of fins. Nasr (2013) explained that, when the passive area of soil pressure in front of a finned pile increases, it causes the lateral deflection to decrease. In comparing pile with fins and piles without fins, Bienen et al. (2012) noted that finned piles resisted a significant pile head deflection compared to piles without fins when subjected to lateral loading.

Parameters that should be noted in designing fins for piles are dimensions of the fin (length, width and thickness), configuration and position of the fins on the pile and the interaction of soil and fin on the pile. The fin parameters have to be properly considered 
for higher stiffness and effective performance. Nasr (2013) recommended the thickness of the fins to be sufficient relative to the length and width of the pile to maintain its stiffness. Increasing the length of the fin reduced the lateral deflection and increased the ultimate lateral capacity.

However, for effective performance of piles with fins, the stiffness of the pile shaft, fins and the soil around the pile must work together (Bienen et al., 2012). Also, the overall penetration resistance offered by finned piles is higher when compared by non-finned piles. Further, the penetration resistance is increased with increasing densification of the soil around the pile. Peng et al. (2004) suggested that a non-dimensional factor, fin efficiency factor: ratio of ultimate lateral load of a finned pile to ultimate lateral load of a regular pile without fins, should be considered in assessing the design of finned piles.

\subsection{Methods for Predicting the Design of Bollards}

According to Dawson and Tennant (2008), different methods can be used for the design of bollards and barriers each with its level of accuracy and limitations. These methods include equivalent force methods, crash tests, energy methods and finite element methods. These methods are described by Dawson and Tennant (2008) briefly with regards to foundation design as follows.

\subsubsection{Crash Methods}

Crash testing can generally provide the performance of the bollard when subjected to impact but does not evaluate the performance based on specific site and subgrade conditions and therefore has restrictions for modifications. Also this method does not provide adequate information required to design the foundation. 


\subsubsection{Equivalent Force Methods}

The equivalent force methods (EFM) can accurately provide the performance of the system resulting in highly conservative foundation design. This method does not consider the energy dissipated from the crash and hence produces larger foundation sizes than required. EFM usually uses the ultimate bending capacity of the bollard for foundation design.

\subsubsection{Energy Methods}

The energy method employs the analysis of the vehicle kinetic energy transferred to the bollard and foundation upon impact. Therefore, it considers the amount of energy dissipated using the elastic and plastic deformation on the bollard. The limitation of this method is that it does not consider the actual energy dissipated from the crashed vehicle.

\subsubsection{Finite Element Methods}

The finite element method (FEM) can accurately predict the performance and strength of the bollard while considering the site specific and subgrade conditions. The FEM can be used to model a system to provide the necessary details such as impact duration, penetrations, varying soil compositions, depth of foundations and site specific and subgrade conditions. This method addresses both energy dissipated from the crash vehicle and the energy absorbed by the bollard and the foundation. The major disadvantage of using FEM is its time-consuming simulation, cost and hardware availability results (Pawlus et al., 2013). Also, selection of the right constitutive soil model is a factor in soil modelling and this can sometimes be very challenging.

There are different types of finite element tools used for modelling which include, Ansis, Abarcus, Adina, Flex, LS-DYNA, etc. The type of finite element tool used for a design depends on the nature of the problem and the analysis to be made while considering 
economic implications. According to Pawlus et al. (2013), in crash vehicle analysis, FEM can be considered as a computational tool which gives a detailed insight into the analysis but requires hardware resources to produce efficient results. However, for efficient results and enhanced outcomes of a simulation, it is ideal to compare FEM models to full scale experimental results.

\subsection{Summary}

Some studies have been conducted on vehicular barriers including anti-ram vehicular bollards. The studies use different methods to simulate vehicle loading on the barriers ranging from using static or impact analysis. However, the previous research mostly focused on the resistance of the bollard material and the type of load it can resist without considering the foundation and cost analysis with regards to the design. For efficient analysis of impact loads on vehicle bollards, all the necessary components must be considered and effectively designed using the equations of conservation of energy and momentum from first principle.

Related research on the impact of vehicular loads on bollards is therefore limiting to some extent. The important components for effective design such as the safety of the bollard and its construction, ease of constructability, type of foundation used to resist the impact and the cost analysis must all be considered. Some research which consider the foundation usually assume that the impact loads from the vehicle will be resisted by any kind of shallow foundation while others do not even conduct studies on the foundation. For example, studies carried out by Itoh et al. (2011) on vehicular barriers and how to effectively increase their performance concentrated on the effect of crash impact on the 
barrier without considering the foundation which will be used to support such barrier systems. This thesis presents full scale testing on a vehicular bollard at the Civil Engineering laboratory at Carleton University considering the loads acting on the bollard and the foundation system needed to support the loads. 


\section{Chapter: Experimental Program}

\subsection{Introduction}

The experimental program conducted in this thesis was done to investigate the design of a vehicular bollard foundation using a hollow structural steel pipe pile with various fin configurations. Sandy soil with known characteristics was used as the foundation soil. A total of five (5) bollards with various configurations were built and subjected to both static and impact loadings in the structures laboratory at Carleton University. The pile load tests were conducted in accordance with the ASTM D3966 standard for pile testing under lateral loading (ASTM D3966, 2007). Tests to determine the particle size distribution, compaction, water content and direct shear strength were conducted to characterize the soil properties.

An MTS 290 actuator, mounted on a reaction frame, was used for the static load test while a cylindrical steel pendulum was used for the impact load test. For each test, string potentiometers (string pots) and a load cell were used to monitor the deflections of the bollard and load applied to the bollard, respectively. Measurements of load and deflections were recorded with a Data Acquisition System (DAQ).

\subsection{Configuration of Vehicle Bollards}

The steel pipes were designed for five (5) bollard-pile configurations as seen in Figure 3-1 and investigated under static and impact load conditions. The bollard-pile configurations were made up of different fin types, which were welded onto the pipes. The location of the fins were selected based on the ease of installation and construction. The part of the bollardpile configuration embedded in the soil (forming part of the foundation) is considered the 
pile. Four (4) bollards with different configurations and sizes of fins and one (1) bollard without fins were tested.

The bollards were made from hollow cylindrical steel pipe (HSS $219 \times 9.5 \mathrm{~mm}$ ) with an outside diameter of $219 \mathrm{~mm}$, a wall thickness of $9.53 \mathrm{~mm}$, and a yield strength $\left(F_{y}\right)$ of $317 \mathrm{MPa}$ according to ASTM A500 Grade C. The total length of each pipe was $1900 \mathrm{~mm}$. All bollard-pile configurations were designed to have an embedment depth of $650 \mathrm{~mm}$ (see Figure 3-2). The point of load application (i.e. static or impact) was maintained at a height $950 \mathrm{~mm}$ from the foundation (ground) level. This is in agreement with Dawson and Tennant (2008) suggestion of maintaining the height of bollards at a minimum of 36 inches or $900 \mathrm{~mm}$ above the ground level to be able to engage a test truck for a crash test.

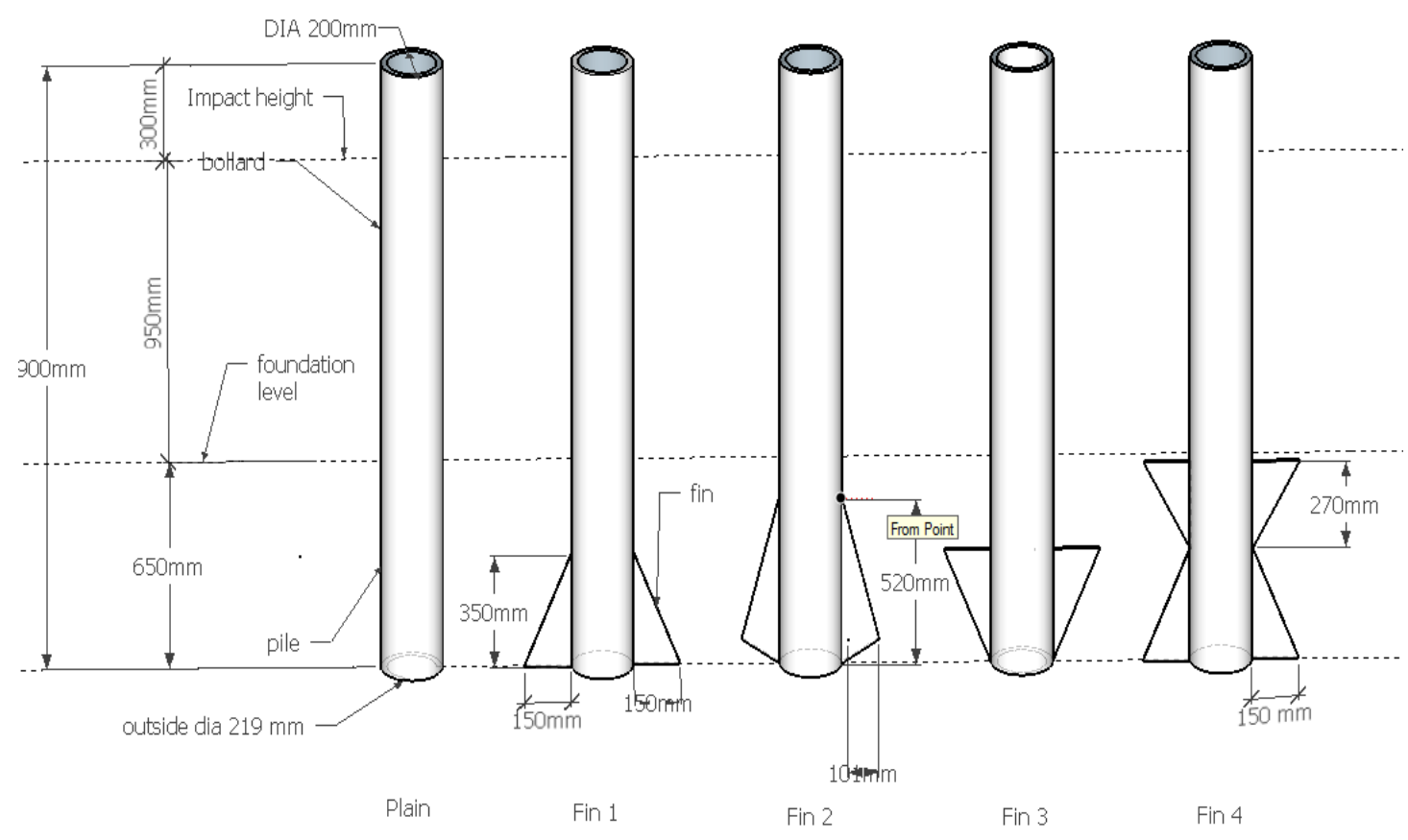

Figure 3-1: Bollard-pile configurations 


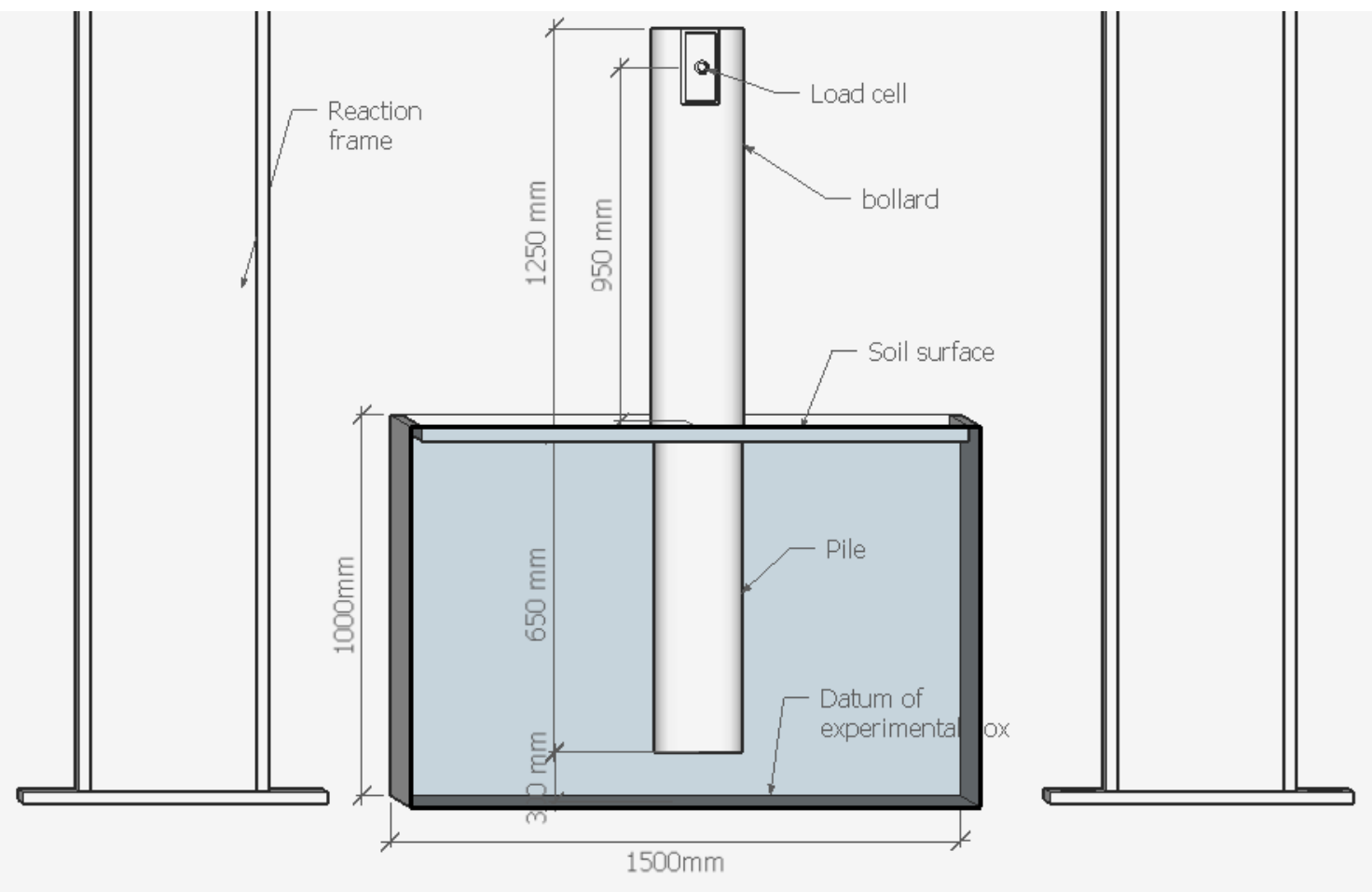

Figure 3-2: Section view of the bollard-pile configuration setup

ASTM A6 steel plate of 12-mm thickness was cut into specified configurations and welded on the pipe as fins for the experiment. The different configurations of the fins were attached to the lowest part of the piles, as seen in Figure 3-1, to investigate the performance on the piles. Three of the different fin types (Fin 1, Fin 2 and Fin 3), each had a surface area of $5.25 \times 10^{4} \mathrm{~mm}^{2}$ while the fourth, Fin 4 , had a surface area of $8.25 \times 10^{4} \mathrm{~mm}^{2}$. In order to achieve efficient results, the fins were designed and attached on the piles such that at least it covered half the embedment depth, which corresponds to the study conducted by Nasr (2013). The fins were also attached considering the direction of lateral load application to the pile and soil interaction. 


\subsection{Soil Properties}

Soil investigations, including sieve analysis, compaction, moisture content and direct shear tests, were conducted in accordance with ASTM standards to characterize the soil used in the experimental program. The soil was purchased from Greely Company in Ottawa, Ontario with its general name as washed sand because it has very few fines and gravel components compared to sand.

\subsubsection{Sieve Analysis}

The sieve analysis was conducted to determine the particle size distribution of the soil. Seven different sieve sizes were arranged from $0.075 \mathrm{~mm}$ to $4.75 \mathrm{~mm}$ from bottom to top. A weighed amount of soil was poured into the top sieve and the whole assembly was placed in an electric shaker for approximately ten (10) min. After shaking, soil particles were retained on each sieve from the top through to the bottom. The percentage of soil retained on each sieve size was calculated as well as the percentage of soil passing through each sieve. The results were plotted on a graph of percentage passing against sieve sizes. The soil was classified according to the unified soil classification system (USCS). The coefficient of uniformity was calculated as 4.4 and coefficient of curvature as 0.66 . The soil was therefore classified as SP (a poorly graded soil) with $97.47 \%$ sand, $1.66 \%$ gravel and $0.87 \%$ fines, which corresponds to ASTM (2007) specification for soil used in the design of foundations under impact loads. Figure 3-3 presents the results of sieve analysis. The soil also corresponded with the classification specified by Greely Company. 


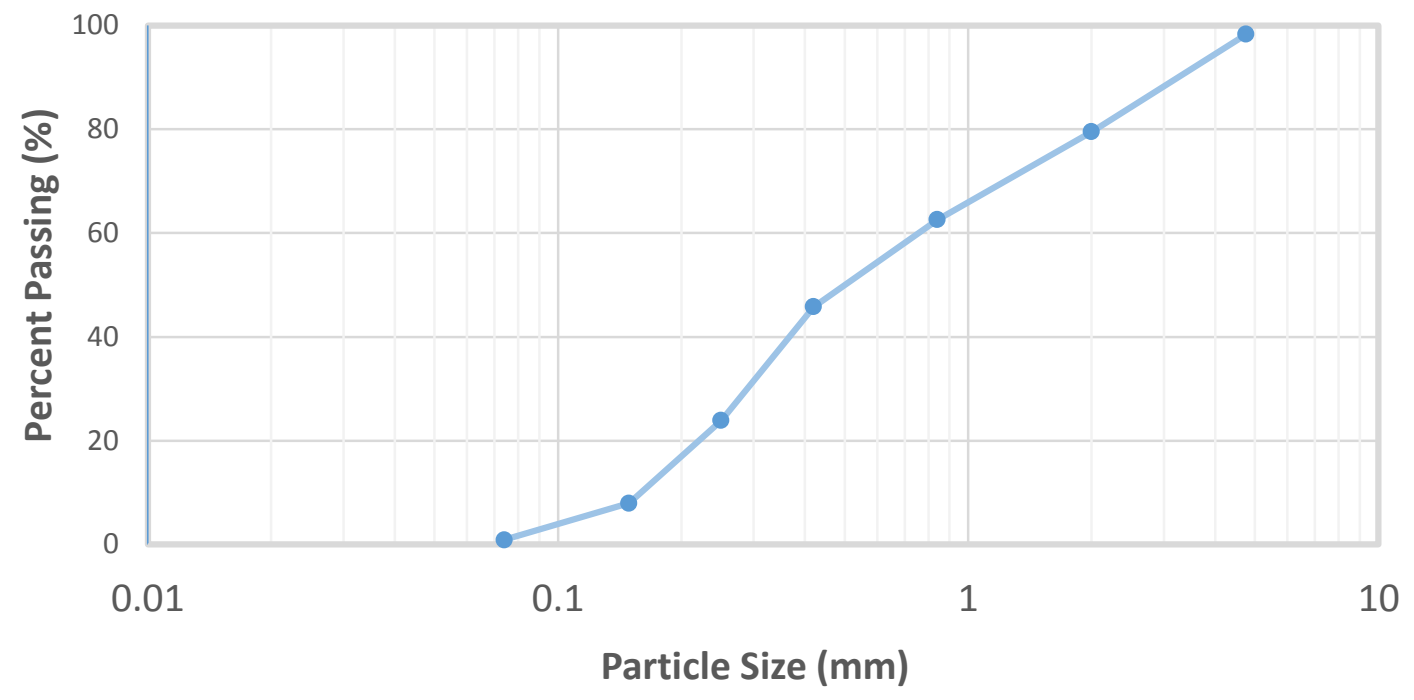

Figure 3-3: Particle size distribution for sand

\subsubsection{Standard Proctor Compaction Test}

A standard proctor compaction test was conducted to find the maximum dry density of the soil. An amount of soil passing the No. 4 sieve was weighed and placed on a metal tray. The weight of the proctor mold and assembly were also recorded. An amount of water to be added was calculated as $5 \%$ of the dry weight of the soil according to a moisture content test. The measured water was mixed with the soil until a uniform mixture was obtained. The mixed soil was placed in the mold in three layers with each layer tamped 25 times with a 12-inch hammer height. The compacted soil, together with the mold, were weighed and recorded. A sample of the compacted soil was taken and placed in an oven to obtain the water content. The procedure was repeated until the maximum density $\left(\rho_{\max }\right)$ was achieved. This was done by increasing the water to be added by 2 to $3 \%$. The mass of soil and water were calculated for each compacted sample. The bulk and dry densities of the soil as well as the water content were also calculated. 
From the test, the maximum dry density and optimum water content $\left(\mathrm{w}_{\mathrm{opt}}\right)$ were obtained. Moisture content test was also done on the soil separately before the compaction test to find the existing amount of water in the soil. Using the standard proctor test for compaction with the 12-in hammer height, the maximum dry density of the soil was calculated as $1,930 \mathrm{~kg} / \mathrm{m}^{3}$ at an optimum water content of $16.4 \% .95 \%$ dry of optimum density was calculated as $1,833 \mathrm{~kg} / \mathrm{m}^{3}$ and used for the experiment (Figure 3-4). The water content test for the existing soil without addition of any water was found to be $4.74 \%$.

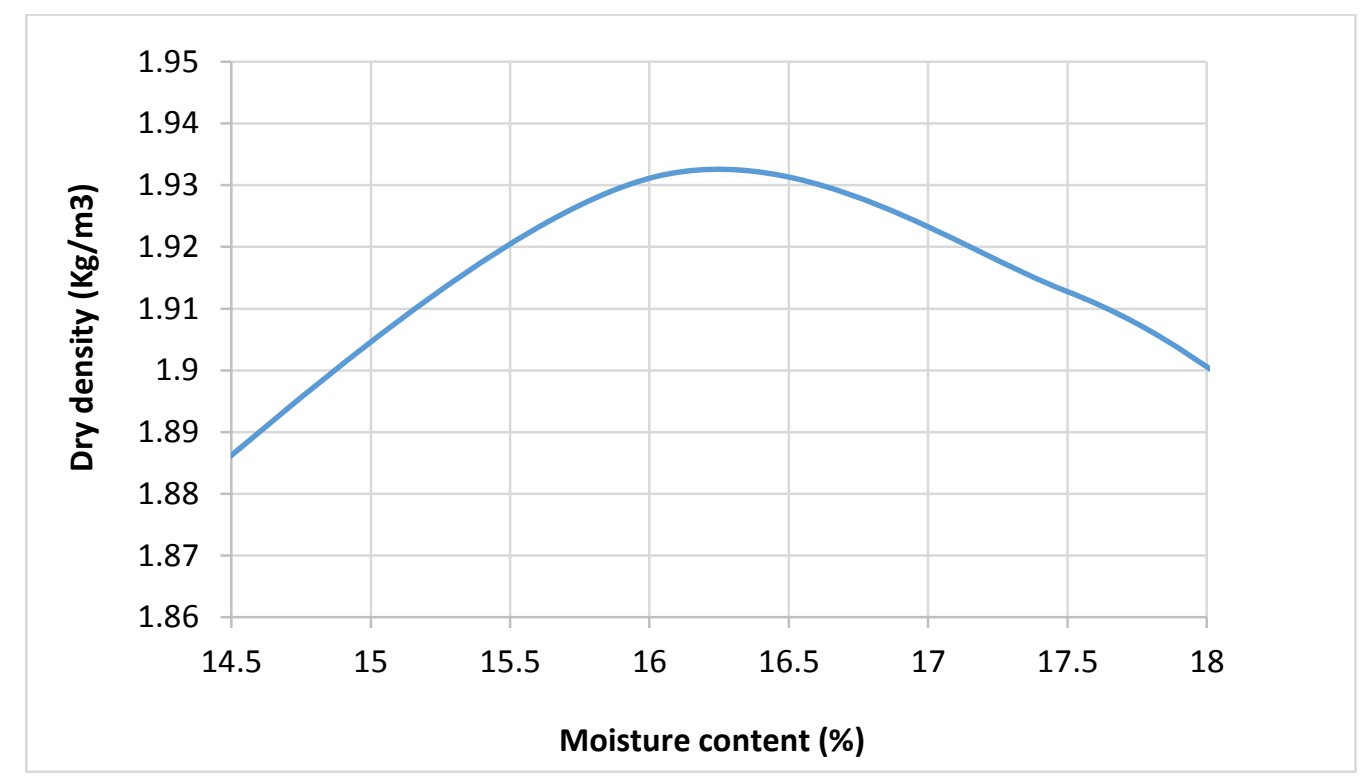

Figure 3-4: Standard proctor compaction test for sand

\subsubsection{Direct Shear Test}

Direct shear test was carried out to obtain the shear strength properties of the soil. Direct shear test was chosen among the different soil strength tests because it is simple and adequate for sandy soils. Although the direct shear test was done under drained conditions, in the case of the impact load test, an undrained case might be encountered. The test was 
conducted with confining pressures of $20 \mathrm{kPa}, 30 \mathrm{kPa}$ and $40 \mathrm{kPa}$ at a loading rate of 0.8 $\mathrm{mm} / \mathrm{min}$. The soil was weighed and placed in the shear box. The assembly was placed in the shear box machine and known weights corresponding to the different pressures were placed on the assembly for each shearing process. The soil was sheared in the lateral direction, and the horizontal and vertical displacements as well as vertical load applications were recorded until failure.

Figure 3-5 shows the results from the direct shear test. From the direct shear test conducted for $20 \mathrm{kPa}, 30 \mathrm{kPa}$ and $40 \mathrm{kPa}$ pressures, the Mohr's coulomb failure criterion was drawn. The shear strength parameters; friction angle and an apparent cohesion were determined to be $40^{\circ}$ and $6 \mathrm{kPa}$ respectively.

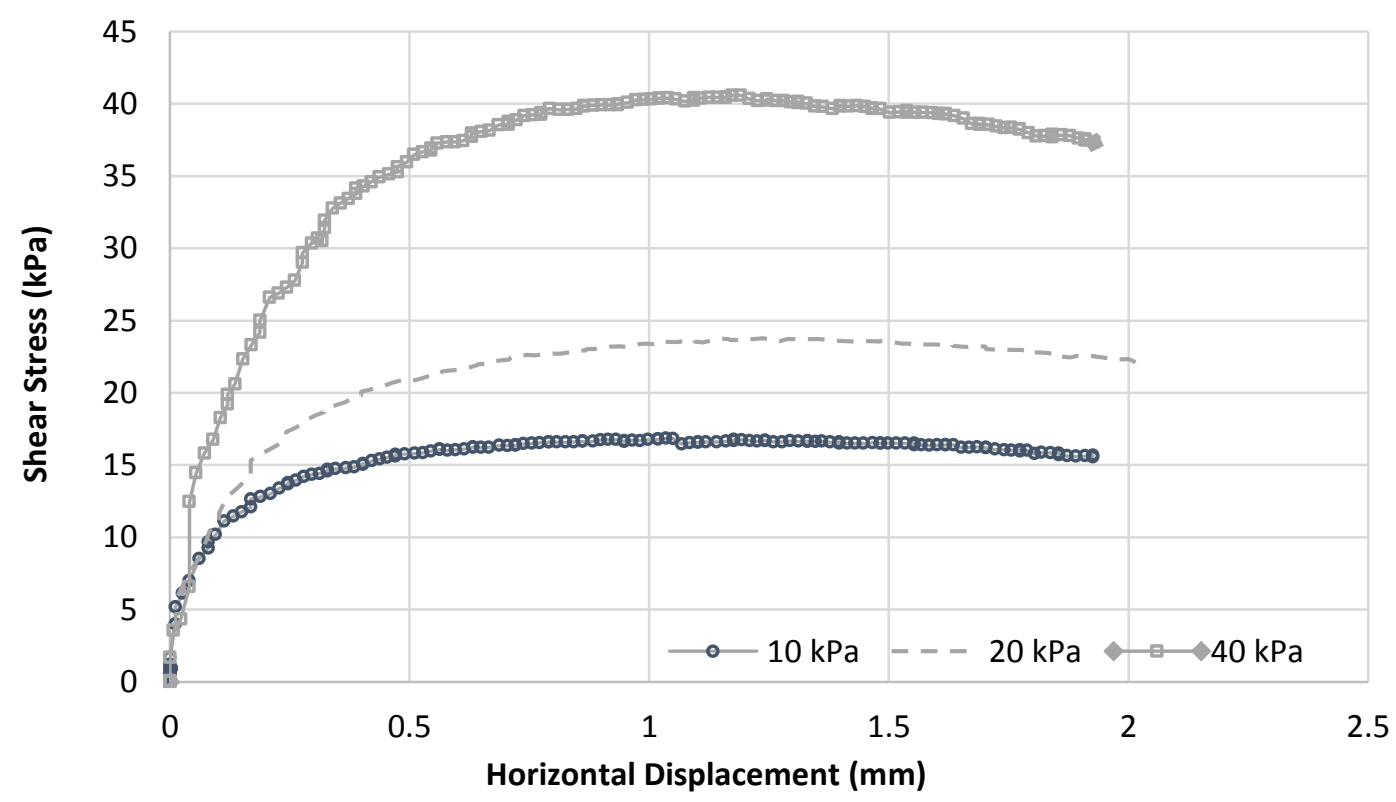

(a) 


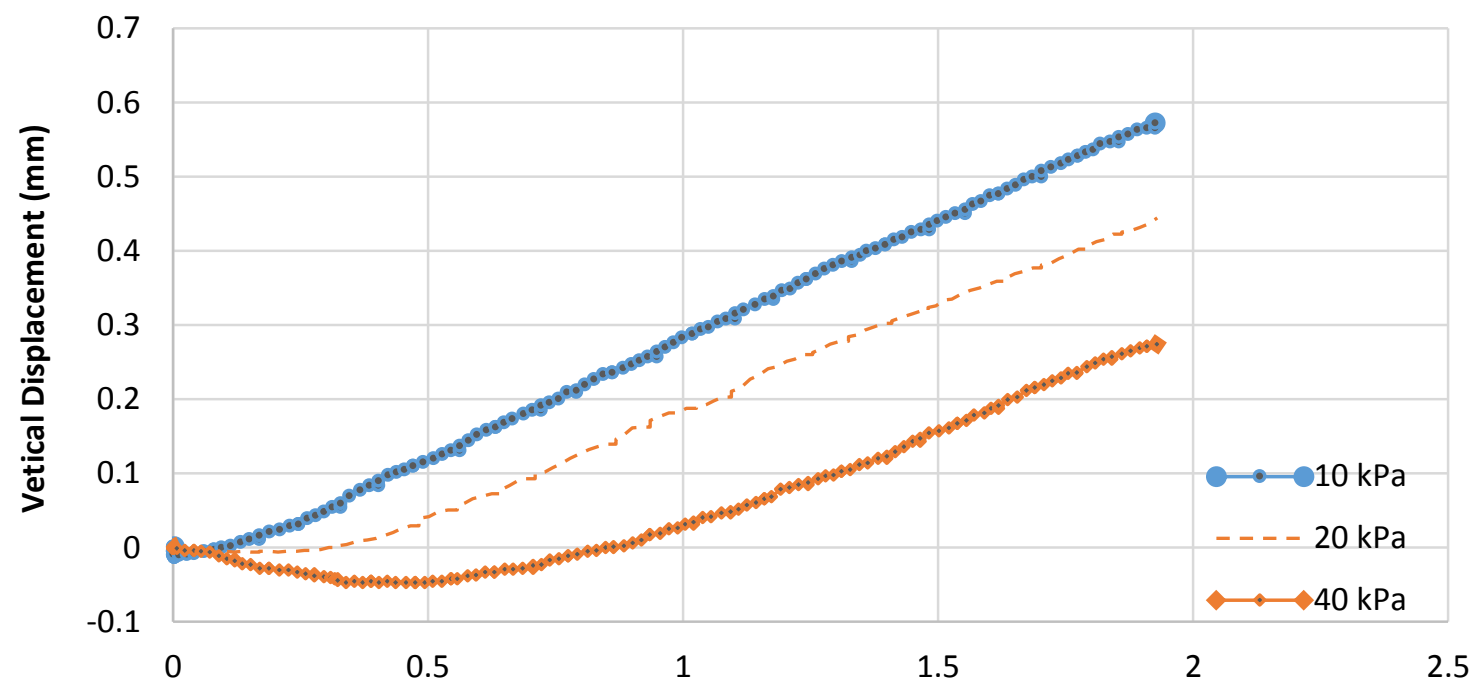

Horizontal Displacement (mm)

(b)

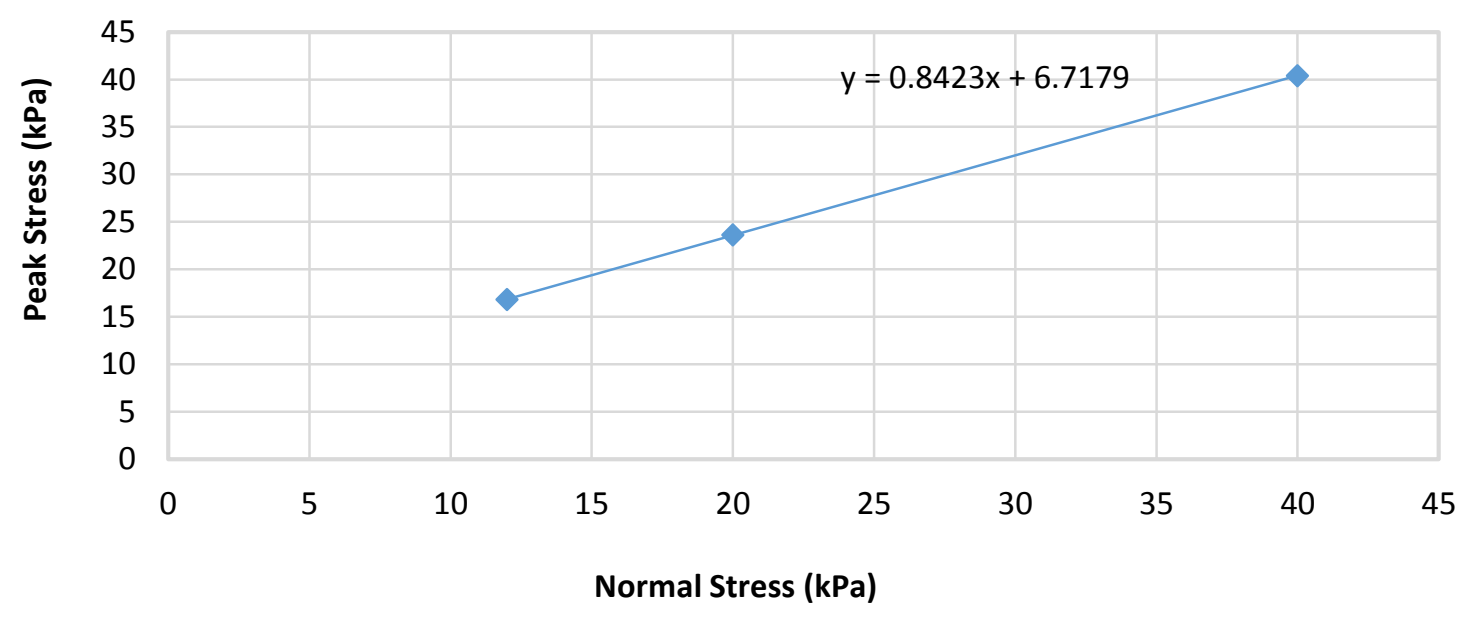

(c)

Figure 3-5: Direct shear test (a) shear stress versus displacement, (b) Vertical versus horizontal displacements, (c) Mohr-Coulomb's failure criterion 


\subsection{Instrumentation and Calibration}

The equipment used in the experimental program included Celesco string potentiometers (SP1-25), 100-kip compression load cell, and Yokogawa DL750P Data Acquisition system as the oscilloscope. The load cell and string potentiometers were calibrated at the laboratory to determine their capacities, mode of operation and to give accurate results for the tests. A sample rate of $200 \mathrm{kS} / \mathrm{sec}$ and appropriate channels (corresponding to modules) were used for acquiring the data from the acquisition system (Yokogawa DL750P). The channels for connecting the instruments were chosen based on the resolution and bandwidth needed to reduce noise. Typically, a bandwidth of $500 \mathrm{~Hz}$ was selected and a minimum resolution of 12-bit was employed for accurate results.

\subsubsection{Calibration of 100-kip Compression Load cell}

The load cell was employed to measure the loads in the impact load test. The load cell had a capacity of $100 \mathrm{kip}(445 \mathrm{kN})$ and was manufactured by transducer techniques with model number CLC-100K. It was mounted on the bollard during the test to measure the compressive load impacted on the bollard. The calibration of the load cell was done with an Instron 5582 machine (used in applying the loads) and the oscilloscope (which recorded the measurements in volts).

The calibration was done by placing the load cell in the intron machine and subsequently applying compressive loads in an axial direction as seen in Figure 3-6. A corresponding change in voltage from the load cell was recorded on the oscilloscope for each load application. The data acquired was plotted on a load versus voltage graph, and the gradient calculated. The results of the load cell calibration are presented in Figure 3-7. 
The gradient equation obtained from the graph was incorporated in the impact load test measurements to convert the measured voltage (in $\mathrm{mV}$ ) to applied loads (in $\mathrm{kN}$ ).

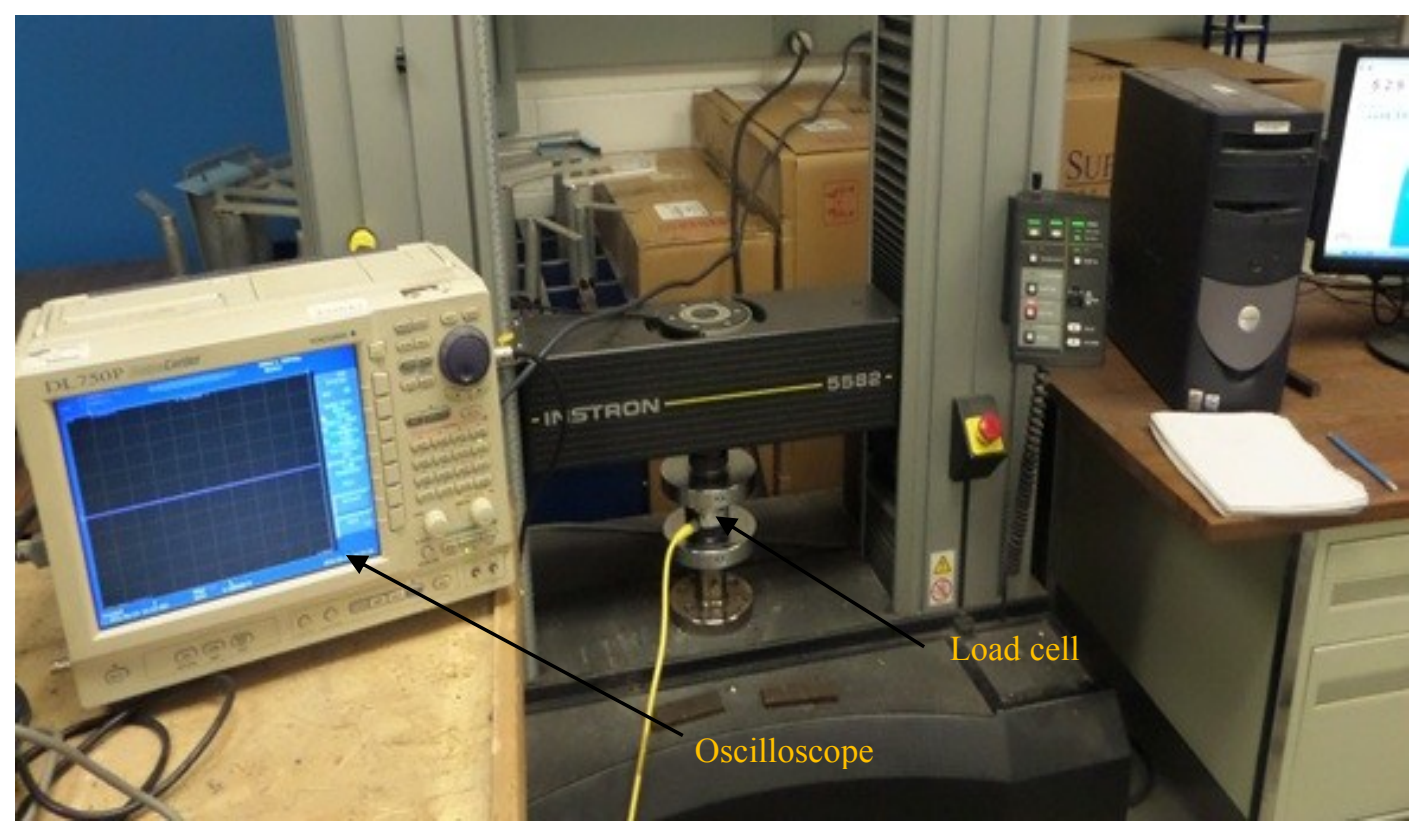

Figure 3-6: Calibration of load cell

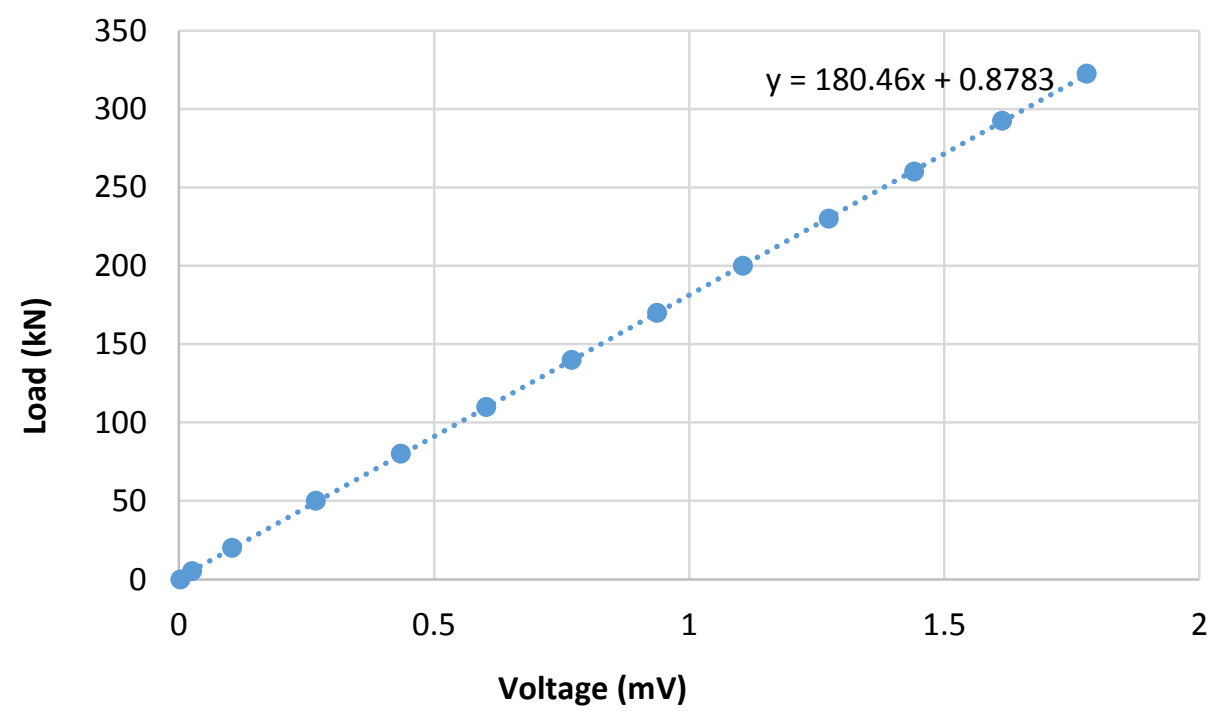

Figure 3-7: 100 kip load cell calibration scale 


\subsubsection{Calibration of Celesco String Potentiometers}

Three string pots were calibrated and used to measure the deflections at three locations along the height of the bollard-pile configurations (top, middle and bottom). The string pots were employed for both the static and impact load tests to convert the measured voltage (in $\mathrm{mV}$ ) to deflection (in $\mathrm{mm}$ ). The oscilloscope and a fabricated horizontal measuring tool with pins spaced at pre-calibrated distances of $50 \mathrm{~mm}$ for a total distance of $800 \mathrm{~mm}$ were used for the calibration. Each string pot was bolted to the measuring tool and the string pulled to stepwise distances at intervals of $50 \mathrm{~mm}$ until the maximum length of the string was reached. The corresponding voltage at each pre-calibrated distance was obtained from the oscilloscope and recorded in millivolts $(\mathrm{mV})$. Figure 3-8 shows an example of the string pot calibration and the results of the calibration can be seen in Figure 3-9. The data obtained was plotted as a graph of voltage (in $\mathrm{mV}$ ) against deflection (in $\mathrm{mm})$. 


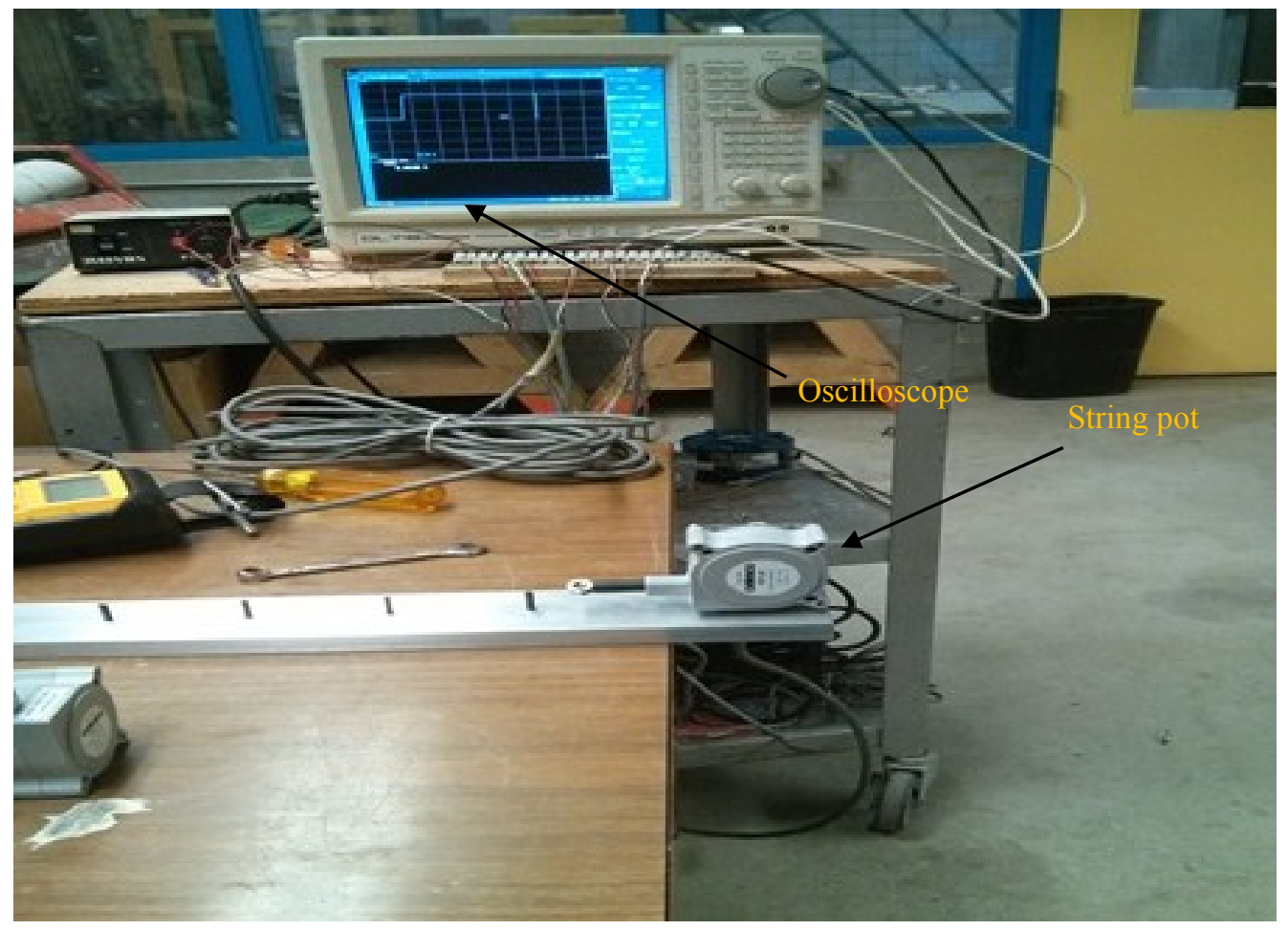

Figure 3-8: Calibration of string pot

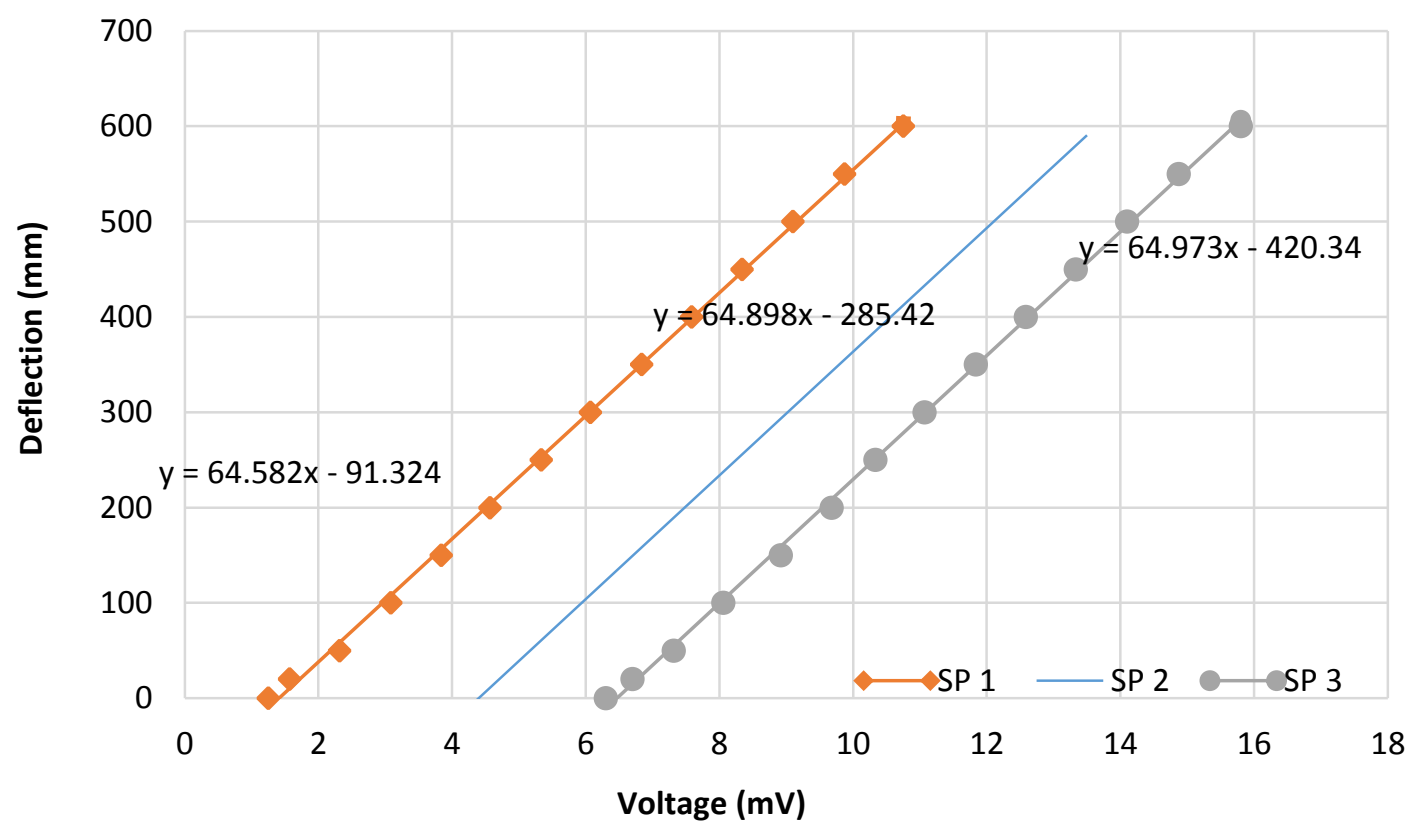

Figure 3-9: String pots calibration scale 


\subsection{Static Load Test}

The static load test involved the application of static loads on the bollards using an MTS 290 actuator. The actuator was connected laterally with high tensile steel rods to pull on the bollard from its initial vertical position. The point of contact between the pulling rods and the bollard was achieved using a fabricated high strength steel plate jointed to a rolling hook to provide a smaller contact surface area. Load measurements from the actuator were obtained from the data acquisition system used to control the actuator. The foundation for the bollard was built with a $2600 \times 1500 \times 1000 \mathrm{~mm}$ experimental (test) box filled with compacted sand. The test box satisfied the requirement for boundary conditions criteria for the experiment. From literature, the minimum space between the pile and the soil container should be such that the width of the test box is greater than $5 \times$ diameter of the pile. For this experiment, the width of test box (i.e. $1500 \mathrm{~mm}$ ) was greater than $5 \times$ diameter of the pile (i.e. $5 \times 219=1095 \mathrm{~mm})$.

\subsubsection{Static Load Test Setup}

The static load test setup involved three distinct stages with each stage contributing uniquely to form a complete setup. The initial stage dealt with calculating the volume of sand required to fill the test box and the compaction of the sand to achieve the expected density. Installation of the cylindrical steel pipe (bollard-pile configuration) with its attachments (fins) followed after the test box was filled partially. The remainder of the box was filled and compacted to the preferred embedment depth. The string pots and actuator were connected at the appropriate stage of the test setup.

The height of the test box used for building the foundation was divided into ten (10) subdivisions (i.e. $100 \mathrm{~mm}$ each to a total height of $1000 \mathrm{~mm}$ ) and marked. This was done 
to make it easy to fill the test box and help the maximum compaction of the sand to be attained adequately. The amount of sand and water needed to achieve the specified dry of optimum density of $1,830 \mathrm{~kg} / \mathrm{m}^{3}$ was computed from the maximum dry density $(1,930$ $\mathrm{kg} / \mathrm{m}^{3}$ ) of the sand. It should be noted that $95 \%$ dry density and less $2 \%$ of the dry of optimum water content was used for the calculations in order to achieve a low hydraulic conductivity and increase the strength properties of the soil as specified by Benson et al. (2001). Knowing the dry of optimum density, the mass of sand and water were backcalculated and obtained as $7,410 \mathrm{~kg}$ and $741 \mathrm{~kg}$ respectively. Premeasured quantities of sand and water at 100-mm depth were mixed to obtain a uniform soil mixture and placed into the test box. A rammer was used to manually compact the soil to the required density and to fill the 100-mm depth. It was assumed that the density was achieved if the soil was compacted to the correct level. Also, before placing the next soil layer at its required level, the surface of the compacted soil layer was made rough to allow suitable bondage between the layers. The placement and compaction of the soil continued to a depth of $300 \mathrm{~mm}$, the toe of the foundation. The bollard-pile configuration was then placed on the compacted soil and held in place while subsequent soil layers were placed and compacted. A crane was used to stabilize (hold) the bollard placed in soil (pile) during the filling and compaction. A sprit level was used to ensure the bollard remained plumb and vertical. The bottom of the pile was covered (plugged) with a wooden cork, cut to size, to provide toe or tip bearing resistance to the pile (Figure 3-10). At a depth of $400 \mathrm{~mm}$, a cylindrical pipe was connected to a 30-mm predrilled hole on the north side of the test box. The cylindrical pipe was used to accommodate the string pot attached to the pile, $100 \mathrm{~mm}$ from the bottom (Figure 3-11). 


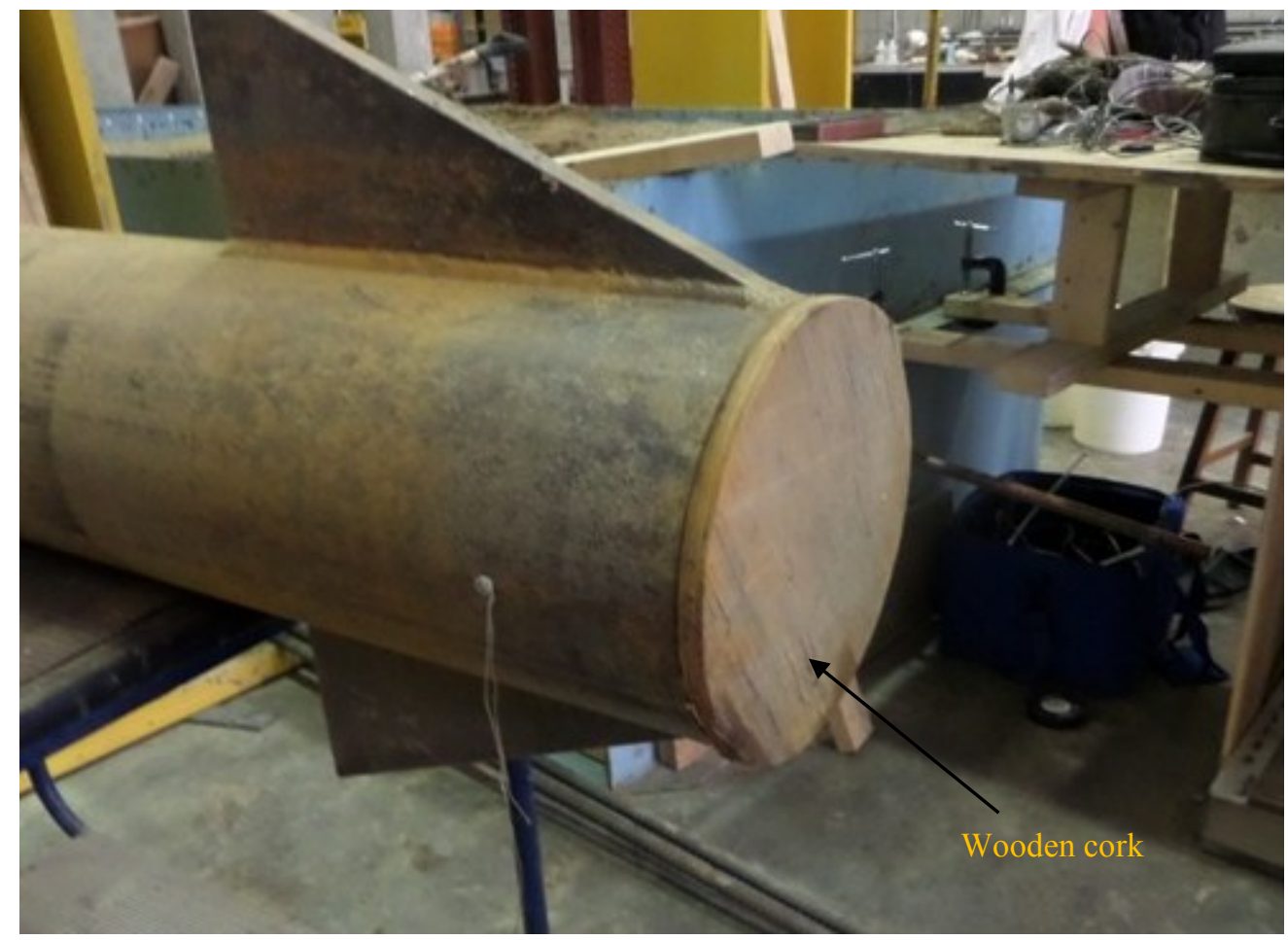

Figure 3-10: Pile with wooden cork

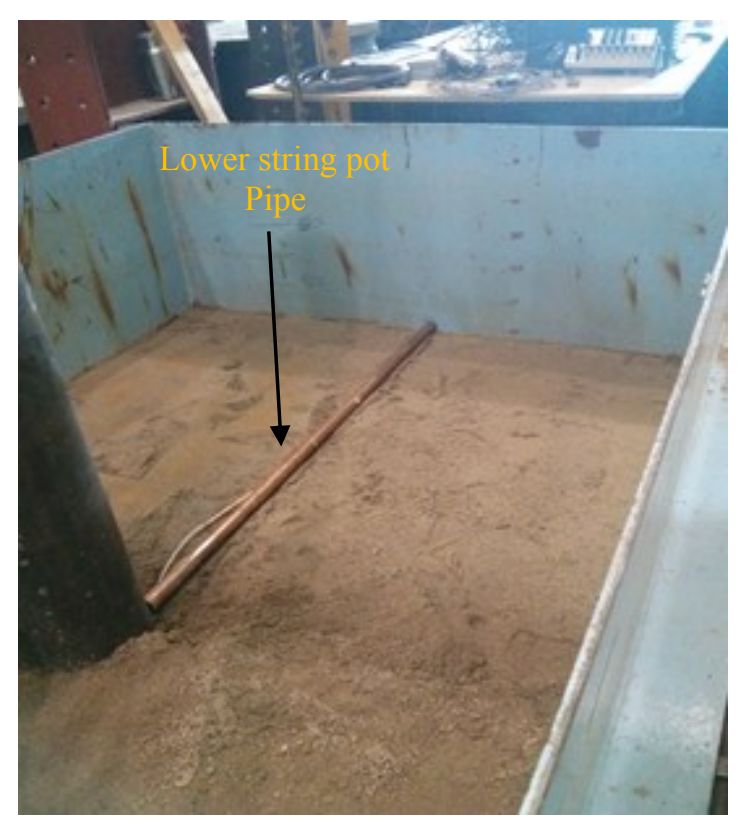

(a)

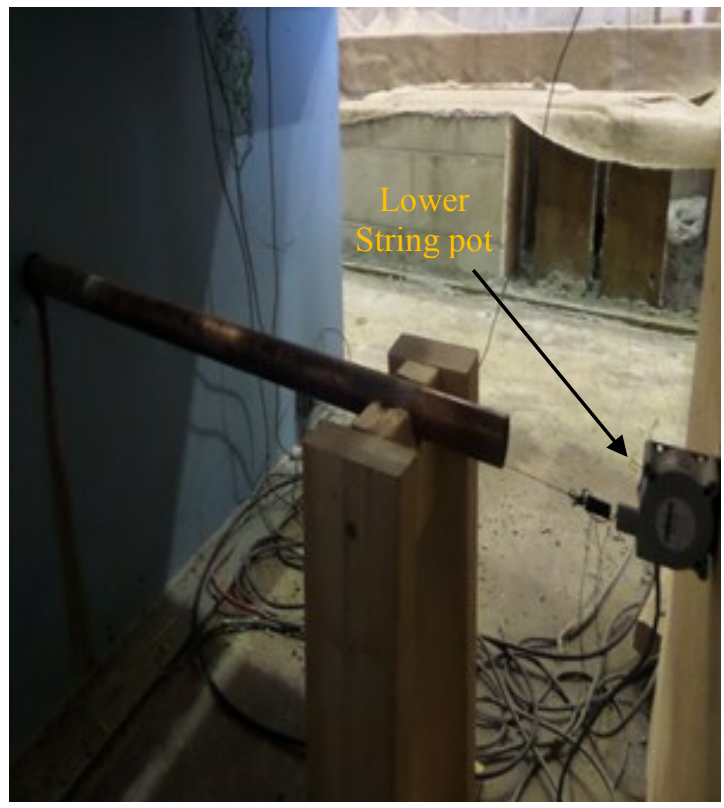

(b)

Figure 3-11: Installation of lower string pot: (a) location of pipe for string pot (b) location of string pot 
Lastly, the test box was completely filled with the sand while maintaining the maximum compaction at each layer (Figure 3-12). In all, the total depth of the sand was $950 \mathrm{~mm}$, with $650 \mathrm{~mm}$ forming the embedment depth of foundation from the toe of the pile. The setup was completed by connecting the actuator, and the middle and top string pots to the bollard. The actuator was connected to the bollard at a height of $1600 \mathrm{~mm}$ from the bottom of the bollard making the impact height from the surface of the foundation level to be $950 \mathrm{~mm}$ with a clearance of $300 \mathrm{~mm}$ at the top of the bollard. The middle and top string pots were attached at $650 \mathrm{~mm}$ and $1600 \mathrm{~mm}$ from the bottom of the bollard-pile configuration as seen in Figure 3-12 and Figure 3-13. Thus, the top string pot was connected at the same point as the actuator load application while the middle string pot was connected parallel on the surface of the foundation. Figure 3-14 presents the setup of the static load test.

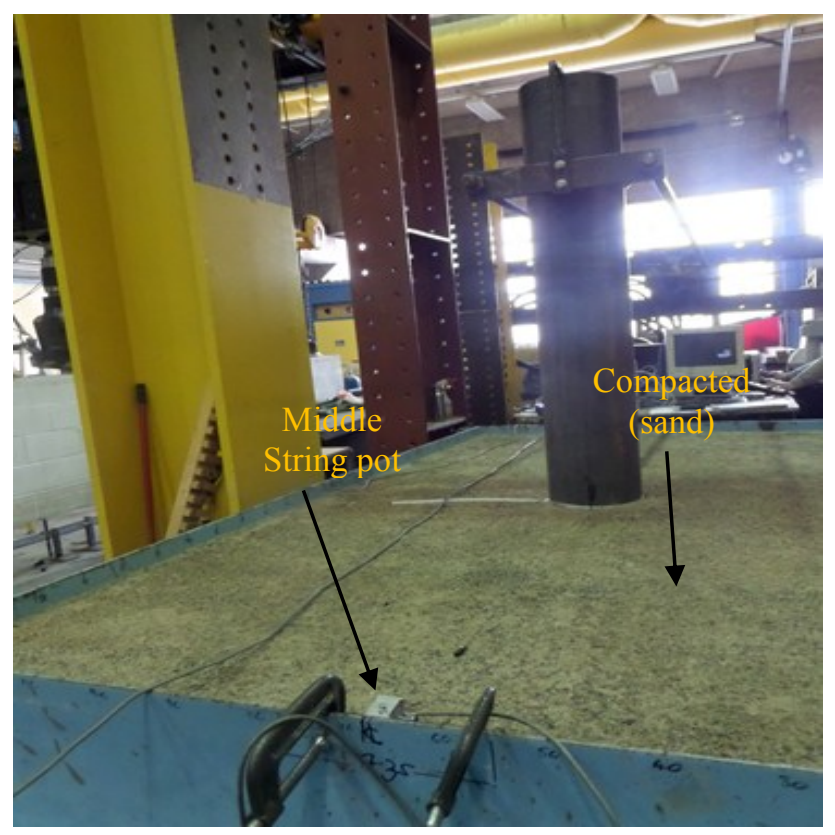

Figure 3-12: Final level of the soil with middle string pot installed 


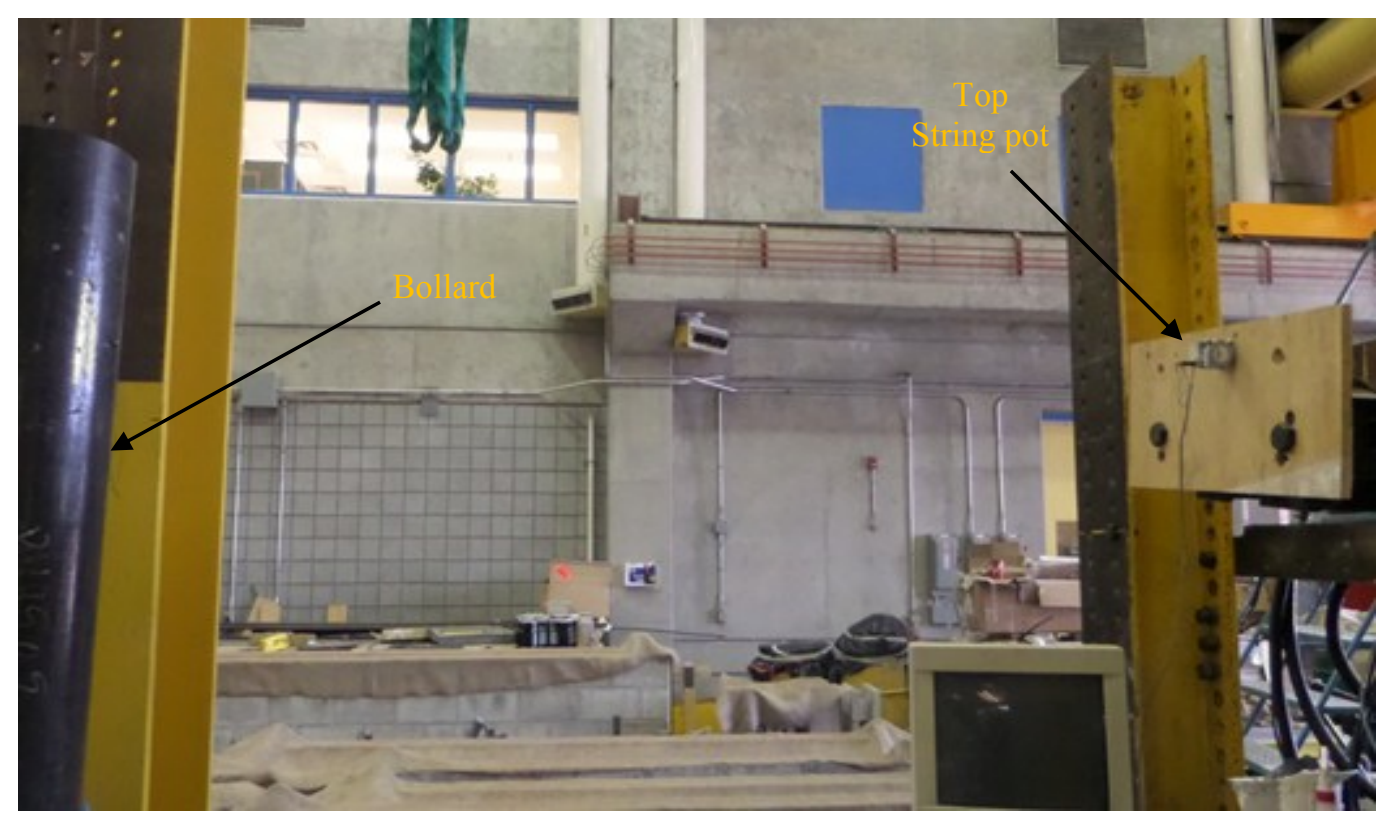

Figure 3-13: Position of top string pot

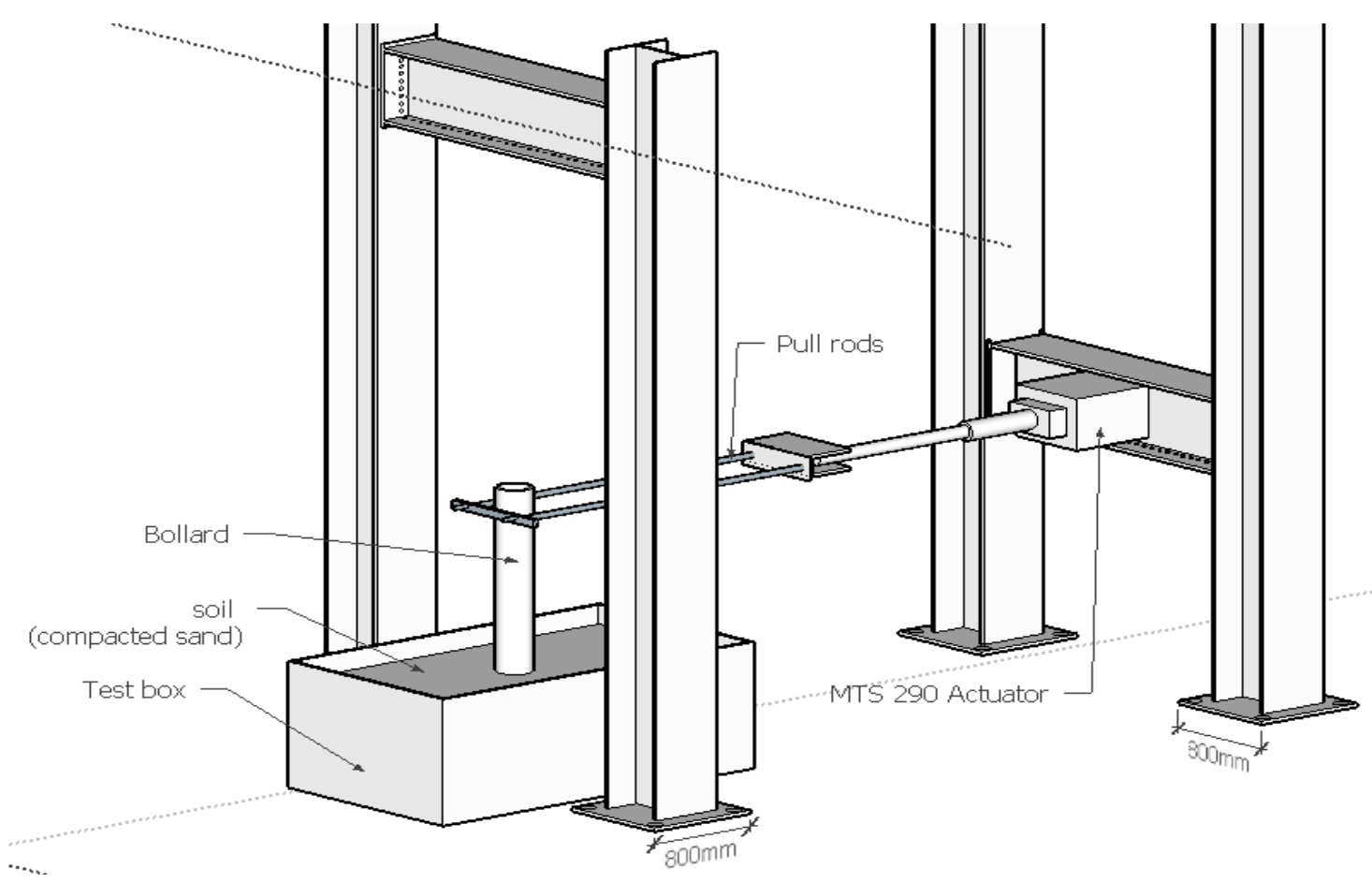

(a) 


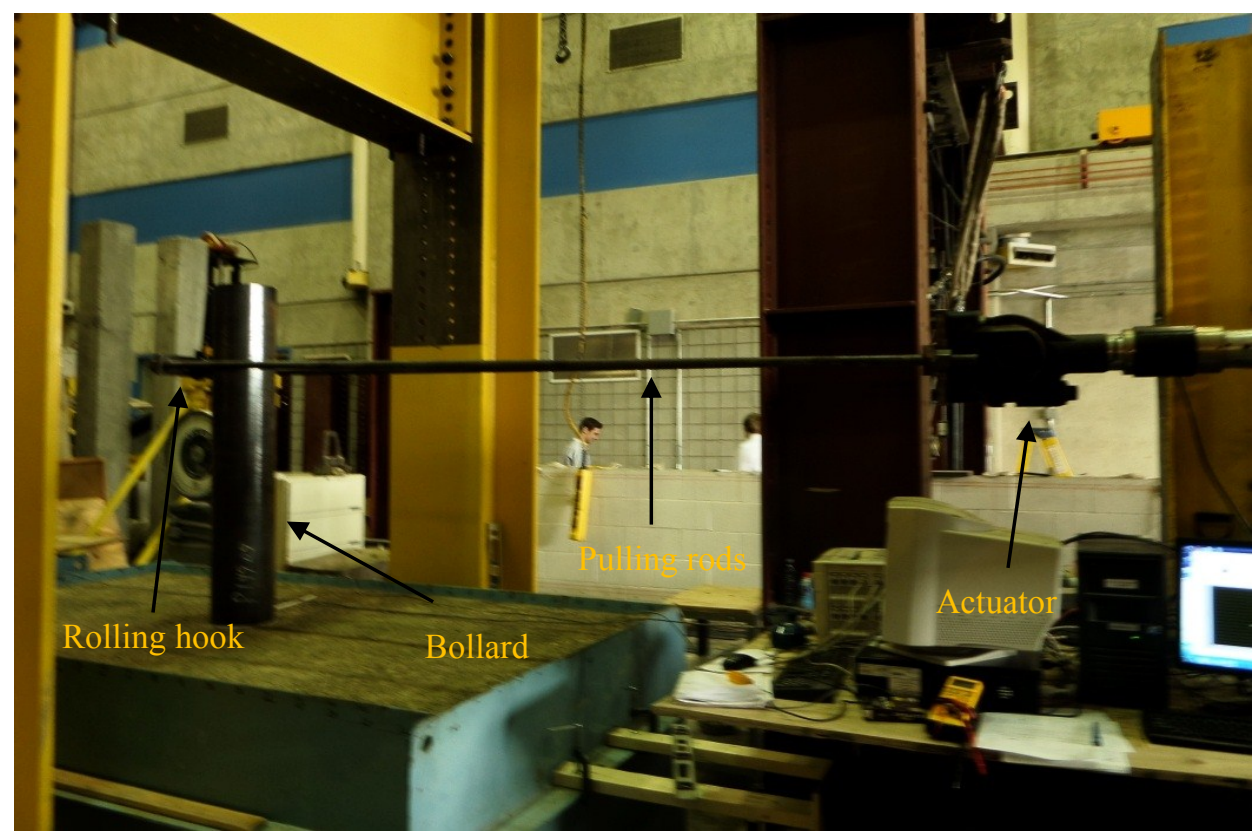

(b)

Figure 3-14: Static load test setup (a) schematic sketch (b) photograph

\subsubsection{Static Load Test Procedure}

All five bollard types were tested under lateral static loading. The test on bollard with Fin type 4 was repeated to investigate repeatability of the test results. Hence a total of six static load tests were conducted. Typically, it took between three (3) to four (4) hours to conduct each test. The tests were done under displacement control. The rate of loading was maintained at $0.5 \mathrm{~mm} / \mathrm{min}$ for each loading stage throughout the static load test. This corresponds to Cudoto (2001) suggestion on the rate of loading of laterally loaded pile under control method. The ASTM standard method for laterally loaded piles was employed in the load application (ASTM D3699, 2007). The applied load was calculated using Broms' method. In accordance with Broms' method (1964), the ultimate lateral load capacity was calculated considering the soil pressure and the pile head fixity for cohesionless soil. With this method, the ultimate load capacity was calculated to be $4 \mathrm{kN}$ 
and the design load after applying a factor of safety of two (2) resulted in $2 \mathrm{kN}$. However, the loads were applied to the maximum capacity of the soil resistance. Table 3-1 specifies the stepwise application of loads for the static load test.

The actuator was used to apply lateral loads statically to the test specimen (bollard). At each load stage, the applied load was held for a specific time (typically 2-5 min) and then continued up to the failure load, at which no significant increase in load was observed. The behavior of the bollard was characterized by bilinear curve. The initial linear region is referred to as elastic region while the second is termed the plastic region. The plastic region is characterized by increase in deflection without an accompanying increase in load. On reaching the maximum load capacity, the load application was stopped and then unloaded.

Table 3-1: Stepwise application of Static loads

\begin{tabular}{|c|l|l|}
\hline Percent of Design Load (\%) & Load Applied & Time (min) \\
\hline $\mathbf{2 5}$ & 0.5 & 2 \\
\hline $\mathbf{5 0}$ & 1 & 2 \\
\hline $\mathbf{1 5 0}$ & 3 & 2 \\
\hline $\mathbf{1 7 5}$ & 3.5 & 2 \\
\hline $\mathbf{2 0 0}$ & 4 & 5 \\
\hline $\mathbf{2 1 0}$ & 4.2 & 5 \\
\hline $\mathbf{2 2 0}$ & 4.4 & 5 \\
\hline $\mathbf{2 3 0}$ & 4.6 & 5 \\
\hline $\mathbf{2 4 0}$ & 4.8 & 5 \\
\hline $\mathbf{2 5 0}$ & 5 & 5 \\
\hline $\mathbf{2 0 0}$ & 4 & 2 \\
\hline $\mathbf{1 5 0}$ & 3 & 2 \\
\hline $\mathbf{1 0 0}$ & 2 & 2 \\
\hline $\mathbf{5 0}$ & 1 & 2 \\
\hline & & \\
\hline & & \\
\hline & & \\
\hline & & \\
\hline & & \\
\hline & & \\
\hline & & \\
\hline
\end{tabular}




\subsection{Impact Load Test}

The impact load test involved the use of a pendulum with a fixed weight and pendulum height to exert impact load on the bollard. The pendulum was used to apply the impact loads. The pendulum was released from different angles (heights) to simulate impact velocities which represented various kinetic energies. The angles used for the impact load test were established after conducting prior tests. Also, an elastomeric pad configuration was investigated and used for testing to obtain effective results. A $3000 \mathrm{~mm}$ long rectangular HSS $102 \times 76 \times 6.4 \mathrm{~mm}$ hollow structural section was attached to a cylindrical steel block and used as the pendulum. The cylindrical steel block had a weight of $165 \mathrm{~kg}$, a diameter of $300 \mathrm{~mm}$, and a height of $450 \mathrm{~mm}$. In order to obtain the load impacted on the bollard, a load cell was mounted on the bollard. The various parts of the pendulum setup were designed and fabricated to form a complete system capable of performing the tests at the Civil Engineering Laboratory at Carleton University.

\subsubsection{Impact Load Test Configuration and Adjustments}

The configuration of impact load was done using a pendulum-weight configuration, a 100 kip load cell, elastomeric pads and a granite block of weight $5500 \mathrm{~kg}$. The main aim of the configuration was to choose the elastomeric pad suitable for the test and to determine the magnitude of loads striking the bollard at different angles.

\subsubsection{Pendulum-weight configuration}

Figure 3-15 shows the cylindrical steel block complete with mounted load configuration. The HSS steel hanger was attached to the cylindrical steel block with four bolts. Four holes were drilled on the top of the cylindrical block while the HSS hanger had a $200 \times 200 \times 15$ mm steel plate welded to it. The steel plate was then bolted to the cylindrical steel block. 
The HSS steel hanger and plate weighed $56 \mathrm{~kg}$. Hence, the total weight of the pendulumweight configuration was $221 \mathrm{~kg}$. An HSS section was cut in half, welded on the midsection of the cylindrical steel block and fashioned to form an impact hammer for impact loading. An elastomeric pad, sandwiched between two steel plates was attached to the HSS section. The elastomeric pad and steel plates were cut into cylindrical shapes with a diameter of 70 $\mathrm{mm}$. Three elastomeric pad thicknesses $(6 \mathrm{~mm}, 12 \mathrm{~mm}$ and $15 \mathrm{~mm})$ were investigated in addition to a hard steel-on-steel plate ( $0 \mathrm{~mm}$ thickness elastomeric pad). The elastomeric pad was a 60 shore A durometer with a compressive strength of 4,134 $\mathrm{kPa}$. The pads were employed to increase the duration of the impact load.

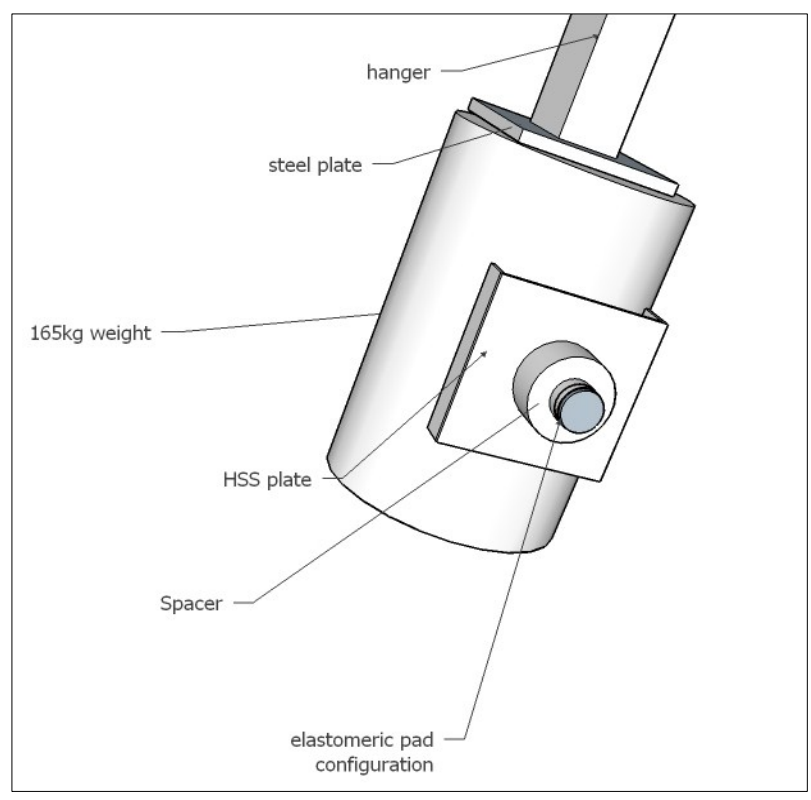

(a)

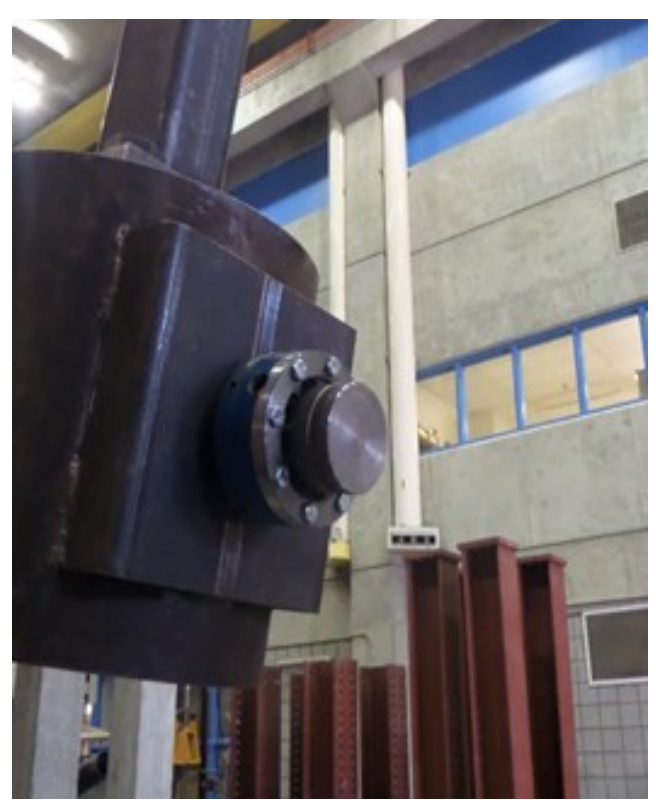

(b)

Figure 3-15: Pendulum-weight configuration (a) sketch (b) photograph 


\subsubsection{Procedure for the impact load configuration with elastomeric pad investigation}

The calibration of the load and selection of elastomeric pad thickness for the test was conducted using five different angles, $5^{\circ}, 10^{\circ}, 12^{\circ}, 15^{\circ}$ and $18^{\circ}$ and the four elastomeric pad configurations ( $0 \mathrm{~mm}, 6 \mathrm{~mm}, 12 \mathrm{~mm}$ and $15 \mathrm{~mm}$ thicknesses $)$. The angles were calculated using simple geometry and represented different impact velocities. These angles were selected to help choose the elastomeric pad and to serve as a basis for primary impact load assessment. The impact velocities were used to calculate the forces and energies acting on the bollard considering the mass of the cylindrical block.

Figure 3-16 shows a schematic sketch of the impact load configuration setup. Firstly, the pendulum was attached to a portal steel frame with two fabricated angular brackets $(300 \times 300 \times 10 \mathrm{~mm})$ on the underside of the cross-beam of the portal steel frame. The upper part of the steel hanger (head of the pendulum setup) was connected to the angular brackets by passing a $27 \mathrm{~mm}$ diameter solid metal shaft through the pre-fabricated $30 \mathrm{~mm}$ diameter hole on the steel hanger. Two bearings were then installed on either side of the bracket to enable free frictionless rotation of the pendulum. The setup components were tightened while ensuring the pendulum arm swings freely in the bearings.

After the cylindrical pendulum was hung on the portal steel frame, a granite block was placed on the test box and lined-up directly in front of the pendulum setup. The calibrated load cell was then fixed on the granite block at the impact point of the cylindrical pendulum. The elastomeric pad configuration was mounted on the cylindrical weight. The load cell was connected to an oscilloscope-based data acquisition system. The data acquisition was set to begin based on a trigger setting on the measured load. A pre-buffer 
setting of $10 \%$ on the trigger position was used to acquire data prior to impact on the load cell.

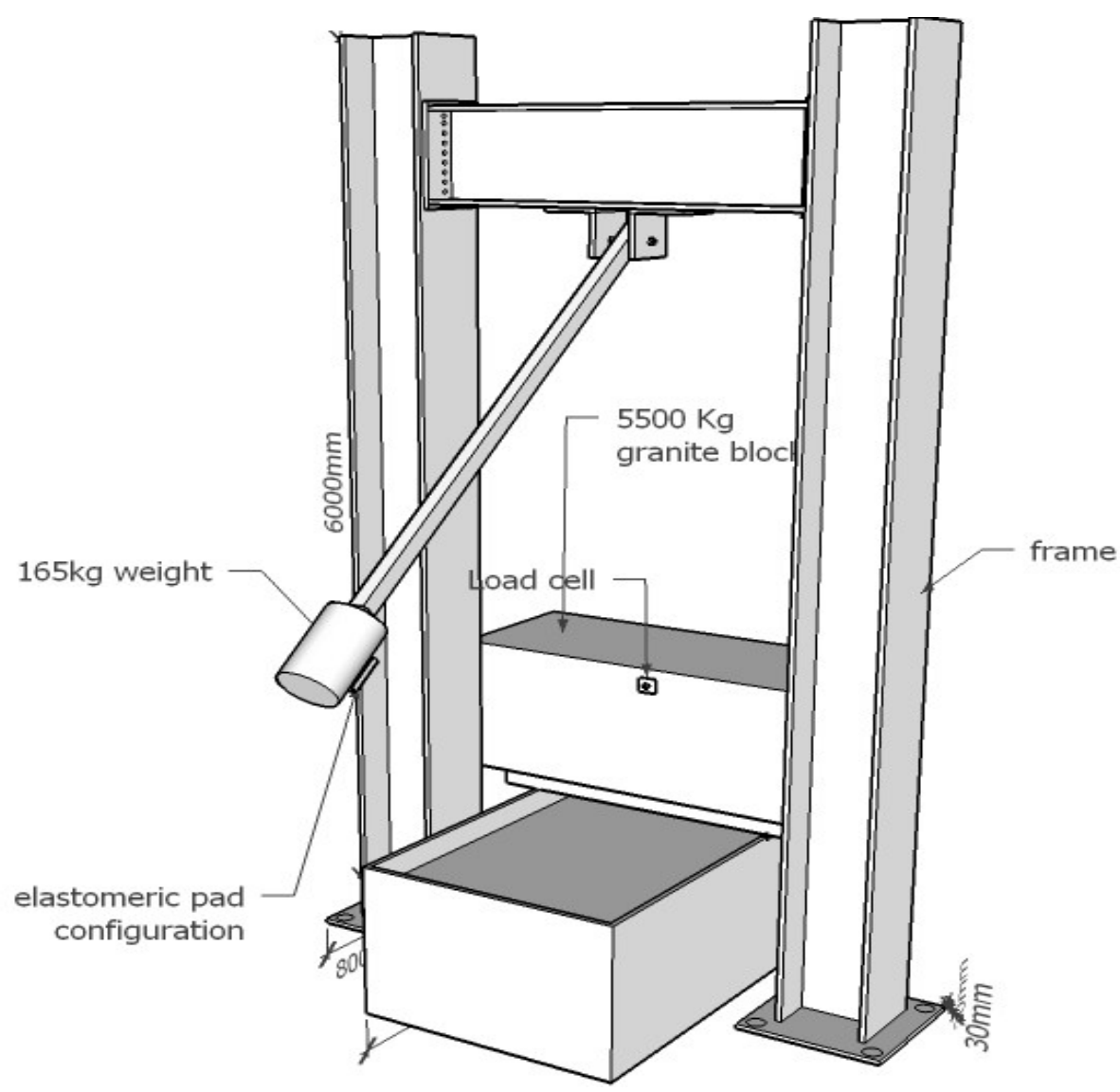

Figure 3-16: Sketch of impact load configuration setup

The pendulum weight was lifted to a particular impact angle using a pulley system connected to a winch. The impact angle was achieved by pulling the pendulum weight backwards to a distance corresponding to the impact angle by cranking the winch. The winch was mounted on a steel reaction frame. The pulley system was connected by passing a high tensile strength rope from the winch to a fabricated rolling rod at a height above the winch, and then to a hook on the pendulum weight system. A release mechanism was 
achieved using a fabricated rod with a rope attached to it. The rod was connected to its hook such that it unlocked from the hook once the attached rope was pulled (Figure 3-17).
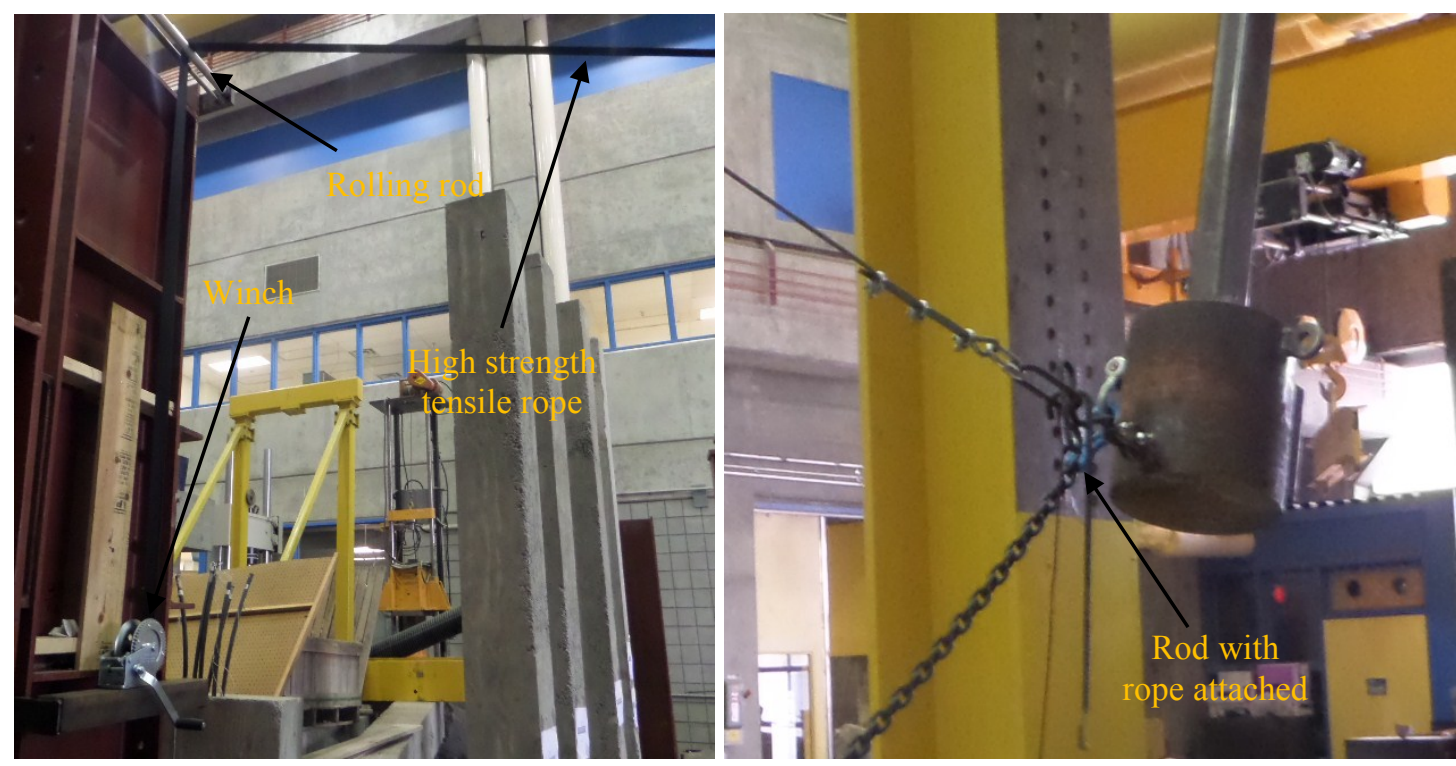

Figure 3-17: Pulley system connection for impact load test (a) pulley connection (b) release mechanism

\subsubsection{Summary of impact load test configuration}

Table 3-2 shows a summary of the impact load configuration results. Detailed graphs for the results can be seen in Appendix A. Three impact load records were observed for most of the calibrations, however, the peaks have been provided in the summary table. The kinetic energies were calculated assuming almost all the potential energy was converted to kinetic energy and resulted in the impact velocity, $v$, in equation 3.1.

$$
M g h=\frac{1}{2} M v^{2}
$$

The kinetic energy was obtained considering the total mass of the pendulum weight to be $221 \mathrm{~kg}$. Also, the change in heights used for the kinetic energy calculations were considered based on the center of gravity of the pendulum weight system. From the results, 
each elastomeric pad configuration provided a different peak load with a corresponding duration. The smaller the thickness of the pad, the higher the peak impact load achieved. This was because the pad absorbed some of the impacted load. But the duration of the impact was longer for the thicker pads. It should be noted that the net area under each curve, impulse, almost remained the same for each angle. This means that most of the load absorption was compensated by longer duration, hence giving similar impulses. However, the $6 \mathrm{~mm}$ elastomeric pad was selected and used for the impact load test. This was chosen due to the fact that the peak loads and durations could be observed clearly for effective analysis.

Table 3-2: Summary of peak impact load configuration results

\begin{tabular}{|c|c|c|c|c|c|c|c|c|c|c|}
\hline \multirow[b]{4}{*}{$\begin{array}{c}\text { Thickness } \\
\text { of Pad }\end{array}$} & \multicolumn{2}{|r|}{$5^{\circ}$} & \multicolumn{2}{|r|}{$10^{\circ}$} & \multicolumn{2}{|c|}{$12^{\circ}$} & \multicolumn{2}{|c|}{$15^{\circ}$} & \multicolumn{2}{|c|}{$18^{\circ}$} \\
\hline & \multicolumn{2}{|c|}{$\begin{array}{c}\text { Velocity }=0.49 \\
(\mathrm{~m} / \mathrm{s})\end{array}$} & \multicolumn{2}{|c|}{$\begin{array}{c}\text { Velocity }=0.98 \\
(\mathrm{~m} / \mathrm{s})\end{array}$} & \multicolumn{2}{|c|}{$\begin{array}{c}\text { Velocity }=1.18 \\
(\mathrm{~m} / \mathrm{s})\end{array}$} & \multicolumn{2}{|c|}{$\begin{array}{l}\text { Velocity }=1.47 \\
(\mathrm{~m} / \mathrm{s})\end{array}$} & \multicolumn{2}{|c|}{$\begin{array}{c}\text { Velocity }=1.76 \\
(\mathrm{~m} / \mathrm{s})\end{array}$} \\
\hline & \multicolumn{2}{|c|}{$\begin{array}{c}\text { Kinetic energy }= \\
26.53 \mathrm{~J}\end{array}$} & \multicolumn{2}{|c|}{$\begin{array}{c}\text { Kinetic energy }= \\
106.12 \mathrm{~J}\end{array}$} & \multicolumn{2}{|c|}{$\begin{array}{c}\text { Kinetic energy = } \\
152.56 \mathrm{~J}\end{array}$} & \multicolumn{2}{|c|}{$\begin{array}{c}\text { Kinetic energy }= \\
237.81 \mathrm{~J}\end{array}$} & \multicolumn{2}{|c|}{$\begin{array}{c}\text { Kinetic energy = } \\
341.51 \mathrm{~J}\end{array}$} \\
\hline & $\begin{array}{l}\text { Load } \\
\text { (KN) }\end{array}$ & $\begin{array}{l}\text { Duration } \\
\text { (ms) }\end{array}$ & $\begin{array}{l}\text { Load } \\
(\mathrm{KN})\end{array}$ & $\begin{array}{l}\text { Duration } \\
\text { (ms) }\end{array}$ & $\begin{array}{l}\text { Load } \\
\text { (KN) }\end{array}$ & $\begin{array}{l}\text { Duration } \\
\text { (ms) }\end{array}$ & $\begin{array}{l}\text { Load } \\
\text { (KN) }\end{array}$ & $\begin{array}{l}\text { Duratio } \\
\text { n (ms) }\end{array}$ & $\begin{array}{l}\text { Load } \\
\text { (KN) }\end{array}$ & $\begin{array}{l}\text { Duratio } \\
\mathrm{n} \text { (ms) }\end{array}$ \\
\hline $0 \mathrm{~mm}$ & $\begin{array}{r}73.8 \\
2\end{array}$ & 6.1 & $\mathrm{~N} / \mathrm{A}$ & N/A & N/A & $\mathrm{N} / \mathrm{A}$ & N/A & N/A & N/A & N/A \\
\hline $6 \mathrm{~mm}$ & $\begin{array}{r}33.3 \\
9 \\
\end{array}$ & 11.6 & 90 & 8.72 & 105 & 8.19 & N/A & $\mathrm{N} / \mathrm{A}$ & N/A & N/A \\
\hline $12 \mathrm{~mm}$ & $\begin{array}{r}17.2 \\
5\end{array}$ & 18.8 & 48.7 & 15.44 & 64.3 & 13.6 & 94 & 12.75 & 113 & 12.44 \\
\hline $15 \mathrm{~mm}$ & $\begin{array}{r}14.3 \\
4\end{array}$ & 22.9 & 44.6 & 18.74 & 55.9 & 16.2 & 72 & 16.23 & 86.3 & 15.16 \\
\hline
\end{tabular}

\subsubsection{Impact Load Test Setup}

The bollard installation in the test box, soil placement and compaction for the impact load test were the same as in the static load test. Also, the level and attachment procedure of the string pots were the same. Instead of the actuator used in the static load test, the cylindrical pendulum was used to impart impact load (velocity) to the bollards. Due to the pendulum 
configuration and setup, the top string pot was installed at the north side facing the pendulum. Thus, it was fixed opposite to the static load test top string pot installation. The pendulum was also pulled and held safely in place at an angle to allow the setup of each test specimen. An HSS rectangular plate with threaded holes drilled at the center was cut into sections and welded firmly at the point of contact of each bollard (Figure 3-18). The string pots and load cell were connected to the base oscilloscope as oppose to the data acquisition system of the actuator in the case of the static load test. The trigger settings were set same as described in the impact load configuration procedure. Figure 3-19 presents the impact load test setup.

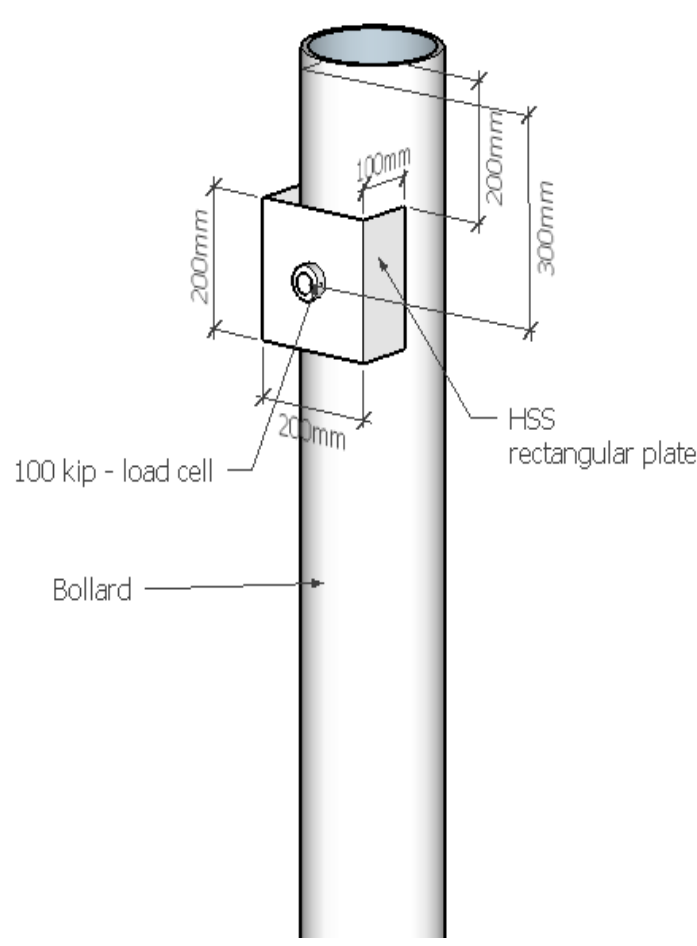

(a)

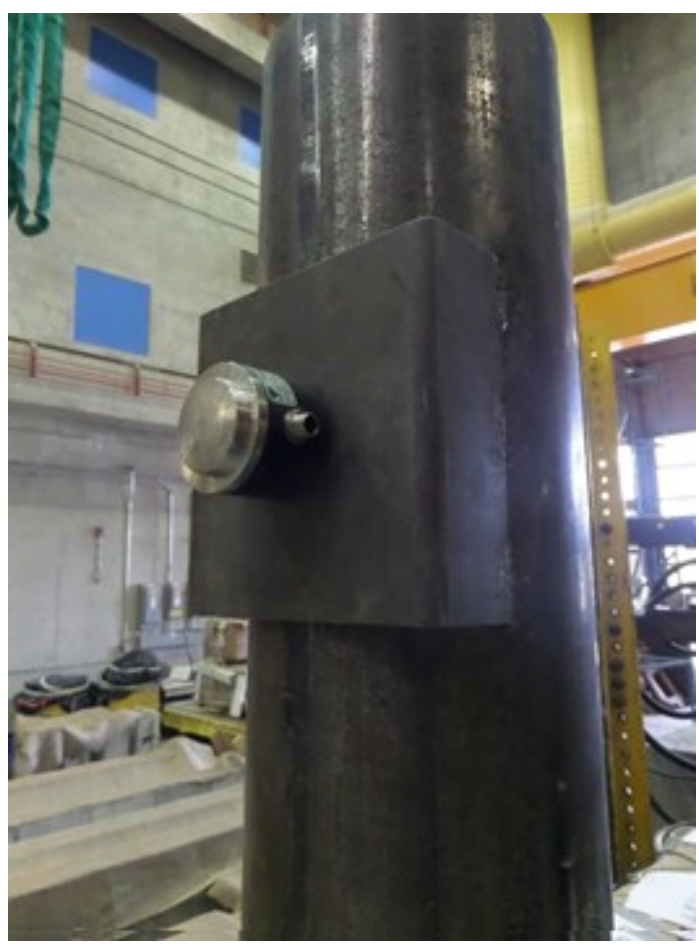

(b)

Figure 3-18: Point of impact configuration on bollard: (a) sketch of configuration (b) bollard with load cell 


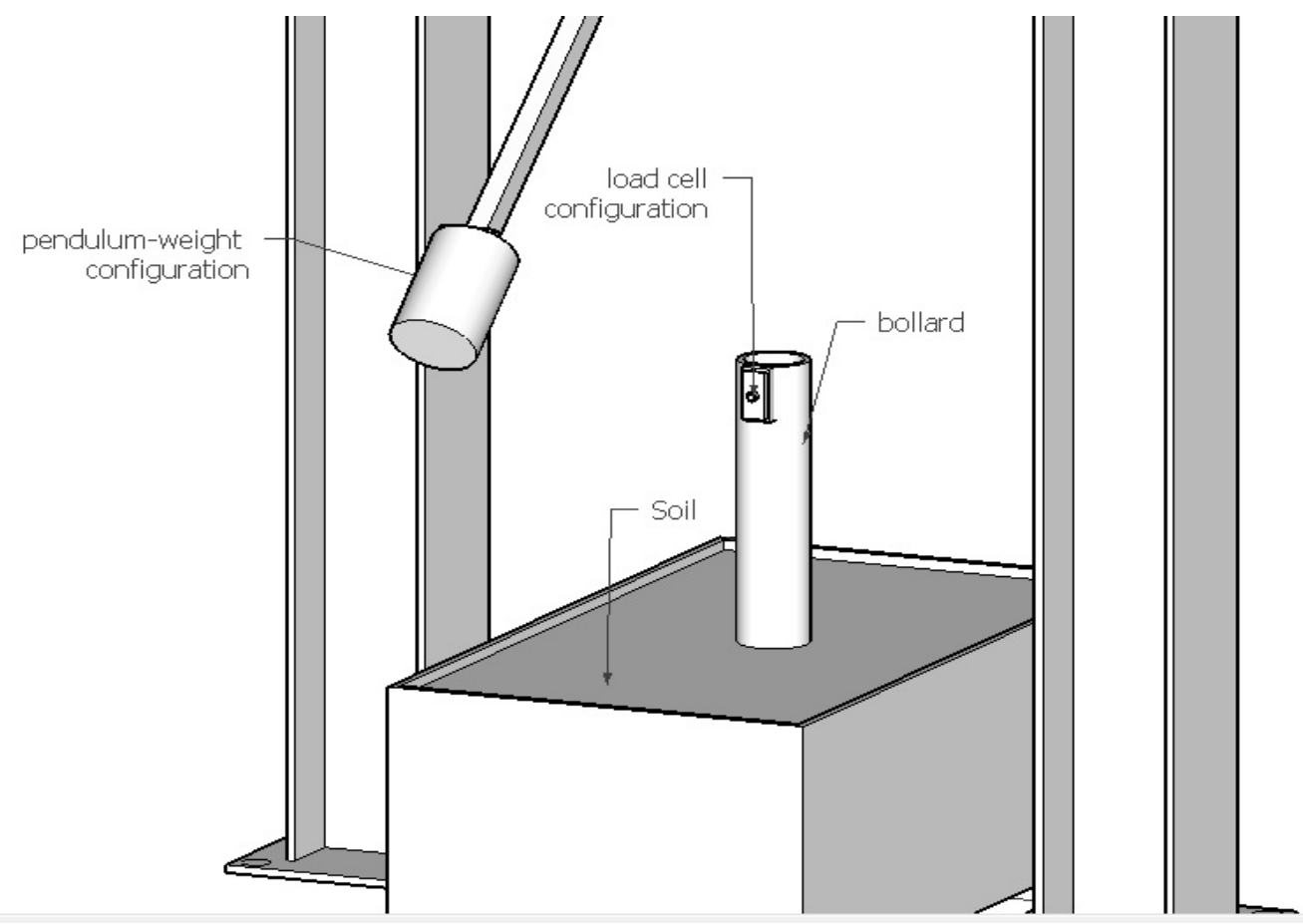

(a)

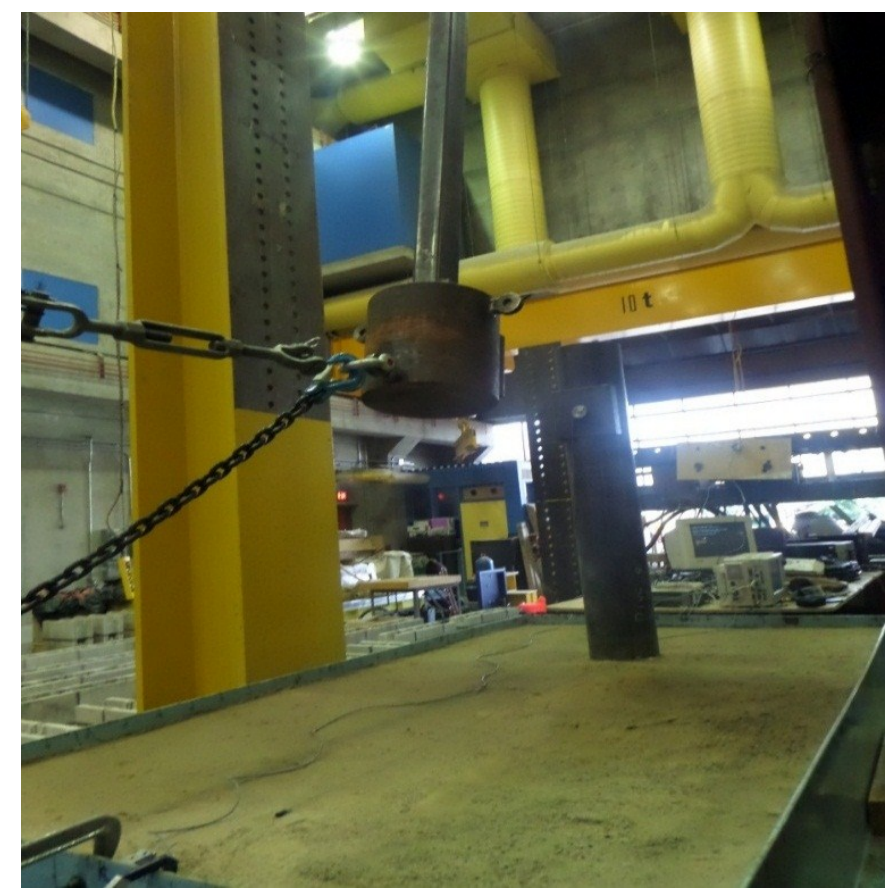

(b)

Figure 3-19: Impact load test setup (a) sketch (b) photograph 


\subsubsection{Impact Load Test Procedure}

Impact load testing was followed after each setup was completed. The load cell was fixed at the $1600 \mathrm{~mm}$ level from the bottom of the bollard-pile configuration, where the impact load was applied. Prior to conducting the impact load test, trial tests were done to obtain the test angle corresponding to the expected impact load at which the subsequent tests were conducted. The results of the trial tests can be observed in Figure 3-20. Three angles ( $15^{\circ}$, $25^{\circ}$ and $37^{\circ}$ ) were used during the trial testing. A proposed $45^{\circ}$ was also to be tried, but due to laboratory constraints a maximum of $37^{\circ}$ was used. The $37^{\circ}$ angle was selected and used for all the tests since it provided the maximum load and deflections which also agreed with the expected impact load from literature. Research shows that the impact load used in vehicular crash test depends on the surrogate vehicle and the type of test. According to AASHTO (2002), the impact load may be $240 \mathrm{kN}$ for a $4,536 \mathrm{~kg}$ vehicle. A study conducted by Bligh et al. (2010) on barrier stability showed that the maximum dynamic load impacted by a 2,268 $\mathrm{kg}$ bogie vehicle was $189 \mathrm{kN}$ at a speed of $20.9 \mathrm{~km} / \mathrm{h}$. Therefore, it was adequate to select the $37^{\circ}$ angle because it provided an impact load of approximately $168.4 \mathrm{kN}$. However, some tests were conducted at $15^{\circ}$ and $25^{\circ}$ angles. 


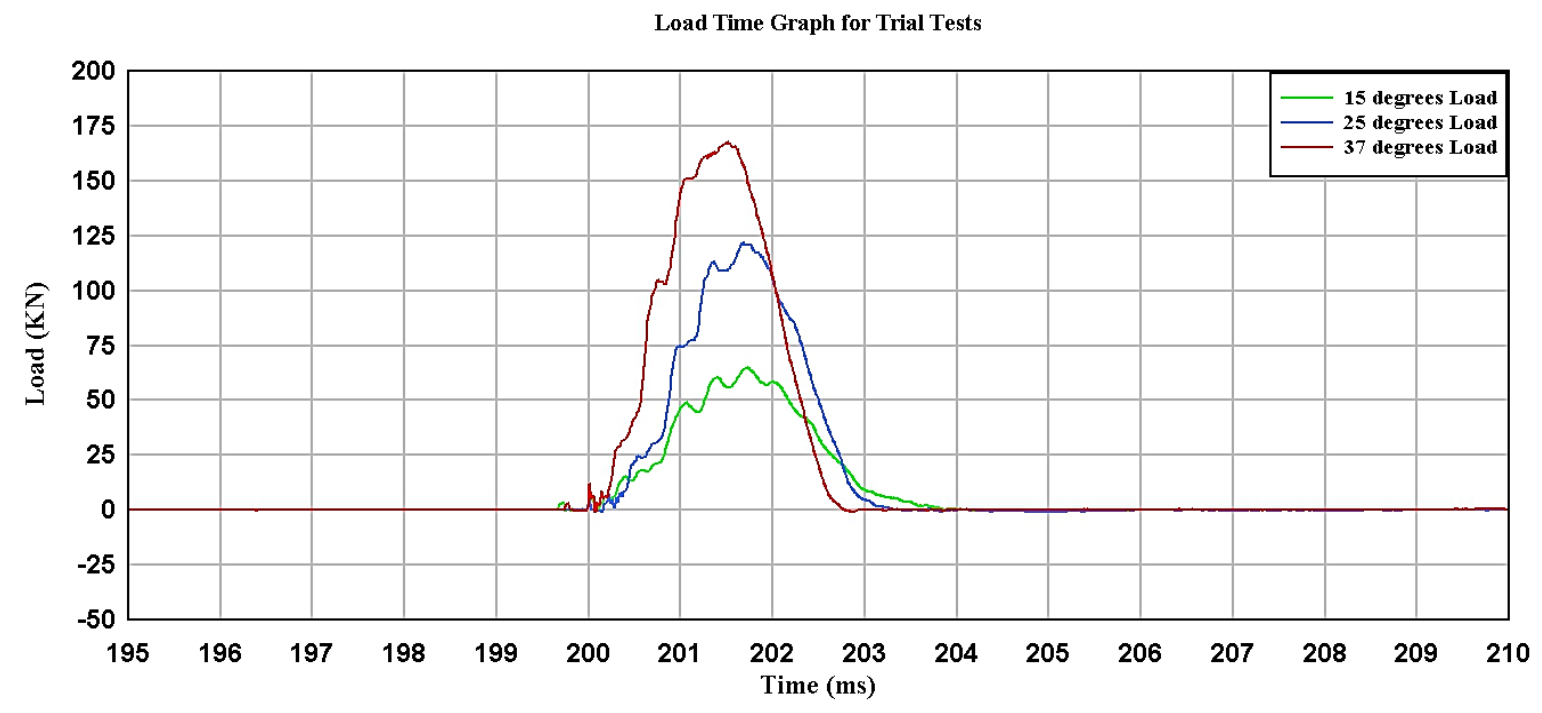

Figure 3-20: Load time profile of trial tests

In total eleven (11) tests were conducted under impact load testing with five specimen. Generally, the impact load test had shorter durations compared to the static load test. According to the results of the impact load configuration, the $6 \mathrm{~mm}$ elastomeric pad configuration was selected and mounted on the pendulum weight.

The pendulum weight was lifted to the $37^{\circ}$ impact angle using a pulley system connected from a winch. The impact angle was achieved by pulling the weight backwards to a distance corresponding to the impact angle. The trigger settings and subsequent instrumentation on the oscilloscope were checked to ensure they were working properly. The pulley was disengaged to release the pendulum. Within a few microseconds, the specimen was impacted with the force of the pendulum-weight. Upon impact, a trigger was sent to the oscilloscope and the impact load and deflections were recorded on the oscilloscope. The results were saved and retrieved for analysis. The procedure was repeated for the other specimen. 


\subsection{Summary}

Static and impact load tests were carried out in the experimental program. In total, seventeen (17) tests were conducted: five (5) and one (1) repeated static load tests, and eleven (11) impact load tests. The setup for both tests were similar. The major difference were the load application and instrumentation. The instrumentation for the impact load test was complex compared with the static load test. Load application for the impact load test was done with a known mass of pendulum- weight configuration and that of the static load test used a constant load from an actuator. Three string pots were connected at three different locations along the bollard-pile configuration to measure the deflections in both tests.

The impact load test took lesser time to complete compared to the static load test which typically took between three (3) to four (4) hours for each test. For the static load test, loading and unloading were applied statically in sequential order with the actuator at a rate of $0.5 \mathrm{~mm} / \mathrm{min}$. The loads were applied using ASTM standard method for applying lateral loading to piles. A constant load was applied throughout the impact load test using impact load application methods.

The results of the impact load test was obtained using a Yokogawa DL750P as an oscilloscope while that of the static load test was obtained using a data acquisition system setup for the actuator. The results were plotted on a load versus deflection curve. The tests were carried out successfully and provided significant results. The results of both tests were compared and analyzed in chapter four. 


\section{Chapter: Results and Discussions}

\subsection{Introduction}

The experimental program consisted of 5 bollard-pile configurations designed and loaded laterally in the static and impact load tests. Five (5) static load tests and one (1) repeat were conducted while eleven (11) impact load tests were completed. The static load test was conducted using an MTS 290 actuator and the impact load test used a pendulum system to simulate vehicular impact on the bollard-pile configuration.

The loading procedure and applied loads varied according to the type of test (static or impact) but for the same type of test, the same procedure was used. It is important to note that although a bollard-pile configuration was used for the tests, the pile is the area of the bollard-pile configuration embedded in the soil, which interacts with the soil to form the foundation. Fins were fabricated and welded on the piles, hence each pile had a different fin configuration. The results of both tests are presented in this chapter. Analysis and relevant conclusions are also discussed.

\subsection{Static Load Test Results}

This section presents the results of the static load test performed on the bollard-pile configurations. During the static load test, the ultimate load resistance and the bollard deflections at the top, middle and bottom were monitored and recorded. The load tests were

conducted using displacement control procedure while the loading was applied at a constant loading rate of $0.5 \mathrm{~mm} / \mathrm{min}$. The purpose of the static load test was to observe the 
behavior of the different bollard-pile configurations under static loading. The results were analyzed to determine the static lateral capacity and ultimate deflection of the bollards.

Figure 4-1 shows the 5 bollard-pile configurations tested under static loading. The nomenclature used for the test specimen is as follows: ST Test 1 denotes static load test number followed by Plain, Fin 1, Fin 2, Fin 3 and Fin 4, which denotes the various bollardpile configurations.

For all the static load tests, both physical and analytical observations were made. The major physical observations for each test included the amount of bollard deflection, observation of cracks and bulging on the surface of the soil after testing. Pre-test photographs for all the tests can be observed in Figure 4-2.

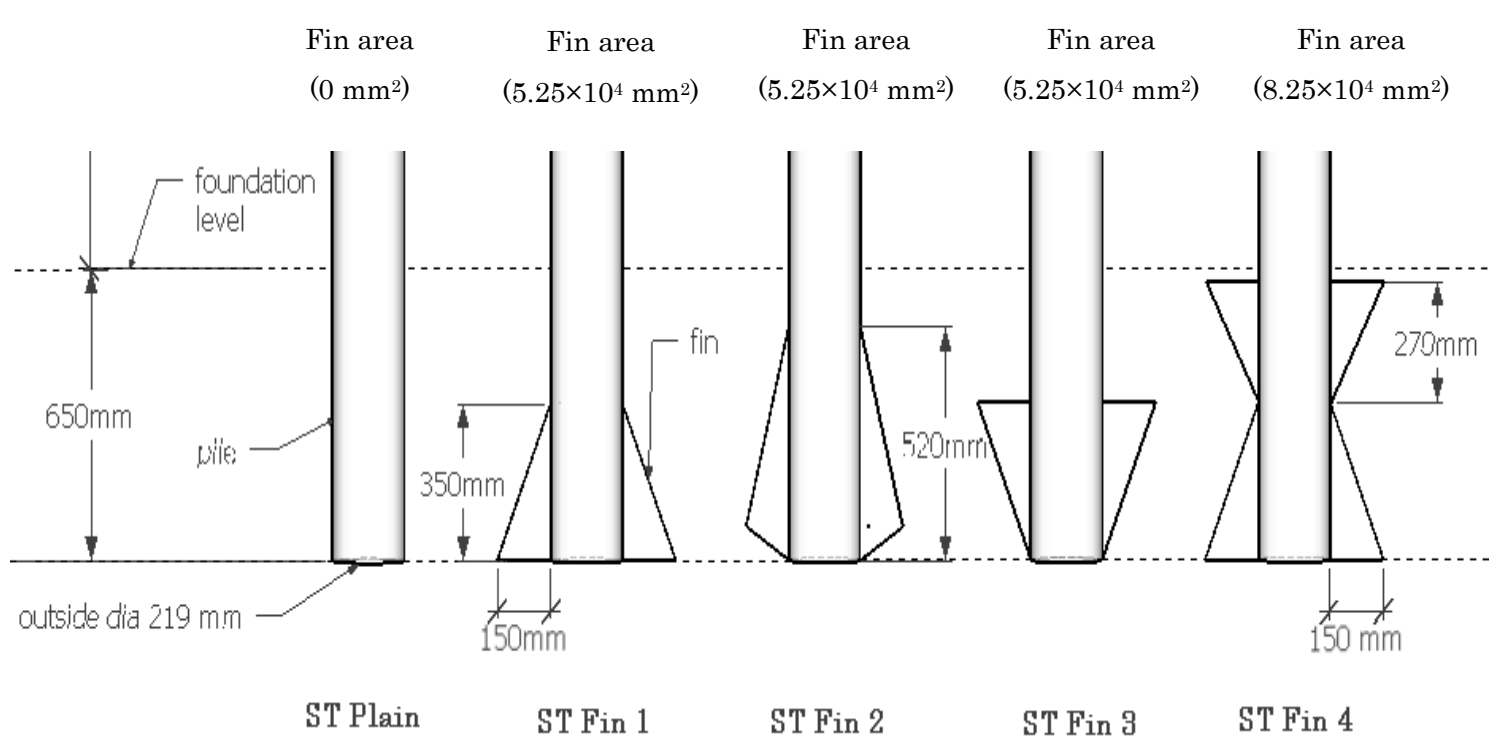

Figure 4-1: Bollard-pile configurations tested under static loading 


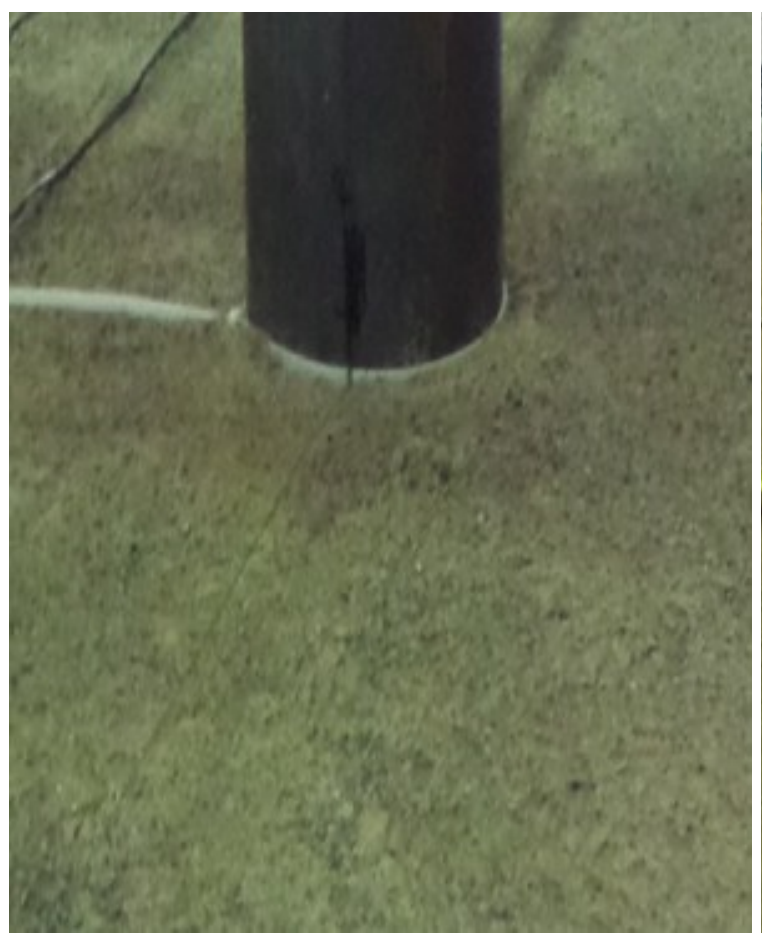

(a)

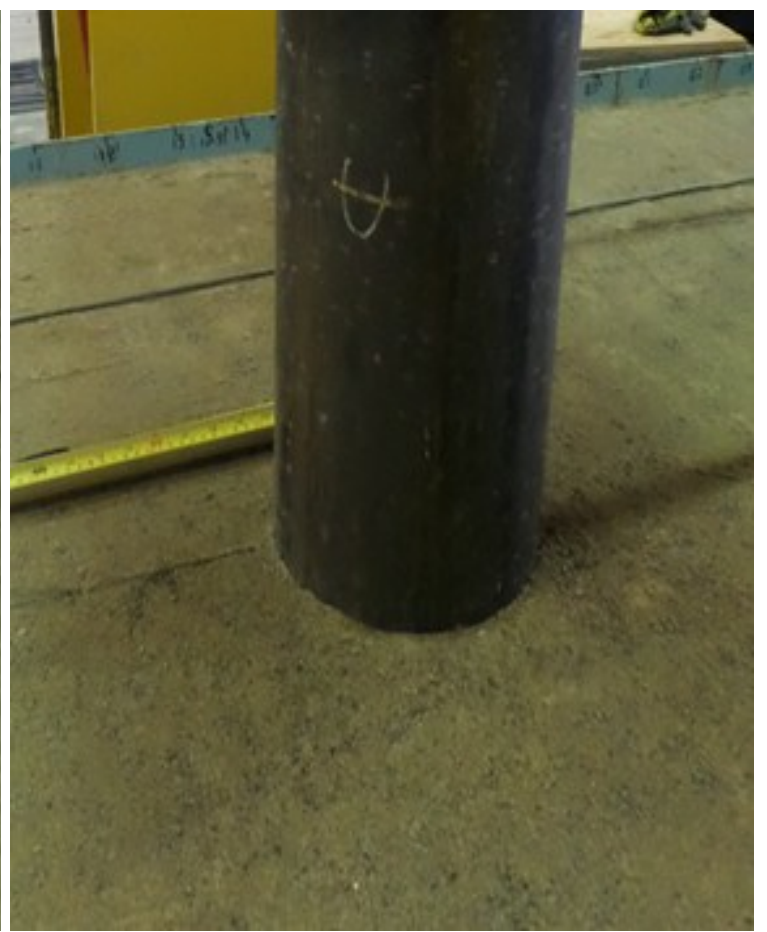

(b)

Figure 4-2: Pretest images of static load test; (a) final surface level (b) measurement of surface level

\subsubsection{ST Test 1-Plain}

Figure 4-3 and Figure 4-4 present the load-deflection response and the post-test photograph of static test on the plain bollard respectively. The ultimate failure load of $4.0 \mathrm{kN}$ was recorded. Deflections recorded at the top, middle and bottom of the bollard were $39.3 \mathrm{~mm}$, $10.9 \mathrm{~mm}$ and $0.1 \mathrm{~mm}$ respectively (Figure 4-3). The recorded deflection at the bottom of the bollard was almost zero, indicating no rotation at this point. Post-test observation showed a small amount of bulging of the soil behind the bollard. Also, separation of the bollard from the soil at surface was observed. 


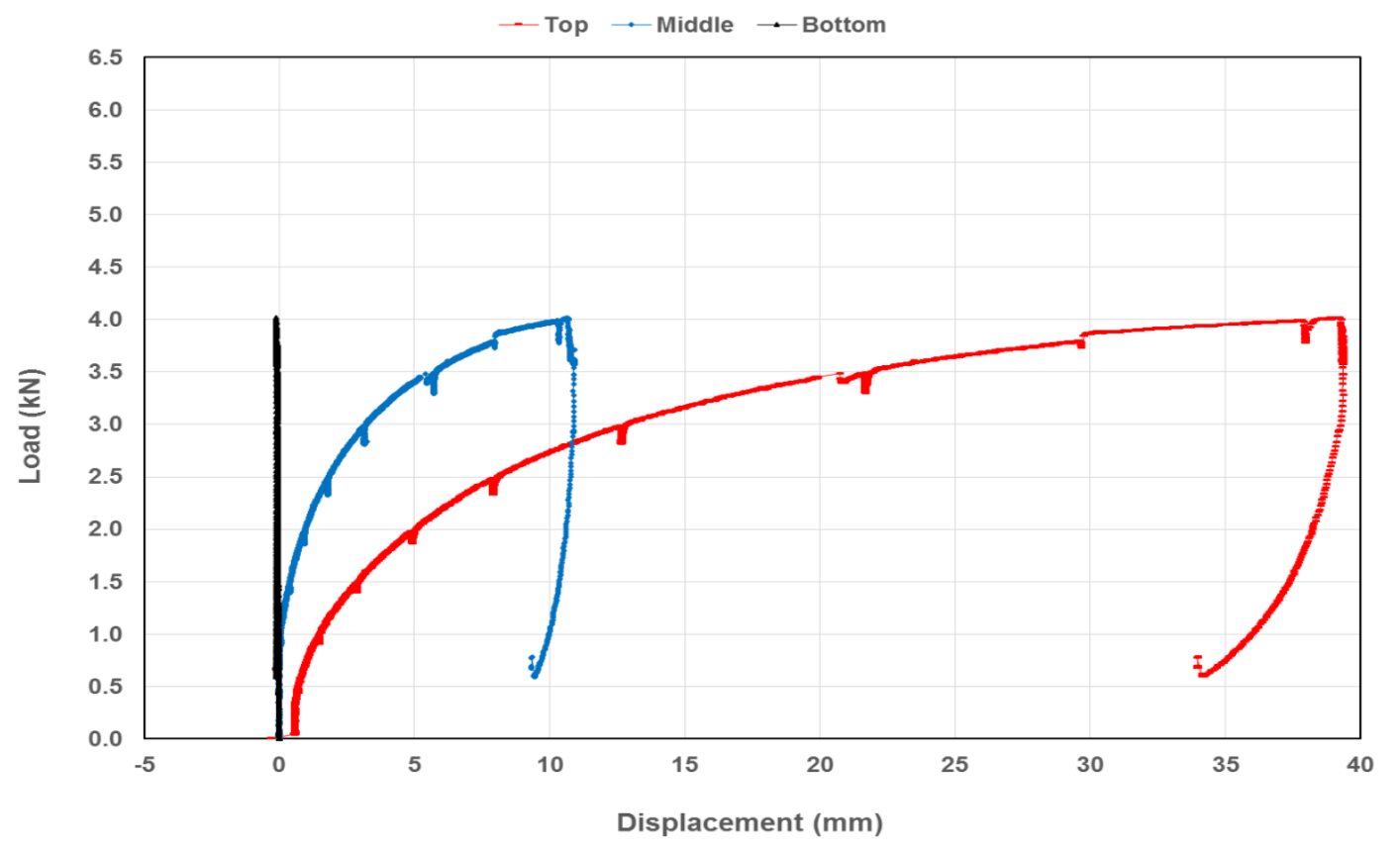

Figure 4-3: Load-deflection response of static test 1 (Plain bollard)

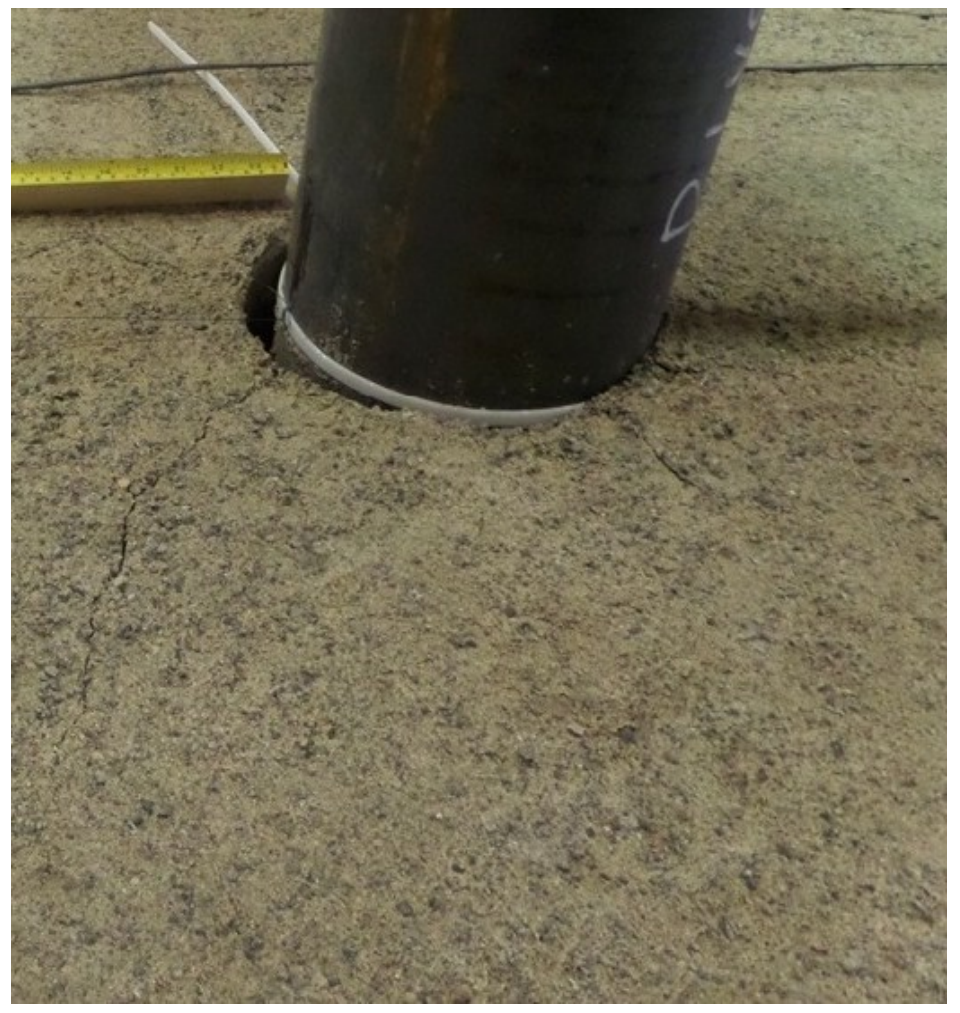

Figure 4-4: Post-test image of static test 1 (Plain) 


\subsubsection{ST Test 2-Fin 1}

ST Test 2-Fin 1 involved a plain bollard with Fin type 1. Fin type 1 had a total fin area of $52500 \mathrm{~mm}^{2}$. Figure 4-5 presents the load-deflection response of the bollard in test 2 . The ultimate load resistance recorded in test 2 was $4.8 \mathrm{kN}$. The deflection of the bollard at the top, middle and bottom were $38.1 \mathrm{~mm}, 10.7 \mathrm{~mm}$ and $0.1 \mathrm{~mm}$ (Figure 4-5). Similar to the Plain bollard, the deflection of the bottom was almost zero. The post-test inspection of the bollard showed cracking on the soil surface for ST Test 2-Fin 1 but no significant bulging behind the bollard was noted. Figure 4-6 shows separation of the bollard from the soil at the soil-pile interface.

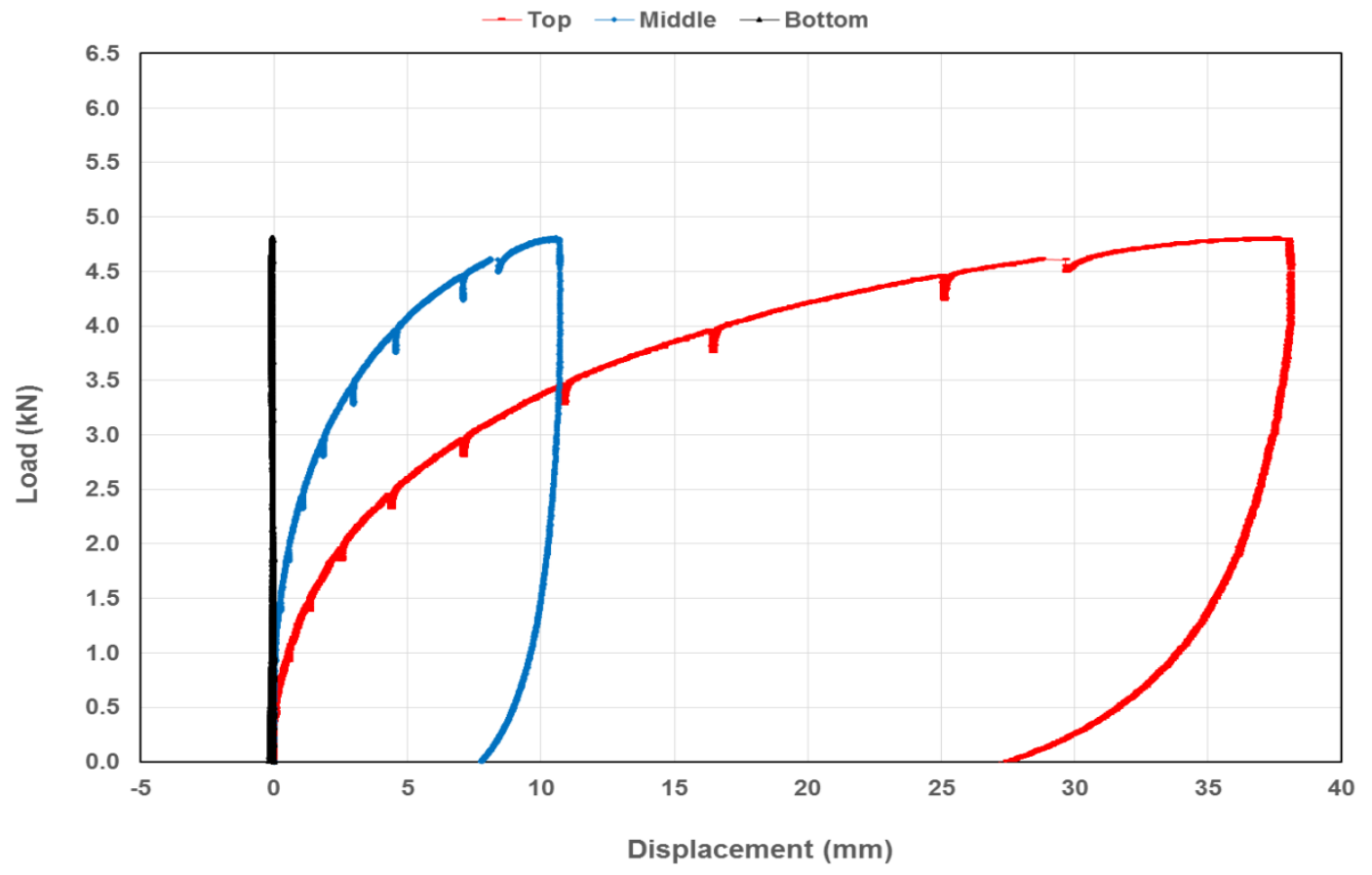

Figure 4-5: Load-deflection response of static test 2 (Fin 1) 


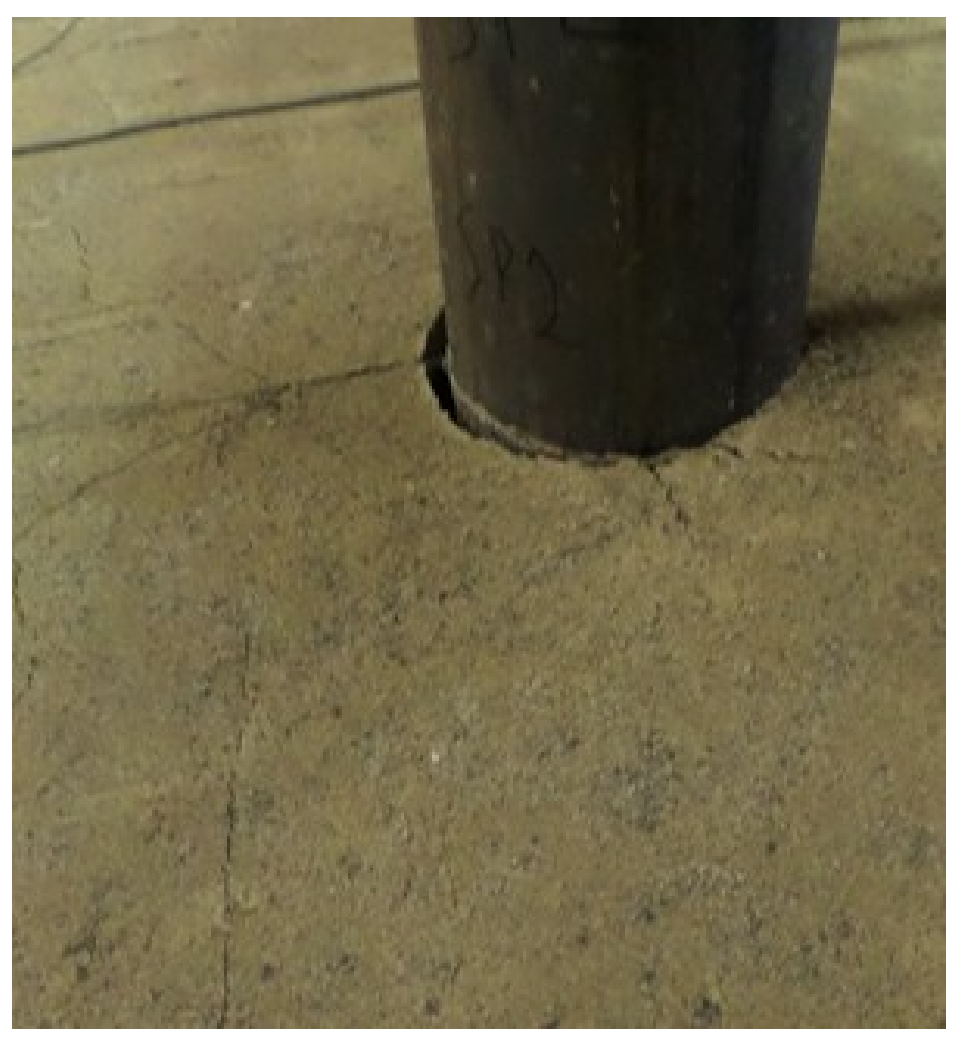

Figure 4-6: Post-test image of static test 2 (Fin 1)

\subsubsection{ST Test 3-Fin 2}

ST Test 3-Fin 2 involved test of plain bollard with Fin type 2. Fin type 2 had a fin area of $52500 \mathrm{~mm}^{2}$. Figure 4-7 presents the load-deflection response of the bollard in test 3 . The ultimate load was recorded at $5.3 \mathrm{kN}$. The top, middle and bottom deflections of the bollard were obtained as $36.2 \mathrm{~mm}, 10.2 \mathrm{~mm}$ and $6.6 \mathrm{~mm}$ respectively (Figure 4-7). Higher deflection at the bottom of the bollard was observed in comparison with Test 1 and Test 2 . No significant bulging was observed behind the bollard but separation of the bollard from the soil at the bollard-soil interface was observed. Some cracks were also seen at the surface. Figure 4-8 shows the post-test photograph of the bollard. 


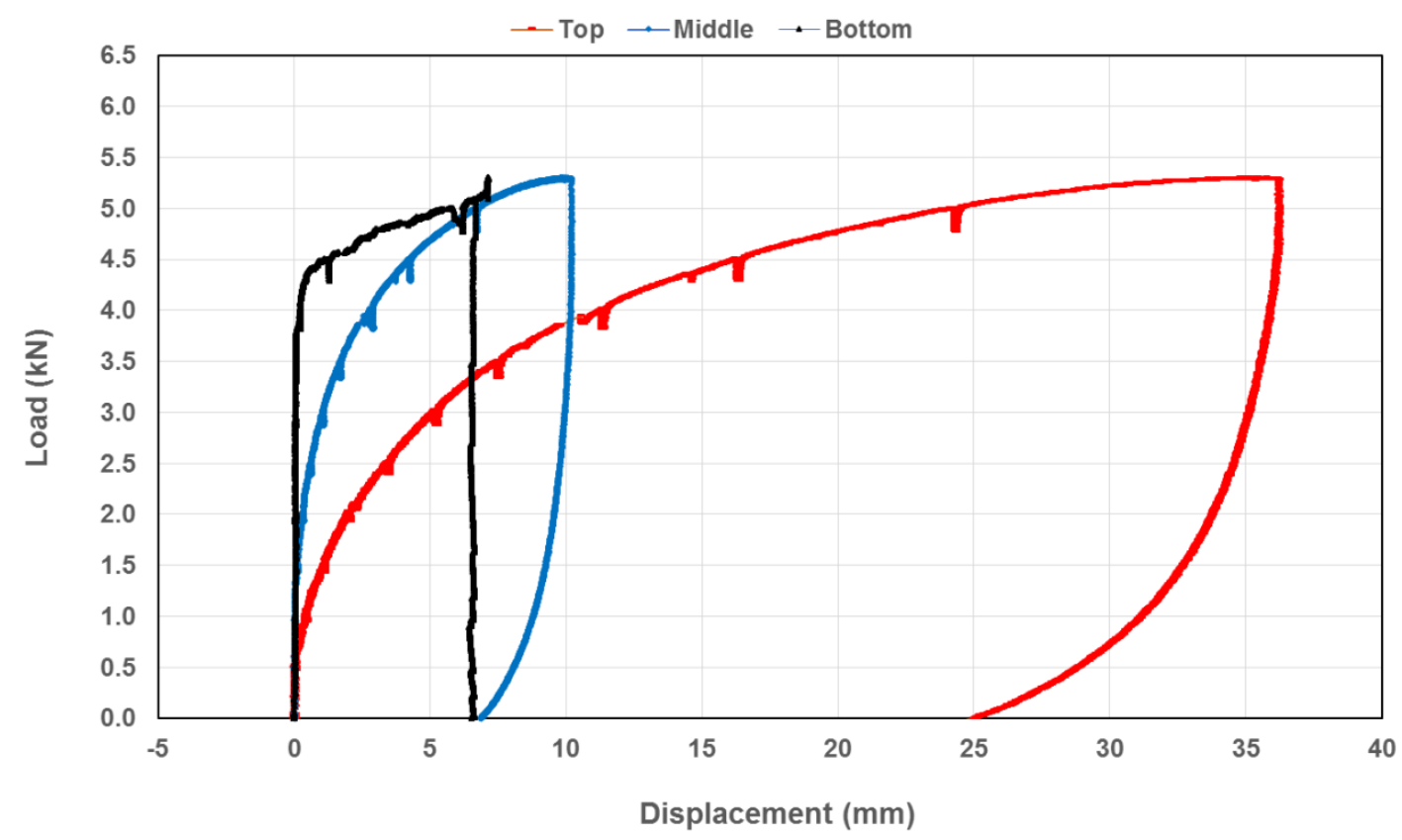

Figure 4-7: Load-deflection response of static test 3 (Fin 2)

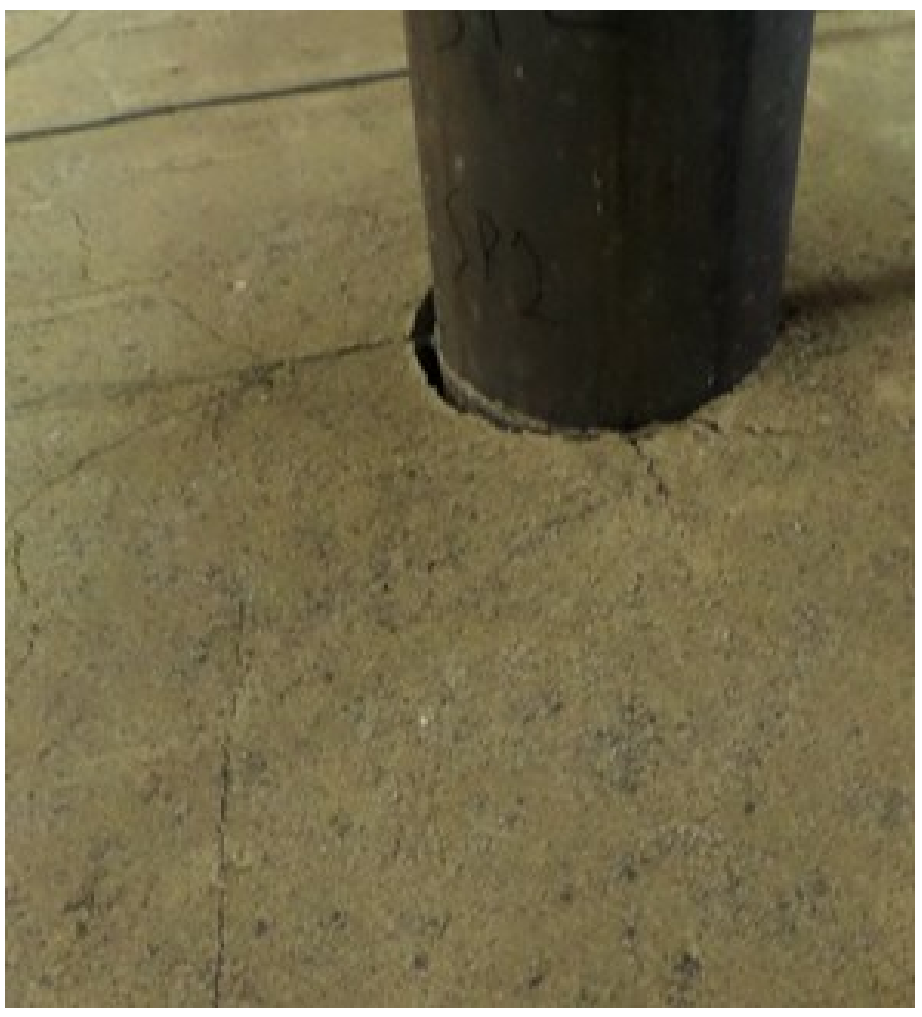

Figure 4-8: Post-test image of static test 3 (Fin 2) 


\subsubsection{ST Test 4-Fin 3}

ST Test 4-Fin 3 involved test of plain bollard with Fin type 3, with a fin area of 52500 $\mathrm{mm}^{2}$. The load-deflection response graph for this test can be observed in Figure 4-9. Deflections at the top, middle and bottom measurements were recorded as $31.3 \mathrm{~mm}, 8.1$ $\mathrm{mm}$ and $3.2 \mathrm{~mm}$. The ultimate load was observed as $4.6 \mathrm{kN}$. Similar to the other tests, some cracks were observed at the surface but no significant bulging was recorded behind the bollard for this test. Separation of the bollard from the soil was seen at the interaction between the pile and soil surface as observed in Figure 4-10.

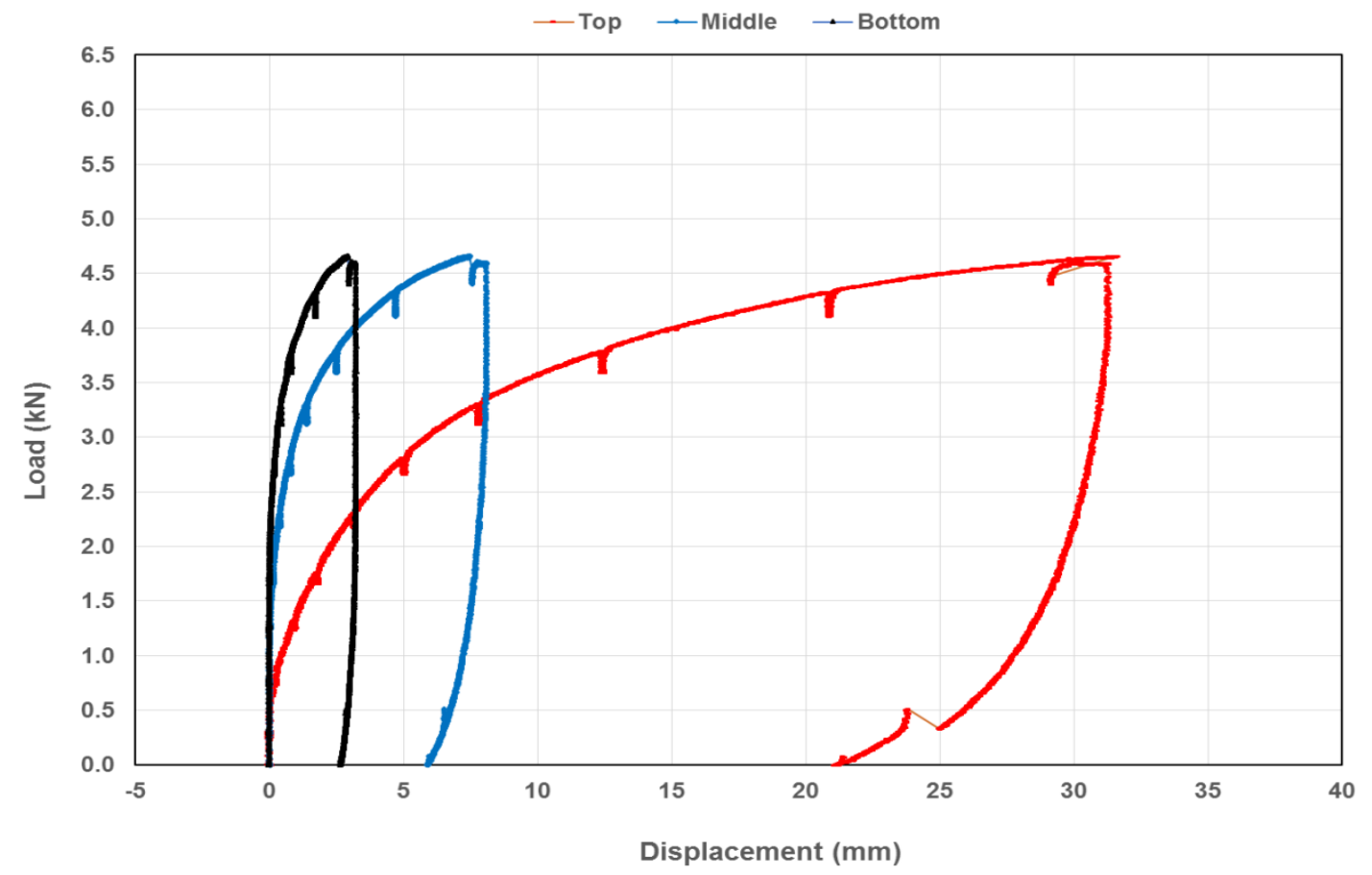

Figure 4-9: Load-deflection response of static test 4 (Fin 3) 


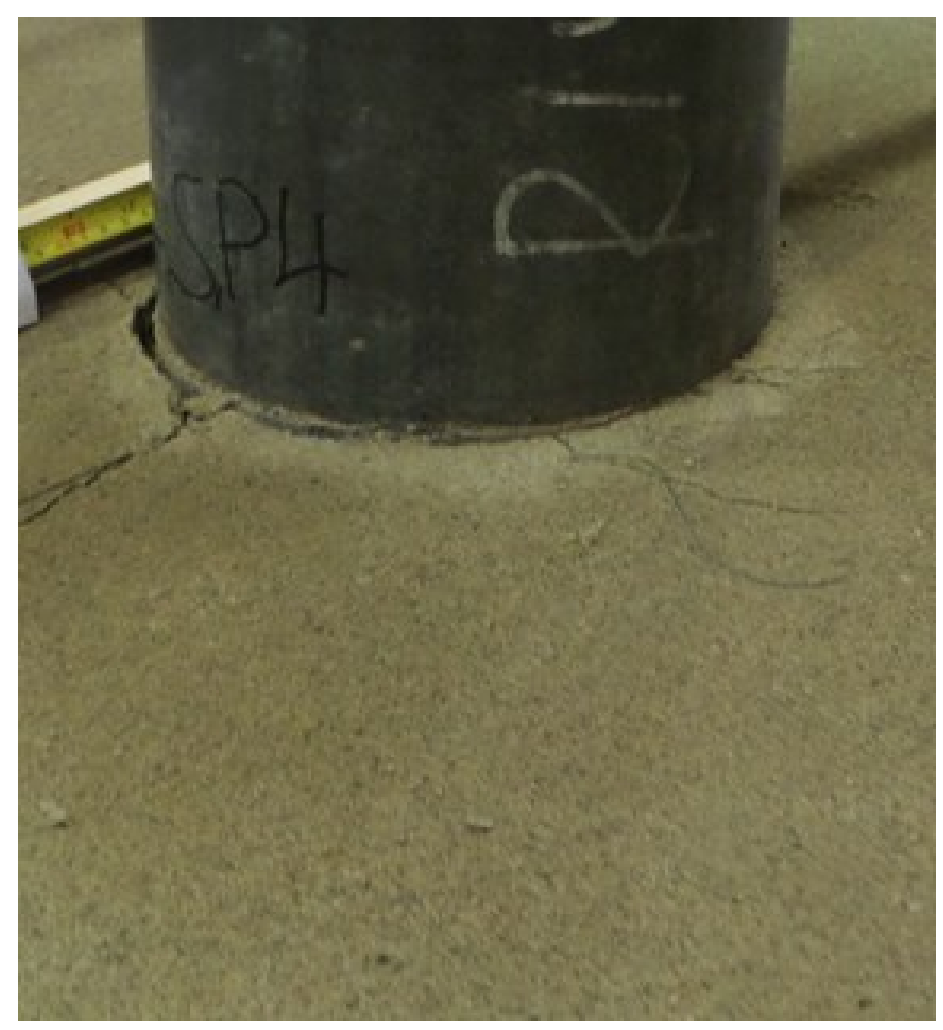

Figure 4-10: Post-test image of static test 4 (Fin 3)

\subsubsection{ST Test 5-Fin 4}

Figure 4-11 and Figure 4-12 present the load-deflection response graph and the post-test photograph of static test 5 respectively. This test involved test of plain bollard with Fin type 4. Fin type 4 had a fin area of $82500 \mathrm{~mm}^{2}$. An ultimate load resistance of $6.2 \mathrm{kN}$ was recorded for ST Test 5-Fin 4. The top, middle and bottom deflections of the bollard were $30 \mathrm{~mm}, 4.7 \mathrm{~mm}$ and $2.3 \mathrm{~mm}$ respectively. No bulging was observed on the soil surface behind the bollard. Separation of the bollard from the soil at the bollard-soil interface was observed with significant number of cracks on the surface. 


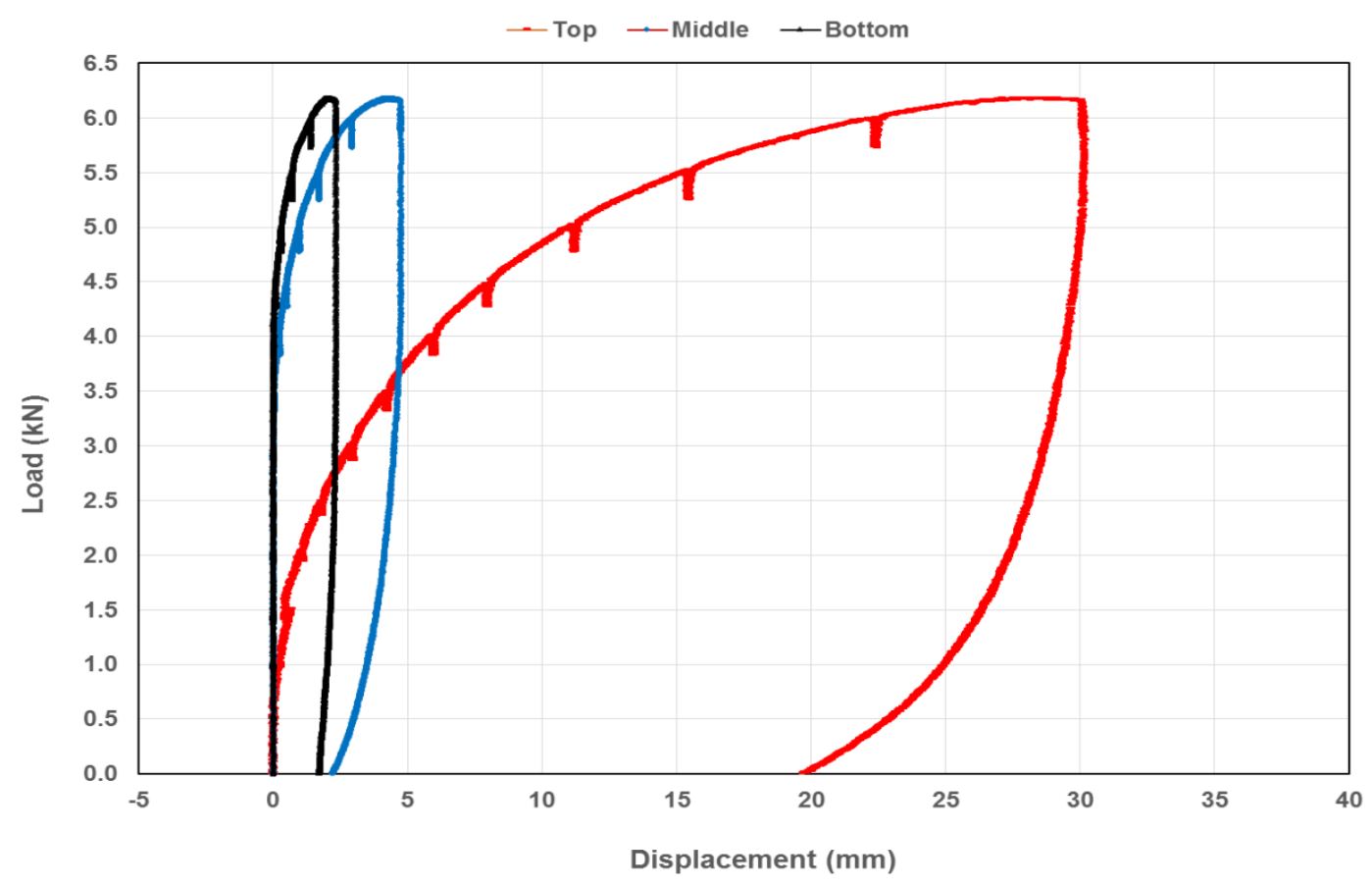

Figure 4-11: Load-deflection response of static test 5 (Fin 4)

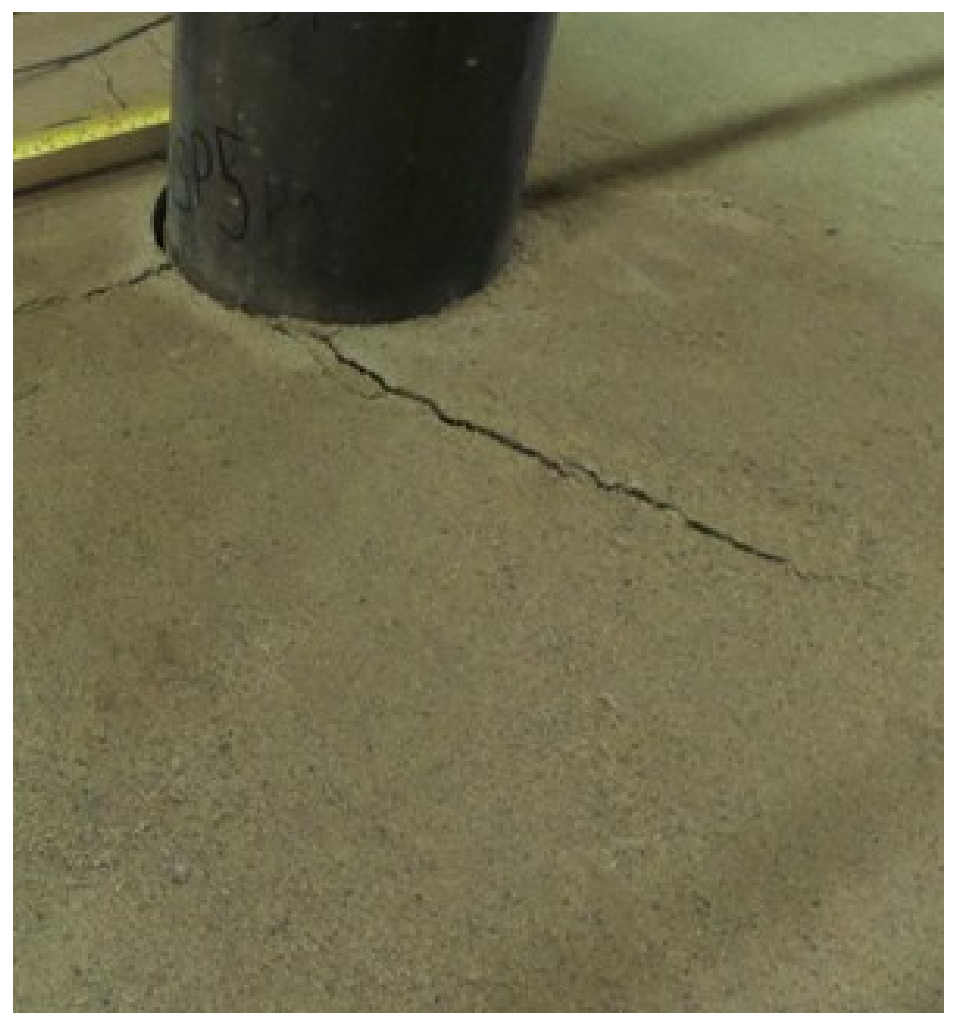

Figure 4-12: Post-test image of static test 5 (Fin 4) 


\subsubsection{Comparison of Bollard Systems under Static Loading}

\subsubsection{Lateral static load capacity}

The peak load capacities of the bollards with various fin configurations were determined from the load-deflection graphs and summarized in Table 4-1 while the response of the bollard systems under the load was compared in Figure 4-13, Figure 4-14 and Figure 4-15. The load capacities of the bollard systems generally depend on the surface area of the fins. The Plain bollard, without fins exhibited the lowest peak load capacity while bollard with Fin type 4, total fin surface area of $82500 \mathrm{~mm}^{2}$, exhibited the highest peak load capacity. Bollard with Fin type 1, Fin type 2, and Fin type 3 had the same fin surface area of 52500 $\mathrm{mm}^{2}$, however Fin type 2 exhibited higher load capacity $(5.3 \mathrm{kN})$ while the peak load capacities of bollard with Fin type 1 and Fin type 3 were similar; $4.6 \mathrm{kN}$ and $4.8 \mathrm{kN}$ respectively. The reason for the higher load capacity of bollard with Fin type 2 is probably due to the higher height of the fins, among bollards with same surface area.

\subsubsection{Lateral static deflection}

The deflections were recorded at three different locations (top, middle and bottom) of each test using string pots. The ultimate deflections for the different configurations with respect to location of measurements for the static load tests have been summarized in Table 4-1. From the table, the bottom deflection measurements for ST Plain and ST Fin 1 show unreasonable values of $0.1 \mathrm{~mm}$ and this may be due to measuring instrument error. The deflections at the top, middle and bottom locations can also be observed in Figure 4-13, Figure 4-14 and Figure 4-15. From the load-deflection response curves, there is an initial linear response followed by a nonlinear response phase. The linear region is known as the 
elastic region while the nonlinear phase is considered as the plastic region. The deflections in the elastic regions are small compared to the plastic regions.

The location of string pots (top, middle and bottom) for measurement of deflection remained the same for each test. The loads applied relative to the location of deflection measurements also remained constant but the deflection changed with regards to the location of string pot. The maximum deflections were recorded at the top locations followed by the middle and bottom. This confirms Cuduto's (2001) suggestion that the highest point of deflection along a pile is the topmost part where the load is applied. Throughout the static load test, the Plain and Fin 4 configurations recorded the maximum and minimum deflections respectively regardless of the measuring location and translate to angles of rotation of $2.4^{\circ}$ and $1.8^{\circ}$ respectively.

Table 4-1: Summary of peak loads and deflections at various locations for static load tests

\begin{tabular}{|c|c|c|c|c|c|}
\hline \multirow{2}{*}{$\begin{array}{c}\text { Test } \\
\text { configuration }\end{array}$} & \multirow{2}{*}{$\begin{array}{c}\text { Lateral Static } \\
\text { Load (kN) }\end{array}$} & \multicolumn{3}{|c|}{ Deflection (mm) } & \multirow{2}{*}{$\begin{array}{c}\text { Deflection } \\
\text { Angle }\left({ }^{\circ}\right)\end{array}$} \\
\hline & & Top & Middle & Bottom & \\
\hline ST Plain & 4 & 39.3 & 10.9 & 0.1 & 2.4 \\
\hline ST Fin 1 & 4.8 & 38.1 & 10.7 & 0.1 & 2.3 \\
\hline ST Fin 2 & 5.3 & 36.2 & 10.2 & 6.6 & 2.2 \\
\hline ST Fin 3 & 4.6 & 31.3 & 8.1 & 3.2 & 1.9 \\
\hline ST Fin 4 & 6.2 & 30 & 4.7 & 2.3 & 1.8 \\
\hline
\end{tabular}




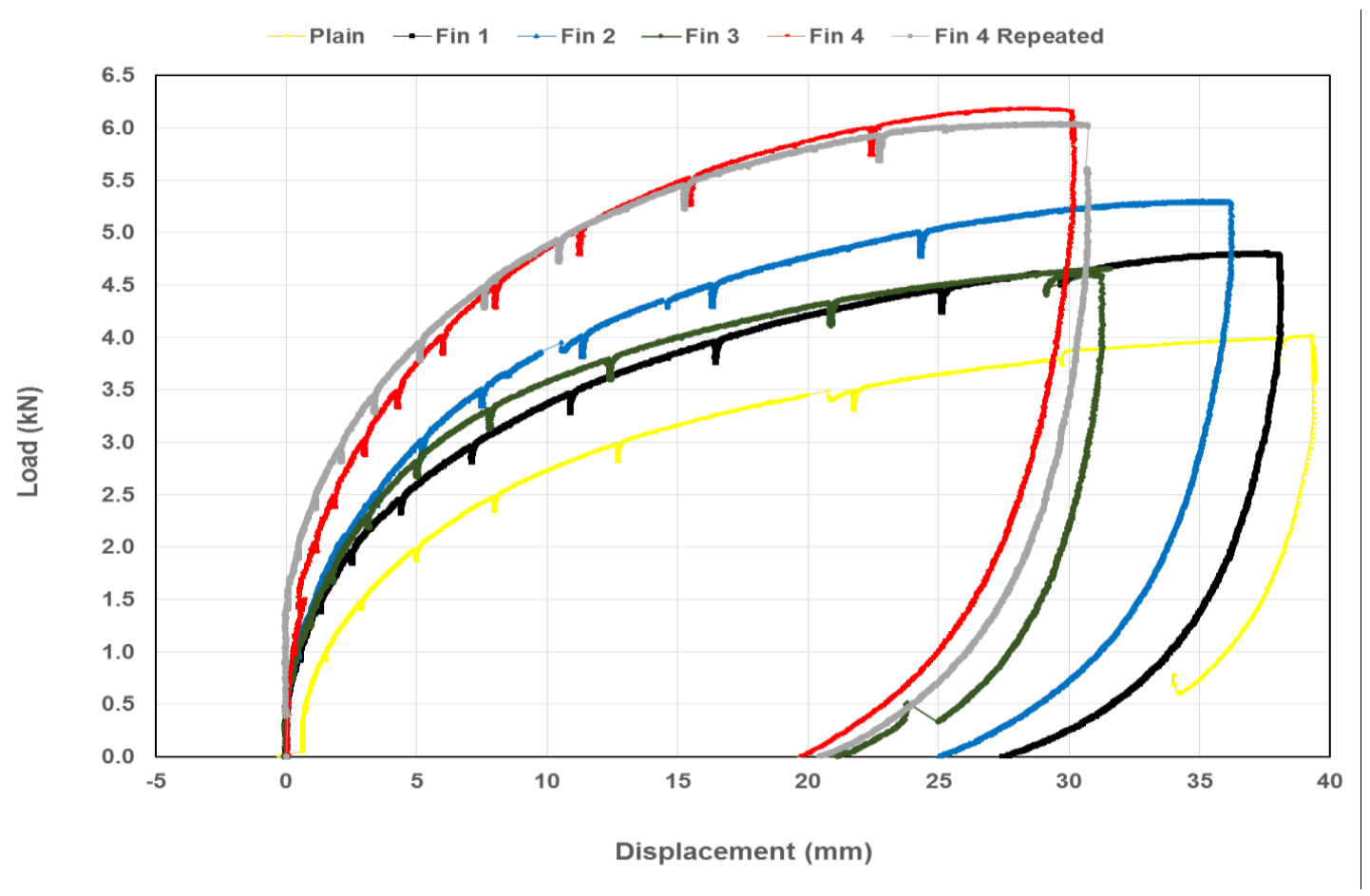

Figure 4-13: Load - deflection graphs for top string pot measurements

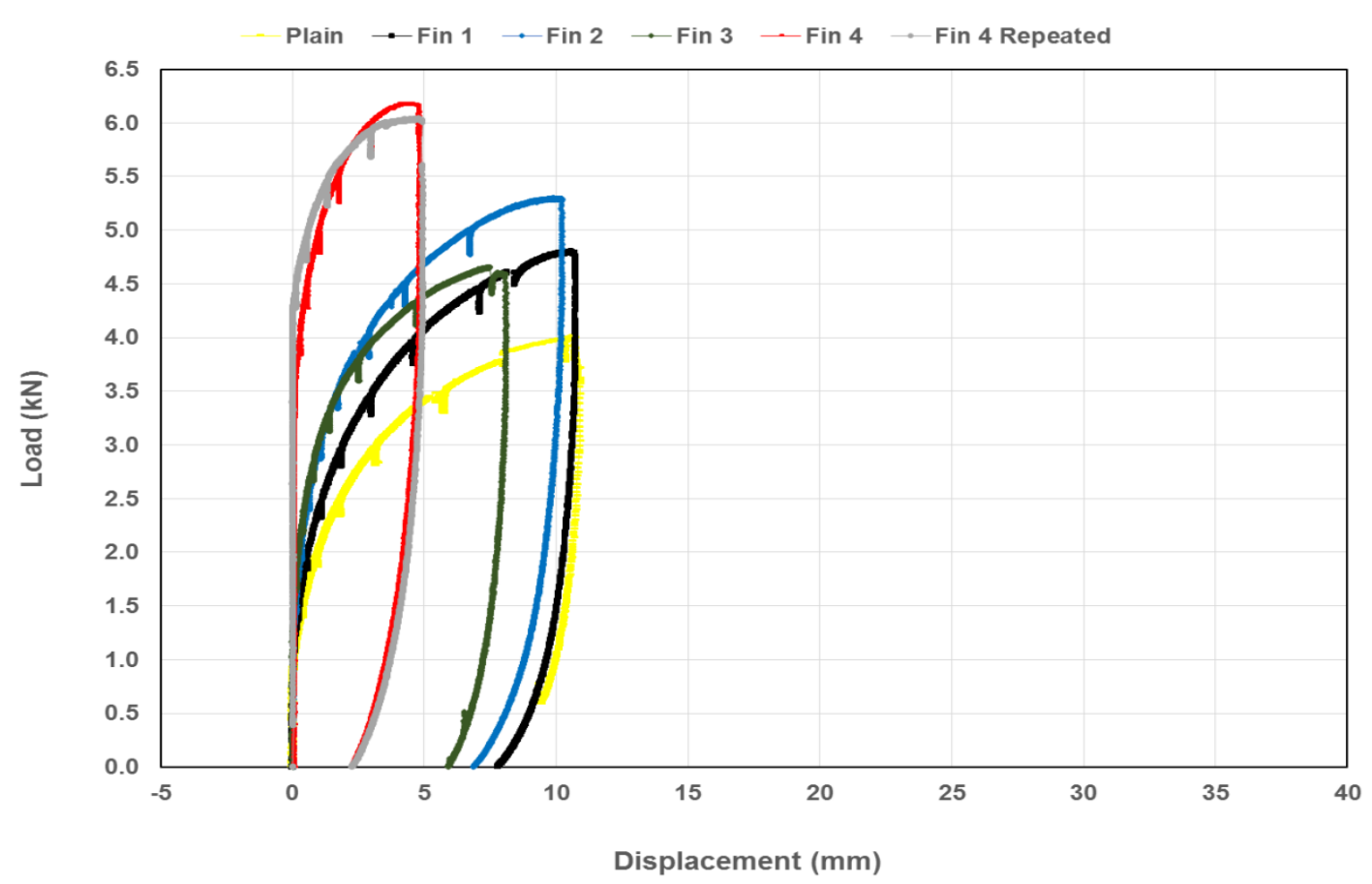

Figure 4-14: Load- deflection graphs for middle string pot measurements 


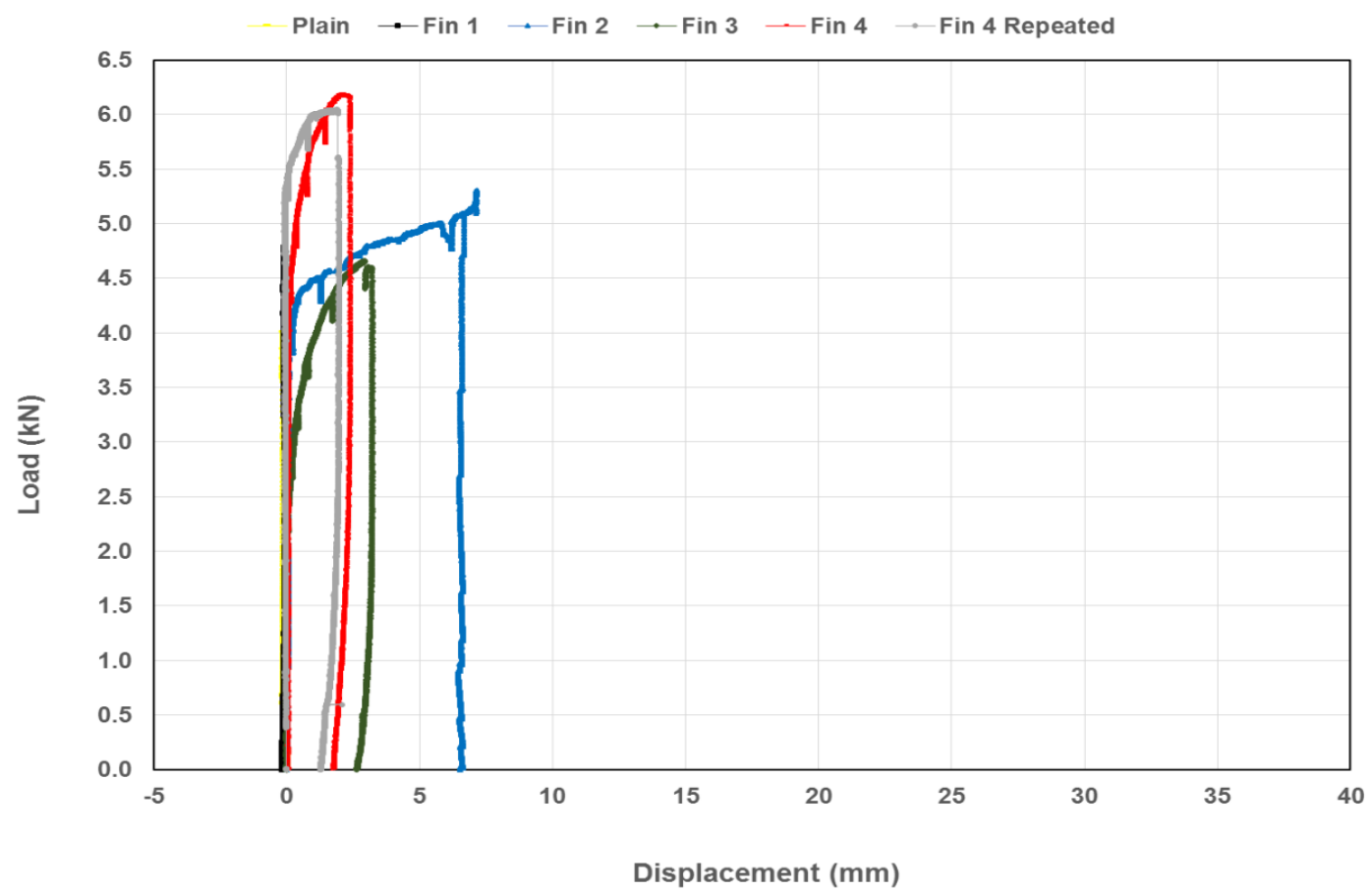

Figure 4-15: Load-deflection graphs for bottom string pot measurements

\subsection{Impact Load Test Results}

The purpose of the impact load test was to explain the behavior of the five bollard-pile configurations under impact loading. The nomenclature used for the test specimen is as follows: IM Test 1 denotes impact load test number followed by Fin 1, Fin 2, Fin 3, Fin 4 and Plain, which denotes the various fin configurations. Figure 4-16 presents the order of bollards tested under impact loading. All the five configurations were conducted at an impact angle of $37^{\circ}$ which provided an impact load of about $168.4 \mathrm{kN}$ (Figure 4-17). Also, three configurations; IM Plain, IM Fin 3 and IM Fin 4 were tested at $15^{\circ}$ and $25^{\circ}$ angles to further investigate the loads and deflections for these specimen and to compare the results to the $37^{\circ}$ angle. Photographs of the bollards before impact load testing for the $15^{\circ}$ and $25^{\circ}$ 
impact angles can be seen in Figure 4-18 and Figure 4-19. The same testing procedures were implemented for all the tests, except when the load applied changed by changing the angle of impact. A total of eleven tests were conducted for the impact load test. The physical observations included cracks, deflection of the bollard and bulging at the surface of the soil. During each impact load test of the bollards, the top, middle and bottom deflections were recorded and plotted on a load- deflection- time graph. The plot of the load-deflection-time response graphs were such that the top and middle deflections were assigned negative to depict the bollard moved away from the impact while the bottom had a positive sign to show the bollard moved towards the impact.

$\begin{array}{ccccc}\text { Fin area } & \text { Fin area } & \text { Fin area } & \text { Fin area } & \text { Fin area } \\ \left(8.25 \times 10^{4} \mathrm{~mm}^{2}\right) & \left(5.25 \times 10^{4} \mathrm{~mm}^{2}\right) & \left(5.25 \times 10^{4} \mathrm{~mm}^{2}\right) & \left(5.25 \times 10^{4} \mathrm{~mm}^{2}\right) & \left(0 \mathrm{~mm}^{2}\right)\end{array}$

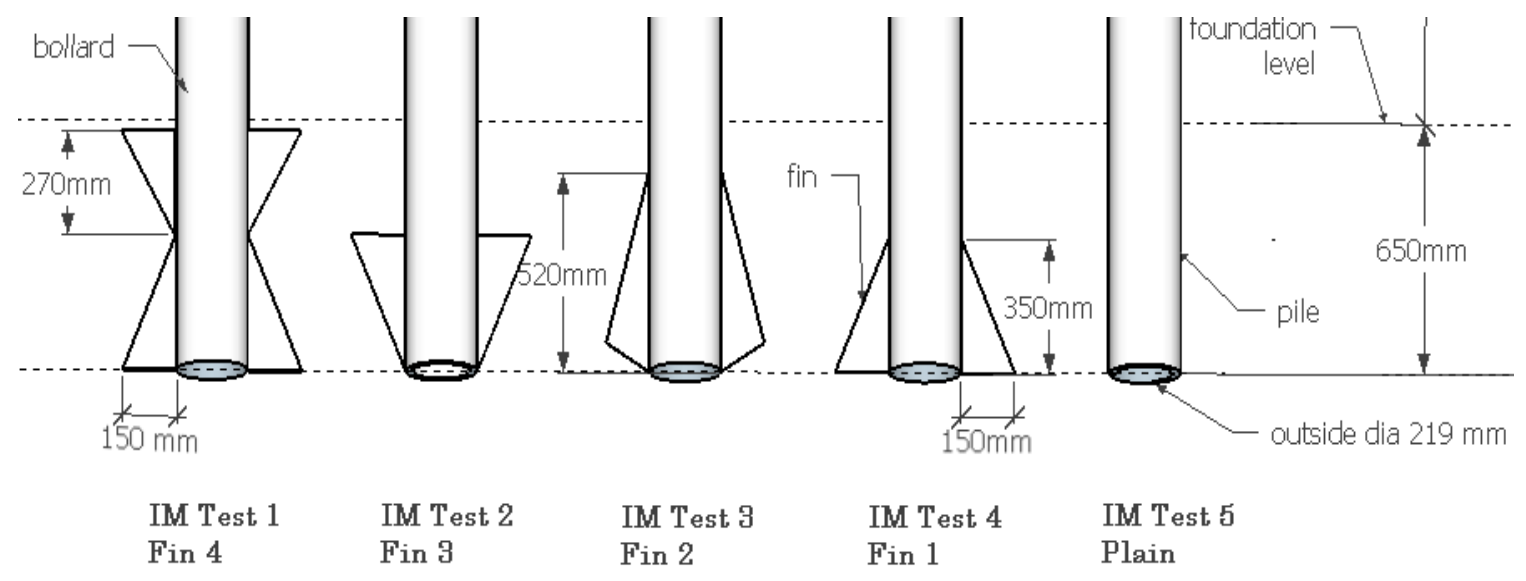

Figure 4-16: Bollard-pile configurations tested under impact loading 


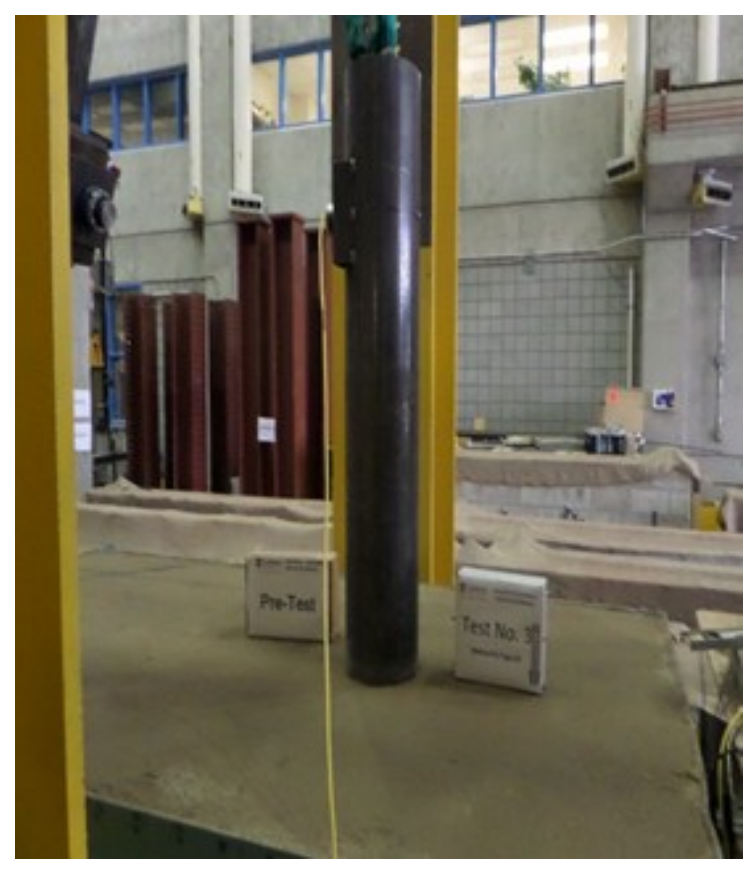

(a)

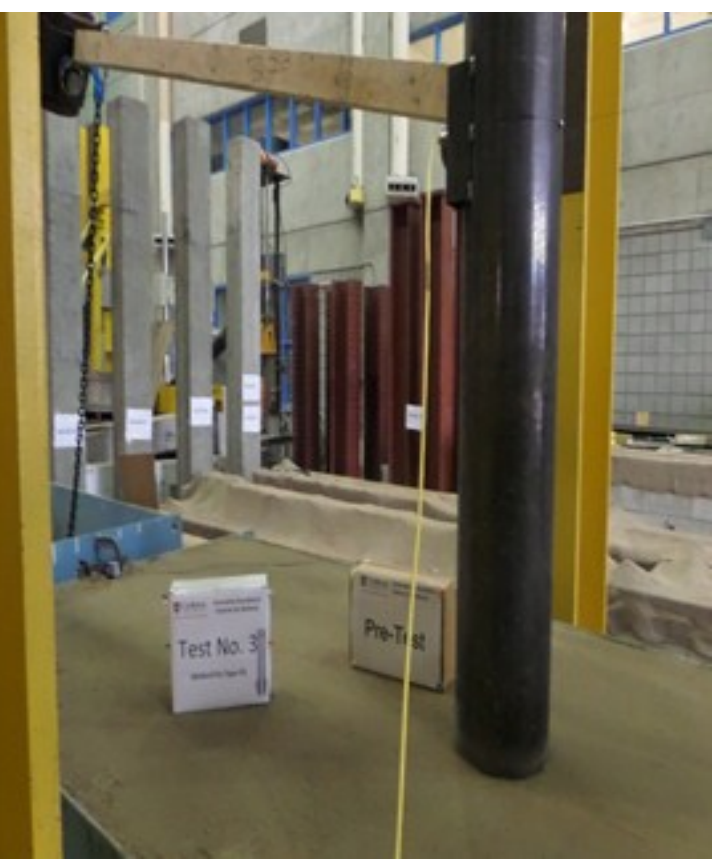

(b)

Figure 4-17: Pre-test images of impact load tests at $37^{\circ}$

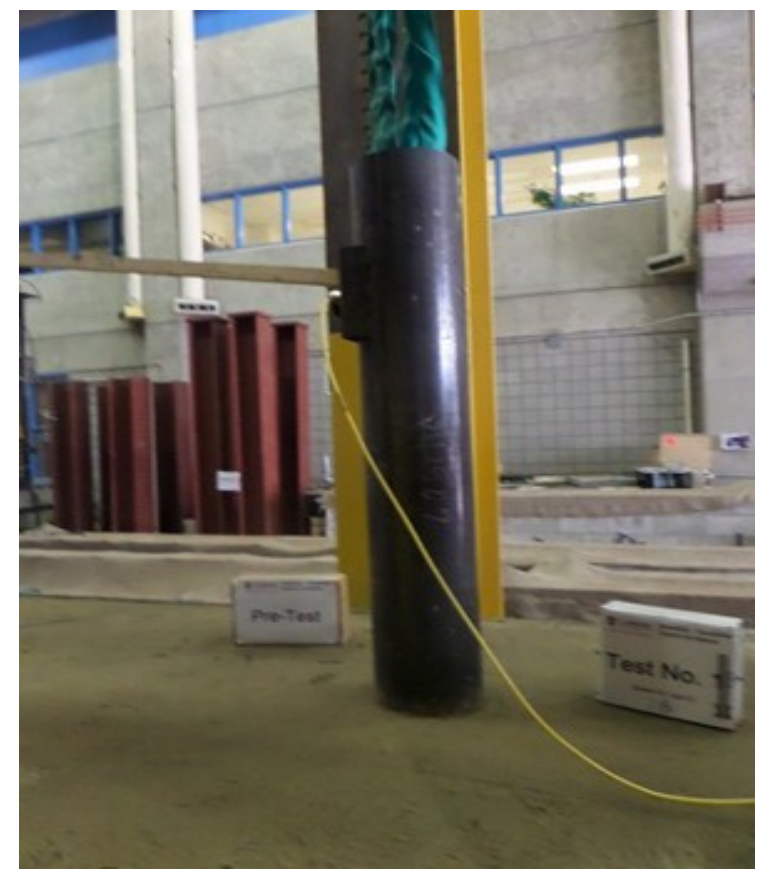

(a)

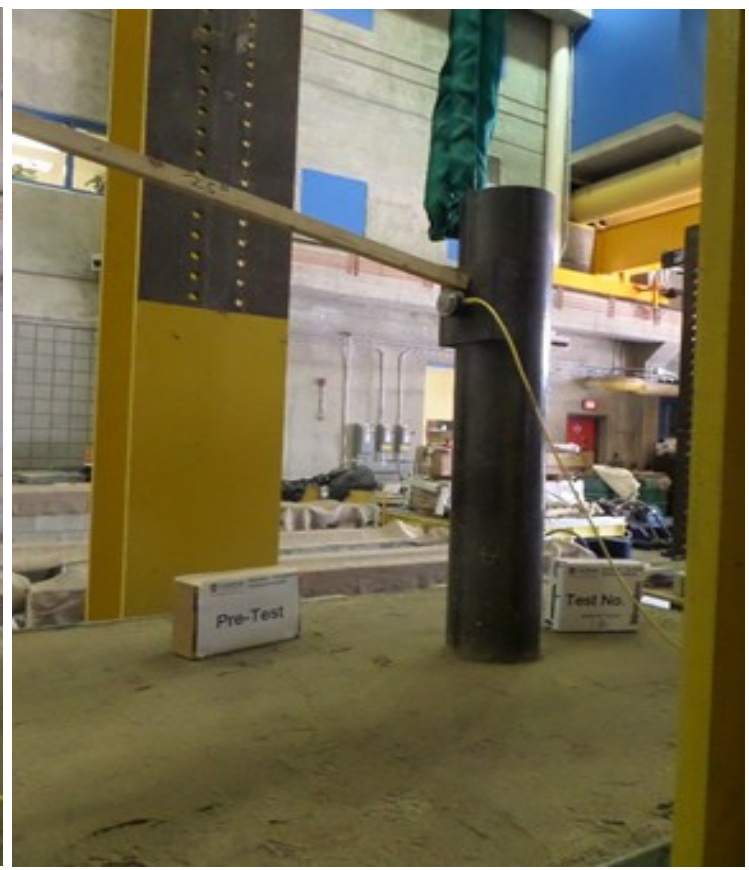

(b)

Figure 4-18: Pre-test images of impact load test at $25^{\circ}$ 


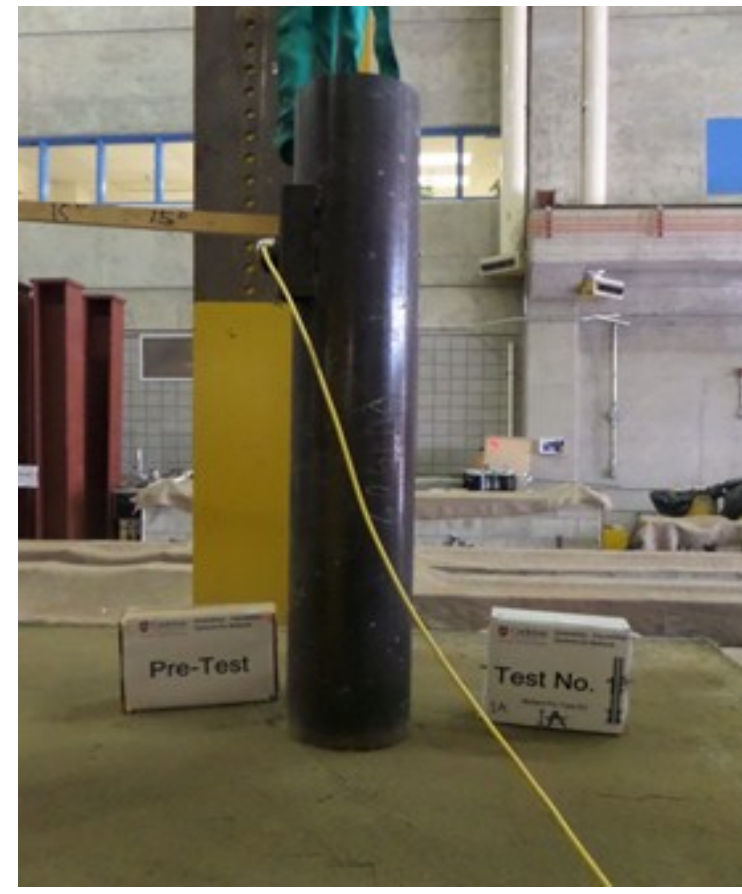

(a)

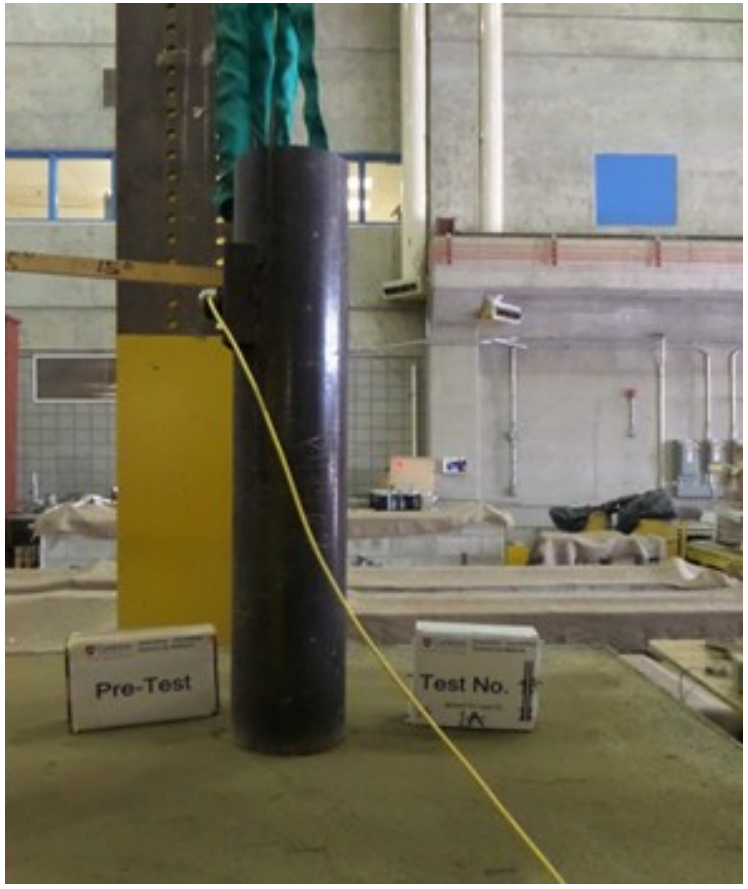

(b)

Figure 4-19: Pre-test images of impact load test at $15^{\circ}$

\subsubsection{IM Test 1-Fin 4}

Three tests were conducted at $37^{\circ}, 25^{\circ}$ and $15^{\circ}$ impact angles for IM-Fin 4 configuration. The $15^{\circ}$ and $25^{\circ}$ angles were labelled Test $1 \mathrm{~A}$ and $1 \mathrm{~B}$ respectively.

\subsubsection{IM Test 1-Fin 4 at $37^{\circ}$}

A graph of the load- and deflection-time responses of the bollard at three locations (top, middle, and bottom) is presented in Figure 4-20. From the plot, the peak load impacted was $168.8 \mathrm{kN}$, with a duration and rise time of the first pulse measured as $2.87 \mathrm{~ms}$ and $1.48 \mathrm{~ms}$ respectively. The impulse was calculated as $249.23 \mathrm{kN}-\mathrm{ms}$. The deflections at the top, middle and bottom were recorded as $164.5 \mathrm{~mm}, 53 \mathrm{~mm}$ and $17.8 \mathrm{~mm}$ respectively, with a deflection angle of $9.8^{\circ}$. Figure 4-21 presents post-test photographs of the bollard. 
Observation of the deformation on the surface of the soil showed cracks along the edge of the bollard. The cracks were spread across the surface to $540 \mathrm{~mm}$ at the front and $400 \mathrm{~mm}$ at the back of the bollard. Longitudinal cracks were observed along the location of the fins. A separation gap of $52 \mathrm{~mm}$ was developed in front of the bollard. Also, there was significant bulging on the soil surface. The maximum height of the bulge behind the bollard was recorded as $10 \mathrm{~mm}$ and $5 \mathrm{~mm}$ at the front. This corresponds to shear failure of the soil around the pile, in which the soil has sheared over a failure plain and induced bulging at the surface.

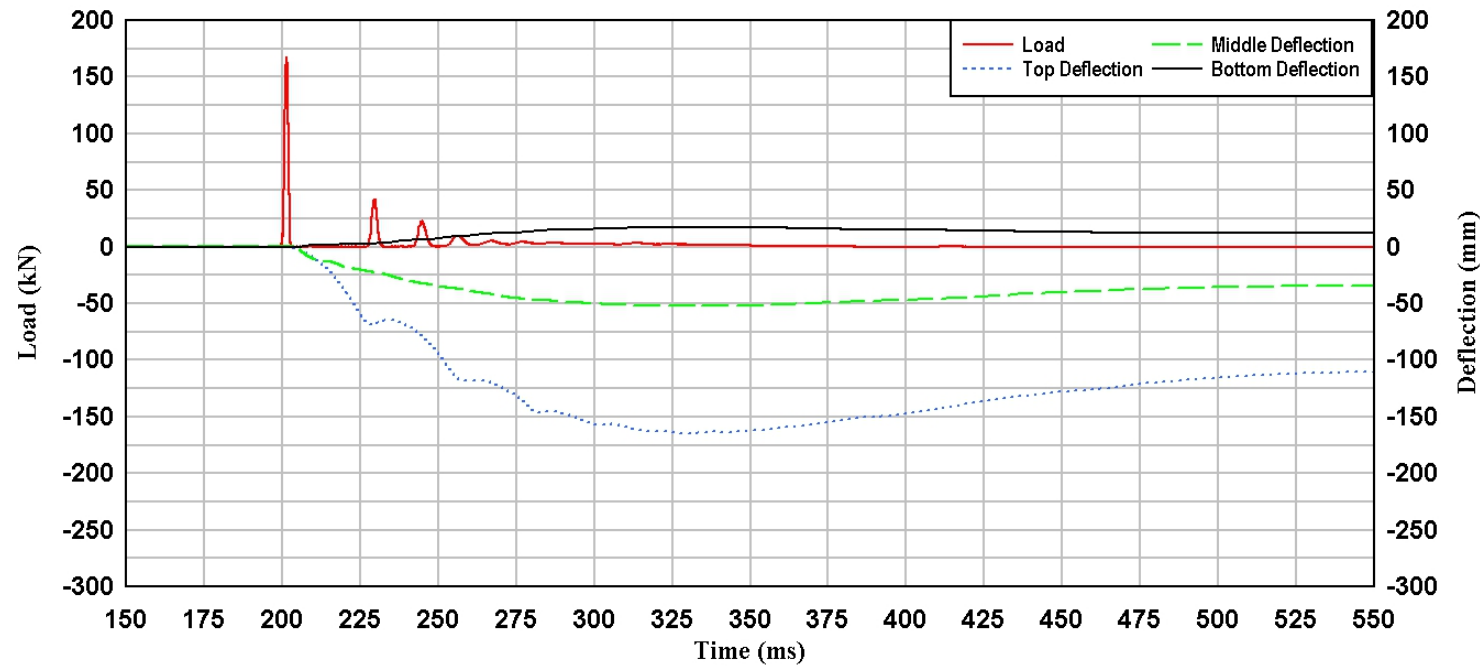

Figure 4-20: Load deflection time graph for Fin 4 at $37^{\circ}$ 


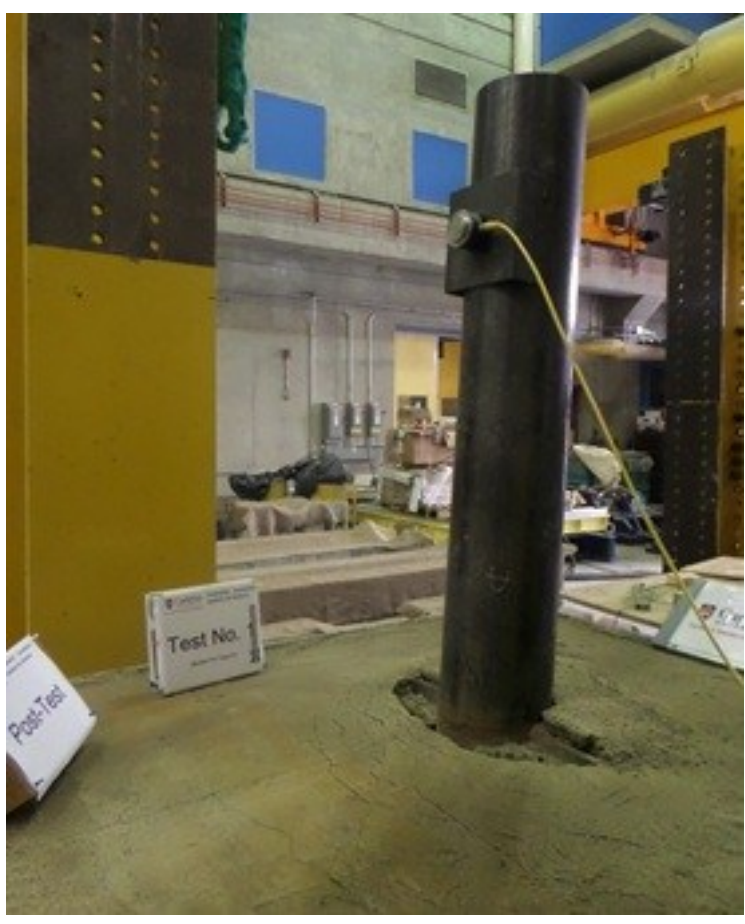

(a)

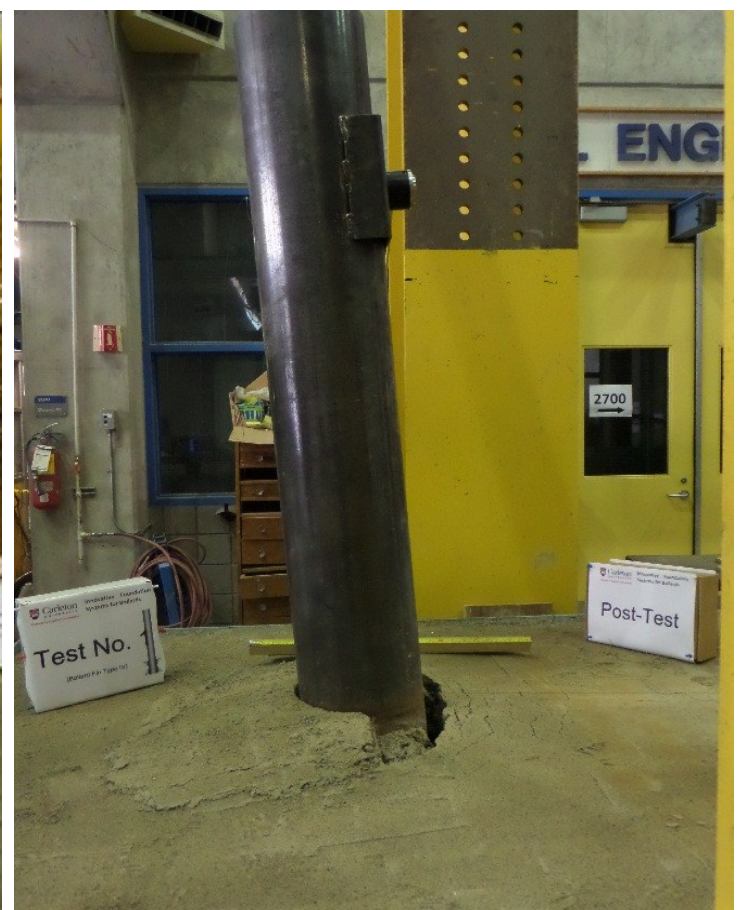

(b)

Figure 4-21: Post-test images of impact load test 1-Fin 4 at $37^{\circ}$

\subsubsection{IM Test 1B-Fin 4 at $25^{\circ}$}

After the impact test at an angle of $37^{\circ}$, the impact angle was reduced to $25^{\circ}$ and the test repeated on the bollard with Fin type 4. The peak impact load obtained from this test was $123.1 \mathrm{kN}$ with a duration and rise time of the first pulse measured as $3.26 \mathrm{~ms}$ and $1.54 \mathrm{~ms}$ respectively. The associated impulse was calculated as $189.42 \mathrm{kN}-\mathrm{ms}$. The maximum deflections of the bollard at the top, middle and bottom were $108.9 \mathrm{~mm}, 28.5 \mathrm{~mm}$ and 3.5 $\mathrm{mm}$ respectively (Figure 4-22). The deflection angle was calculated as $6.5^{\circ}$. Post-test photograph for this configuration is presented in Figure 4-23. After testing, the cracks observed at the surface of the soil covered a length of $200 \mathrm{~mm}$ and $150 \mathrm{~mm}$ at the front face and back face of the bollard. The separation gap of the bollard from the soil in front of the bollard was measured at $17 \mathrm{~mm}$. No significant bulging was observed on the surface. 


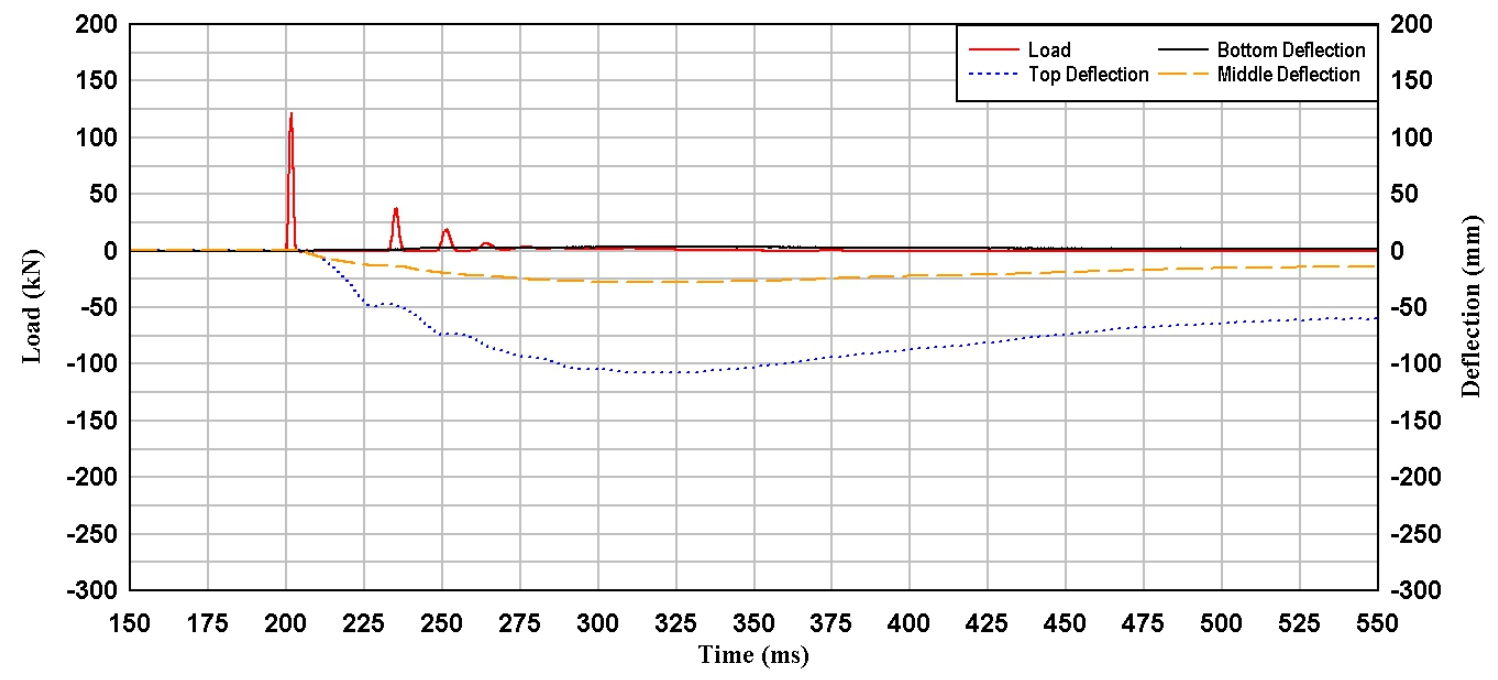

Figure 4-22: Load deflection time graph for Fin 4 at $25^{\circ}$

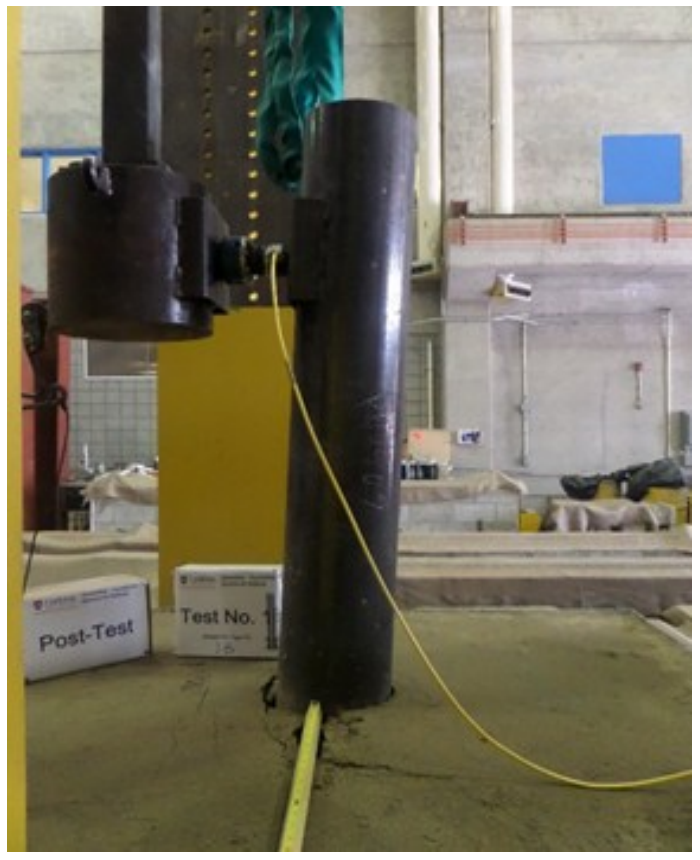

(a)

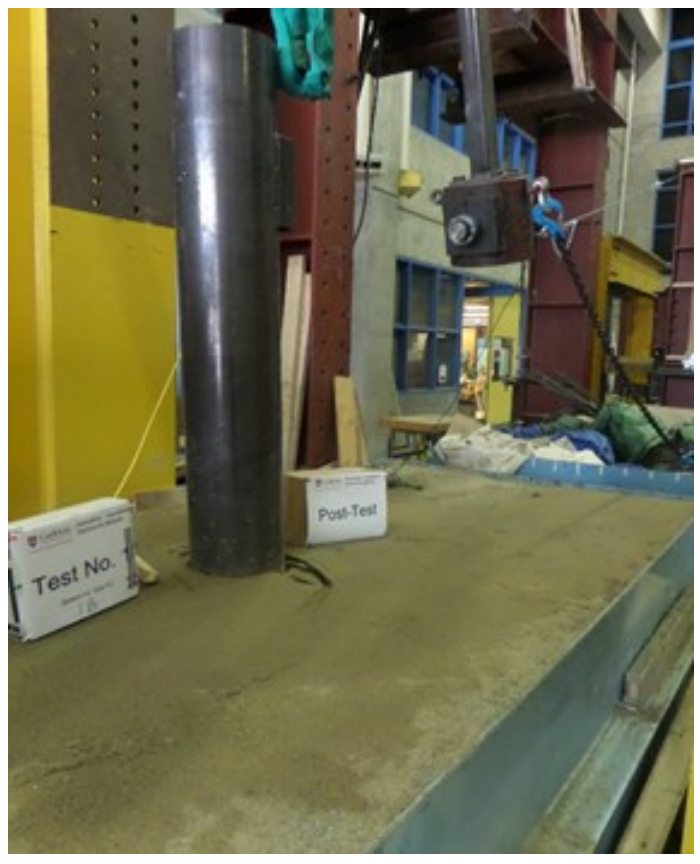

(b)

Figure 4-23: Post-test images of impact load test 1-Fin 4 at $25^{\circ}$ 


\subsubsection{IM Test 1A-Fin 4 at $15^{\circ}$}

The bollard with Fin type 4 was also tested at an impact angle of $15^{\circ}$. The peak impact load recorded during this test was $65.46 \mathrm{kN}$ with a duration of $3.77 \mathrm{~ms}$ and rise time of $1.65 \mathrm{~ms}$ for the first pulse. The associated impulse was calculated as $108.08 \mathrm{kN}-\mathrm{ms}$. The maximum deflections at the top, middle and bottom of the bollard were $54.7 \mathrm{~mm}, 15.63 \mathrm{~mm}$ and 1.06 mm (Figure 4-24). The deflection angle was calculated as $3.3^{\circ}$. Cracks were observed to cover a length of $160 \mathrm{~mm}$ at the front surface of the bollard. The back surface recorded about $100 \mathrm{~mm}$ of crack length. Similarly to the $25^{\circ}$, no bulging was observed at the surface. The separation gap developed at the interface of the soil and the front of the bollard was 9 mm (Figure 4-25).

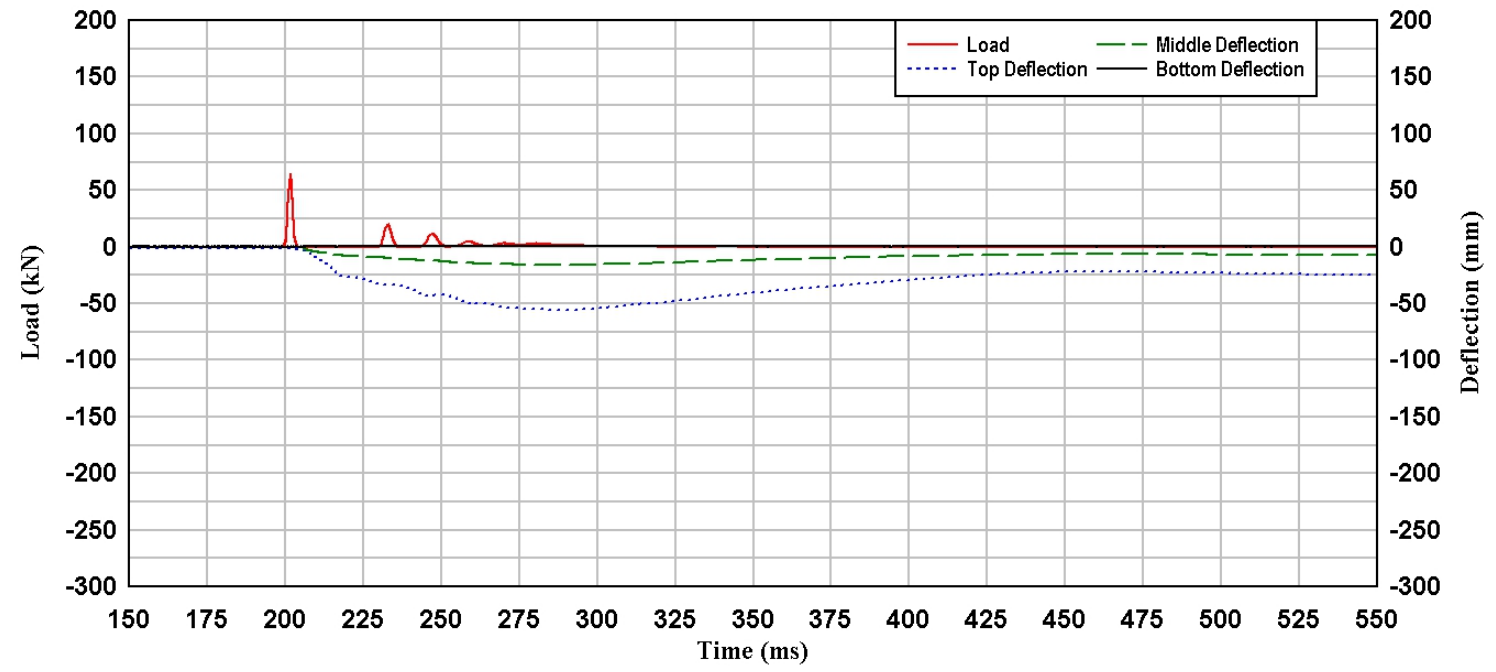

Figure 4-24: Load deflection time graph for Fin 4 at $15^{\circ}$ 


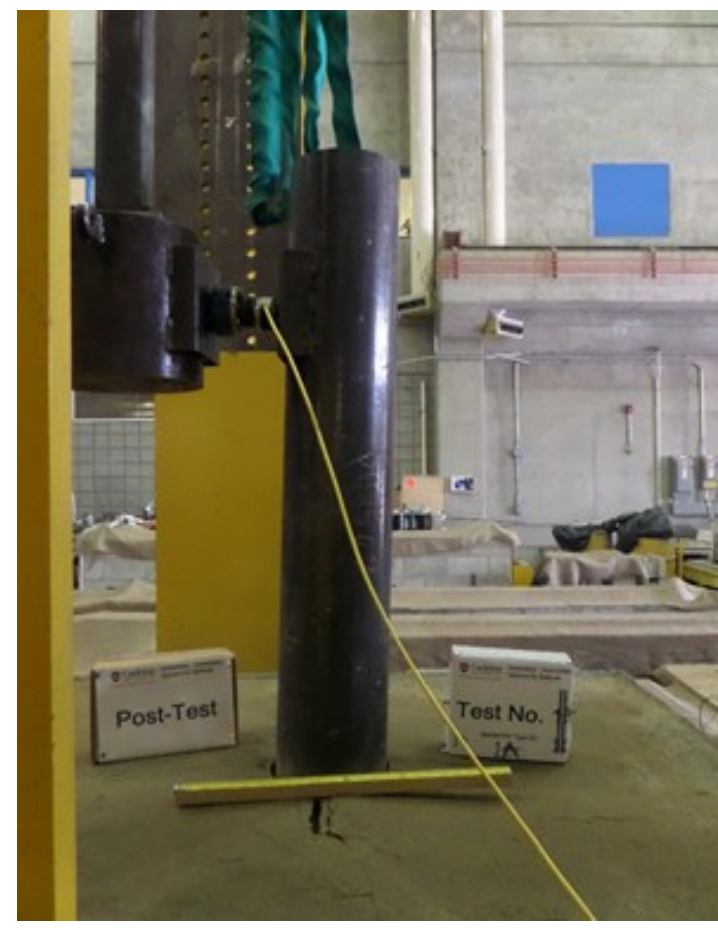

(a)

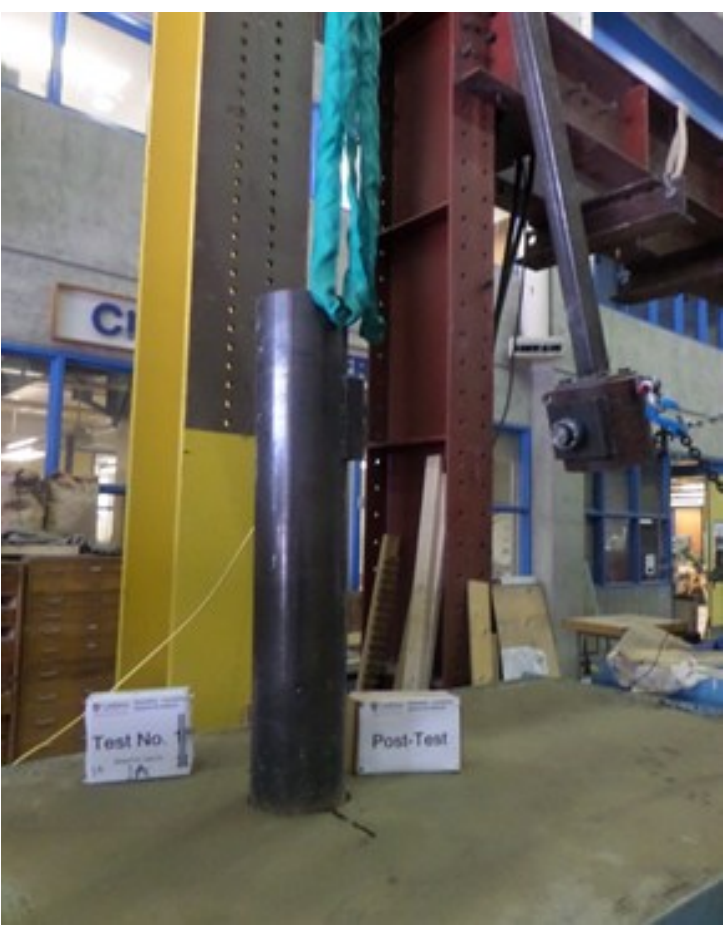

(b)

Figure 4-25: Post-test images of impact load test 1-Fin 4 at $15^{\circ}$

Figure 4-26 presents a comparison of load- and deflection-time response of the bollard in IM Test 1-Fin 4. From the results, changing from $25^{\circ}$ to $37^{\circ}$ impact angle resulted in an increase of $55.6 \mathrm{~mm}, 24.5 \mathrm{~mm}$ and $14.32 \mathrm{~mm}$ at the top, middle and bottom deflections respectively with a $45.7 \mathrm{kN}$ increase in peak impact load. Also, an increase of $109.84 \mathrm{~mm}, 37.36 \mathrm{~mm}$ and $16.76 \mathrm{~mm}$ were observed for the top, middle and bottom deflections respectively when the angle was changed from $15^{\circ}$ to $37^{\circ}$ with a $103.33 \mathrm{kN}$ increase in peak impact load. In general, an increase in impact angle (corresponding to impact load) resulted in increased bollard deflection. 


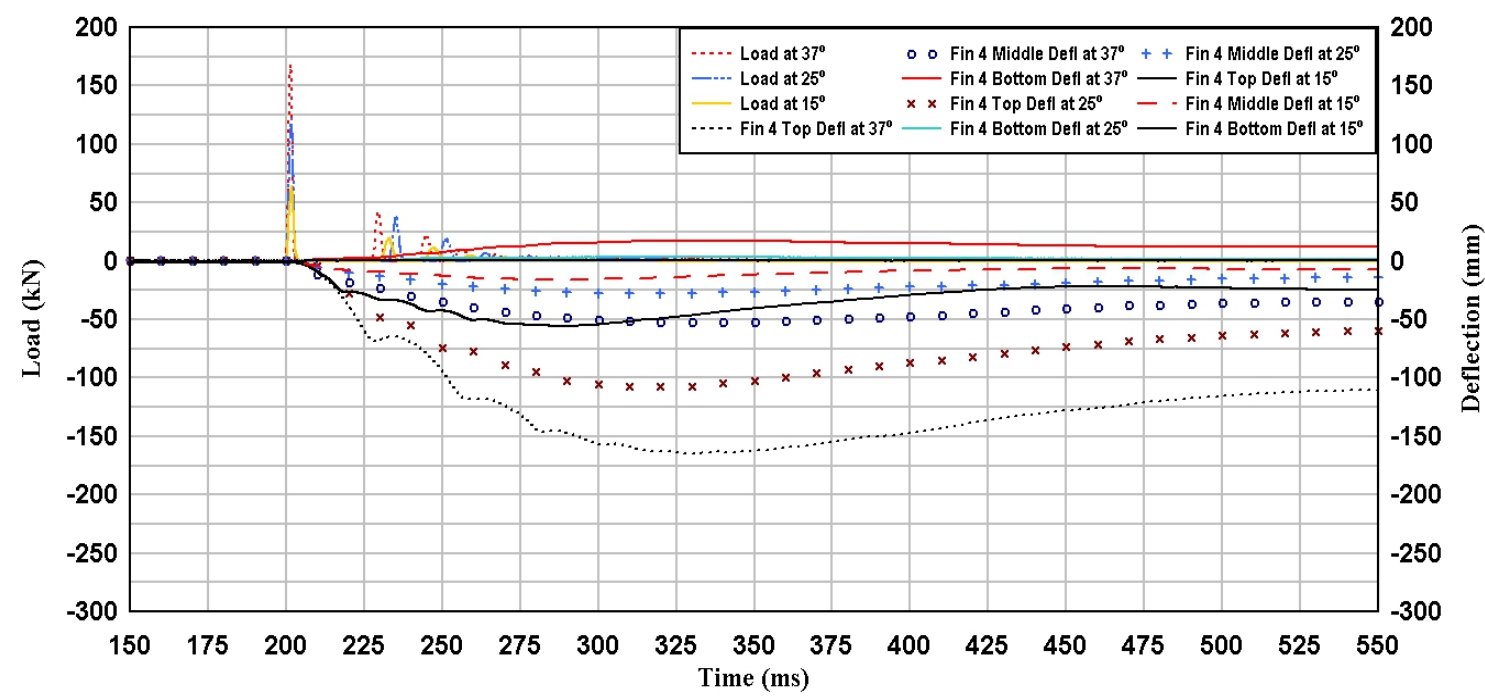

Figure 4-26: Load deflection time graph for Fin 4 at $37^{\circ}, 25^{\circ}$ and $15^{\circ}$

\subsubsection{IM Test 2-Fin 3}

Three tests were conducted on the bollard with Fin type 3 at impact angles of $37^{\circ}, 25^{\circ}$ and $15^{\circ}$, similar to IM Test 1 . The test at impact angles of $15^{\circ}$ and $25^{\circ}$ were labelled Test $2 \mathrm{~A}$ and Test $2 \mathrm{~B}$.

\subsubsection{IM Test 2-Fin 3 at $37^{\circ}$}

The maximum deflections at the top, middle and bottom of the bollard under impact loading from $37^{\circ}$ were recorded as $207.8 \mathrm{~mm}, 55.7 \mathrm{~mm}$ and $36.3 \mathrm{~mm}$ respectively, with a deflection angle of $12.3^{\circ}$. The peak impact load was $167.6 \mathrm{kN}$, with a duration of $3.13 \mathrm{~ms}$ (see Figure 4-27). The rise time and impulse were calculated as $1.61 \mathrm{~ms}$ and $271.12 \mathrm{kN}$ ms for the first pulse. The crack development on the surface of the soil covered a length of $660 \mathrm{~mm}$ in front and $500 \mathrm{~mm}$ behind the bollard. The bulging at the surface was recorded between $30 \mathrm{~mm}$ to $5 \mathrm{~mm}$ at the back and between $15 \mathrm{~mm}$ and $5 \mathrm{~mm}$ in front of the bollard. On impact, the separation gap developed in front of the bollard was observed to be $62 \mathrm{~mm}$ (Figure 4-28). 


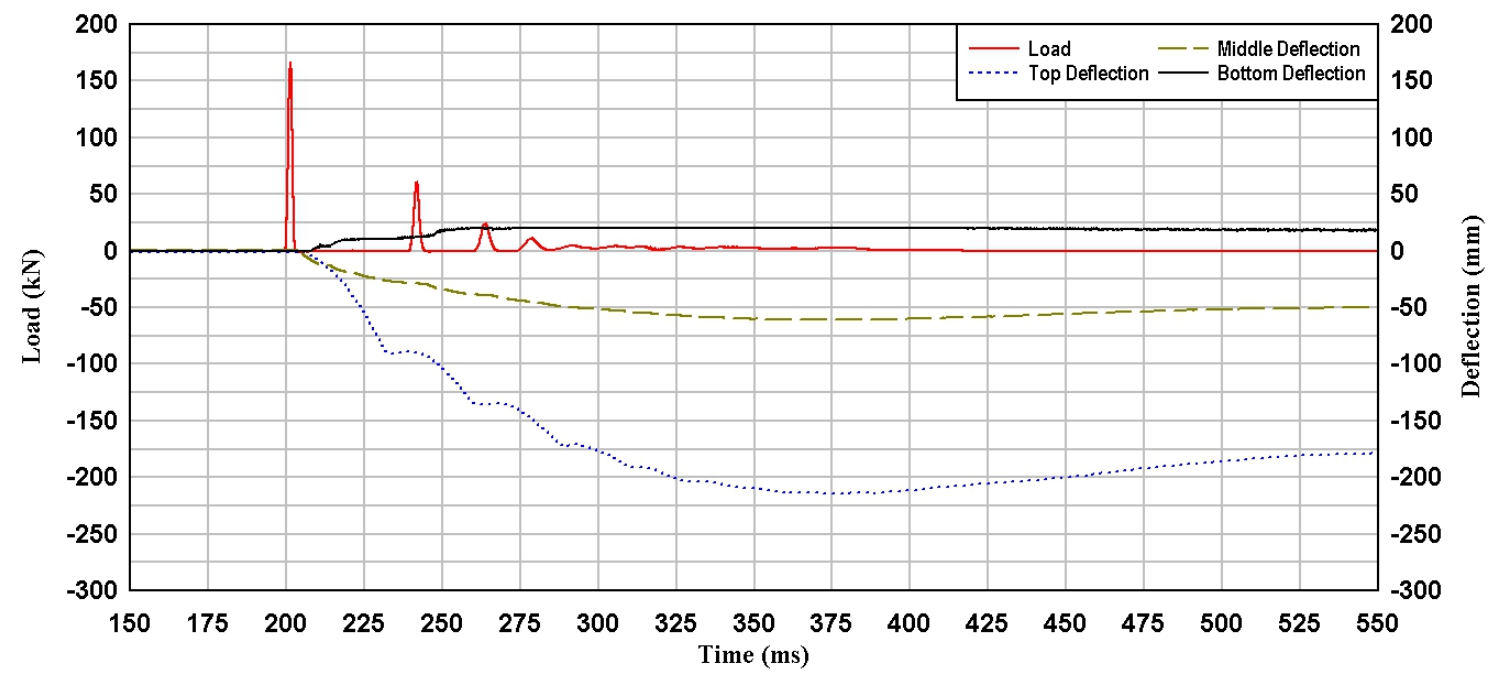

Figure 4-27: Load deflection time graph for Fin 3 at $37^{\circ}$

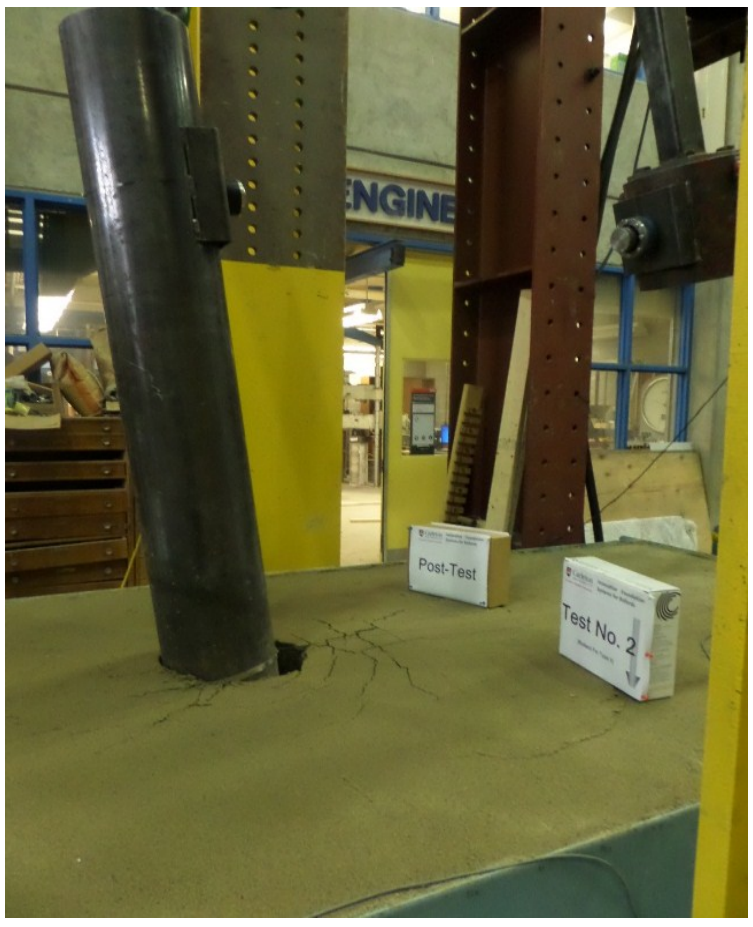

(a)

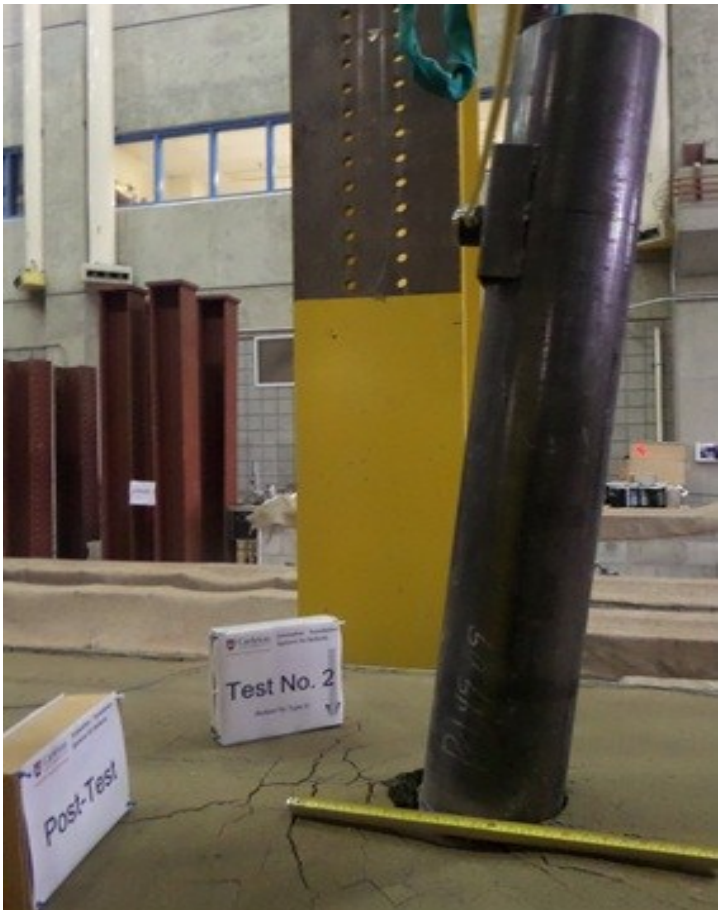

(b)

Figure 4-28: Post-test images of impact load test 2-Fin 3 at $37^{\circ}$ 


\subsubsection{IM Test $2 B$-Fin 3 at $25^{\circ}$}

The peak impact load under $25^{\circ}$ impact angle was recorded as $122.09 \mathrm{kN}$, with a duration and rise time of the first pulse of $3.21 \mathrm{~ms}$ and $1.58 \mathrm{~ms}$ respectively. The impulse was also calculated as $194.34 \mathrm{kN}-\mathrm{ms}$. The bollard deflections at the top, middle and bottom deflections were measured as $118.1 \mathrm{~mm}, 32.9 \mathrm{~mm}$ and $4.7 \mathrm{~mm}$ (Figure 4-29). The deflection angle was calculated as $7.1^{\circ}$. The cracks developed across the soil surface covered a length of $450 \mathrm{~mm}$ in front and $300 \mathrm{~mm}$ behind the bollard. A small amount of bulging, less than $8 \mathrm{~mm}$ in maximum height, was observed behind the bollard while an insignificant amount of bulging was observed in front of the bollard. A separation gap of $20 \mathrm{~mm}$ width was recorded in front of the bollard (see Figure 4-30).

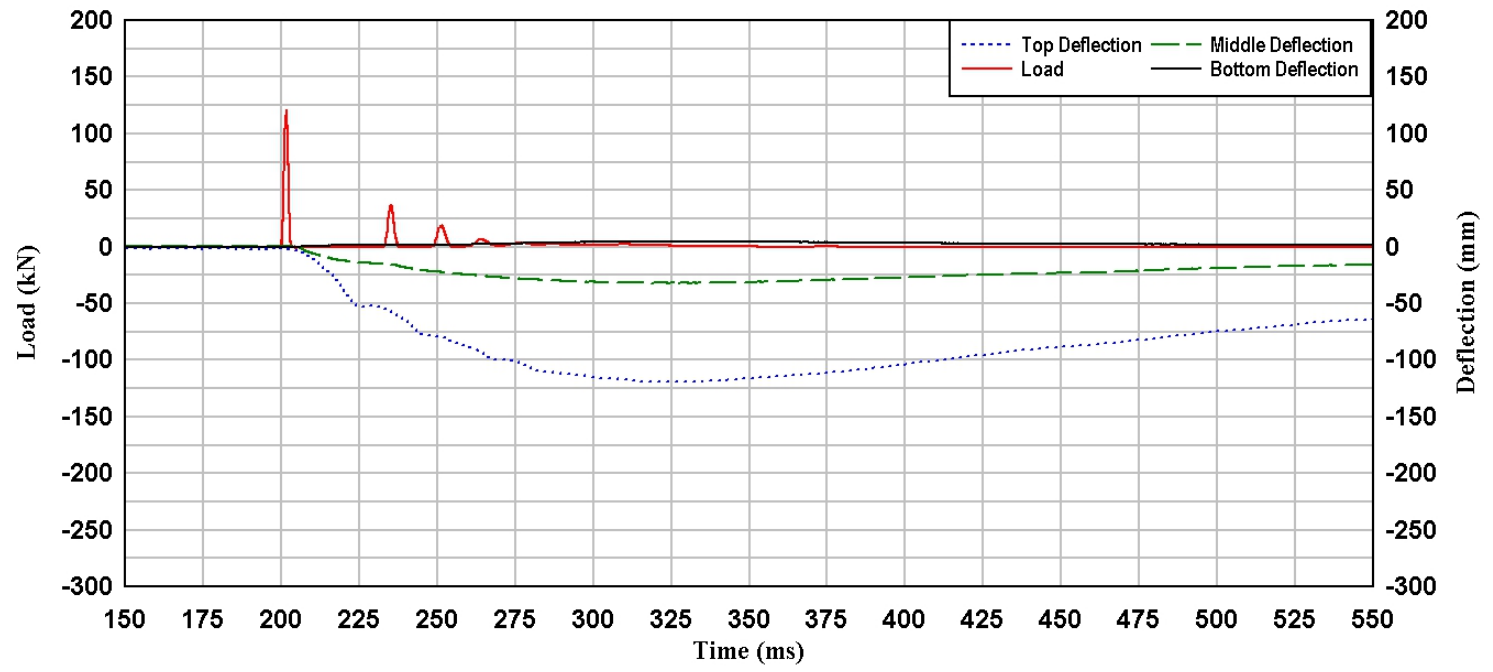

Figure 4-29: Load deflection time graph for Fin 3 at $25^{\circ}$ 


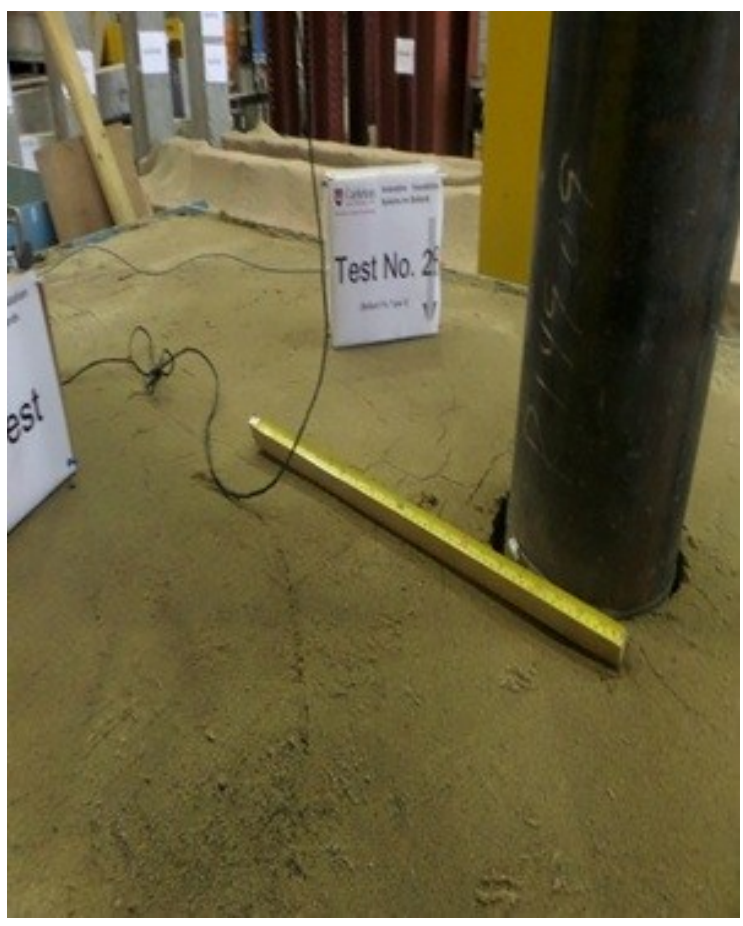

(a)

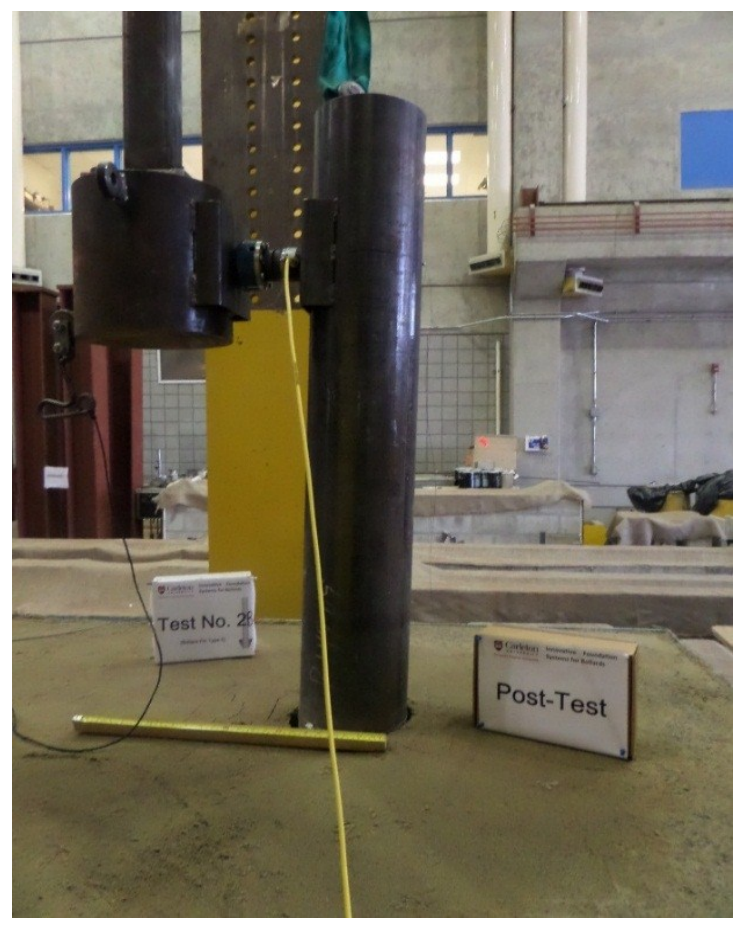

(b)

Figure 4-30: Post-test images of impact load test 2-Fin 3 at $25^{\circ}$

\subsubsection{IM Test 2 A-Fin 3 at $15^{\circ}$}

At the impact angle of $15^{\circ}$, the peak impact load on the bollard was $66.37 \mathrm{kN}$, with a duration of $4.01 \mathrm{~ms}$ for the first pulse. The rise time was measured as $1.73 \mathrm{~ms}$ (the associated impulse to this load was $113.33 \mathrm{kN}-\mathrm{ms}$ ). The deflections of the bollard at top, middle and bottom were $59.9 \mathrm{~mm}, 17.96 \mathrm{~mm}$ and $1.18 \mathrm{~mm}$ respectively, with a deflection angle of $3.6^{\circ}$. Figure 4-31 presents the load- and deflection-time graph. No bulging was observed for this test. The separation gap developed at the front of the bollard was measured as $11 \mathrm{~mm}$ on the surface. The cracks were spread on the soil surface in front of the bollard to $100 \mathrm{~mm}$ and less than $50 \mathrm{~mm}$ behind the bollard. The post-test photographs of the bollard are presented in Figure 4-32. 


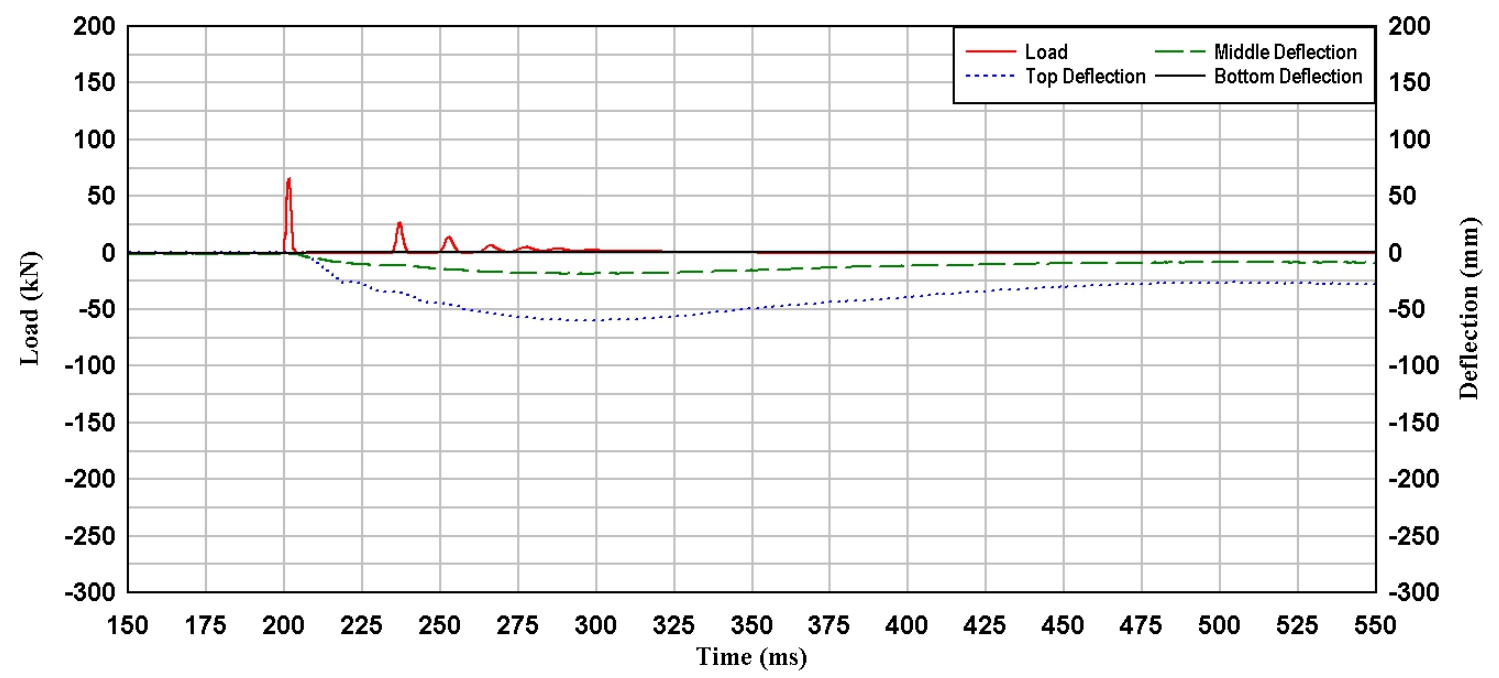

Figure 4-31: Load deflection time graph for Fin 3 at $15^{\circ}$

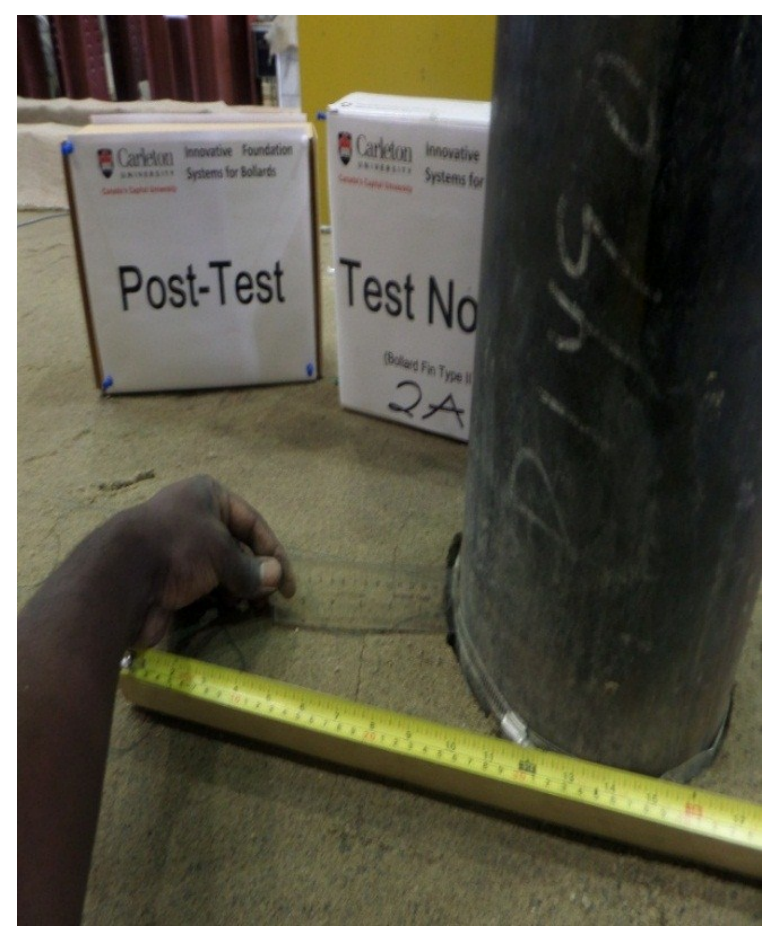

(a)

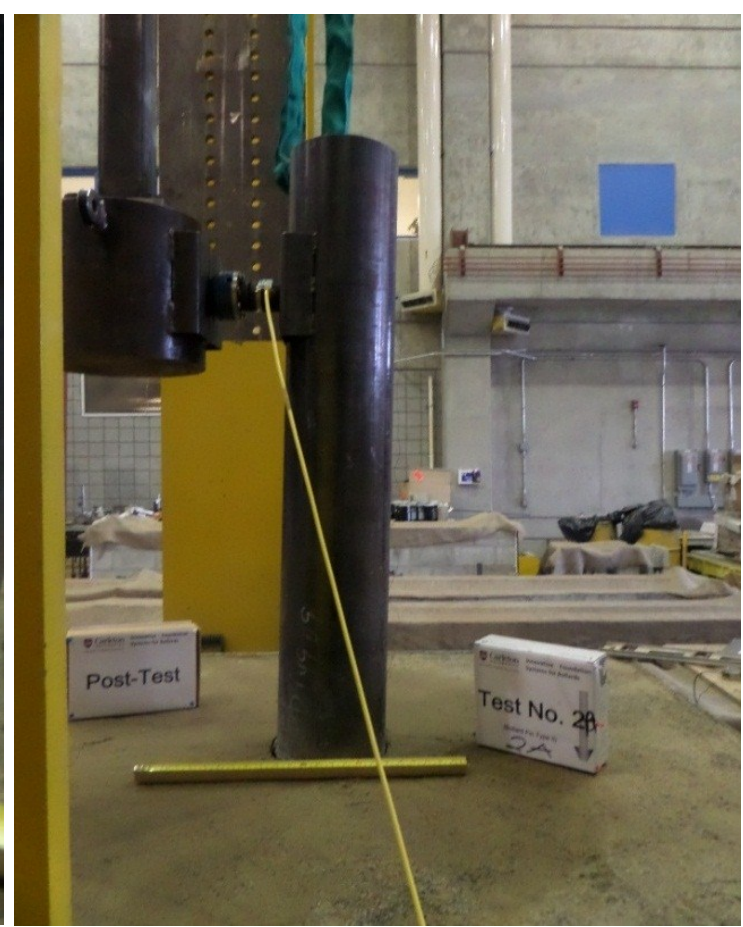

(b)

Figure 4-32: Post-test images of impact load test 2-Fin 3 at $15^{\circ}$ 
Figure 4-33 presents a comparison of load- and deflection-time response of the bollard in IM Test 2-Fin 3. An increase of $45.5 \mathrm{kN}$ in peak impact load was observed when the impact angle was changed from $25^{\circ}$ to $37^{\circ}$ causing a top, middle and bottom deflections increase of $89.66 \mathrm{~mm}, 22.74 \mathrm{~mm}$ and $31.67 \mathrm{~mm}$ respectively. Also, an increase of 101.2 $\mathrm{kN}$ in peak impact load was observed when the impact angle was changed from $15^{\circ}$ to $37^{\circ}$, which resulted in an increase of $147.86 \mathrm{~mm}, 37.71 \mathrm{~mm}$ and $35.19 \mathrm{~mm}$ for the top, middle and bottom deflections respectively. Similar to IM Test 1-Fin 4, increasing the impact angle resulted in bollard deflection increase.

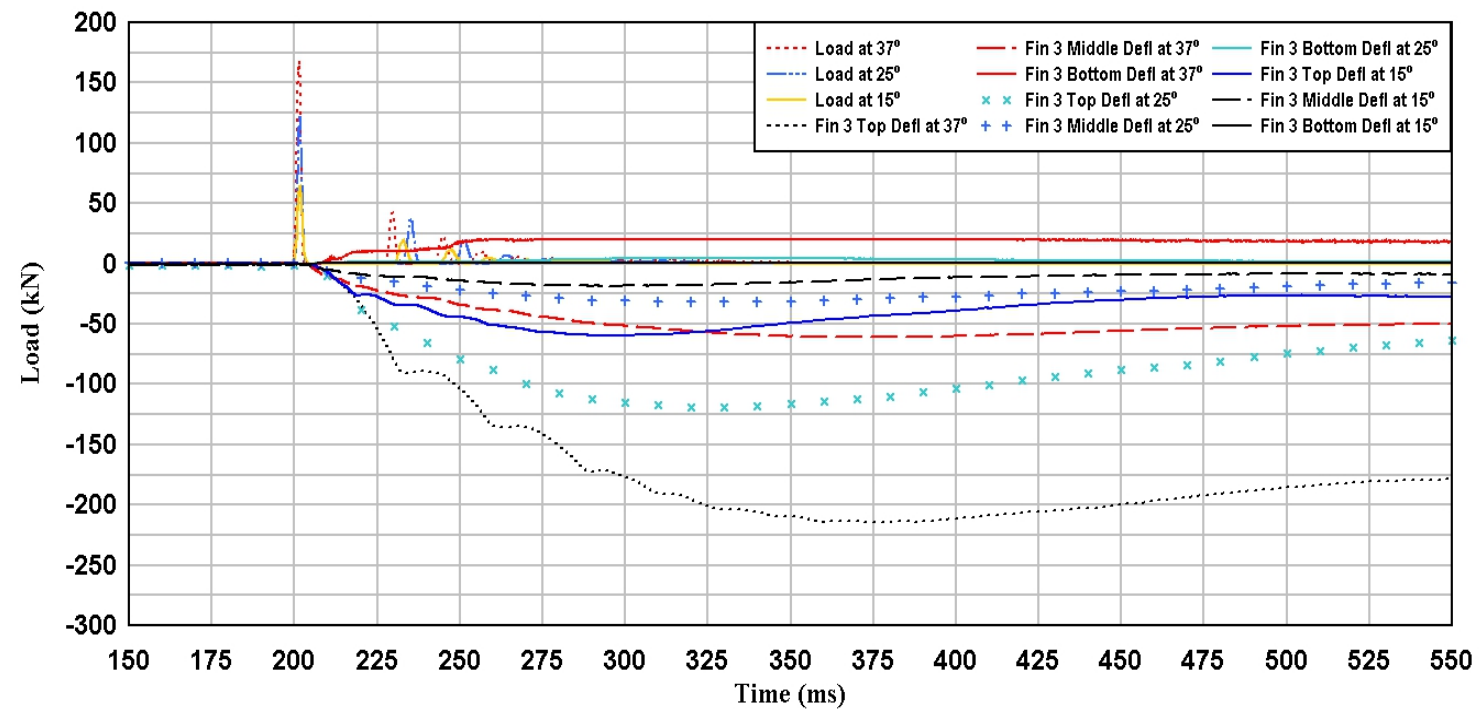

Figure 4-33: Load deflection time graph for Fin 3 at $37^{\circ}, 25^{\circ}$ and $15^{\circ}$

\subsubsection{IM Test 3-Fin 2}

Figure 4-34 presents the load- and deflection-time response for IM Test 3-Fin 2. The peak impact load at an impact angle of $37^{\circ}$ was recorded as $168.7 \mathrm{kN}$, with a duration and rise time of $3.56 \mathrm{~ms}$ and $1.54 \mathrm{~ms}$ for the first pulse (associated impulse was $258.5 \mathrm{kN}-\mathrm{ms}$ ). The deflections of the bollard at the top, middle and bottom were $213.9 \mathrm{~mm}, 61.7 \mathrm{~mm}$ and 20.6 
$\mathrm{mm}$ respectively, with a deflection angle of $12.7^{\circ}$. Photographs of the post-test results are presented in Figure 4-35. From physical observation, a $60 \mathrm{~mm}$ separation gap was noticed in front of the bollard while crack lengths of $650 \mathrm{~mm}$ and $520 \mathrm{~mm}$ developed on the surface of the soil at the front and back of the bollard respectively. The cracks were observed to be predominantly concentrated around the bollard. The highest bulging was observed to be 28 $\mathrm{mm}$ at the back of the bollard and $10 \mathrm{~mm}$ in front of the bollard.

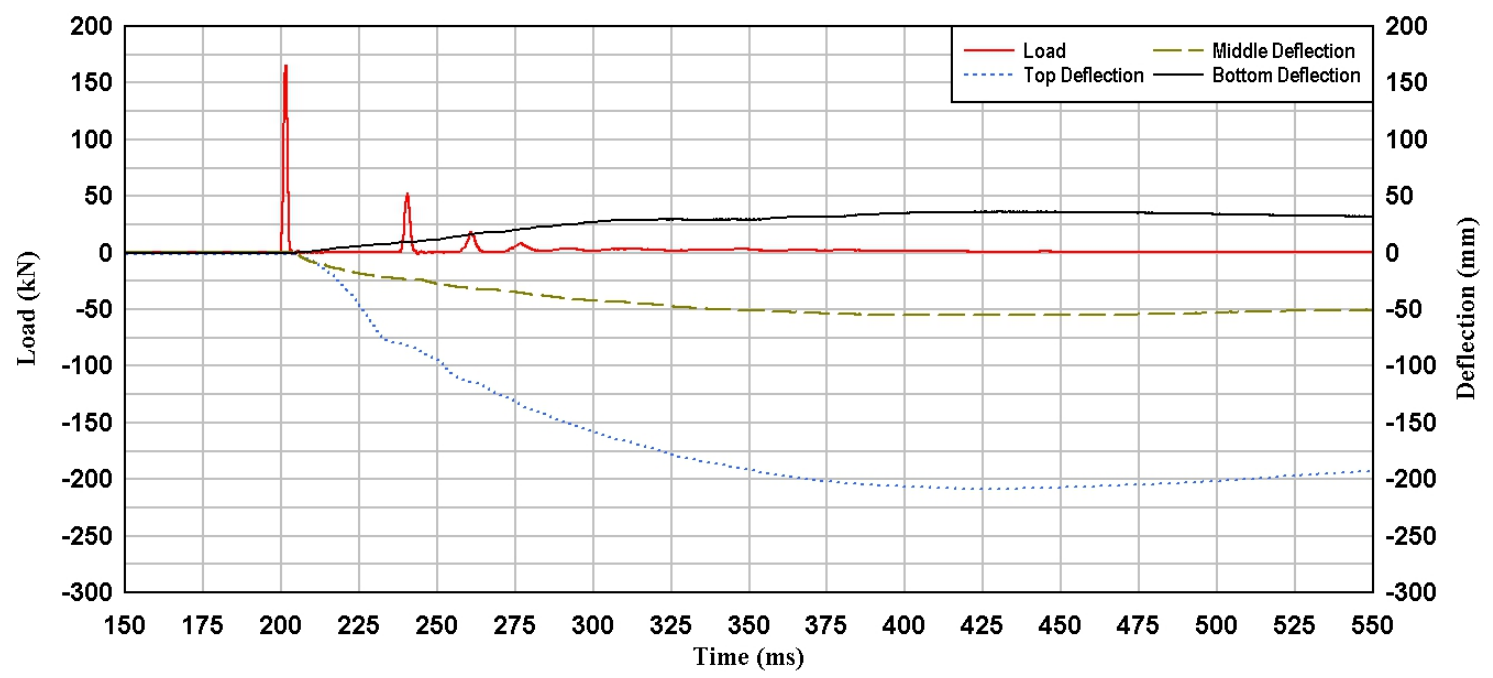

Figure 4-34: Load deflection time graph for Fin 2 at $37^{\circ}$ 


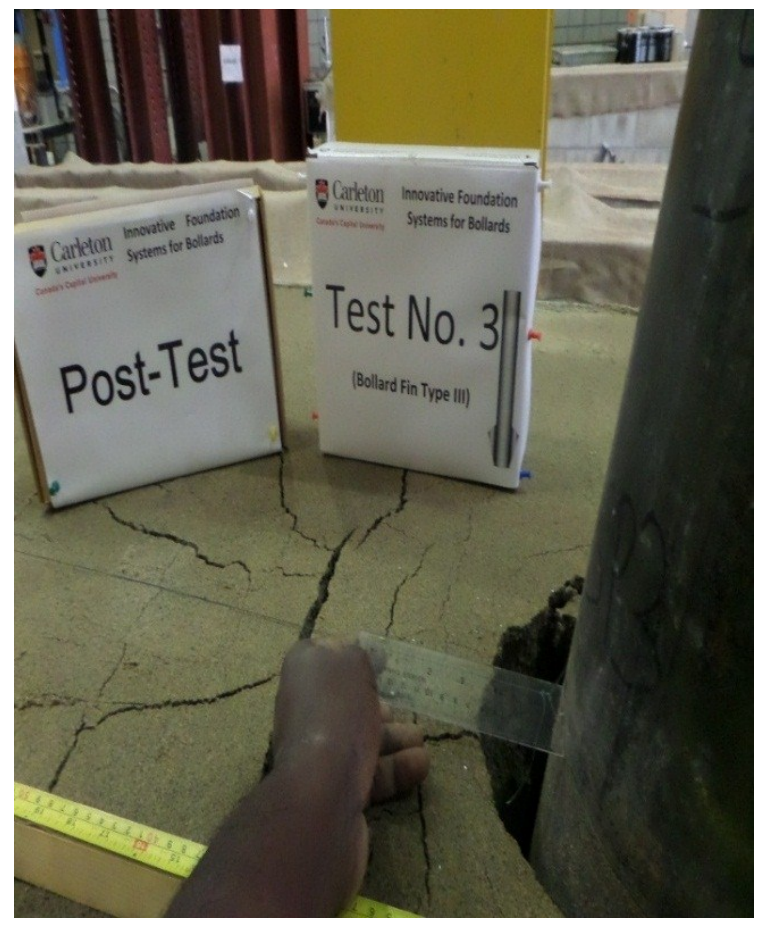

(a)

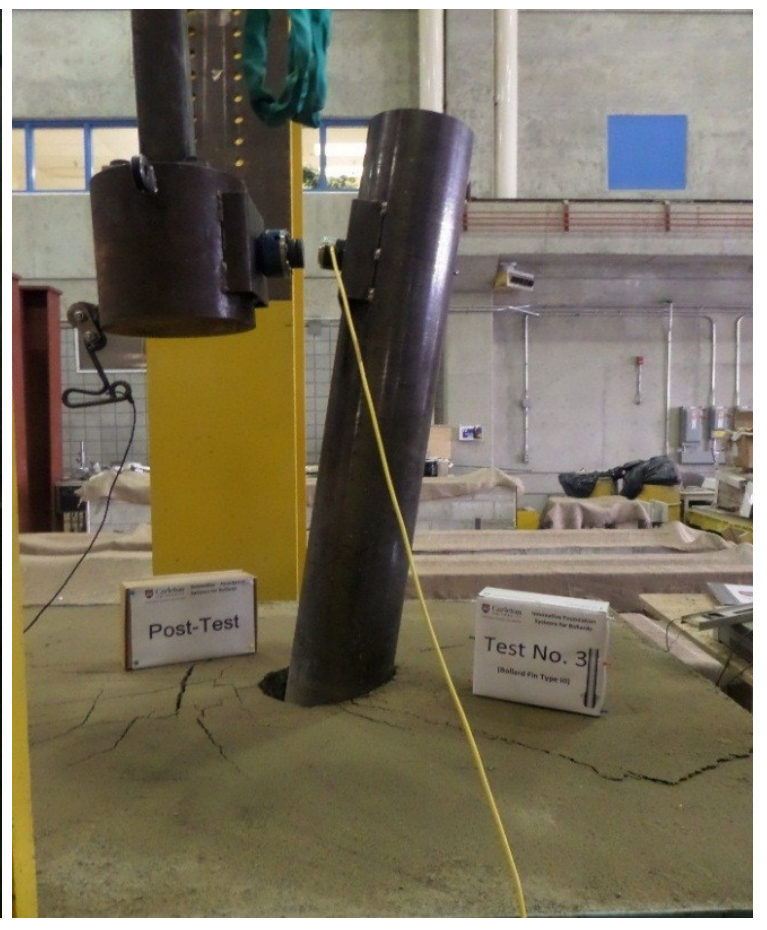

(b)

Figure 4-35: Post-test images of impact load test 3-Fin 2 at $37^{\circ}$

\subsubsection{IM Test 4-Fin 1}

From the load- and deflection-time response (Figure 4-36), the top, middle and bottom deflections were obtained as $220.3 \mathrm{~mm}, 68.3 \mathrm{~mm}, 21.9 \mathrm{~mm}$ respectively, with a deflection angle of $13.1^{\circ}$. The peak impact load at an impact angle of $37^{\circ}$ was recorded as $168.95 \mathrm{kN}$, with a duration of $2.9 \mathrm{~ms}$ (the impulse and rise time were $250.07 \mathrm{kN}$-ms and $1.49 \mathrm{~ms}$ for the first pulse). Observation of cracks developed at the surface of the soil covered a length of $720 \mathrm{~mm}$ in front of the bollard and $610 \mathrm{~mm}$ behind the bollard. A $65 \mathrm{~mm}$ separation gap was noticed in front of the bollard as well. The bulging at the surface was recorded between $15 \mathrm{~mm}$ to $5 \mathrm{~mm}$ in front of the bollard and between $35 \mathrm{~mm}$ and $5 \mathrm{~mm}$ behind the bollard. Figure 4-37 presents the post-test photographs for this test. 


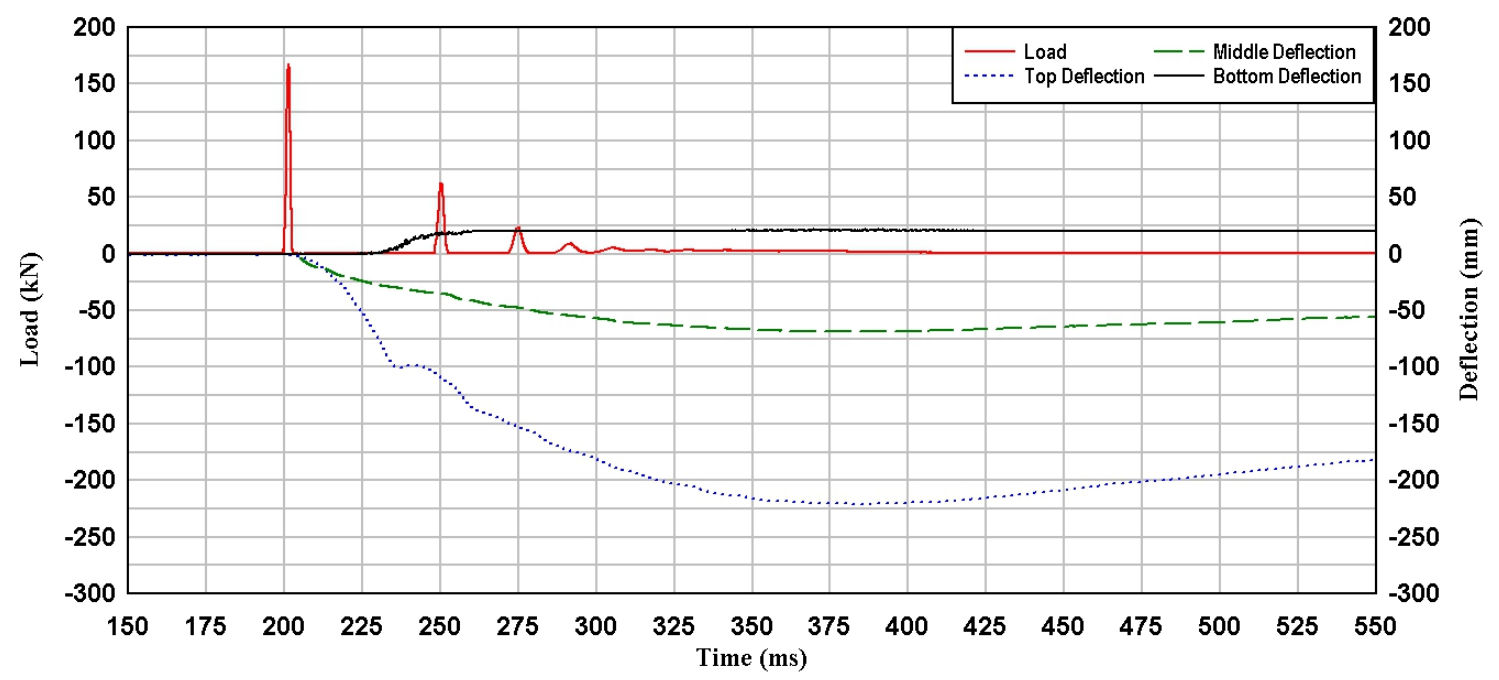

Figure 4-36: Load deflection time graph for Fin 1 at $37^{\circ}$

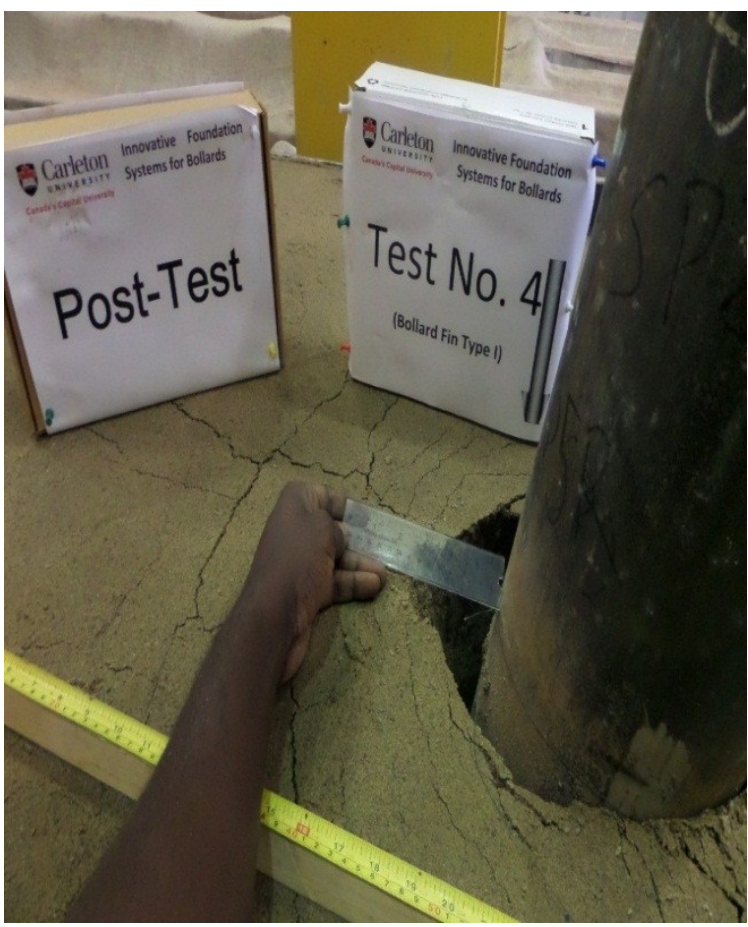

(a)

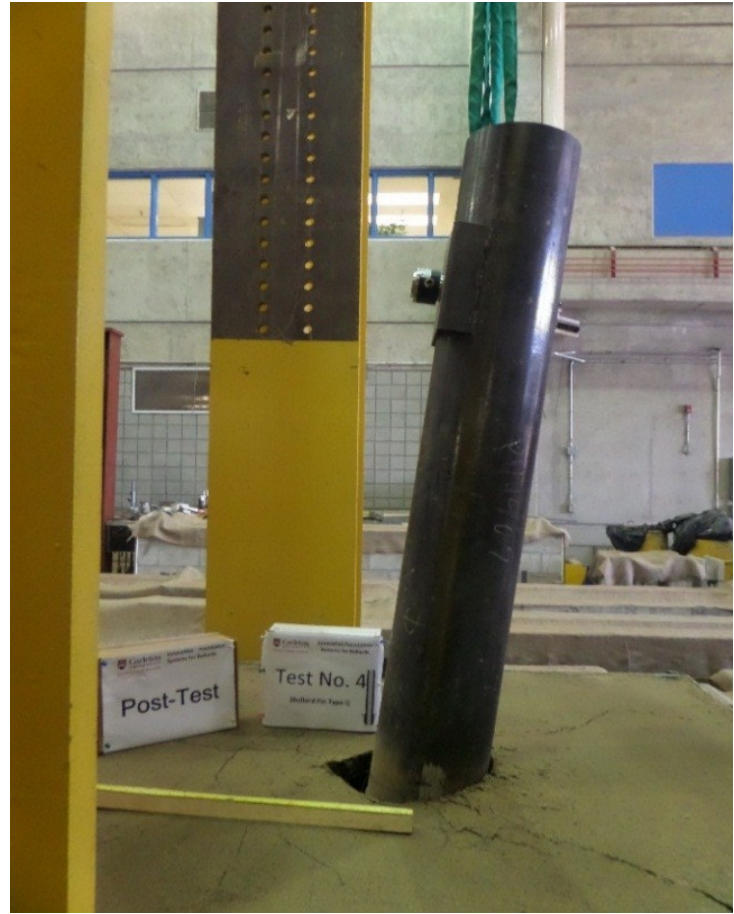

(b)

Figure 4-37: Post-test images of impact load test 4-Fin 1 at $37^{\circ}$ 


\subsubsection{IM Test 5-Plain}

IM Test 5-Plain configuration was tested for the three impact angles $\left(15^{\circ}, 25^{\circ}\right.$ and $\left.37^{\circ}\right)$. The tests were done in order of $37^{\circ}, 25^{\circ}$ and $15^{\circ}$. The $15^{\circ}$ and $25^{\circ}$ were labelled Test $5 \mathrm{~A}$ and $5 \mathrm{~B}$ respectively, similar to IM Tests 1 and 2.

\subsubsection{IM Test 5-Plain at $37^{\circ}$}

The deflections recorded at the top, middle and bottom of the bollard under impact loading from an impact angle of $37^{\circ}$ were $283.4 \mathrm{~mm}, 81.4 \mathrm{~mm}$ and $31.3 \mathrm{~mm}$ respectively, at a peak impact load of $168.13 \mathrm{kN}$ (Figure 4-38). A deflection angle of $16.6^{\circ}$ was calculated after impact. The duration and rise time of the impact load were $2.98 \mathrm{~ms}$ and $1.64 \mathrm{~ms}$. The associated impulse calculated for the first pulse was $276.18 \mathrm{kN}$-ms. Post-test photographs of the bollard test are presented in Figure 4-39. Cracks were observed to spread across the surface to a length of $760 \mathrm{~mm}$ at the front face of the bollard and $700 \mathrm{~mm}$ at the back face of the bollard. The separation gap developed at the front of the bollard was $70 \mathrm{~mm}$ wide. The bulging was very pronounced. Behind the bollard, a maximum bulge of $45 \mathrm{~mm}$ to a lowest value of $5 \mathrm{~mm}$ was observed while $15 \mathrm{~mm}$ to $5 \mathrm{~mm}$ was noticed at the front. 


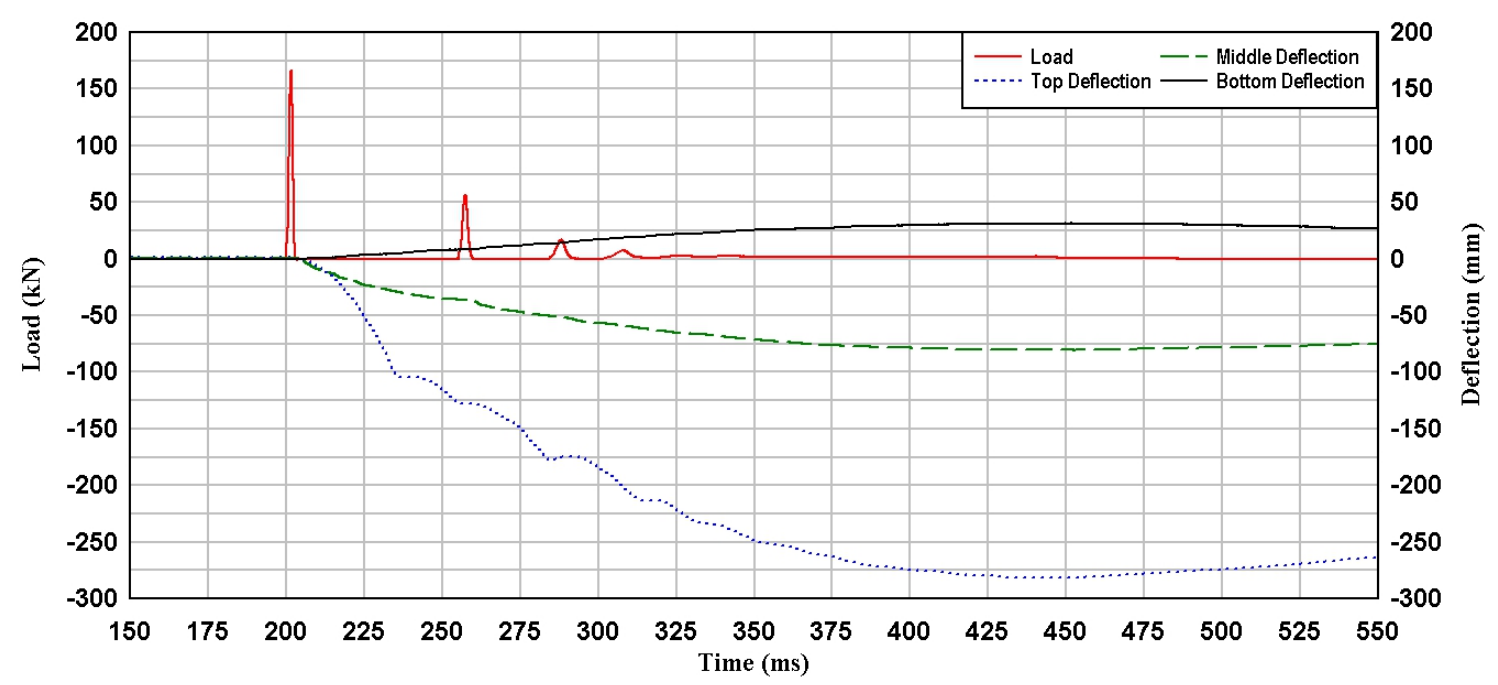

Figure 4-38: Load deflection time graph for Plain at $37^{\circ}$

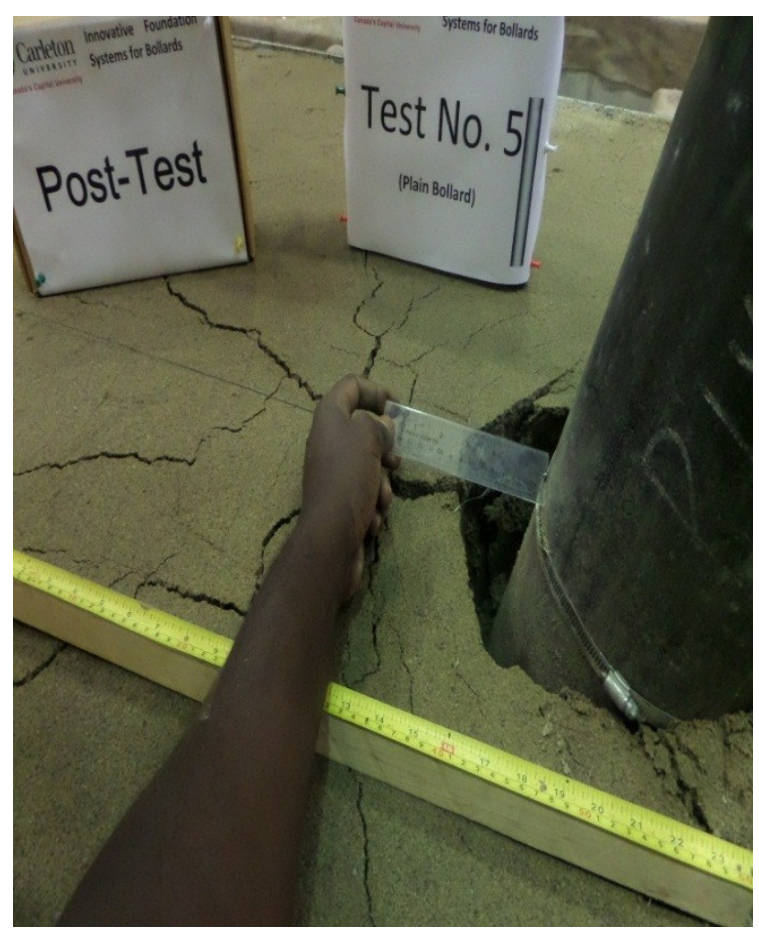

(a)

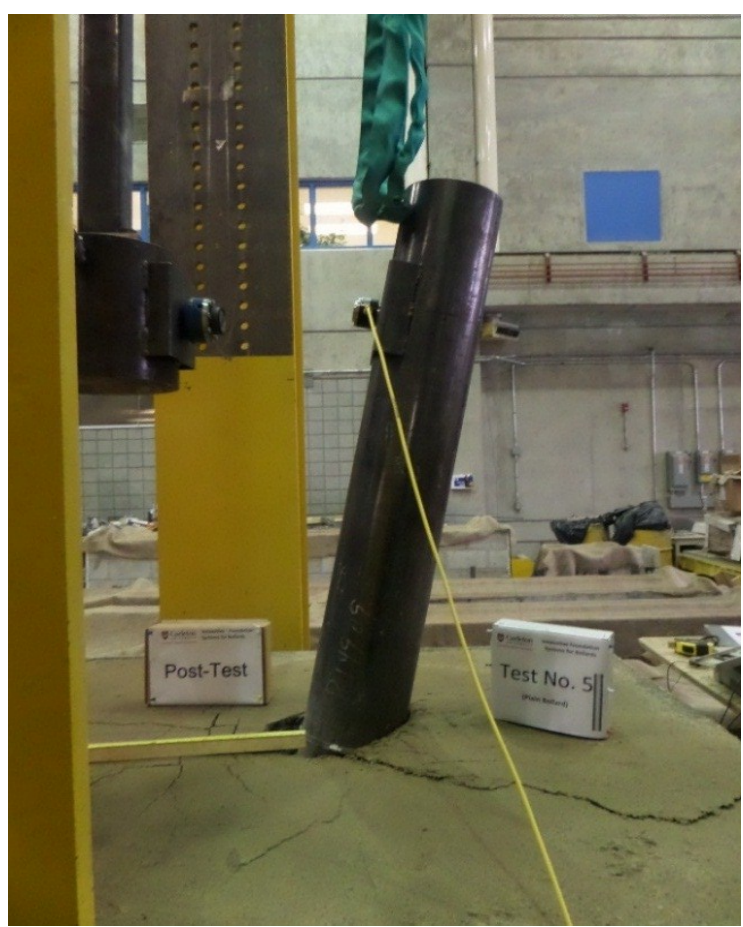

(b)

Figure 4-39: Post-test images of impact load test 5-Plain at $37^{\circ}$ 


\subsubsection{IM Test 5B-Plain at $25^{\circ}$}

The load- and deflection-time response graph for the impact load test on the plain bollard at an impact angle of $25^{\circ}$ is presented in Figure 4-40. From the graph, the maximum impact load was obtained as $123.67 \mathrm{kN}$ with a duration and rise time of $3.72 \mathrm{~ms}$ and $1.68 \mathrm{~ms}$ respectively (the impulse of the first pulse was $206.03 \mathrm{kN}-\mathrm{ms}$ ). The deflections of the bollard at top, middle and bottom were $104.9 \mathrm{~mm}, 41 \mathrm{~mm}$ and $6.4 \mathrm{~mm}$ respectively, with a deflection angle of $8.4^{\circ}$. The crack length for this test was $600 \mathrm{~mm}$ measured in front and $500 \mathrm{~mm}$ at the back of the bollard. A $32 \mathrm{~mm}$ separation gap was observed in front of the bollard after testing. The bulging recorded behind the bollard was $20 \mathrm{~mm}$ to $10 \mathrm{~mm}$ and less than $5 \mathrm{~mm}$ at the front. Figure $4-41$ shows the post-test photographs of this test.

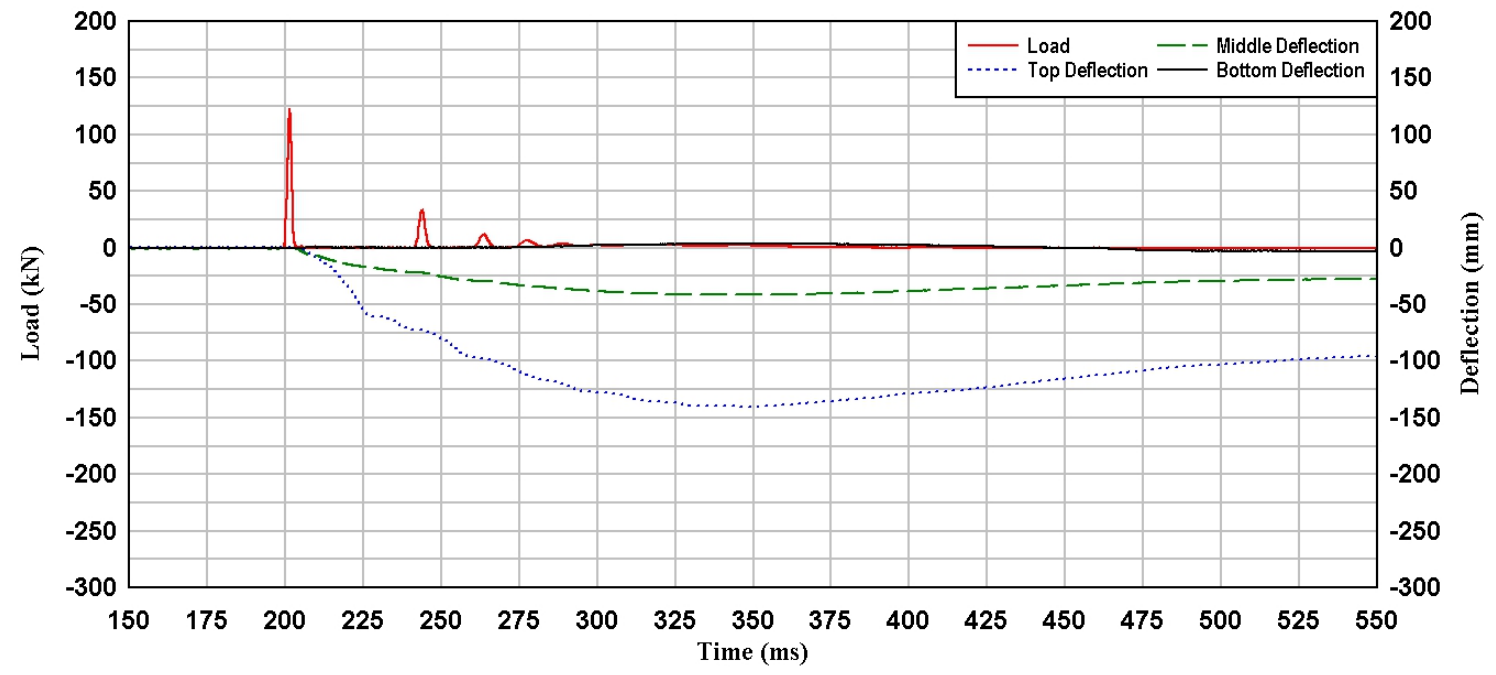

Figure 4-40: Load deflection time graph for Plain at $25^{\circ}$ 


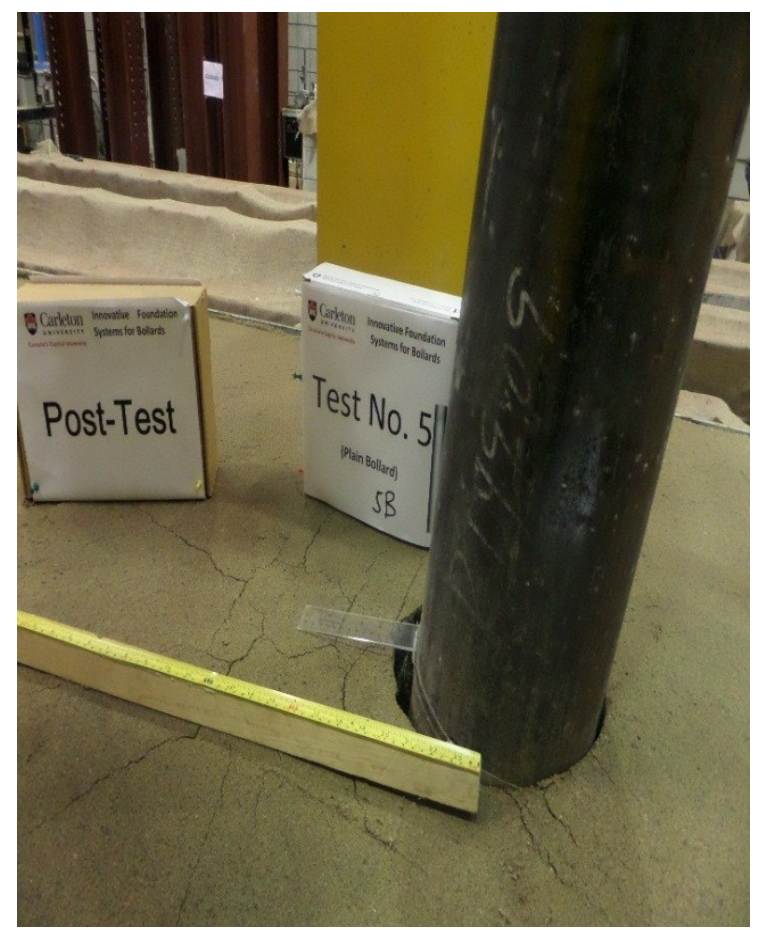

(a)

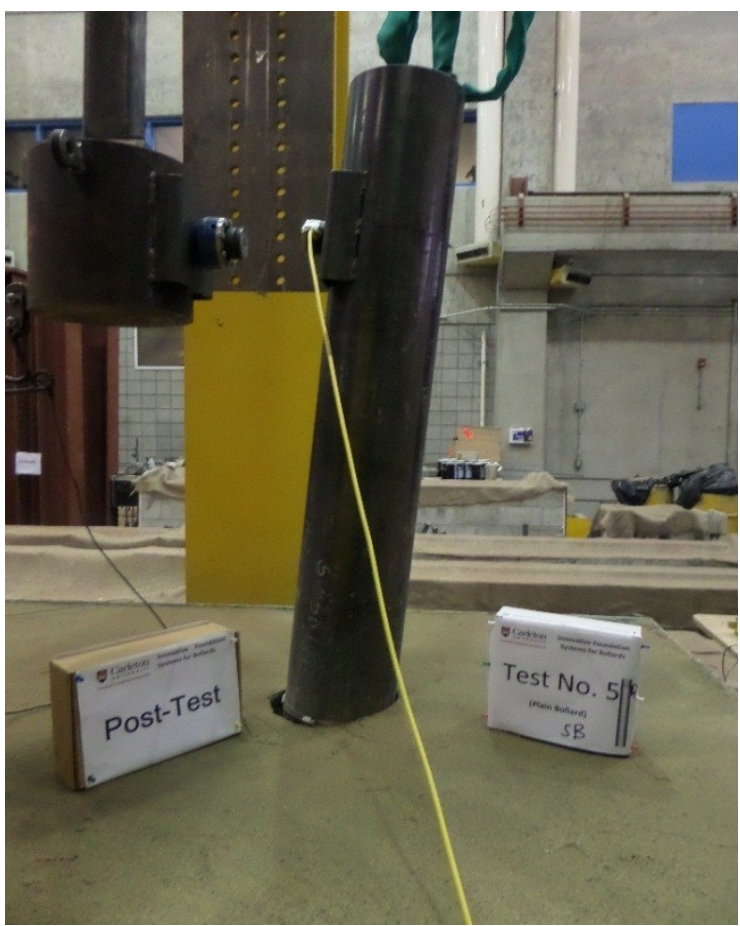

(b)

Figure 4-41: Post-test images of impact load test 5-Plain at $25^{\circ}$

\subsubsection{IM Test 5A-Plain at $15^{\circ}$}

Figure 4-42 presents the load- and deflection-time response graph of this test. The peak impact load recorded at the $15^{\circ}$ impact angle was $65.18 \mathrm{kN}$ with a duration of $4.08 \mathrm{~ms}$ (the impulse and rise time were $116.62 \mathrm{kN}-\mathrm{ms}$ and $1.78 \mathrm{~ms}$ for the first pulse). The bollard deflections at the top, middle and bottom were $76.1 \mathrm{~mm}, 21.93 \mathrm{~mm}$ and $1.18 \mathrm{~mm}$ respectively, with a deflection angle of $4.6^{\circ}$. For this test, no significant bulging was noticed after testing. A separation gap of $20 \mathrm{~mm}$ was developed at the soil-pile interaction surface. The cracks observed at the surface of the soil covered $250 \mathrm{~mm}$ in front and 150 $\mathrm{mm}$ at the back of the bollard (Figure 4-43). 


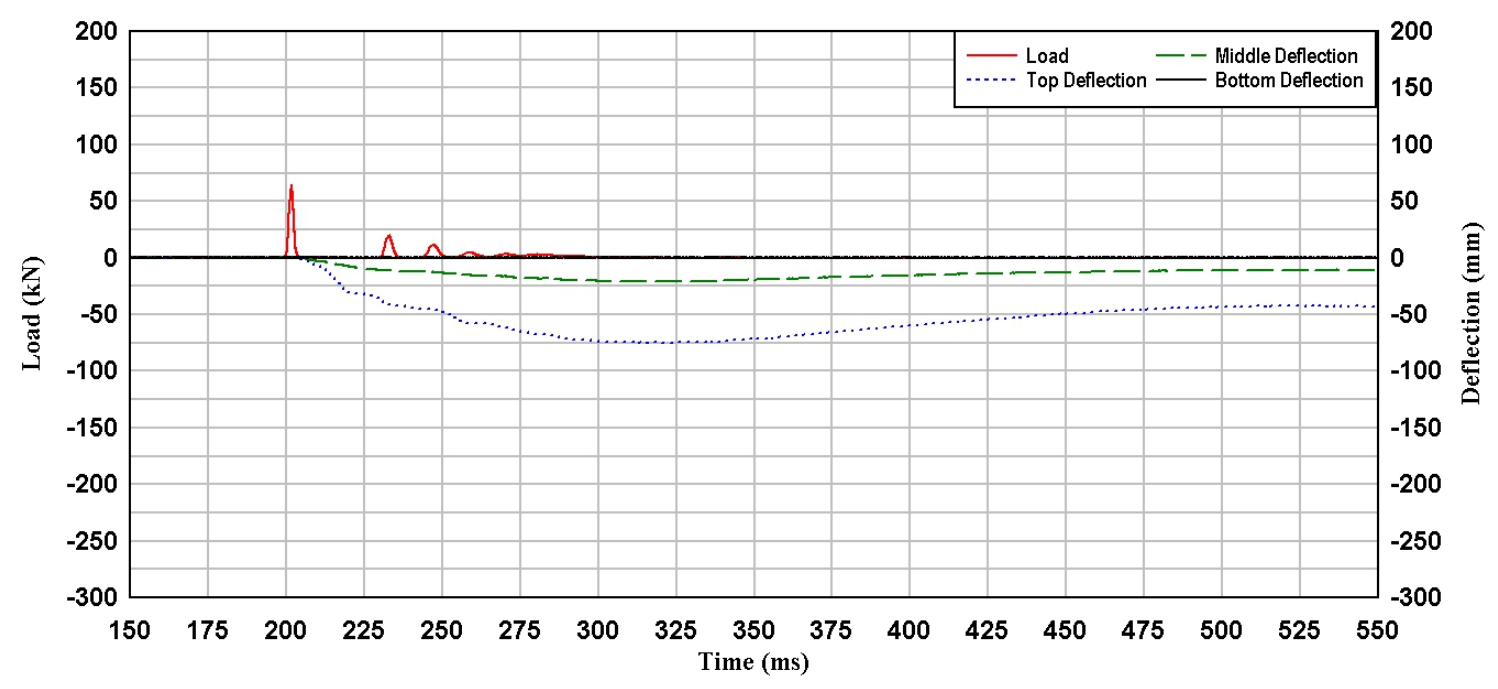

Figure 4-42: Load deflection time graph for Plain at $15^{\circ}$

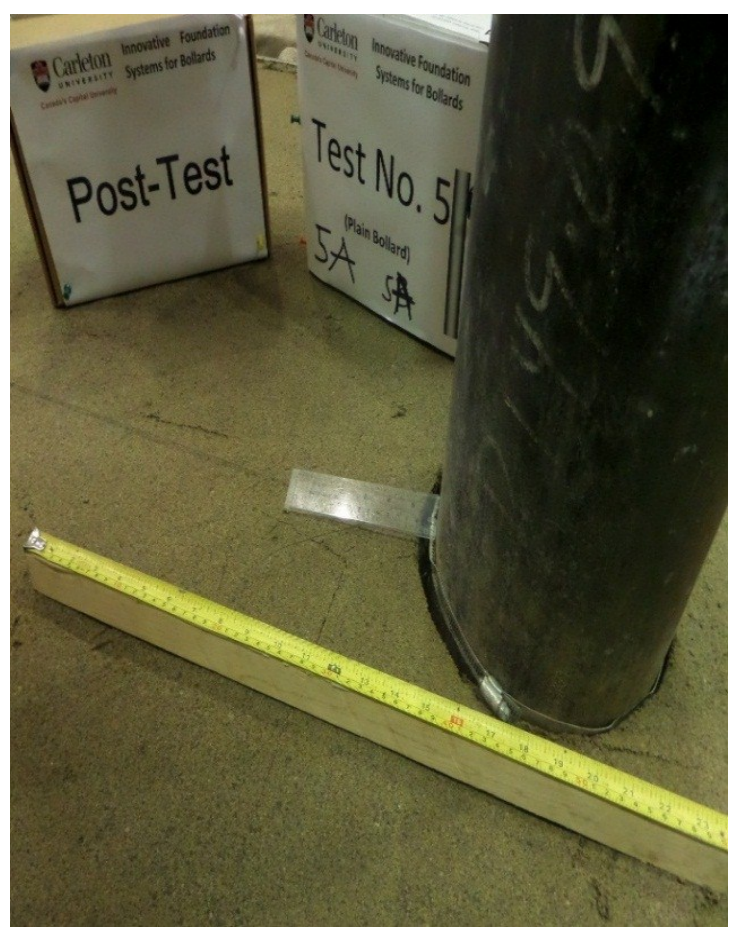

(a)

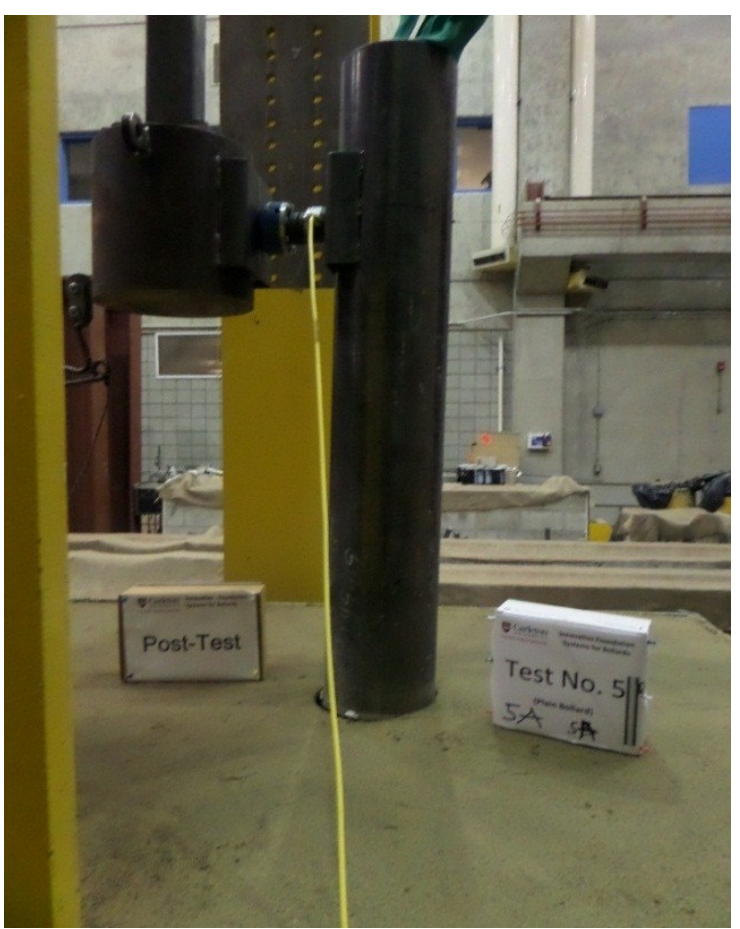

(b)

Figure 4-43: Post-test images of impact load test 5-Plain at $15^{\circ}$ 
A comparison of the load- and deflection-time response graph for IM Test 5-Plain is presented in Figure 4-44. An increase of $142.44 \mathrm{~mm}, 40.42 \mathrm{~mm}$ and $24.85 \mathrm{~mm}$ were observed for the top, middle and bottom deflections respectively when the impact angle was changed from $25^{\circ}$ to $37^{\circ}$ with a $44.5 \mathrm{kN}$ increase in peak impact load. Changing from $15^{\circ}$ to $37^{\circ}$ impact angle also caused an increase of $207.26 \mathrm{~mm}, 59.52 \mathrm{~mm}$ and $30.12 \mathrm{~mm}$ for the top, middle and bottom deflections respectively with a peak impact load increase of $103 \mathrm{kN}$.

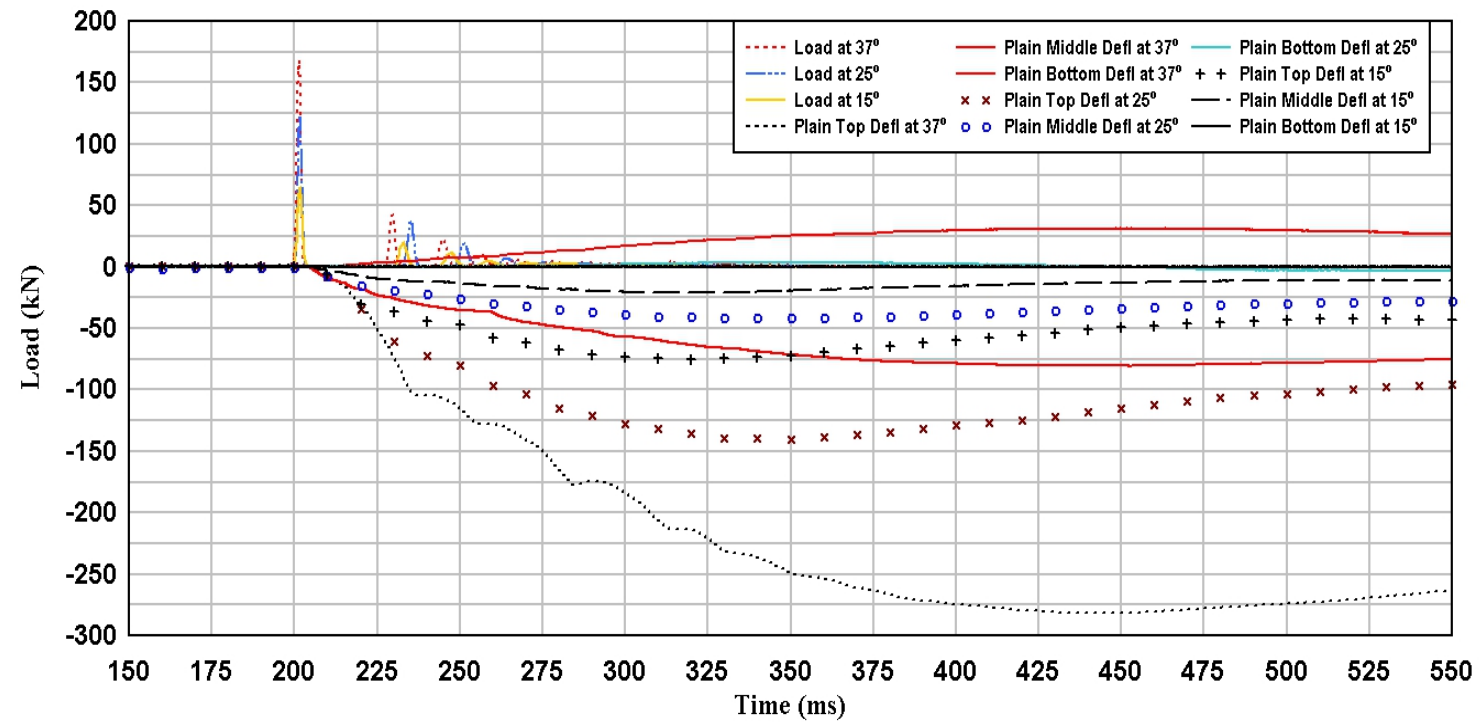

Figure 4-44: Load deflection time graph for Plain at $37^{\circ}, 25^{\circ}$ and $15^{\circ}$

\subsubsection{Comparison of Bollard Systems under Impact Loading}

A summary of the peak impact loads and maximum deflections of the various bollard systems are provided in Table 4-2, Table 4-3 and Table 4-4 for impact angles of $37^{\circ}, 25^{\circ}$, and $15^{\circ}$ respectively. 
Table 4-2: Impact loads and deflections at $37^{\circ}$ angle

\begin{tabular}{|c|c|c|c|c|c|}
\hline \multicolumn{6}{|c|}{$37^{\circ}$ angle } \\
\hline \multirow[b]{2}{*}{$\begin{array}{c}\text { Test } \\
\text { configuration }\end{array}$} & \multirow{2}{*}{$\begin{array}{c}\begin{array}{c}\text { Lateral Impact } \\
\text { Load (kN) }\end{array} \\
\text { Average Impact } \\
\text { Load = } 168.4 \text { kN }\end{array}$} & \multicolumn{3}{|c|}{ Deflection (mm) } & \multirow[b]{2}{*}{$\begin{array}{c}\text { Deflection } \\
\left.\text { Angle ( }{ }^{\circ}\right)\end{array}$} \\
\hline & & Top & Middle & Bottom & \\
\hline IM Test 1 (Fin 4) & 168.79 & 164.54 & 53 & 17.82 & 9.8 \\
\hline IM Test 2 (Fin 3$)$ & 167.59 & 207.76 & 55.66 & 36.37 & 12.3 \\
\hline IM Test 3 (Fin 2) & 168.72 & 213.92 & 61.69 & 20.64 & 12.7 \\
\hline IM Test 4 (Fin 1) & 168.95 & 220.25 & 68.28 & 21.9 & 13.1 \\
\hline IM Test 5 (Plain) & 168.13 & 283.36 & 81.45 & 31.3 & 16.6 \\
\hline
\end{tabular}

Table 4-3: Impact loads and deflections at $25^{\circ}$ angle

\begin{tabular}{|c|c|c|c|c|r|}
\hline \multirow{2}{*}{$\begin{array}{c}\text { Test } \\
\text { configuration }\end{array}$} & $\begin{array}{c}\text { Lateral Impact } \\
\text { Load (kN) }\end{array}$ & \multicolumn{2}{c|}{ Deflection (mm) } & \\
\cline { 2 - 6 } & $\begin{array}{c}\text { Average Impact } \\
\text { Load = 123.0 kN }\end{array}$ & \multicolumn{1}{c|}{ Top } & Middle & Bottom & $\begin{array}{c}\text { Deflection } \\
\text { Angle ( }\end{array}$ \\
\hline IM Test 1 (Fin 4) & 123.1 & 108.94 & 28.5 & 3.5 & 6.5 \\
\hline IM Test 2 (Fin 3) & 122.09 & 118.1 & 32.92 & 4.7 & 7.1 \\
\hline IM Test 5 (Plain) & 123.67 & 140.92 & 41.03 & 6.45 & 8.4 \\
\hline
\end{tabular}

Table 4-4: Impact loads and deflections at $15^{\circ}$ angle

\begin{tabular}{|c|c|c|c|c|r|}
\hline \multirow{2}{*}{$\begin{array}{c}\text { Test } \\
\text { configuration }\end{array}$} & $\begin{array}{c}\text { Lateral Impact } \\
\text { Load (kN) }\end{array}$ & \multicolumn{2}{|c|}{ Deflection (mm) } & \\
\cline { 2 - 6 } & $\begin{array}{c}\text { Average Impact } \\
\text { Load = 65.7 kN }\end{array}$ & Top & Middle & Bottom & $\begin{array}{c}\text { Deflection } \\
\text { Angle ( }\end{array}$ \\
\hline IM Test 1 (Fin 4) & 65.46 & 54.7 & 15.64 & 1.06 & 3.3 \\
\hline IM Test 2 (Fin 3) & 66.37 & 59.9 & 17.95 & 1.18 & 3.6 \\
\hline IM Test 5 (Plain) & 65.18 & 76.1 & 21.93 & 1.18 & 4.6 \\
\hline
\end{tabular}

\subsubsection{Lateral impact load capacity}

The peak impact loads are approximately the same for each impact angle; $65.7 \mathrm{kN}$ for $15^{\circ}$, $123.0 \mathrm{kN}$ for $25^{\circ}$, and $168.4 \mathrm{kN}$ for $37^{\circ}$. Four impacts were recorded for each test, however, the first pulse loads were considered in the discussions of bollard resistance (capacity) 
(Figure 4-45). The peak impact loads recorded varies according to the angle of impact; increasing as the impact angle increases.

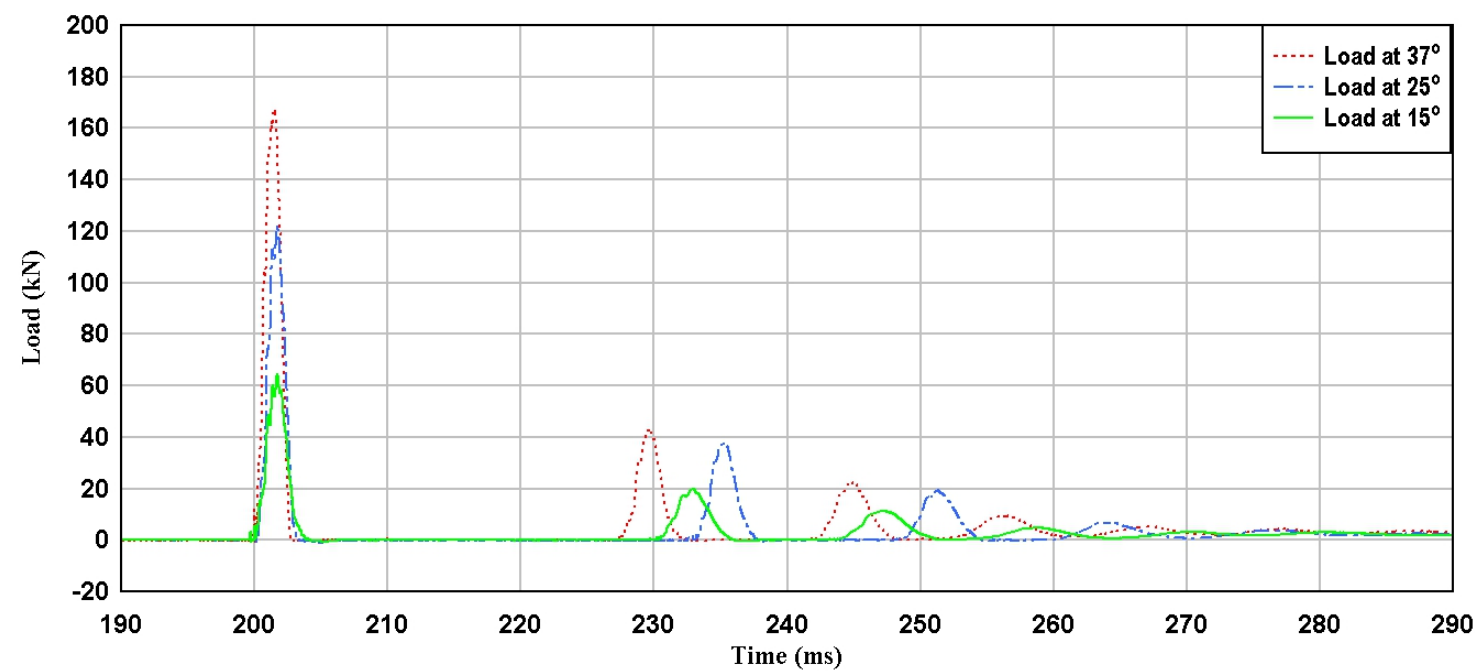

Figure 4-45: Load time profile for impact load test

The duration and rise times for the first pulse loads for the tests were approximately the same for a particular impact angle. The kinetic energies and impulses were also similar for a particular impact angle. However, the kinetic energy and impulse increased with increasing angle of impact (Table 4-5).

Table 4-5: Kinetic energy and impulse for impact loads

\begin{tabular}{|c|r|r|r|r|r|}
\hline $\begin{array}{c}\text { Test } \\
\text { configuration }\end{array}$ & $\begin{array}{c}\text { Average Impact } \\
\text { Load }(\underline{\mathbf{k N}})\end{array}$ & $\begin{array}{c}\text { Velocity } \\
\left(\mathbf{m s}^{-1}\right)\end{array}$ & $\begin{array}{c}\text { Kinetic } \\
\text { Energy (J) }\end{array}$ & $\begin{array}{c}\text { Average Rise } \\
\text { Time (ms) }\end{array}$ & $\begin{array}{c}\text { Average Impulse } \\
(\mathbf{k N}-\mathbf{m s})\end{array}$ \\
\hline IM Test $@ \mathbf{1 5}^{\circ}$ & 65.70 & 1.47 & 237.81 & 1.72 & 113.00 \\
\hline IM Test $@ \mathbf{2 5}^{\circ}$ & 123.00 & 2.43 & 654.10 & 1.60 & 196.80 \\
\hline IM Test $@ \mathbf{3 7}^{\circ}$ & 168.40 & 3.57 & 1405.95 & 1.55 & 261.02 \\
\hline
\end{tabular}




\subsubsection{Lateral impact deflection}

Similar to the peak impact loads, lateral deflections of the bollards varies with the angle of impact. For each bollard system, the higher the angle of impact, the higher the lateral deflection measured. In general, the lateral deflection of the bollards decreased with increase in fin area. The bollard with Fin Type 4 exhibited the least lateral deflection while the plain bollard without any fins exhibited the highest deflection. Figure 4-46, Figure 4-47 and Figure 4-48 present the load- and deflection-time response graphs for the top, middle and bottom locations of the bollards respectively for impact load test. It should be noted that the center of rotation of the bollard for the impact load test was between the middle and bottom measurement locations.

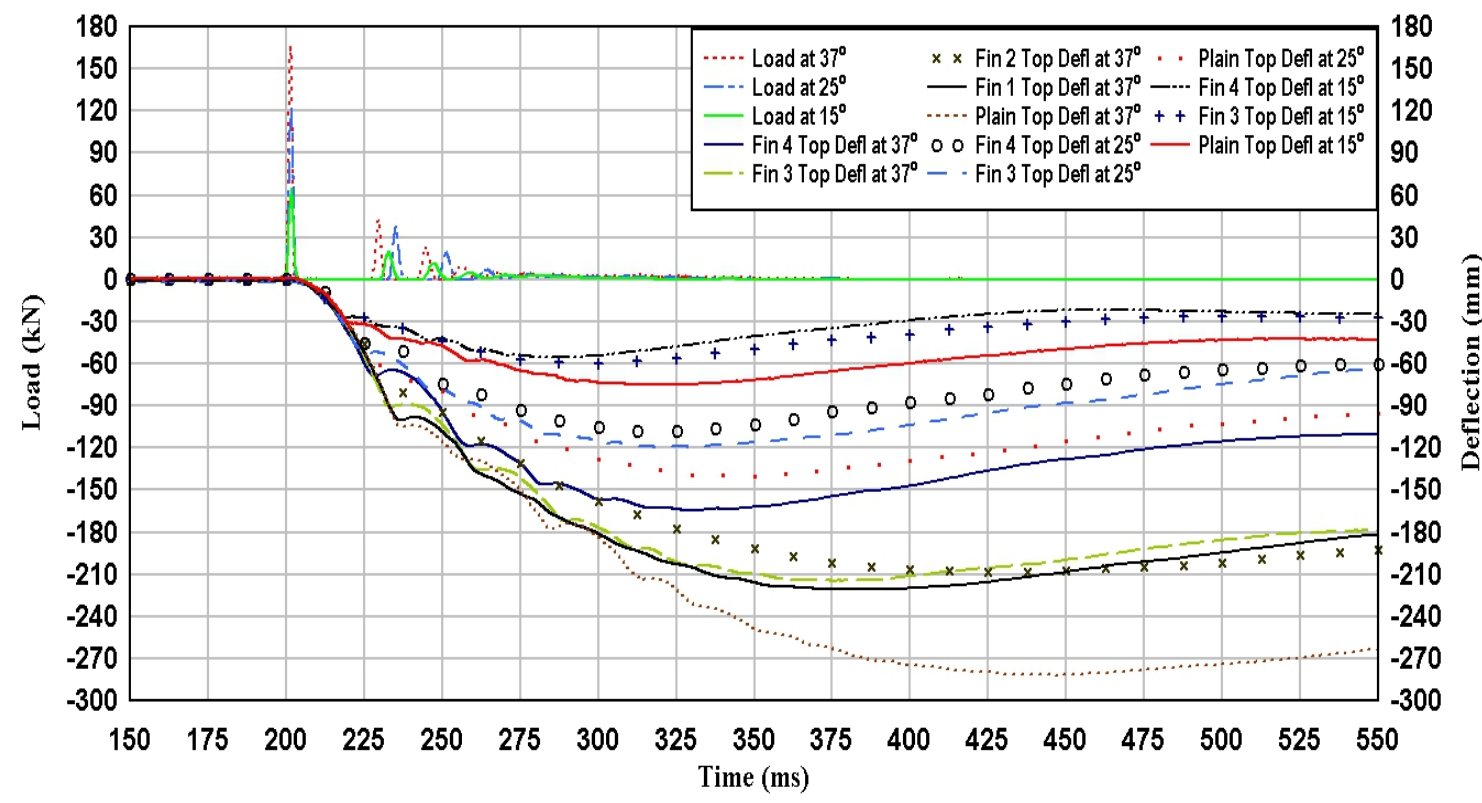

Figure 4-46: Top deflections for Impact load test 


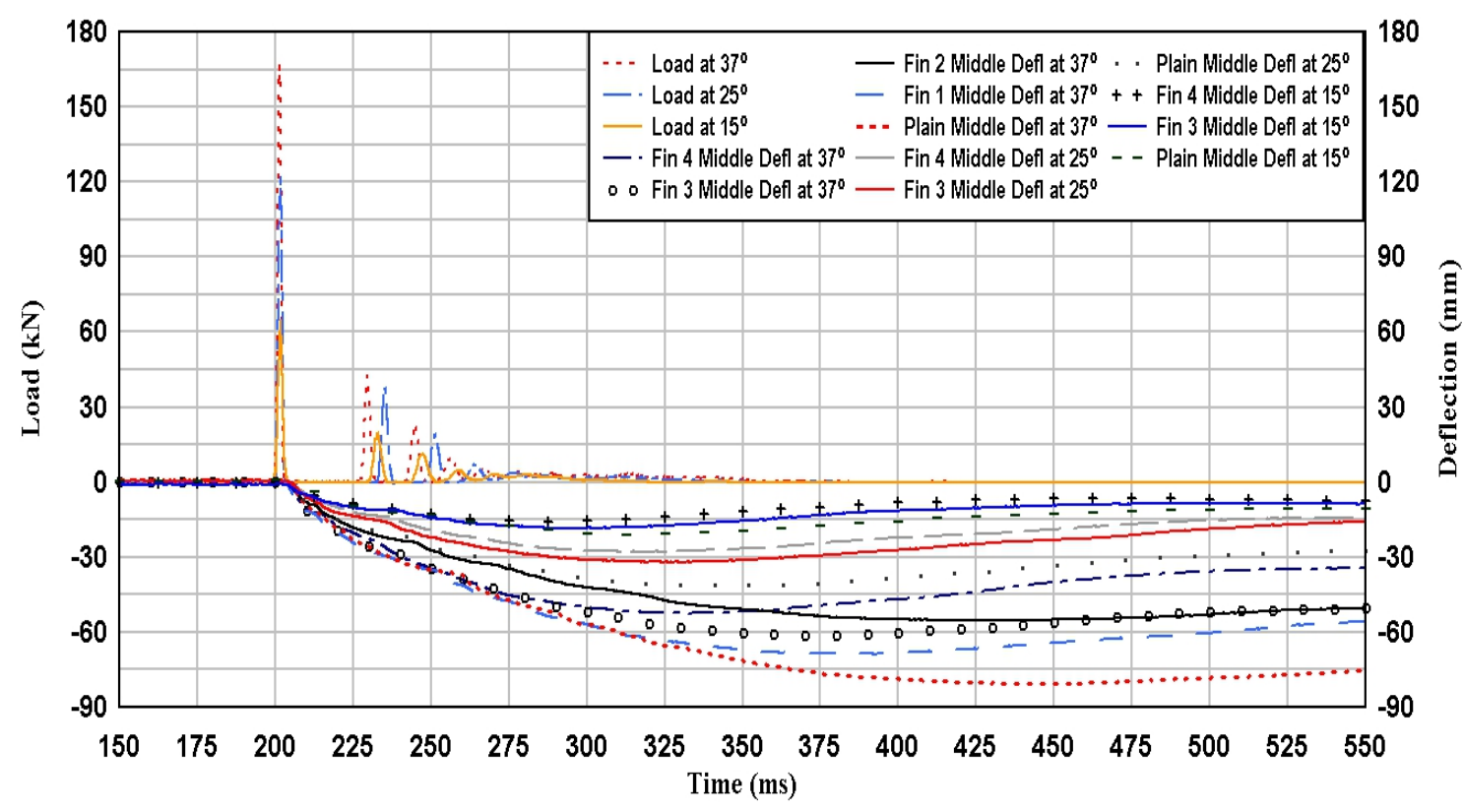

Figure 4-47: Middle deflections for Impact load test

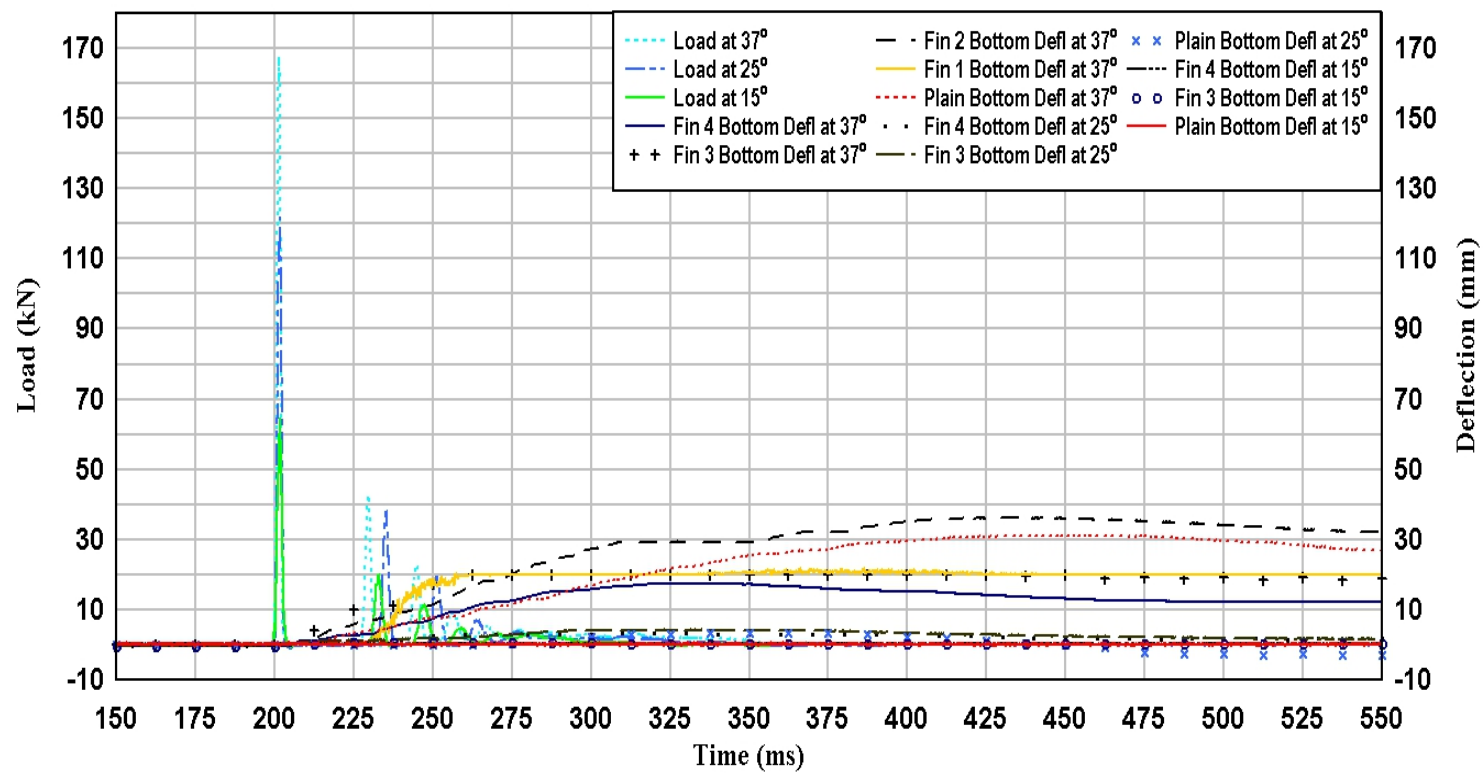

Figure 4-48: Bottom deflections for Impact load test 


\subsection{Discussion of Results}

Results reported from the tests provided relevant information with regards to the load capacities and deflections of the bollard-pile configurations considered in the research program. The results also varied depending on the type of test; static or impact. The static load test was conducted according to the ASTM standard test for laterally loaded piles (ASTM D3699, 2007) since the foundation for the bollard was designed as a short pile. The type of impact load applied to the bollard can be classified as hard impact since the kinetic energy of the impact is transferred to the impacted body and acts for a short duration. This corresponds to the study conducted by Miyamoto et al. (1991) on the classification of impact loads and their effects on foundations.

\subsubsection{Comparison of Load and Deflection Results for Static and Impact Load Tests}

\subsubsection{Lateral load capacity}

The load capacity for static and impact load tests varied significantly. In the case of the static load test, the load capacity varied from $4.0 \mathrm{kN}$ to $6.2 \mathrm{kN}$ under constant rate of loading. This provided the ability to determine the capacity of each configuration. ST Fin 4 had the highest load capacity while ST Plain configuration recorded the lowest load capacity. The load capacity of Fin 4 increased by about 55\% over the Plain. The increase in bollard capacity is attributed to the addition of fins to the plain bollard, which provided higher surface area and hence higher lateral resistance. The bollards with the same fin area exhibited similar capacities.

Unlike the static load test, the load capacity of the bollards under impact loading could not be easily determined. The impact load applied resulted in a given response of the 
bollard system. The higher the impact angle, the higher the impact load and deflection obtained. The impact loading from the three impact angles investigated yielded almost the same peak impact load at each impact angle. At the $37^{\circ}$ angle, the maximum load was approximately $168.4 \mathrm{kN}$. With the $25^{\circ}$ angle, the average maximum load was $123.0 \mathrm{kN}$ while an average maximum load of $65.7 \mathrm{kN}$ was obtained from the $15^{\circ}$ angle.

\subsubsection{Lateral deflections}

The deflection of the bollard systems followed similar trend for both the static and impact load tests but the deflection capacities varied significantly. Generally, the top deflections were the highest followed by the middle and bottom for all tests. The maximum deflections were observed for the Plain configuration regardless of the position of measurement while Fin 4 configuration recorded the lowest deflections. This was simply attributed to the surface area of the piles as well as the location of the fins. In the bollard with Fin 4 configuration, the fins were located where the highest passive earth pressure is normally generated due to the rotation of the pile. Allocating fins with high surface area in those locations (i.e., regions near the ground surface) led to higher passive earth pressure developed around the pile and, hence, provided higher lateral resistance and lower deflection in the pile.

For the static load test, the deflections ranged from $30 \mathrm{~mm}$ to $39.3 \mathrm{~mm}$ for the top, $10.9 \mathrm{~mm}$ to $4.7 \mathrm{~mm}$ for the middle and $6.6 \mathrm{~mm}$ to $2.7 \mathrm{~mm}$ for the bottom. The deflections at the bottom were not consistent showing unreasonable values of $0.1 \mathrm{~mm}$ for the ST Plain and ST Fin 1 configurations. The difference in top deflection for the maximum and minimum was $9.30 \mathrm{~mm}$ which represented about $31 \%$ of the minimum. The top deflections for the remaining configurations at this location were in decreasing order as ST Fin 1, ST 
Fin 2 and ST Fin 3. At the middle location, the maximum deflection was recorded at ST Plain followed by ST Fin 1, ST Fin 2, ST Fin 3 and ST Fin 4 in that order. The values of the maximum and minimum deflections at this location were $10.9 \mathrm{~mm}$ and $4.7 \mathrm{~mm}$ for ST Plain and ST Fin 4 respectively, showing a difference of $6.2 \mathrm{~mm}$ (Table 4-1).

For the impact load test, the deflections recorded were as follows: for the $168.4 \mathrm{kN}$ impact load, it ranged from $283.36 \mathrm{~mm}$ to $164.54 \mathrm{~mm}, 81.45 \mathrm{~mm}$ to $53 \mathrm{~mm}$ and $31.3 \mathrm{~mm}$ to $17.82 \mathrm{~mm}$ for the top, middle and bottom deflections in that order. In the same manner, $140.92 \mathrm{~mm}$ to $108.94 \mathrm{~mm}, 41.03 \mathrm{~mm}$ to $28.5 \mathrm{~mm}$ and $6.45 \mathrm{~mm}$ to $3.5 \mathrm{~mm}$ were observed for the $123.0 \mathrm{kN}$ impact load while $76.10 \mathrm{~mm}$ to $54.70 \mathrm{~mm}, 21.93 \mathrm{~mm}$ to $15.64 \mathrm{~mm}$ and $1.18 \mathrm{~mm}$ to $1.06 \mathrm{~mm}$ were reached for the $65.7 \mathrm{kN}$ impact load (Table 4-2, Table 4-3 and Table 4-4). Similar to the static load tests, the maximum and minimum deflections were observed for IM Plain and IM Fin 4 configurations respectively.

\subsubsection{Analysis of deflections for static and impact load tests}

Considering Plain and Fin 4 bollard configurations which showed the highest and lowest load and deflection values, some interpretations can be made. Critical observation of the results shows that for the static load test, the higher load resistance ability leads to lower pile deflection. For instance, a 31\% increase in top deflection was observed between Fin 4 and Plain configurations of the static load test. Similarly, for the impact load test, where almost the same loads were impacted at a particular angle configurations, the deflections of the Plain were higher than Fin 4 at the top by $42 \%$ for the $168.4 \mathrm{kN}$ load, $23 \%$ for the $123.0 \mathrm{kN}$ load and $28 \%$ for the $65.7 \mathrm{kN}$ load. Thus, a significant increase in deflection for the Plain compared to Fin 4 bollard can be observed for both tests, which corresponds to lower surface area of the plain pile. 
Considering load resistance to deflection ratios, the impact load test had a higher load resistance to deflection ratio compared to the static load test regardless of the location of measurement. The load resistance to deflection ratio is calculated as the load capacity divided by the corresponding deflection at a particular location. For example considering the top deflection measurements of Plain configuration, the load resistance to deflection ratios of 0.59 and 0.10 can be calculated for impact load test ( $37^{\circ}$ angle of impact) and static load test respectively. Similar trends follow for the middle deflection measurements. $37^{\circ}$ angle of impact load test produced load resistance to deflection ratio of 2.1 while static test resulted in 0.37 . This proves that the impact load test had higher load resistance to deflection ratios compared to the static load test.

However, the $25^{\circ}$ and $15^{\circ}$ impact angles ( $123.0 \mathrm{kN}$ and $65.7 \mathrm{kN}$ impact load tests) were not critical compared to the $37^{\circ}$ angle $(168.4 \mathrm{kN})$ impact load tests. Physical and analytical observation of the $25^{\circ}$ and $15^{\circ}$ angles of impact load tests showed that the recorded deflections were lower compared with the $37^{\circ}$ angle of impact. Nonetheless, the $25^{\circ}$ and $15^{\circ}$ impact angles showed more representative results compare to the static load test. The $25^{\circ}$ and $15^{\circ}$ impact angles provided information to buttress the point that impact loads should be considered on studies concerning crash barriers. This reinforces research work conducted by El-Sakawaky et al. (2004), El-Tawil (2004) and Itoh et al. (2011) on the importance of considering impact loads in the design of anti-ram vehicle crash bollards.

\subsubsection{Effects of Fins on Lateral Capacity and Deflection}

The structural properties of the cylindrical pipe used as the bollard-pile configuration and the sandy soil used for the foundation remained the same for all the tests. Also, the procedure employed for each tests (i.e. static or impact) and the foundation built for each 
test was maintained throughout testing. The different fin configurations which were attached to the bollard-pile configurations were the major difference in each test. The fins were welded on the piles (part of bollard-pile configuration embedded in soil and acting as the foundation). It was noticed that piles with fins had higher load resistance (capacity) and smaller deflections compared to piles without fins as Bienen et al. (2012) noted.

In total, five configurations were tested; Plain, Fin 1, Fin 2, Fin 3 and Fin 4. Fin 3 was an inversion of Fin 1 which was right angle triangle in shape. Fin 2 had a shape of an obtuse triangle. Fin 4 was made of two fins facing each other in opposite directions. Three of the Fins (Fin 1, Fin 2 and Fin 3) had the same surface area of $5.25 \times 10^{4} \mathrm{~mm}^{2}$ while Fin4 had a surface area of $8.25 \times 10^{4} \mathrm{~mm}^{2}$. Although Fin 1, Fin 2 and Fin 3 had the same surface area, Fin 2 had the highest height, thus it was closest to the soil surface. The Plain configuration had no Fins attached to it. The Fins were made of $12 \mathrm{~mm}$ thickness and cut into various shapes to form different configurations. Each Fin was attached to the bottom of the pile. Application of loads to each test gave different results for both static and impact and this can be attributed to the fin configurations which included the shape, location and surface area of Fins.

\subsubsection{Shape of Fins}

The different shapes of the Fins were used in both the static and impact load tests. Considering the static load test, it is clear that using any shape of fins significantly improved the lateral load capacity of the pile. Fin 1 with the lowest lateral load capacity among the finned piles exhibited a lateral capacity increase of $20 \%$ over the Plain bollard without fins. For finned piles, the lateral load capacity also varied according to the shape of the fins. Fin 4, double shaped fins, had the highest load capacity of $6.2 \mathrm{kN}$, but its surface 
area was the largest among the finned piles. Among fins with same surface area, Fin 2 recorded the highest lateral load capacity of $5.3 \mathrm{kN}$ followed by Fin 1 with $4.8 \mathrm{kN}$ and Fin 3 with $4.6 \mathrm{kN}$. Thus, the lateral capacity of Fin 1 and Fin 3 were similar but that of Fin 2 showed an increase of $10 \%$ over Fin 1 . Hence, it can be suggested that the shape of the Fins has an effect on the load resistance. Since the impact load test employed the same load application for each test procedure, no inference can be drawn considering the lateral impact load capacity. However, the deflection results provided basis for comparison for both tests with respect to shape of fins.

For the static load test, Fin 4 had the lowest deflection followed by Fin 3, Fin 2, Fin 1 and Plain. Comparing the top deflection measurements, the difference in lateral deflection between the Plain and Fin 1 piles indicated an increase of 3\% of Plain over Fin 1. Comparing piles with same fin surface area, the lateral deflection of Fin 1 increased by 22\% over Fin 3 and 5\% over Fin 2.

In similar sense to the static load test, the deflections of the impact load test were lowest for Fin 4 and highest for Plain. Fin 3, Fin 2 and Fin 1 followed in increasing order of lateral deflection for all the tests regardless of the location of measurement. Considering the top deflection measurements for $37^{\circ}$ angle of impact, the Plain pile showed $29 \%$ increase over Fin 1. Comparing piles with the same fin area, Fin 3 recorded the lowest deflection followed by Fin 2 and Fin 1 . Fin 1 showed an increase of $6 \%$ over Fin 3 when Fin 3 was changed to Fin 1 . The lateral deflection of Fin 1 also increased by $3 \%$ over Fin 2.

From the analyses, Fin 4 with the double shaped fins, recorded the highest lateral load capacity for the static load test and lowest lateral deflection for both tests. However, 
the surface area of Fin 4 compared to the other configurations was higher. When fins with the same surface area were compared, Fin 3 with a shape opposite to Fin 1, emerged with the lowest lateral deflection while Fin 1 recorded the highest for both tests. The significant decrease in lateral deflection for Fin 3 is due to the contribution of the shape. Although Fin 3 and Fin 1 were right angle triangle in shape, Fin 3 had its widest part (base of the triangle) at the top and the lowest edge at the bottom, increasing the resistance close to the soil surface.

\subsubsection{Surface area of Fins}

The surface area of the fins was the same for all configurations except Fin 4. The surface area of Fin 4 was $8.25 \times 10^{4} \mathrm{~mm}^{2}$ which is 1.57 times the surface area of the other fin types $\left(5.25 \times 10^{4} \mathrm{~mm}^{2}\right)$. Due to the higher surface area of Fin 4, it recorded the highest lateral load capacity and lowest lateral deflections for all the tests. The effect of fin surface area was phenomenal when fin efficiency factor was considered (Table 4-6). Fin efficiency factor is expressed as the ratio of ultimate lateral load of a finned pile to ultimate lateral load of a regular pile without fins (Peng et al., 2004). From the static load test, fin efficiency factor increased significantly for Fin 4 compared with the other fins. Fin 4 increased by $60 \%$ over Plain, 30\% over Fin 1 and Fin 3, and 23\% over Fin 2.

Table 4-6: Fin efficiency factors for static load tests

\begin{tabular}{|l|r|r|}
\hline $\begin{array}{c}\text { Test } \\
\text { configuration }\end{array}$ & \multicolumn{1}{c|}{$\begin{array}{c}\text { Lateral Static } \\
\text { Load (kN) }\end{array}$} & \multicolumn{2}{|c|}{$\begin{array}{c}\text { Fin Efficiency } \\
\text { Factor }\end{array}$} \\
\hline ST Plain & 4 & 1.0 \\
\hline ST Fin 1 & 4.8 & 1.2 \\
\hline ST Fin 2 & 5.3 & 1.3 \\
\hline ST Fin 3 & 4.6 & 1.2 \\
\hline ST Fin 4 & 6.2 & 1.6 \\
\hline
\end{tabular}


Also, the impact test load results proved significant difference in the lateral deflection results. For instance, in considering the top deflection measurements of $37^{\circ}$ angle of impact load tests, Fin 4 recorded a decrease in lateral deflection by $42 \%$ over Plain, 25\% over Fin 1, 23\% over Fin 2 and 21\% over Fin 3 (Figure 4-49). The wider surface area of Fin 4 compared to the other fin types increased the passive area of soil pressure in front of the pile causing a higher lateral load resistance and lower lateral deflection, and this corresponds to research work conducted by Nasr (2013).

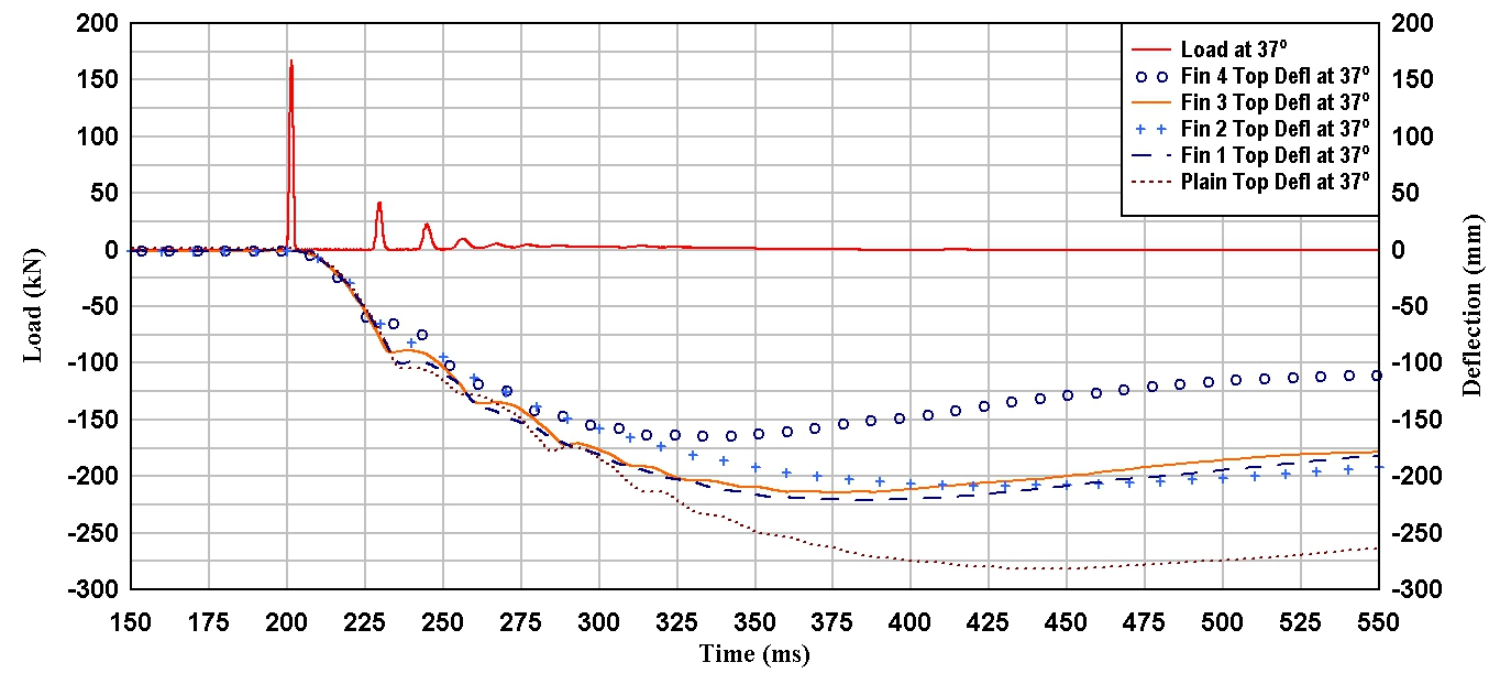

Figure 4-49: Load deflection time graph for $37^{\circ}$ impact angle considering top deflections

\subsubsection{Position and depth of Fins}

Analyses of the position and depth of the fins attached for each configuration showed some relevant results. The fins were welded to the bottom of the piles perpendicular to the loads applied. In terms of the load capacity when using the static load test, Fin 2 exhibited highest lateral load capacity for finned piles having the same surface area. Fin 2 recorded $5.3 \mathrm{kN}$ 
compared to Fin $1(4.8 \mathrm{kN})$ and Fin $3(4.6 \mathrm{kN})$. The reason for the higher lateral load resistance of Fin 2 is due to the position of the fins. The height of fins for Fin 2 was highest among piles of the same surface area, and hence increased the resistance to static load application. However, the width of fins for Fin 2 was narrower compared to Fin 3, and this resulted in the lower lateral deflection values compared to Fin 3. Thus, for effectiveness, parameters of the fins (length, width, thickness and surface area) must be designed to provide higher resistance to lateral loads while reducing lateral deflections. The design of Fin 4; fin length relative to pile length (position) and shape of the fin provided the ability to resist higher lateral loads and decrease lateral deflections, which confirms Peng et al., (2004) study on finned piles.

\subsubsection{Comparison of Conventional Bollard Foundation to Proposed Pile Foundation}

In current design practice, with the use of a shallow foundation for bollards, concrete is normally poured around the base of the bollard underneath the soil. The depth and amount of concrete used depends on the type of vehicular loading to be resisted. For high impact loading resistance, rebar may be incorporated to reinforce the concrete shallow foundation. The foundation is also backfilled with high strength soil to keep the foundation in place. In a study conducted by Bligh (2010) in which a shallow concrete foundation was used for a barrier, the maximum impact load of $189 \mathrm{kN}$ caused a maximum deflection of $200 \mathrm{~mm}$. In the current study, a $168.4 \mathrm{kN}$ impact load caused a maximum deflection of $164.5 \mathrm{~mm}$ for the finned pile with the highest surface area. However, it is important to note that the elastomeric pad absorbed part of the impact loading which reduced the measured impact load (i.e., the actual impact load is likely to be higher than $168.4 \mathrm{kN}$ ). The simple pile foundation system developed in this study provided significant passive soil pressure to 
resist the impact loads. This method is less time consuming and economical as well as easy to install compared to the conventional shallow foundation designs. The design edict for the proposed pile foundation may consider the use of a backfill material as opposed to the inclusion of concrete and rebar in the case of the shallow concrete foundation system. 


\section{Chapter: Conclusion and Recommendations}

\subsection{Conclusion}

The use of a simple pile to support the foundation for a bollard system has been investigated. Review of literature shows a number of research works on the design of vehicle bollards under impact loading. But most of these studies do not investigate the foundation system for vehicle bollards. Many researchers focus on the capacity of the bollard to resist the loads acting on it. For effective design of anti-ram vehicle bollards, the design of the foundation used to support the loads should be considered. The design of the foundation used to resist the vehicular loads in this thesis considered a simple pile system with fins attached to it. Different fin configurations were attached to the piles and investigated against a pile without Fins (Plain bollard). Both static and impact load tests were conducted as part of the investigation. The results of the test provided important information for the analyses and design of bollard systems. The lateral load capacities and deflections were analyzed to assess the performance of the different bollard configurations. The conclusions that were drawn from the studies presented in this work are as follows:

- A simple pile foundation system can be used to resist the loads acting on a bollard.

- The attachment of fins on the pile in the foundation design increases the lateral load resistance and decrease the lateral deflection of the bollard to vehicular loads.

- The configuration of the fins including, the shape, surface area and location of the fins significantly influence the resistance to vehicular loads.

- The soil and fin on pile interaction should be considered for effective performance of the finned piled foundation system. 
- For effective design of anti-ram vehicle bollards, both the foundation and structural capacity of the bollard should be considered.

- The load resistance of the bollard system increases the load carrying capacity of bollards for impact loading.

\subsection{Recommendations}

The results presented in this thesis indicate that a simple pile foundation system can be implemented in the design of vehicle bollards. The use of the simple pile foundation will have advantages compared to the current traditional shallow footing design methods used. These advantages will span from cost effectiveness, its simplicity and ease of construction. However, more research can be done for improvement in this technology. Some recommendations for future works include:

- Experimental studies should also be done to investigate foundation systems for other security barriers such as jersey barriers, cable barriers, planters and gates, etc.

- In designing the foundation for the bollards sand was used as the soil. Further studies should be done considering other soils such as clay.

- Field experiments should be conducted to investigate the effect of weather conditions including frost susceptibility. 


\section{References}

AASHTO (1990). Guide specifications for highway construction. American Association of State Highway and Transportation Officials (AASHTO). Washington, D.C., U.S.A.

AASHTO (2002). Standard specification for highway bridges. $17^{\text {th }}$ Edition. American Association of State Highway and Transportation Officials (AASHTO). Washington, D.C., U.S.A.

AASHTO (2004). Roadside Design Guide. American Association of State Highway and Transportation Officials (AASHTO). Washington, D.C., U.S.A.

Ashford, S., A., Scott, M., H., and Rayamajhi, D. (2013). Reducing seismic risk to highway mobility: Assessment and design examples for pile foundations affected by lateral spreading. OTREC-RR-13-05.

ASTM (2007). Standard test method for vehicle crash testing of perimeter barriers. American Society of Testing Materials. West Conshohocken, PA, U.S.A.

ASTM D3699 (2007). Standard test methods for deep foundations under lateral load. American Society of Testing Materials. West Conshohocken, PA, U.S.A. DOI: 10.1520/D3699-07.

ASTM D4945 (2007). Standard test methods for high-strain dynamic testing of deep foundations. American Society of Testing Materials. West Conshohocken, PA, U.S.A. DOI: 10.1520/D4945-12. 
Baker, R. P and Benny, D. J. (2013). The complete guide to physical infrastructure: Chapter 4. Security construction projects. Taylor and Francis Group. CRC Press.

Basu, D., Salgado, R., and Prezzi, M. (2008). Analysis of laterally loaded piles in multilayered soil deposits. Purdue University, IN, U.S.A. FWHA/IN/JTRP-2007/23.

Basu, D., Salgado, R., and Prezzi, M. (2009). A continuum-based model for analysis of laterally loaded piles in layered soils. Géotechnique, 59(2), 127-140.

Benson, C. H., Abichou, T., Albright, W., Gee, G. and Roesler, A. (2001). Field evaluation of alternative earthen final covers. International Journal Phytoremediation, 3(1), 1-21.

Bienen, B., Dührkop, J., Grabe, J., Randolph, M.F., and White, D. (2012). Response of piles with wings to monotonic and cyclic lateral loading in sand. Journal of Geotechnical and Geoenvironmental Engineering, 138(3): 364-375. (ASCE)

Bligh, R. P., Briaud, J., Kim, K. M. and Abu-Odeh, A. (2010). Design of roadside barrier systems placed on MSE retaining walls. NCHRP Report 663. Transportation Research Board. Washington, D.C., U.S.A.

Borovinsek, M., Vesenjak, M., Ulbin, M., and Ren, Z. (2007). Simulation of crash tests for high containment levels of rad safety barriers. Science Direct. Engineering Failure Analysis $14,1711-1718$.

Bowles, J. E. (1997). Foundation analysis and design. 5th edition, pp. 867-1053. Singapore: MaGraw-Hill. 
Broms, B. B. (1964). Lateral resistance of piles in cohesive soils. Proceedings of ASCE, Journal of Soil Mechanics Foundation Engineering Division, 90(SM2), 27-64.

Broms, B. B. (1964). Lateral resistance of piles in cohesionless soils. Proceedings of ASCE, Journal of Soil Mechanics Foundation Engineering Division, 90(SM3), 123-156.

Chopra, A. K. (2001). Dynamics of structures: Theory and application to earthquake engineering. $2^{\text {nd }}$ edition. Prentice hall.

Cudoto, D. P. (2001). Foundation design principles and practices. $2^{\text {nd }}$ edition. ISBN: 0-13589706-8. Prentice hall, Upper Saddle River, NJ, U.S.A.

Das, B. M. (2010). Principles of foundation engineering. $7^{\text {th }}$ edition. Cengage Learning, Stamford, CT, U.S.A.

Dawson, H. and Tennant, D. (2008). Inelastic dynamic finite-element design of bollard systems to impact loading. ASCE, Structures Congress: Crossing borders. Vancouver, British Columbia, Canada. ISBN: 978-0-7844-1016-5.

De Clerck, B., Segers, E., Kakogiannis, D. Vantomme, J. and Suleau, S. (2012). Study of the resistance of bollards against impact loads. $9^{\text {th }}$ National congress on theoretical and applied mechanics. Brussels.

Dusenberry, D. O. (2010). Handbook for blast-resistant design of buildings. John Wiley and Sons Incorporation. Hoboken, NJ, U.S.A.

El Naggar, M. H. (2008). Design of machine foundation. Lecture notes. University of Western Ontario. London, ON, Canada. 
El-Sakawaky, E., Masmoudi, R., Benmokrane, B., Briere, F. and Desgagne, G. (2004). Pendulum impacts into concrete bridge barriers reinforced with glass fibre reinforced polymer composite bars. Canadian Journal of Civil Engineering. 31: 539-552.

El-Tawil, S. (2004). Vehicle collision with bridge piers. PhD thesis. University of Michigan. Ann Arbor, MI. U.S.A.

FHWA (2010). Concrete barriers. Federal Highway Administration (FHWA). FHWA Safety Program. Washington, D.C., U.S.A.

Gabler, H. C., Gabauer, J. D. and Bowen, D. (2005). Evaluation of cross median crashes. Bowen Rowan University, Department of Mechanical Engineering, Glassboro, NJ, U.S.A. FHWA-NJ-2005-004.

Grzebieta, R. and Rechnitzer, G. (2013). Designing and testing bollards to protect pedestrians. Proceedings of the 2013 Australasian Road Safety Research, Policing and Education Conference. Brisbane, Queensland.

Gunaratne, M. (2013). Design of driven piles and pile groups. In the Foundation Engineering Handbook. $2^{\text {nd }}$ Edition (pp. 283-350). CRC Press.

Hanson, W. E., and Oglesby, D. D. (2005). Safety in foundation engineering: Unity of the WSD (ASD) and LRFD methods. John Wiley and Sons, Incorporation. New York, U.S.A.

Itoh, S., Itoh, Y. and Takadoh, O. (2011). Collision performance of new bridge guard fences using the numerical simulation. $9^{\text {th }}$ International conference on shock and impact loads on structures. Fukuoka, Japan. 
Itoh, Y., Liu, C. and Kusama, R. (2007). Dynamic simulation of collisions of heavy highspeed truck with concrete barriers. Chaos, Solitons and Fractals 34, 1239-1244.

Matlock, H. and Ingram, W. B. (1963). Bending and buckling of soil-supported structural elements. Proceedings of 2nd Pan-American Conference on Soil Mechanics and Foundation Engineering, Brazil.

Miyamoto, A., King, M. W. and Fuji, M. (1991). Nonlinear dynamic analysis of reinforced concrete slabs under impulsive loads. ACI Structural Journal. V. 88. No. 4.

Nasr, A. M. A. (2013). Experimental and theoretical studies of laterally loaded finned piles in sand. NRC Research Press. Canadian Geotechnical Journal. 51: 381-393 (2014).

Novak, M. (1974). Dynamic stiffness and damping of piles. Canadian Geotechnical Journal. Volume 2. 574-598.

Pawlus, W., Karimi, R. H. and Robbersmyr, K. G. (2013). Investigation of vehicle crash techniques: theory and application. International Journal of Advance Manufacturing Technology.

Pile Dynamics, Inc. (2010). Pile driving analyzer. (Online) Available at: http://www.pile.com/pdi (Accessed 5 August 2015).

Poulos, H. G., and Davis, E. H. (1980). Pile foundation analysis and design. University of Sydney. Rainbow-Bridge Book Comapany, No. 554786. 
Peng, J., Rouainia, M., Clarke, B., Allan, P., and Irvine, J. (2004). Lateral resistance of finned piles established from model tests. Proceedings of the International Conference on Geotechnical Engineering, CFMS, Beirut, Lebanon. pp. 565-571.

Prakash, S. and Chandrasekaran, V. (1973). Pile foundation under lateral dynamic loads. Conference on Soil Mechanics and Foundation Engineering. Moscow. V2, p199-202.

Puri, V. and Prakash, S. (2010). Foundations for dynamic loads. GeoFlorida 2010: Art of Foundation Engineering Practice, 20-24.

Reese, L., C. and Matlock, H. (1956). Non-dimensional solutions for laterally loaded piles with modulus assumed proportional to depth. Proceedings of $8^{\text {th }}$ Texas Conference.

Reese, L. C. (1975). Laterally loaded piles. Proceedings of the Seminar Series, Design, Construction and Performance of Deep Foundations, Geotechnical Group and Continuing Education Committee, San Francisco Section, ASCE, University of California.

Richart, F. E., Hall, J. R. and Woods, R. D. (1970). Vibrations of soils and foundations. The National Academies of Sciences, Engineering and Medicine. Transportation Research Board.

Ross, H. E. (1971). Dynamic response of offshore piling. $3^{\text {rd }}$ Offshore Technical Conference, Texas.

Ross, H. E., Sicking, D. L., Zimmer, R. A. and Michie, J. D. (1993). Recommended procedures for the safety performance evaluation of highway features. NCHRP Report 350. 
National Cooperative Highway Research Program, Transportation Research Board, National Academy Press, Washington, D.C.

U.S. Department of State (2003). Specification for vehicle crash test of perimeter barriers and gates. SD-STD-02.01, Revision A. Physical Security Division.

Wright, C. (2012). Introduction to structural impact. PDH online course.

Zhang, L. (2009). Nonlinear analysis of laterally loaded rigid piles in cohesionless soil. Computers and Geotechnics, 36(5), 718-724. 


\section{Appendix A}

Results of Sieve analysis

\begin{tabular}{|c|c|c|c|c|}
\hline sieve sizes $(\mathrm{mm})$ & $\begin{array}{c}\text { sieve } \\
\text { number }\end{array}$ & $\begin{array}{c}\text { mass retained } \\
\text { in each sieve } \\
\text { (g) }\end{array}$ & $\begin{array}{l}\text { cum mass } \\
\text { passing }(g)\end{array}$ & $\begin{array}{c}\text { total } \\
\% \\
\text { passing }\end{array}$ \\
\hline 4.75 & No. 4 & 16.6 & 983.4 & 98.34 \\
\hline 2 & No. 10 & 188.2 & 795.2 & 79.52 \\
\hline 0.841 & No. 20 & 169.3 & 625.9 & 62.59 \\
\hline 0.42 & No. 40 & 168 & 457.9 & 45.79 \\
\hline 0.25 & No. 60 & 219.1 & 238.8 & 23.88 \\
\hline 0.149 & No. 100 & 159.5 & 79.3 & 7.93 \\
\hline 0.075 & No. 200 & 70.6 & 8.7 & 0.87 \\
\hline & Pan & 8.7 & $1.03 \mathrm{E}-13$ & 0.00 \\
\hline Diameter (D10) & \multicolumn{4}{|l|}{0.17} \\
\hline Diameter (D30) & \multicolumn{4}{|l|}{0.29} \\
\hline Diameter (D60) & \multicolumn{4}{|l|}{0.75} \\
\hline $\begin{array}{l}\text { Coefficient of uniformity } \\
\text { (Cu) }\end{array}$ & \multicolumn{4}{|l|}{$4.4>4$} \\
\hline $\begin{array}{l}\text { Coefficient of curvature } \\
\text { (Cc) }\end{array}$ & \multicolumn{4}{|c|}{0.66 does not range in 1 to 3} \\
\hline$\%$ Gravel & \multicolumn{4}{|l|}{1.66} \\
\hline$\%$ Sand & \multicolumn{4}{|l|}{97.47} \\
\hline \% fines & \multicolumn{4}{|l|}{0.87} \\
\hline
\end{tabular}


Results for compaction test

\begin{tabular}{|c|c|c|c|c|c|c|c|c|}
\hline $\begin{array}{l}\text { mass of proctor } \\
\text { mold and base } \\
\text { (g) }\end{array}$ & \multicolumn{8}{|l|}{4283.5} \\
\hline $\begin{array}{l}\text { volume of mold } \\
\text { container (m3) }\end{array}$ & \multicolumn{8}{|l|}{944.5} \\
\hline Test No. & 1 & 2 & 3 & 4 & 5 & 6 & 7 & 8 \\
\hline $\begin{array}{l}\text { mass of proctor } \\
\text { mold and base } \\
+ \text { compacted } \\
\text { soil }(g)\end{array}$ & $\begin{array}{r}6059 . \\
1\end{array}$ & $\begin{array}{r}6117 . \\
5\end{array}$ & $\begin{array}{r}6186 . \\
7\end{array}$ & $\begin{array}{r}6284 . \\
6\end{array}$ & $\begin{array}{r}6326 . \\
9\end{array}$ & 6386 & $\begin{array}{r}6365 . \\
9\end{array}$ & $\begin{array}{r}6342 . \\
5\end{array}$ \\
\hline $\begin{array}{l}\text { mass of soil } \\
\text { moisture } \\
\text { container (g) }\end{array}$ & 28.6 & 19.6 & 20.1 & 19.9 & 20.2 & 20.1 & 20.2 & 20.1 \\
\hline $\begin{array}{l}\text { mass of } \\
\text { container }+ \\
\text { moist soil (g) }\end{array}$ & 71.8 & 78.8 & 78.3 & 78.7 & 77.9 & 86 & 86.7 & 87.3 \\
\hline $\begin{array}{l}\text { mass of } \\
\text { container + dry } \\
\text { soil (g) }\end{array}$ & 69.8 & 74.9 & 73.1 & 71.7 & 70.7 & 76.9 & 76.8 & 76.9 \\
\hline mass of soil (g) & 41.2 & 55.3 & 53 & 51.8 & 50.5 & 56.8 & 56.6 & 56.8 \\
\hline $\begin{array}{l}\text { mass of water } \\
\text { (g) }\end{array}$ & 2 & 3.9 & 5.2 & 7 & 7.2 & 9.1 & 9.9 & 10.4 \\
\hline $\begin{array}{l}\text { mass of } \\
\text { compacted soil } \\
\text { in mold }(\mathrm{g})\end{array}$ & $\begin{array}{r}1775 . \\
6\end{array}$ & 1834 & $\begin{array}{r}1903 . \\
2\end{array}$ & $\begin{array}{r}2001 . \\
1\end{array}$ & $\begin{array}{r}2043 . \\
4\end{array}$ & $\begin{array}{r}2102 . \\
5\end{array}$ & $\begin{array}{r}2082 . \\
4\end{array}$ & 2059 \\
\hline density Kg/m3) & 1.88 & 1.94 & 2.02 & 2.12 & 2.16 & 2.23 & 2.20 & 2.18 \\
\hline $\begin{array}{l}\text { dry density of } \\
\text { soil }(\mathrm{Kg} / \mathrm{m} 3)\end{array}$ & 1.63 & 1.68 & 1.75 & 1.84 & 1.88 & 1.93 & 1.91 & 1.89 \\
\hline $\begin{array}{l}\text { Moisture } \\
\text { content }(\%)\end{array}$ & 4.85 & 7.05 & 9.81 & 13.51 & 14.26 & 16.02 & 17.49 & 18.31 \\
\hline
\end{tabular}

Results of moisture content test

\begin{tabular}{|l|r|r|r|}
\hline depth of soil in box (mm) & $\mathbf{2 0 0}$ & $\mathbf{3 5 0}$ & $\mathbf{5 0 0}$ \\
\hline mass of empty container $\mathbf{( g )}$ & 19.9 & 28.5 & 20 \\
\hline initial mass of soil (g) & 91.9 & 93.8 & 95.7 \\
\hline dry mass of soil (g) & 89.1 & 90.9 & 92.3 \\
\hline water content (\%) & $\mathbf{4 . 0 4 6 2 4 3}$ & $\mathbf{4 . 6 4 7 4 3 6}$ & $\mathbf{4 . 7 0 2 6 2 8}$ \\
\hline average water content (\%) & $\mathbf{4 . 4 6 5 4 3 6}$ & & \\
\hline
\end{tabular}


Direct shear test values

\begin{tabular}{|c|c|c|}
\hline & Pressure & Horizontal \\
\hline Test No. & & $\begin{array}{c}\text { pressure } \\
(\mathrm{kPa})\end{array}$ \\
\hline 1 & 20 & 17 \\
\hline 2 & 40 & 38 \\
\hline 3 & 60 & 62 \\
\hline angle of friction (o) & $\tan ^{\wedge}(1.1)=$ & 43 \\
\hline Cohesion & & 6 \\
\hline
\end{tabular}




\section{Appendix B}

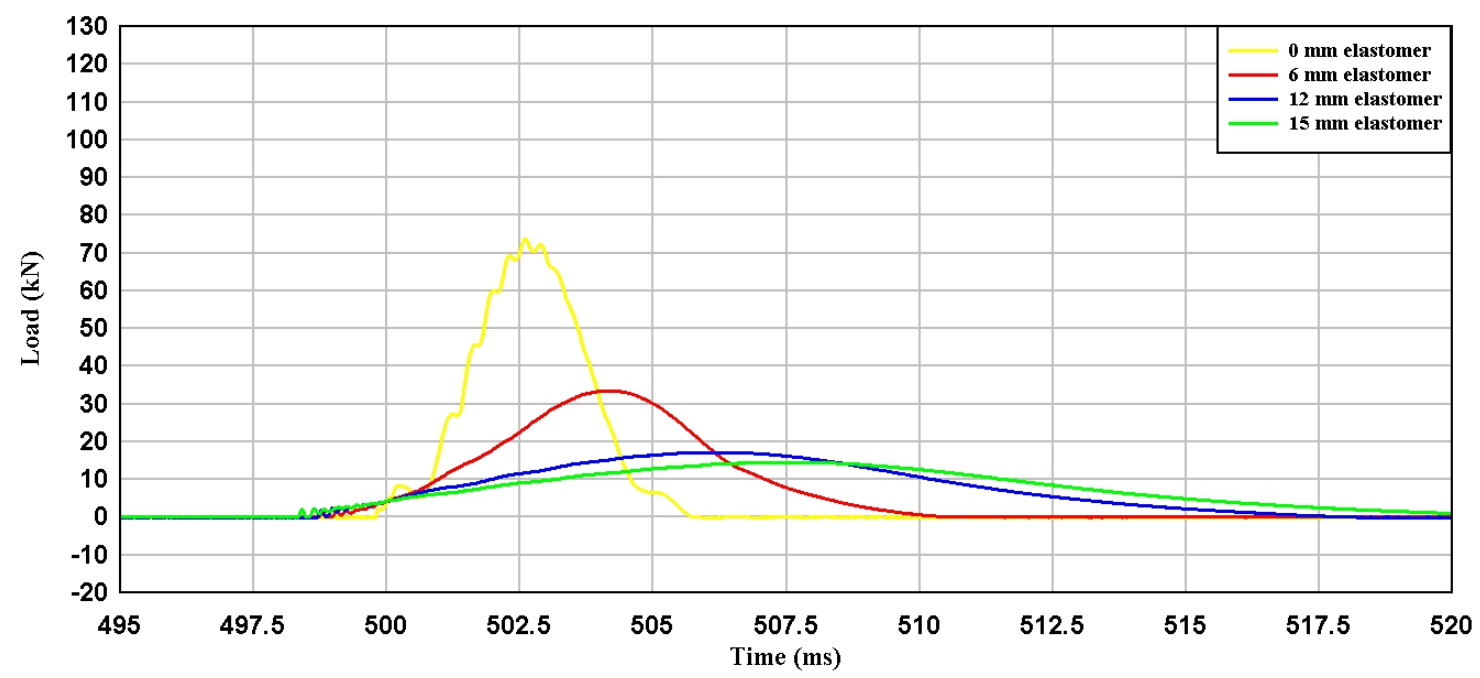

Impact load configuration at $5^{\circ}$

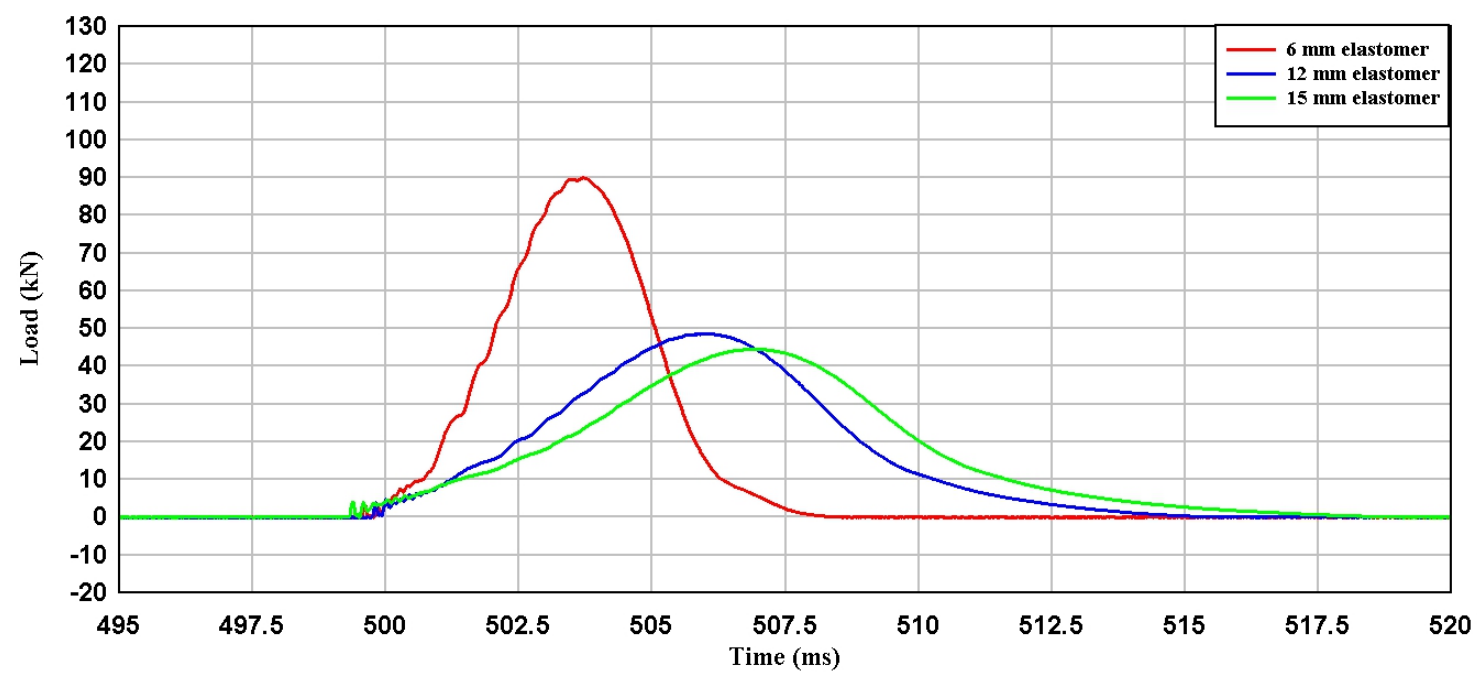

Impact load configuration at $10^{\circ}$ 


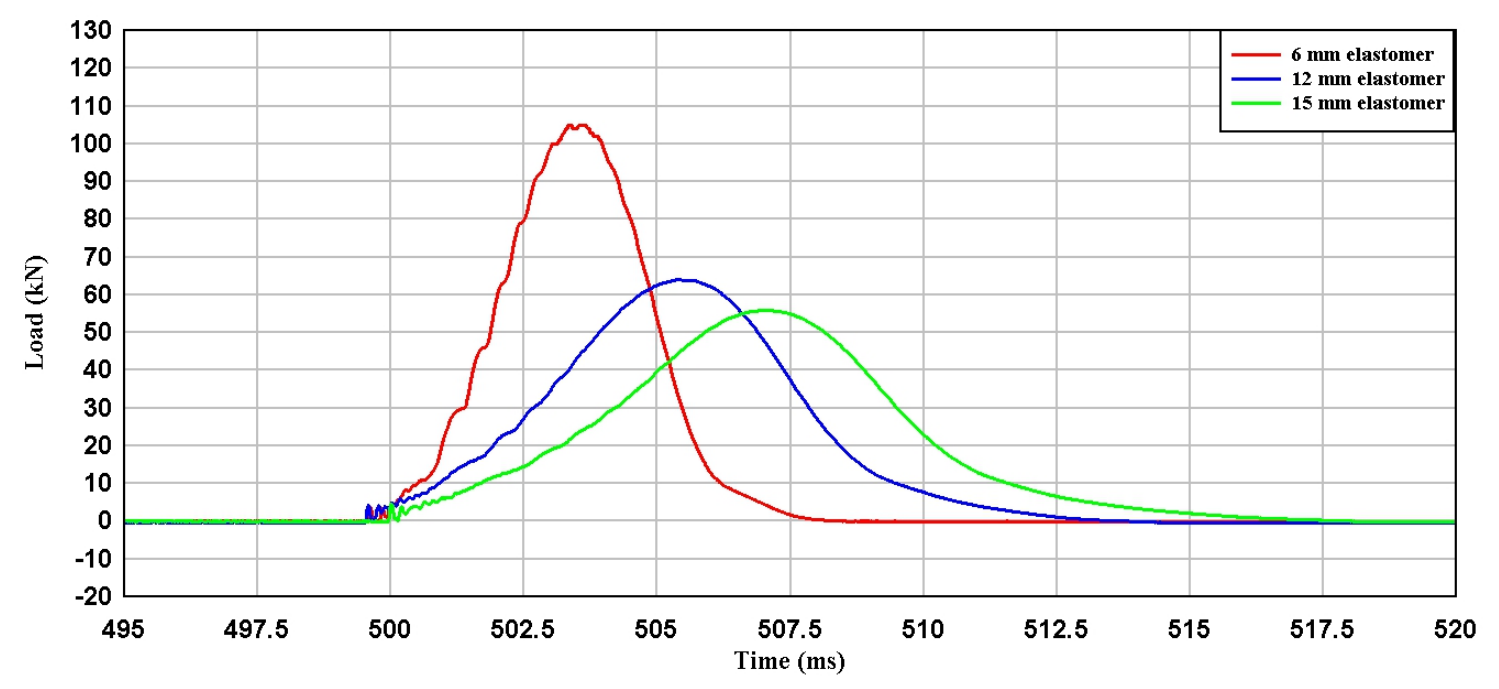

Impact load configuration at $12^{\circ}$

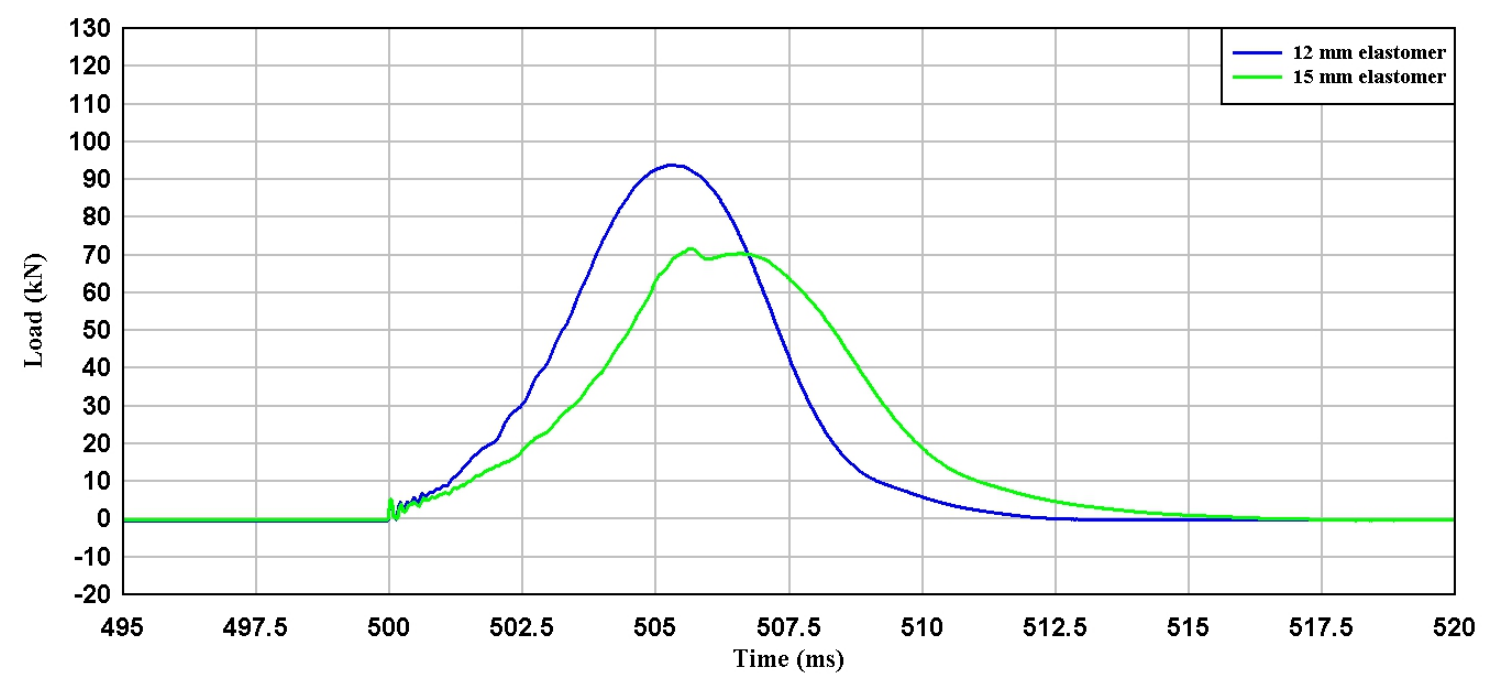

Impact load configuration at $15^{\circ}$ 


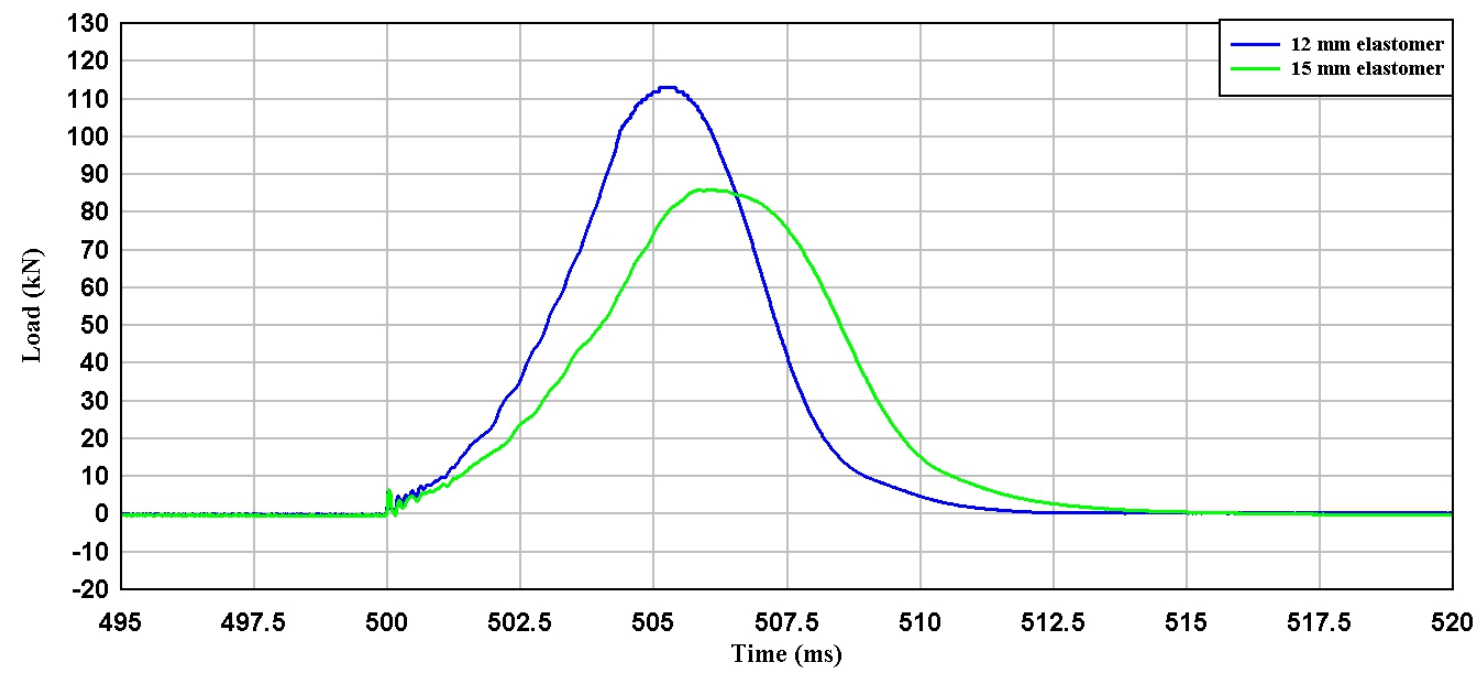

Impact load configuration at $18^{\circ}$ 